DEVELOPING THE SPEAKING COMPETENCES OF PRIMARY SCHOOL STUDENTS IN ENGLISH AS A FOREIGN LANGUAGE CLASSES IN VIETNAM THROUGH DRAMA ACTIVITIES

Dissertation

In Partial Fulfillment of the Requirements for the Degree of Doctor of Philosophy (PhD) of the Faculty of Philosophy Georg-August-University of Göttingen, Germany

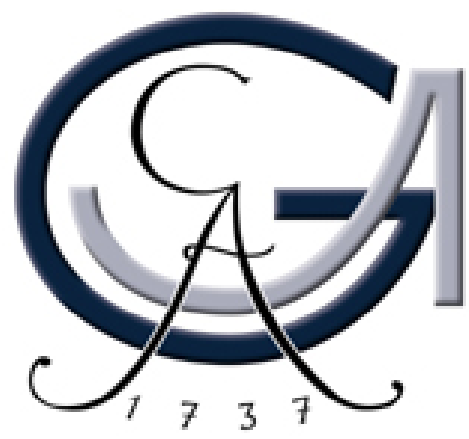

Submitted by

Bui Thi Hong Minh

Born in Phu Tho, Viet Nam

Göttingen 2016 



\section{DEVELOPING THE SPEAKING COMPETENCES OF PRIMARY SCHOOL STUDENTS IN ENGLISH AS A FOREIGN LANGUAGE CLASSES IN VIETNAM THROUGH DRAMA ACTIVITIES}

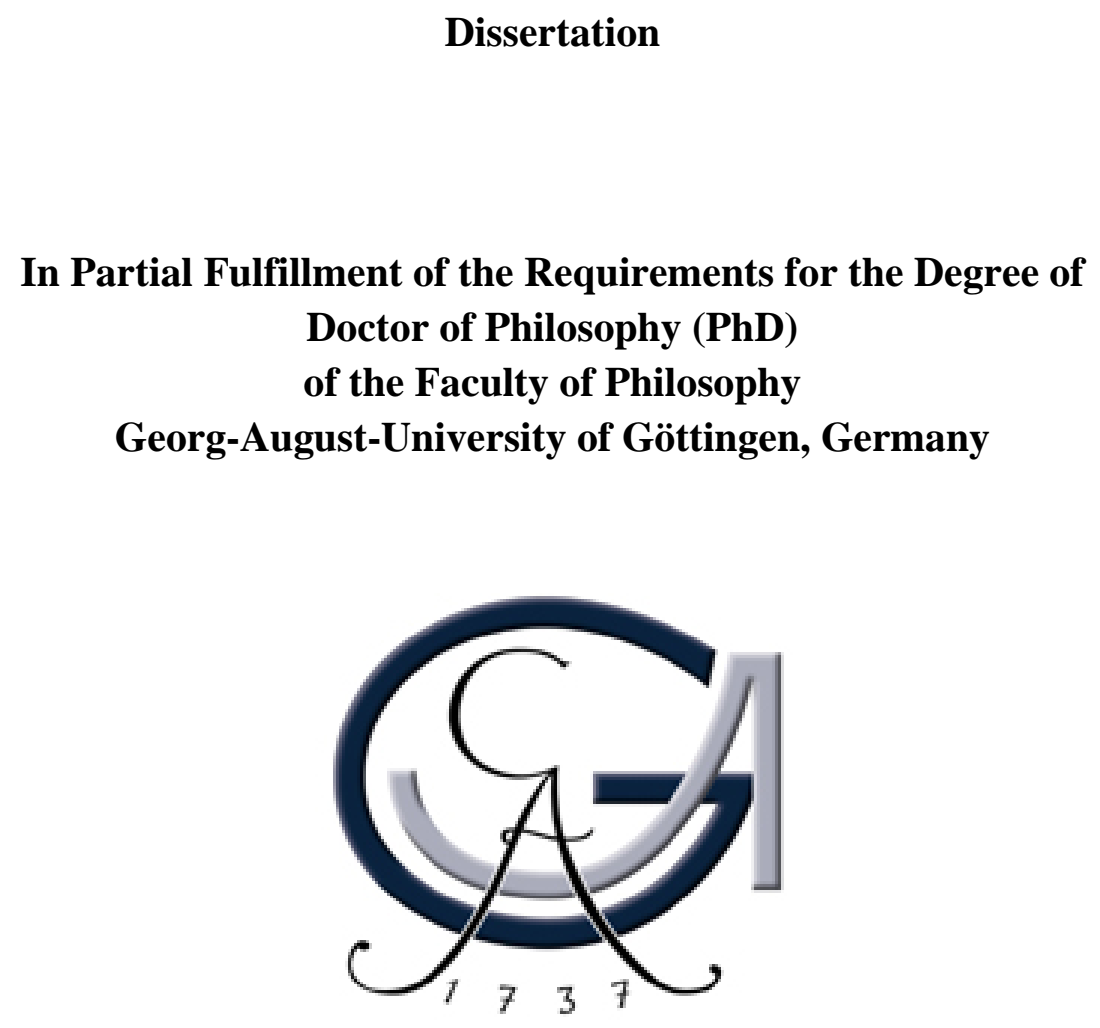

Submitted by

Bui Thi Hong Minh

Born in Phu Tho, Viet Nam

Göttingen 2016 
Referee: Prof. Dr. Carola Surkamp

Co-referee: Prof. Dr. Henning Klöter

Prof. Dr. Birgit Schädlich

Date of examination: 05/ 12/ 2016 (13.00 - 15.00) 


\section{Declaration}

"I herewith affirm that I wrote the submitted dissertation (specification of title) independently and without any prohibited help. I did not make use of any aids and papers other than those indicated by me. I have marked all word-by-word (direct) or implied citations of the writings of other authors. The treatise has not been published yet and not been object of a doctoral process yet.” 


\section{Acknowledgements}

I would like to firstly express my greatest appreciation to my supervisor Prof. Dr. Carola Surkamp for giving me the chance to study in such an excellent environment, for the topic of this work, and for her unconditional support, guidance and useful advice. She has always encouraged me to overcome the difficulties in my academic career and in my personal life as well. I am sincerely thankful to Prof. Dr. Henning Klöter from the Department of Asian and African Studies at the Humboldt University of Berlin for agreeing to be my second supervisor and to Prof. Dr. Birgit Schädlich from the Department of Romance Studies for agreeing to be my third supervisor.

I would like to thank Franziska Ellis, who is studying the same topic of drama, for her courses and valuable resources on this topic. Her course, "Introduction to English Teaching”, was my first course at the University of Göttingen, and I was really impressed by her methods of teaching.

I would like to thank those who helped, supported and encouraged me along the way: Sarah, Lingwei, Mrs Ninh's family, the HVU group and my Vietnamese friends in Germany. You are the people who made my journey become more meaningful.

I would like to thank the teachers and students of Truong Thinh Primary School who participated in my experiment in Vietnam. Without their presence, my study would not have been completed.

I would like to extend my thanks to the Office of 165 in Vietnam for the scholarship that allowed me to pursue my Ph.D. in Education at the Georg-AugustUniversität Göttingen.

Finally, my deepest gratitude and love goes to my beloved family, who continuously supported and encouraged me during my entire period of studies. My acknowledgments would not be complete without thanking my beloved husband, Nguyen Ngoc Quynh, who shared with me all the happiness and difficulties in our seven years of marriage and study, for his constant love, continuous encouragement, patience and unlimited emotional support. Thanks must also go to my two lovely sons, Nguyen Minh $\mathrm{Vu}$ and Nguyen Minh Khang, for being my motivation to fight against the obstacles on the 
way. I am grateful for my parents and my parents-in-law, my sisters, and my big family in Vietnam, without their support I could not have achieved this difficult task.

Last, but not least, I would like to express my sincere gratitude to the Phu Tho Province, Phu Tho Medical College, for giving me the chance to go to Germany to pursue this Ph.D. degree. 


\begin{abstract}
English was first introduced as a taught foreign language in Vietnam in 1986, yet more than 40 years later the Vietnamese people still find it difficult to speak the language. To improve the students' proficiency in speaking English, the Vietnamese government developed a series of new textbooks based on the Communicative Language Teaching (CLT) approach. CLT is a learner-centred, interaction-driven and authentic materialsdriven teaching approach. The CLT method of interest in this study is the teaching of drama. Learners have shown significant improvements in their speaking-related parameters through drama studies all over the world. However, the CLT approach has found little success in Vietnam in the past (Ellis 1994). The reasons why CLT has failed to be successfully applied in Vietnam may be due to a number of reasons, such as the influence of Confucianism on Vietnamese culture, the traditional grammar-based examination system, the number of students per class, and the infrequent use of the English language in daily life. To overcome these challenges, this research project is designed as an experimental study that aspires to increase the students' competency in speaking English by using drama activities in order to employ the advantages of CLT, while at the same time minimizing the effects of the above-mentioned factors. In this study, a group of Grade 4 students in a rural primary school in Vietnam was randomly assigned to a control or experimental group. Before starting the experiment, both groups were administered questionnaires to measure their initial levels of motivation and their attitudes to learning a foreign language. They were also tested to evaluate their speech competence levels. The research group followed a learner-centred syllabus, based on drama activities; meanwhile, the control group continued with their daily routine in the English language class. After the four months of the experiment, both groups were administered post-experiment questionnaires to check their levels of motivation and their attitudes. Post-experiment speech competence tests were given to both groups to again test the development of their total speaking competences. As a result of the drama lesson plans, the experimental group showed statistically significant increases in all measures of their speaking competences in comparison to the control group, while the control group showed increases in a limited number of areas such as grammar. The findings of this study differ from the literature, which has found that a CLT approach cannot be applied in Vietnam (Ellis 1994), and are promising from the perspectives of parents, educators and policymakers.
\end{abstract}




\begin{abstract}
Abstrakt
Englisch wurde 1986 in Vietnam eingeführt. Mehr als 40 Jahre später finden es Vietnamesen immer noch schwierig diese Sprache zu sprechen. Zur Verbesserungen der Fertigkeit Sprechen entwickelte die Regierung eine Reihe neuer Lehrbücher auf der Grundlage des Kommunikativen Sprachunterricht Ansatzes (CLT). CLT ist eine lernerzentrierte Interaktions- und Lehrmethode, die auf authentischen Materialien basiert. Die hier betrachtete CLT-Methode ist Theater. In Theaterstudien zeigten Lernende aus der ganzen Welt eine enorme Verbesserung ihres mündlichen Ausdrucks. Jedoch fand CLT bisher wenig Erfolg in Vietnam (Ellis 1994). Die Gründe, warum CLT sich nicht erfolgreich in Vietnam etabliert hat, sind unter anderem die traditionellen grammatikbasierten Prüfungen, der Einfluss des Konfuzianismus auf die vietnamesische Kultur, die Zahl der Schüler pro Klasse und die seltene Anwendung der englischen Sprache im täglichen Leben. Um diese Herausforderungen zu überwinden, wurde im vorliegenden Dissertationsprojekt eine Experimentalstudie entworfen, mit dem Ziel die Fertigkeit Sprechen bei Schülern zu verbessern. Hierbei wurden Theateraktivitäten durchgeführt, um die Vorteile des CLT zu nutzen, gleichzeitig wurden die oben genannten Effekte minimiert. In dieser experimentellen Studie wurde per Zufallsprinzip eine Gruppe Viertklässler in einer ländlichen Grundschule in Vietnam als Kontroll- und Versuchsgruppe gewählt. Vor Beginn des Experiments wurde bei beiden Gruppen mit Hilfe von Fragebögen die Motivationniveaus und Einstellung zum Fremdspracherwerb ermittelt. Auch die Sprechkompetenz wurde getestet, um das Niveau der Versuchspersonen zu evaluieren. Die Versuchsgruppe folgte einem auf Theateraktivitäten beruhendem lernerzentriertem Lehrplan, während die Kontrollgruppe dem regulärem Englischunterricht folgte. Nach den vier Monaten des Experiments wurden wieder durch Fragebögen die Niveaus der Motivation und Einstellungen der Schüler beurteilt. Ferner wurden erneut Sprechkompetenztests bei beiden Gruppen durchgeführt, um die Entwicklung der Gesamtsprachkompetenz zu testen. Die Schüler wurden zu Beginn der Studie und am Ende der Studie beurteilt. Gepaarte t-Tests wurden durchgeführt, um zu bestimmen, ob es statistisch signifikante Unterschiede zu verschiedenen Zeitpunkten oder zwischen den beiden Gruppen gab. Als Ergebnis des Theaterunterrichtplans zeigt die Versuchsgruppe eine statistisch signifikante Steigerung in allen Parametern der Sprechkompetenz im
\end{abstract}


Vergleich zu der Kontrollgruppe, während die Kontrollgruppe Steigerungen in einer begrenzten Anzahl von Bereichen wie der Grammatik zeigte.

Diese Ergebnisse unterscheiden sich von der Literatur, laut derer die CLT nicht in Vietnam angewendet werden kann (Ellis 1994) und ist eine vielversprechende Perspektive für übergeordnete Erzieher und politische Entscheidungsträger. 


\section{Table of Contents}

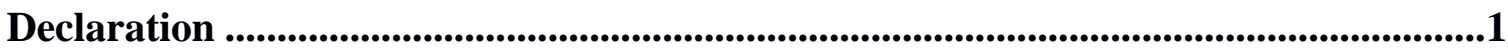

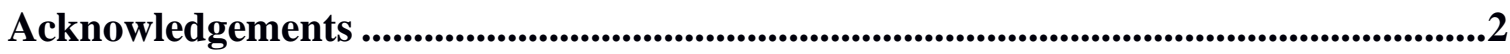

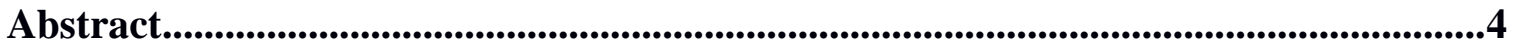

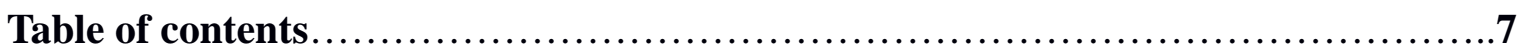

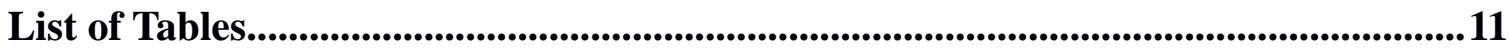

List of Figures.............................................................................................................13

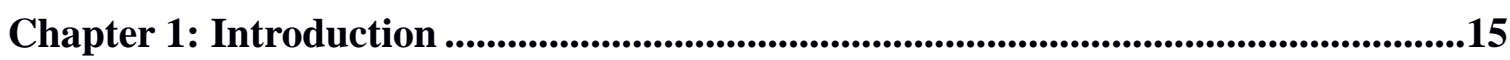

Chapter 2: State of the Research .........................................................................18

Chapter 3: Research Contexts ........................................................................................................24

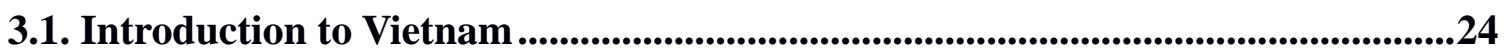

3.2. Confucianism in Vietnamese Culture and Education ..........................................27

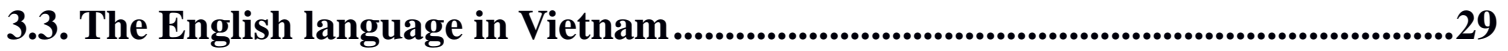

3.4. The English language teaching in primary schools in Vietnam.............................31

Chapter 4: Communicative Language Teaching (CLT) ...............................................38

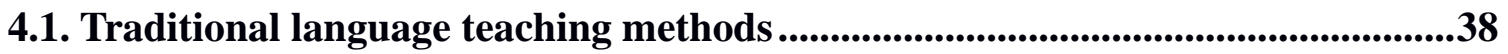

4.2. Communicative Language Teaching ............................................................................41

Chapter 5: Speaking Competence .....................................................................................57

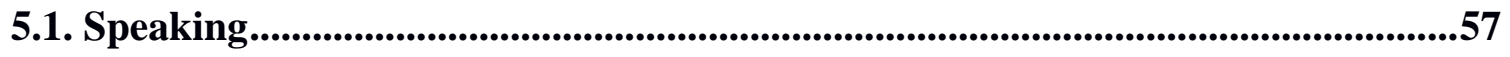

5.2. Speaking competence...................................................................................................................59

5.3. Speaking sub-competence ............................................................................6.60

5.4. The importance of acquiring speaking competence ...........................................64

5.5. How to develop competence in speaking................................................................65

5.6. Characteristics of a successful speaking classroom .........................................66

5.7. Problems with achieving speaking competence in English language classrooms67

Chapter 6: Drama Activities in EFL Classrooms......................................................70

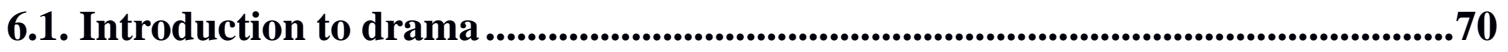




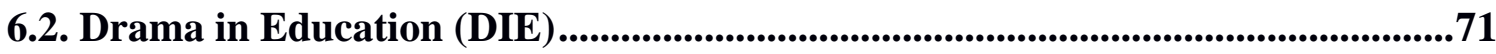

6.3. The benefits of drama activities in EFL classrooms ........................................73

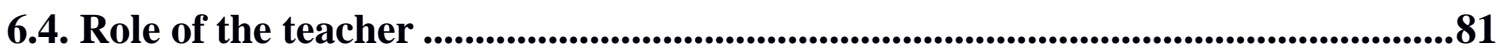

Chapter 7: The Implementation of Drama in the Communicative Approach ............83

7.1. Communicative Language Teaching in Practice....................................................83

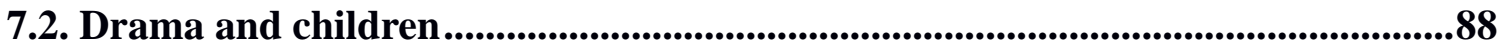

7.3. How drama techniques fulfill each speaking sub-competence .............................90

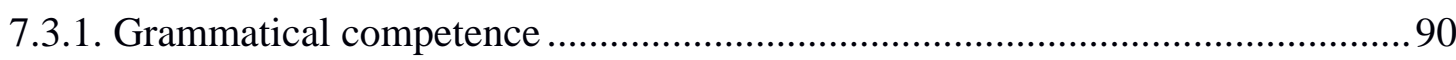

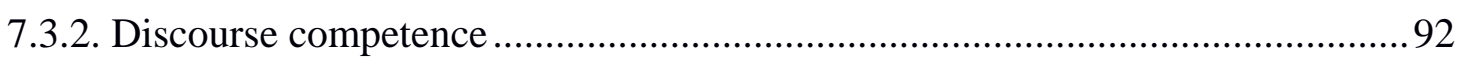

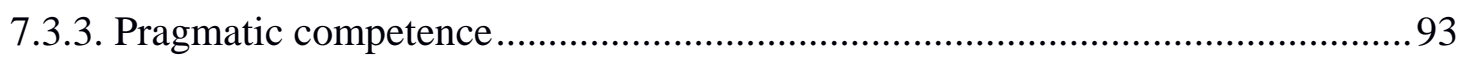

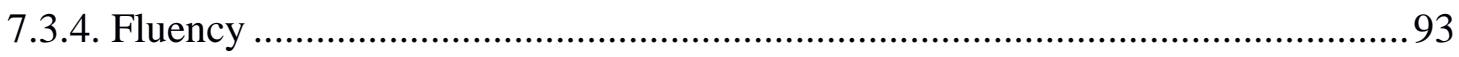

7.3.5. Attitude and Motivation.................................................................................... 93

7.4. Implementation of drama activities in the EFL classroom ................................94

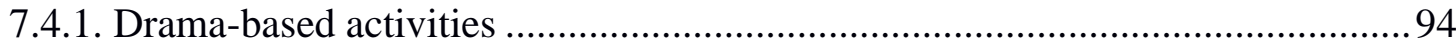

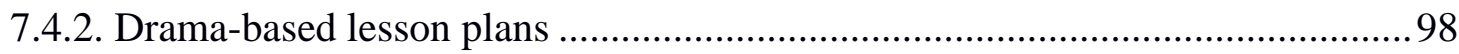

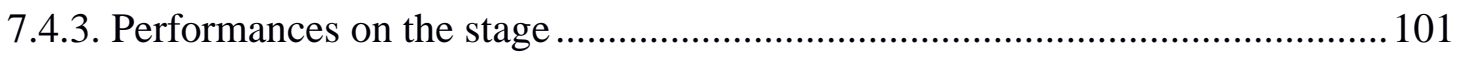

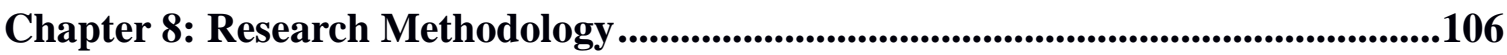

8.1. The institutional context.........................................................................................................106

8.2. Population and sample ....................................................................................................110

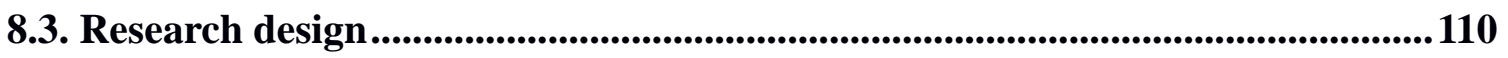

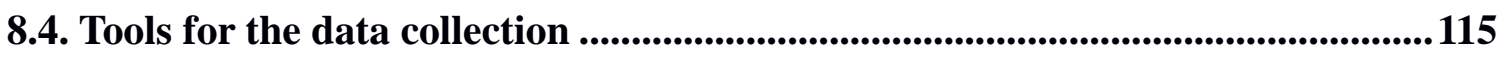

8.4.1. Pre- and post-speaking tests to measure the primary school students' speaking

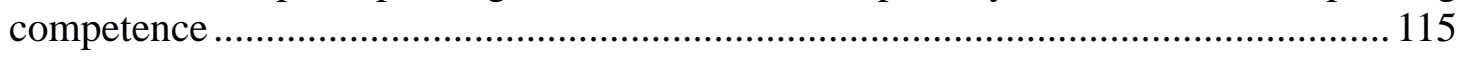

8.4.2. Proposed lesson plan using drama techniques to develop the speaking competence of the experimental group (Intervention) ….......................................... 117

8.4.3. Questionnaire to measure the attitudes and motivation of the primary school students towards English language learning before and after the intervention ........... 187

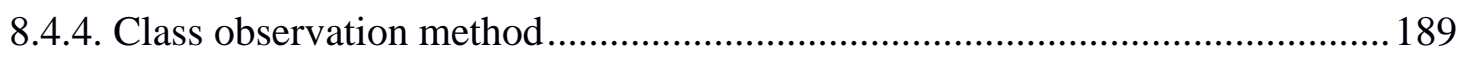


9.1.1. The control and experimental groups started at the same level of speaking competence

9.1.2. There was a significant increase in the experimental group's speaking competence, compared to the control group, after implementing drama techniques into the lesson plan 196

9.1.3. There was no significant improvement in the speaking competence of the control group after 4 months of regular instruction, with the exception of grammar in the grammatical competence..... 200

9.1.4. There were significant improvements in the speaking competence in the experimental group after using drama techniques.

9.1.5. The control and experimental groups started with similar attitudes and motivation levels

9.1.6. There were statistically significant improvements in the attitudes and motivation in the experimental group after the treatment.

9.1.7. Similarly, the attitudes and motivation of the experimental group were statistically different from the control group post-treatment.

9.1.8. The results of class observation supported the results of the speaking competence tests before and after the intervention of drama activities..... 208

9.2. Discussion .210

9.2.1. The control and experimental groups started at the same level of speaking competence......

9.2.2. There was a significant increase in the experimental group's speaking competence, compared to the control group, after implementing the drama based program.

9.2.3. There was no significant improvement in the speaking competences of the control group after 4 months of regular instruction, with the exception of grammar in the grammatical competence.

9.2.4. The control and experimental groups started with similar attitudes and motivation levels, but after the intervention the attitudes and motivation of the experimental group was raised significantly compared with the control group......... 218 
10.2. Significance

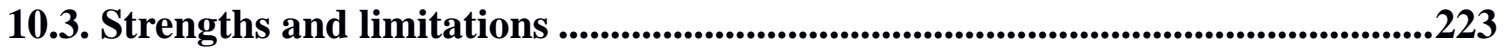

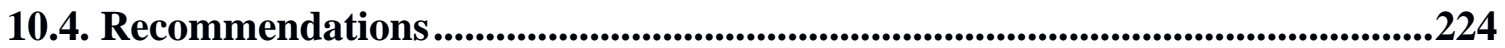

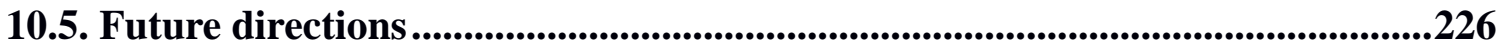

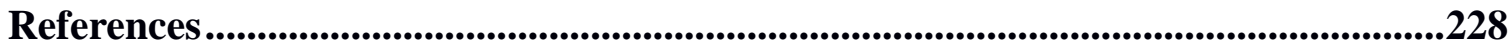

Appendix A | Tools of data collection ......................................................................250

Appendix B |Attitude and Motivation.................................................................257

Appendix C | Performance on Stage .........................................................................................263

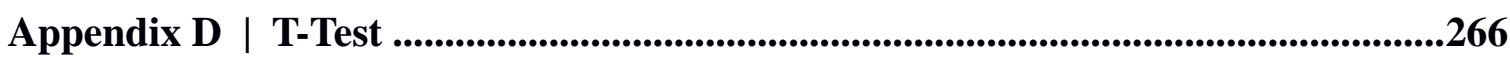

Appendix E | Typescript's for Pre-test and Post-test ................................................2270 


\section{List of Tables}

Table 1. The number of school teachers and students from the school years 1999-2000 to 2010-2011 (Thai 2005).

Table 2. The criteria for the A1 level in the European Framework of Reference for Languages (Council for Cultural Co-operation 2009, 24-26).

Table 3. An example of a book map from an English textbook, "English 4" (Van et al. 2010)

Table 4. A description of CLT (Badger and Yan 2008). 54

Table 5. Comparison of the three traditional foreign language teaching methods with communicative language teaching (Dr Bill Flick, Director of ESL at Auburn).

Table 6. Detailed description and focus of “Getting started” activities (Phillips 2000, Farmer 2007)

Table 7. Detailed description and focus of "Songs, rhymes and chants" activities (Phillips 2000, Farmer 2007)

Table 8. Detailed description and focus of "Developing skills" activities. (Phillips 2000, Farmer 2007)

Table 9. The four stages of a drama-based lesson plan (Billíková and Kissová 2013)........101

Table 10. The percentages for each Item in the Attitudes and Motivation test. 104

Table 11. T-tests for the Attitudes and Motivation Items, comparing the control and experimental groups pre- and post-intervention (i.e. lesson plan).

Table 12. The pre- and post-test control and experimental group design.

Table 13. Speaking competence analysis.

Table 14. The three activities of the pre- and post-speaking tests. Adapted from the Greek National Foreign Languages Curriculum Sub-project 2:2007-2013 for the A1 speaking level.

Table 15. The six units of the drama-based lesson plan, their associated targeted 118 
Table 16. Difference and similarities between two instructions 186

Table 17. Classroom observation parameters for both classrooms: 190

Table 18. General information about the teachers who were involved in the study: 190

Table 19. Features of observation method 191

Table 20. The percentages for each Item in the Attitudes and Motivation test. .206

Table 21. T-tests for the Attitudes and Motivation Items, comparing the control and experimental groups pre- and post-intervention (i.e. lesson plan) 207 


\section{List of Figures}

Figure 1. The educational structure in Vietnam (UNESCO 2007). .25

Figure 2. The number of school teachers and students from the school year 1999-2000 to 20102011(46th Icho 2014). 26

Figure 3. An example of an information gap activity. Person A and Person B must communicate to determine what is in their missing cells.

Figure 4. Sample unit outline from Book map - English 4 . 50

Figure 5. An example of a task-based material. The students are instructed to complete the sentence based on the pictures given (English 4).

Figure 6. An example of a realia. Students are instructed to describe the situation, people, etc., in the picture.

Figure 7: An example of a dialogue exercise from a textbook .58

Figure 8: The seven meanings of the sentence "I never said she stole my money 62

Figure 9: Examples of drama-based activities for primary school students

Figure 10: Location of the Truong Trinh primary school.

Figure 11: The experimental outline.

Figure 12: The mean pre-test scores and standard deviations of the overall speaking competences and sub-competences of the control and experimental groups

Figure 13: The mean post-test scores and standard deviations of the control group and experimental group in overall speaking performance and speaking sub-competences.

Figure 14. The mean post-test scores and standard deviations of the control group and experimental group in overall speaking performance and speaking sub-competences.

Figure 15. The mean scores and standard deviations of the control group comparing the pre-test and post-test results for overall speaking and speaking sub-competences. 200

Figure 16. The mean scores and standard deviations of the control group in the pre-tests and post-tests in the grammatical sub-competences. 
Figure 17. The mean scores and standard deviations of the experimental group in the pre-tests and post-tests in their overall speaking performance and speaking sub-competences..........202

Figure 18: The mean scores and standard deviations of the experimental group in the pre-tests and post-tests in the grammatical sub-competences...................................203 


\section{Chapter 1: Introduction}

English is one of the most common languages in the world, and the most popular second language of study in Vietnam (Crystal 2012). A series of economic reforms in 1986 and 1993 have created a surge in the number of people learning English (Tri 2001). Following Vietnam becoming a member of the Association of Southeast Asian Nations (ASEAN) in 1995 and the World Trade Organization (WTO) in 2006, many foreigners and investors began to arrive in Vietnam. Vietnam's economic progress has created a growing demand for English speakers and a demand for a greater number of people learning English as a Foreign Language (EFL).

The recent developments in the country, together with increased globalization, have created more career opportunities for the Vietnamese people. Needless to say, the citizens of Vietnam increasingly need to use English in their work and daily lives. The Vietnamese government has disbursed a substantial amount of resources and funding to the EFL program, but the number of fluent English speakers in Vietnam remains relatively low (Son 2011).

The reasons for the discrepancies between the numbers of the expected and actual fluent English speakers in the country might be due to the teacher-centred model of teaching, and the ways that Vietnamese students study and are evaluated (Liu and Littlewood 1997). In this model, the focus is on the teacher, while the students sit quietly and listen as the teacher instructs the class. The teacher's responsibility is viewed as being the content delivery, whereas the student's role is absorbing the content (Pratt et al. 1999). Furthermore, the Vietnamese students believe that learning is memorizing the books or information provided by teachers in class (Kennedy 2002). The teacher is usually the sole source of verbal English input for the students. Thus, the students normally do not participate in classroom activities, are unwilling to give answers or ask questions and are reliant on the teacher (Braddock et al. 1995). The teacher-centred model results in a passive learning style on the part of the students, and a situation where the students are not comfortable speaking the foreign language outside the classroom.

In addition, the EFL education system and examinations focus almost entirely on grammar and vocabulary (Peterson 2014). Since the Vietnamese students study English to pass examinations and to move to further study (Denham 1992), they tend to overlook the verbal communication 
parts, such as pronunciation, speaking and listening. The grammar- and vocabulary-heavy curriculum and examinations mean that the students rarely have the chance to practice communicating with each other in English in the classroom.

According to Kayi (2006, 5), foreign language teacher should pay much attention to teaching speaking because "the ability to communicate in a foreign language clearly and efficiently contributes to the success of the learner in school and success later in every phase of life". Instead of leading students to purely learn by memorization, language teachers should provide a rich environment for the students, where meaningful communication can take place.

The term to denote one's competency in speaking a language is aptly named speaking competence. Speaking competence is one's skills, knowledge, and motivation to speak to anyone in any context. For example, you may speak differently in front of an audience during a presentation than with your fellow students or coworkers in a normal conversation. To develop these speaking competences, it is important to teach and encourage verbal communication.

To improve the speaking competences of Vietnamese students in English, and to increase their experience of speaking the language, this study uses a well-established methodology, known as Communicative Language Teaching (CLT). CLT is "a set of principles about the goals of language teaching, how learners learn a language, the kinds of classroom activities that best facilitate learning, and the roles of teachers and learners in the classroom" (Richards 2006, 1). The purpose of the communicative approach ${ }^{1}$ is to communicate with other people in a classroom and later in a society. Among the CLT methods, drama is the one that has received much attention and is deemed as the effective in improving speaking competence (Heathcote and Bolton 1994, Kao and O’Neil 1998, Anderson 2010, O’Connor 2010, Nicholson 2011, Winston 2011).

Drama combines both the verbal and the non-verbal elements of communication, all of which are important in a spoken language (Dundar 2013). Holden (1981) defined drama as any activity where the participants portray themselves in a fictional situation, or to portray another person in a fictional situation. Drama provides the opportunity for people to express themselves verbally or physically using their imagination and memory (Sam

\footnotetext{
${ }^{1}$ The communicative approach is the beliefs and theories of language teaching that emphasizes that the goals of language teaching are communicative competence (Richards and Rogers 2001, 159).
} 
1990). Drama is an ideal CLT method because it can be customized to the needs and interests of the students (Huang 2008). Some typical drama activities include warm-ups, role-playing, simulations and performances on stage. These activities and other similar activities can be applied in different ways with different methods.

This study aims to explore whether or not drama can develop the speaking competence of Vietnamese students according to the communicative approach. Since Vietnamese students start learning English as a foreign language at Grade 3, this study will focus on primary school students. Thus, the principal research question in this study is: Can the speaking competence of primary school students in an EFL classroom in Vietnam be improved through drama activities?

To answer the research question about developing the speaking competence of primary school students in Vietnam, this study presents a theoretical background to the study and its methodology, together with results and discussions, in ten chapters. Chapter 1 is an introduction to the study, problem statements, hypotheses and research questions. The state of the research in this field is established in Chapter 2. In Chapter 3, the research context, including an overview of Vietnam, the history of the English language in Vietnam and the current situation of teaching and learning this foreign language in Vietnamese primary schools are discussed. Chapter 4 provides a brief overview of CLT in the EFL classroom and its impacts on developing communicative skills, which is further elaborated in Chapter 5. In Chapter 6, the drama methods and activities are discussed. This chapter explores in detail the principles, techniques, and benefits of drama methods and activities in developing the foreign languages of primary school 7 explores the relationship between drama, children and CLT, and describes how the integration of drama techniques were developed into the curriculum for the primary school students by the researcher. In Chapter 8 , an analysis of the research methods, including the research design, study population, the tools for collecting the data and the statistical formula are presented. The research findings and discussion are then presented in Chapter 9. Chapter 10 brings the dissertation to a conclusion with a review of its contributions and suggestions for further research. The Appendices contain related documents, such as: the tools for the data collection, the questionnaire of attitudes and motivation, proposed drama-based lesson plans, non-drama lesson plans, the script for the performance on the stage, the results of the T-tests and the typescripts for the pre-tests and post-tests. 


\section{Chapter 2: State of the Research}

Drama has been used for language teaching and has been gaining popularity in EFL and ESL classrooms since the 1950s. However, research into the methodologies of drama in language teaching has only started to flourish since the 1980s (Zafeiriadou 2009). Studies have been successfully carried out in all stretches of the world, such as in the U.S.A., Germany, France and Italy. The language of study is mostly English, German or French. However, the majority of the research today is done in universities and in countries where English is the native language. There are also only a very limited number of studies on the use of drama to teach EFL in primary schools, and no published studies on the use of drama to teach English in Vietnam. The purpose of this thesis is to explore whether or not drama in a foreign language primary school classroom is effective in a rapidly developing Third World country such as Vietnam.

In 1973, Hines stated that drama is "a valuable and valid means of mastering a language" (Hines 1973, ii). Since then, there have been many other studies that have explored the effectiveness of drama in English language teaching. Various studies have reported that drama has led to improvements in the speaking, reading and writing skills of the participants, as well as in their personal growth, attitudes and motivation, as is demonstrated in the following studies.

When compared to traditional instruction methods or teaching methods, drama was effective in enhancing the communication skills of ESL students and increasing the interest in English in school students. Vitz (1984) compared an eight week drama-based ESL program to a traditional ESL instruction program with regard to the oral drills. The results showed both groups of grade 1-3 students had improvements in their oral English language skills, however the drama group had significantly higher scores in their total verbal output and mean length of utterances than the control group (Vitz 1984). Gomez (2010) studied Spanish-speaking students in a public school in Madrid, Spain. Either drama or traditional instructions were given to two classes from the same year group over a three-week period. They were examined before and after instruction. T-tests were used to analyze the data in order to examine whether either method was more effective. The results of the study concluded that drama was more effective in teaching English than traditional methods. 
In Coleman's study (2005) of Korean EFL students, the students demonstrated significant increases in their English speaking skills after participating in a 5-day drama-based program. The students also reported being more relaxed and confident about speaking English. Stinson and Freebody (2006) invited four classes of EFL students in Singapore to participate in an English speaking drama program. Their intervention group received 10 hours of drama pedagogy to improve their oral language skills, while their comparison group carried on with their usual English classes. The students showed significant post-test increases in their English speaking skills, while the control groups did not. Students also felt that they were more confident about speaking English, and most of them wanted to continue in a drama program. College student teachers and their primary school students found that creative drama helped in the students' oral speaking skills and personal growth (Sparch 2004). Creative drama refers to improvisational, process-oriented drama, where learners are helped by the teacher to imagine, act and reflect. The study was conducted with thirty-four junior college student teachers at the National Formosa University, Taiwan, and primary school students in collaborative communities (Sparch 2004). The primary school student's oral speaking skills improved. Based on their responses, the majority of the primary school students grew more confident after this creative drama activity. The results of this study showed that drama-related activities simultaneously improved the student's English communication skills and accelerated their personal development.

Ulas (2008) found that utilizing drama activities was efficient in developing the pronunciation and interpretation of fourth-year students in Erzurum, Turkey. The control group received the traditional, teacher-centred course book method while the experimental group received native language instruction lessons that were implemented with drama activities. Ulas developed an observation form to assess the primary school students' oral communication skills before and after 14 weeks of instructions. The results showed that the experimental and control groups had a significant difference in their scores for oral communication skills, where the most improvement, on average, was in the scores of the experiment group. In another case study, a class of beginner German students participated in an experimental three-week improvisational theatre workshop (Matthias 2007). The workshop consisted of improvisational drama exercises and physical enactments of intercultural situations in German. This anecdote-based study showed that even beginner German learners benefited from drama-based activities, which enabled them to overcome cognitive and psychological barriers to achieving speaking competency and fluency 
(Matthias 2007). Based on the empirical data, drama activities improve the language learning of primary school students.

It has been shown that drama can improve the communication skills in university ESL students. Stern (1980) studied the effects of drama techniques in an ESL classroom at the University of California, Los Angeles (UCLA). He studied 24 non-native English speakers from three ESL classes. They were involved in dramatic activities and answered questions about drama usage in these classes. The results from his study showed that drama improved their communication, self-esteem, motivation and empathy,.

To study the relationship between counselling techniques and vocabulary acquisition for adult second language learners, Uddin (2009) utilized role-play and storytelling. The statistical analysis of the participants' pre- and post-test scores showed that the participants could enhance their vocabulary, and to use these words while role-playing and storytelling. Role-play improved their fluency, which is a prerequisite for vocabulary development. Storytelling allowed the participants to reflect on their own stories and to make use of the new words which they had acquired earlier. These techniques allowed the students to become independent learners, to own their language skills and to empower them. The results indicated that role-play and storytelling helped adult ESL learners to enhance vocabulary and their communication.

Studies have shown that drama activities can help cultivate the students' reading skills in primary school. In a group of 51 fifth-grade remedial reading students, Dupont (2010) divided them into three equal groups of 17 students. The Group 1 students read six select works of children's literature and participated in creative drama activities daily for six weeks. The students participated in a dramatic activity related to the story, and dramatized the events of the story in the appropriate order. The Group 2 students discussed the same children's story in "traditional” reading practices, e.g., vocabulary exercises and teacherled classroom discussions. The Group 3 students only received their usual program during the day. All groups were given the Metropolitan Regarding Comprehension Test (MAT6) before (pre-test) and after the study (post-test). The statistical analysis of the scores showed that all three groups were at the same level in reading comprehension at the beginning of the study. However, only Group 1 showed a significant improvement in the post-tests compared to the pre-tests. In the post-tests, Group 2 had a significant decrease while Group 3 had no significant difference in comparison to the pre-tests. In a drama activity students interact with others, decode what others say and do, and construct their own self. In other 
words, drama helps to develop the student's reading skills, because reading is a process that consists of making predictions, interacting with the text, and decoding the meaning embedded in the text (Tortello 2004).

Research has shown that dramatic activities can be incorporated to instruct English script reading, to foster group work and to enhance students' interest in English in EFL primary school students. Lin (2015) used Reader's Theatre (RT), a form of dramatic presentation, to study 32 sixth-grade students in a primary school in Taichung, Taiwan. Before and after the RT training, the participants took a standardized English proficiency test and questionnaire. During the 44 days of RT training, the subjects read the English scripts aloud, performed on the stage, and worked in groups. The findings demonstrated that the teachers could use the RT activities to instruct the students in script reading. Due to the RT activities, the students were more motivated to read and to appreciate English books, and gained important experiences as the characters themselves. The teachers fostered the students' cooperation and interest in learning English.

Studies have also shown that drama can improve students’ writing skills. McNaughton (1997) divided a group of primary school students into control and experimental groups. The control group received twenty lessons of discussions, while the experimental group received twenty lessons of drama. To close each lesson, the students were asked to write a poem, story or report. The writings were given a score by an independent examiner. On average, the experimental group scored $24.50 \%$ better than the control group, because they wrote more effective and longer pieces, and used more emotional and expressive vocabulary. The experimental group showed a better grasp of issues and possessed a stronger voice, like“get[ting] under the skin' of the character and identify with him/her on an affective as well as cognitive level” (McNaughton 1997, 79). Neelands, Booth and Ziegler (1993) indicated that drama enhanced secondary school students' attitudes to writing, and that the students recognized the reinforcing relationship between drama, writing and empathy. Similarly, when working with secondary school learners, Wagner (1986) showed that role-play can improve persuasive writing, and Goalen (1996) shared the point that role-play can improve historical writing. The Scottish Office Education Department (1992) stated that drama-related experience can be used as a setting for future writing, thus, students in the drama group scored higher in creative writing. Moore and Caldwell $(1990,1993)$ observed that drama was a better activity to improve writing than 
simply planning and discussing. Other studies have also observed that drama can improve the participants’ writing skills (Wagner 1998, Wooland 1993, Booth and Neelands 1998).

Nevertheless, it has been shown that a combination of drama techniques with teaching practices in the primary second language classroom can be more beneficial. Baraldi (2009) followed 27 fourth- and fifth-grade students over a period of 6 weeks. The classroom also included five English Language Learner (ELL) students. The strategies used to teach each unit were as follows: engage students in conversation; encourage cooperative learning; form small groups; promote writing; incorporate body use; and utilize the students' prior knowledge. Field notes, participant observations, and interviews were used to gather data. The students were observed when they were participating in the drama sessions, interacting with each other, and interacting with the teacher. The participants were interviewed at several stages to get their reactions and responses about this project. The results of this research suggested that "all the participants appreciated the use of drama in the classroom, learned the content of the economics unit, and would use drama in other subject areas. In particular, the ELL students expressed an interest and desire to use drama and theatre techniques to learn English in the future. The participants' experiences suggested that combining each field's similar teaching tools can benefit both language and content learning” (Baraldi 2009 summary).

Studies have demonstrated that drama inspires the motivation and language competence improvements in foreign language students. Cheng (2007) studied how students perceive drama activities in an advanced English major class at the National Chengchi University, Taiwan. Many of the students believed that drama helped with their oral communication skills development because they were able to practice speaking in English extensively. The students also appreciated the chance to work with their peers and thought drama was a motivation for interaction.

The above mentioned studies have demonstrated that drama has been effective in different areas of language learning, such as writing, reading, oral communication, anxiety reduction, increased motivation, etc., and with different educational levels, from kindergarten to universities students. However the differences of this study, compared with previous studies, are that the drama activities were employed in order to teach primary school students in accordance with communicative approaches and to develop their speaking competences, which are quite different from normal speaking skills, and required not only speaking skills but also speaking knowledge. The participants in this study were 
also different because they also had the attitudes and motivations of learners whose backgrounds had been significantly influenced by the Confucian heritage of Asian cultures. Because of these different starting points, with different goals to develop, this study used not only pre/post-tests for both groups, to see what levels they were before and after the intervention of the drama activities, but also used questionnaires before and after the intervention to measure the levels of the students' attitudes and motivation to learning English as a foreign language. Additionally, observation was the method used from the beginning until the end of the experiment. The following chapters explore the suitability of drama for EFL classrooms in general, and in Vietnam in particular, and then examine whether or not drama activities can be applied to develop the speaking competences of Vietnamese primary students through the drama-based lesson plans designed by the researcher. 


\section{Chapter 3: Research Contexts}

In order to realize the aims of this study, it is necessary to understand the research contexts in which the study was carried out. This chapter will provide the socioeconomic and cultural backgrounds and history of Vietnam, as well as how they have influenced the education system and the teaching and learning of English in Vietnam. The shortcomings of the English language teaching in Vietnam and the reforms led by the government will be discussed in detail. The status of the English language teaching in Vietnamese primary schools will also be reviewed.

\subsection{Introduction to Vietnam}

Vietnam is a developing country in Southeast Asia. Vietnam is an S-shaped country located in the Indochina Peninsula. It is the most eastern country in Southeast Asia, bordered by China, Laos, Cambodia and the South China Sea. Due to its geographical location, many ethnic groups reside in the country and many languages are spoken as well. Due to its multicultural and multilingual makeup and geopolitical diversity, the government of Vietnam has had difficulties in implementing and reinforcing English as a Foreign Language in Vietnam. After the Vietnam War, Hanoi became the capital of Vietnam in 1976. The rest of the country is divided into 64 provinces, 659 districts and 10,732 communes, quarters, and towns. The large number of provinces and subsidiary districts has made enforcing national plans problematic in the past.

The population of Vietnam is approximately 90.5 million. Vietnam is the $13^{\text {th }}$ most populated country in the world and the $8^{\text {th }}$ most populated country in Asia (Vietnam's General Statistics Office, 2014).

Vietnam is a poor country, but the reforms launched in 1986 transformed Vietnam "from one of the world's poorest countries to a lower middle-income country” (Conference 2016). ${ }^{2}$ Vietnam's per capital income increased from 98 USD in 1990 to 2000 USD per capita income in 2014 (World Bank Report 2015). The government of Vietnam has tried to increase its per

2 “Thirty Years of Đổi Mới-”Reform) in Vietnam - Expectations, Challenges and Achievements” Conference, Department for Southeast Asian Studies, University of Bonn, March 2016 (https://30-years-doi-moi.de/conference$\operatorname{program} /$ ) 
capita income by controlling the population growth rate, raising the living standards, eradicating poverty and hunger in rural areas, improving the education system and literacy rates, and promoting gender equality and health-related services (UNESCO 2011). From 1990 to 2006, the gross domestic product (GDP) of Vietnam increased by $7.5 \%$ annually (Word Bank Report 2015). In 2014, Vietnam had the $56^{\text {th }}$ largest economy in the world, with a GDP of around 180 billion USD (Word Bank Report 2015).

In the area of education, Vietnam has made remarkable achievements. The main goal of education is to improve the citizen's general knowledge and to recognize and support the young and talented (UNESCO 2011). Compared to other similar countries, more than $90 \%$ of the working population in Vietnam are literate, and more than $98 \%$ of children attend primary schools (Word Bank Report 2015).

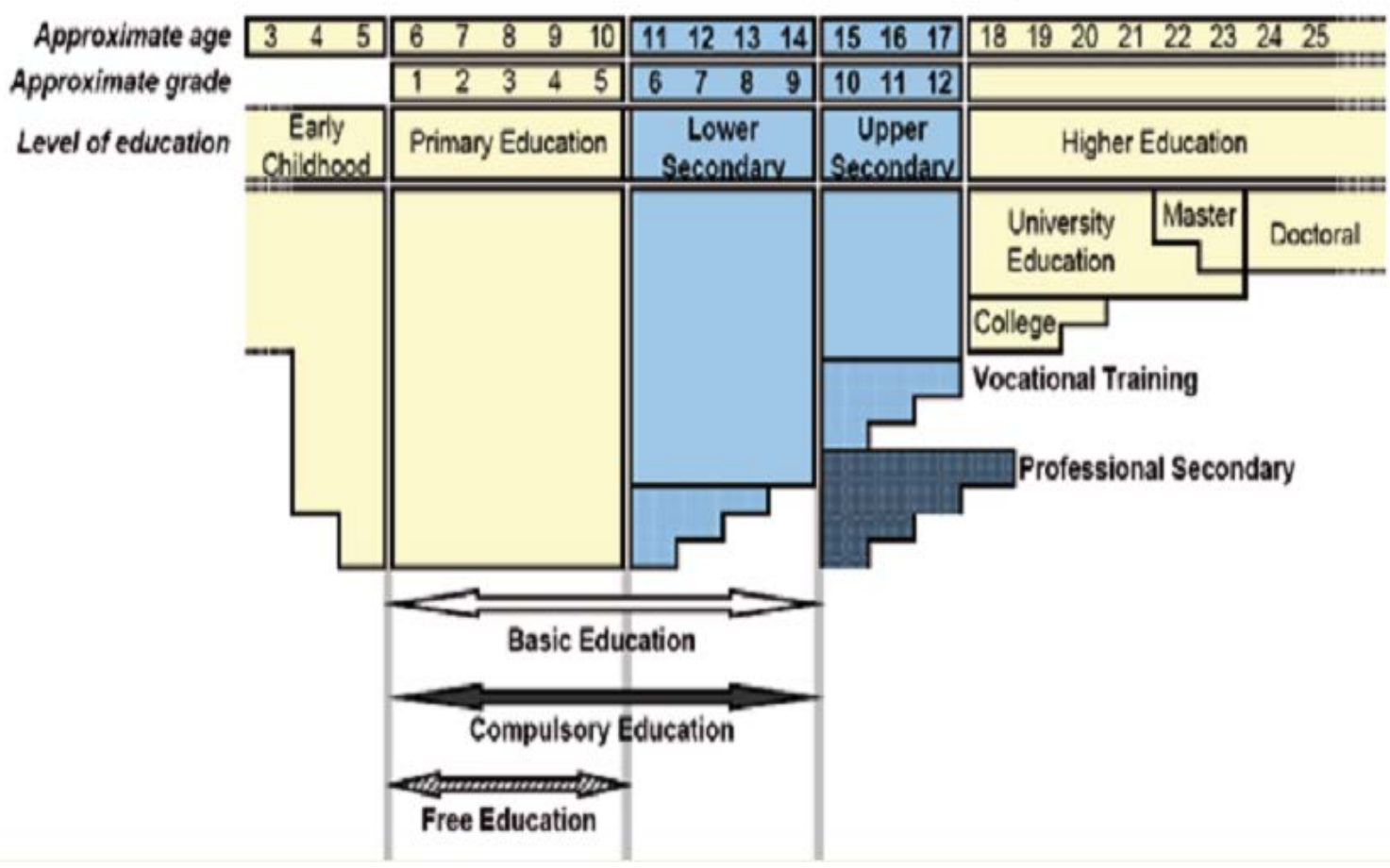

Figure 1: The educational structure in Vietnam (UNESCO 2007).

The Vietnamese education system consists of pre-school (early childhood, from 3 to 5 years old of age), twelve years of basic education (5 years of the primary level, 4 years of the secondary level, and 3 years of high school), and higher education (from the age of 18 onwards). The national education system of Vietnam is shown in Figure 1, with the approximate ages and durations.

As seen in Figure 2, the number of schools and teachers has increased across all levels from 1999 to 2011 (46th Icho 2014). Although the number of primary and lower secondary 
students actually decreased, the rise in the number of schools and teachers in these two levels highlight the emphasis that the Vietnamese government puts on early childhood education.

A.

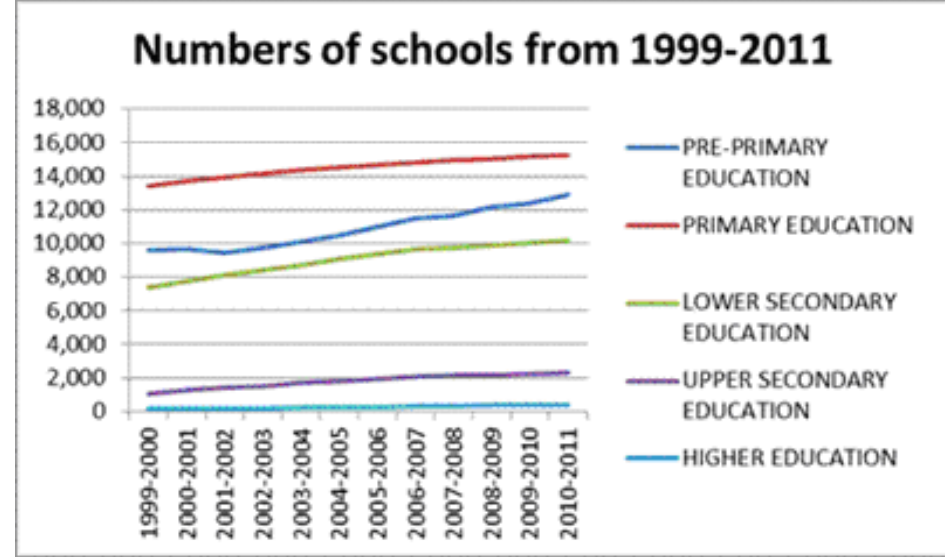

B.

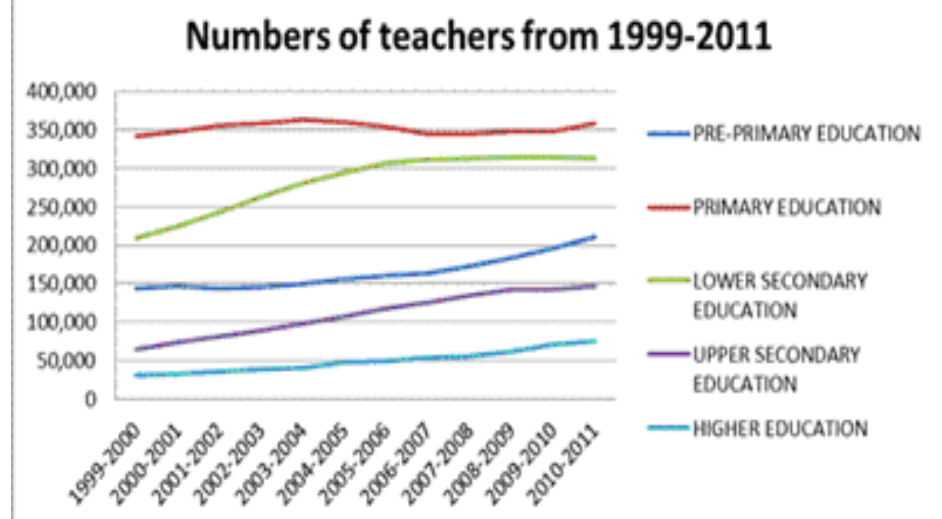

C.

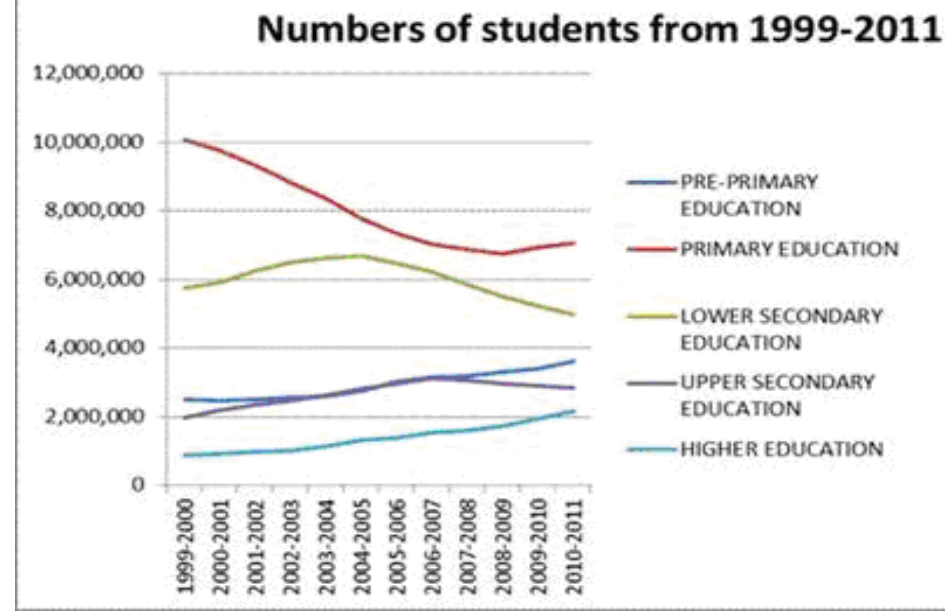

A. The number of schools in all levels of education had risen within twelve years (9\%). The number of schools in primary education increased by $6 \%$.

B. The number of teachers increased in all levels of education (14\%) as expected as the number of schools increased. The number of teachers in primary education increased by $3 \%$.

C. The number of students at all levels decreased by $9 \%$ while primary education decreased by $17.62 \%$. This is due to Vietnam's aging population.

Figure 2. The number of school teachers and students from the school year 1999-2000 to 2010-2011(46th Icho 2014). ${ }^{3}$

\footnotetext{
3 The data was collected from "Educational statistics from school year 1999-2000 to 2010-2011" on the website of the Vietnamese MOET: http://www.moet.gov.vn/?page=11.10andview=3544
} 


\subsection{Confucianism in Vietnamese Culture and Education}

According to Huang and Gove (2012), what is now known as Confucianism was produced by the greatest Chinese logician, Confucius, and is a theory which concentrates on the direction and practices of individuals in their day by day lives. It is an arrangement of moral and good decisions that direct how a man relates to others. It assumes a part in shaping the standards of the social and ethical qualities which impact on individual, familial and social connections.

In Confucianism, it is believed that procuring a higher education, going to higher positioned schools, and getting higher degrees are unquestionable courses to accomplishment. The framework of educational expectations have various levels, and since the system is very much organized, it is superfluous to plan one's own particular course. Confucianism has impacted on instruction in various ways. Firstly, the place of the family is considered. There are five essential connections for people in Confucian thought: fatherchild, head subject, spouse wife, senior more youthful and companion. Three out of the five bases of these relations happen in the family (Chang and Holt 1991). Unmistakably, one ought to endeavour to extend the prosperity and authority of one's family on the grounds that the family is the focal point of an individual's life, including their education.

Furthermore, education is viewed as a matter of family prestige. In Confucianism, guardians believe that their youngsters' educational accomplishments are significantly impacted by their child-rearing practices. They take on their youngsters' disappointments as their own since they feel that they have not done their best to work with their children. When youngsters don't accomplish, the guardians feel frustrated, on edge and humiliated (Kim 2006). The weight of accomplishment can be high on both the guardians and the children, and the children are affected by their guardians' feelings and desires. If a child succeeds scholastically, it speaks for the whole family and is considered a family accomplishment.

Thirdly, the chain of importance and concordance are also focal ideas in Confucianism. These ethics affect an individual's basic sense of leadership. Confucian tenet particularly expressed the idea: Let the sovereign be a ruler, the pastor a priest, the father a father, and the son a son (Kao 2006). Every individual plainly has his own obligations and part to play. In Confucianism, it is believed that children who have regard for their parents will turn out to be good citizens and pioneers. Their obedient devotion is reflected in the childrens' regard for, and submission to, parental requests and power. By and large, they don't have 
many options, however, but to agree to their parents' desires. The parent's power can be seen as instructive in basic leadership and practices towards homework, exams, school races, professional decisions, etc. The children regularly obey and fit in with their parents' directions and suggestions.

Confucianism advances social agreement in human connections, including family connections (Chang and Holt 1991), which rely on considering the parents' power, congruity, and the parts and obligations of every person (Miller and Yang 1997). Accordingly, the choices that children make in regards to their education are also connected with family agreement. It is clear to see that in Confucianism, the children's education is dependent on what their parents want and decide (Lien 2006). It is practically similar to a religious practice, one which influences the entire family's everyday collaborations and schedules. Parents may talk with their children in regard to their education, for example, their test results or homework when the children return home from school.

Confucianism has its own diversity of culture and has its own meaningful values. On the other side, Confucianism impacts on education training in China, Singapore, Korea, Japan, Taiwan, Hong Kong and Vietnam. Researchers have portrayed Asian students as surface learners, regularly depending upon repetition learning, and that they have latent learning styles (Holliday 1994, Subramaniam 2008). They are seen as latent learners, showing consistent acquiescence, and are concerned just with retaining learning instead of comprehending it (Purdie, Hattie, and Douglas 1996). It has been argued that in Confucianism, children are relied upon to be submissive and to have regard for individuals who are more established and who have higher positions, in this way the teacher is considered as the 'literary style of learning', and the understudies should endeavor to accomplish that information (Holliday 1994a).

Among the developing nations, Vietnam is a country which has been much influenced by the Chinese education system after 1000 years of Chinese domination. One of these influences is Confucianism, which was initially introduced into Vietnam in the first century. However, it was only after Vietnam achieved autonomy from China that the Chinese impact and Confucianism became more important. As a political system sympathetic to the government, Confucianism was advanced and promoted by the administration. Vietnam was viewed as a Confucian state until the mid-nineteenth century. In Vietnam, official support for the Confucian system of reasoning is less conspicuous in 
later times, yet its practice is still regular among government administrators and leaders. Therefore, similar to other countries which share a Confucian culture heritage, Vietnamese students have been typically seen as respectful, bashful and unwilling to scrutinize their instructors in class. Diverse studies have demonstrated that the dependent style of learning is still prominent now, and that students still consider the teachers to be the primary wellsprings of information. As Thompson has stated, "students are expected to accept the knowledge provided by the instructor as truth” (2009, 68). Additionally, the process of Vietnamese learning is described as aloof, and just includes listening to lectures, taking notes and remembering data for exams. References to the uninvolved learning style of Vietnamese students can be found in numerous articles and in the media. However, Tuyet (2013) stated that while there is evidence of social components influencing the students learning, the unequivocal elements are the Confucian cultural legacy, as well as the education framework itself, with respect to the educational program, strategies for instructing, learning and testing styles, restricted access to other scholarly assets and the studying conditions. However, this study only mentioned the impacts of the Confucian cultural heritage on the methods of teaching and learning which lead to students being passive in communication and weak at their speaking competence, which will be discussed in more detail in the following sections, after an overview of the status of the English language in Vietnam.

\subsection{The English language in Vietnam}

Vietnamese is the official language in Vietnam. However, due to historical and geographical reasons, there are a variety of languages spoken in Vietnam, such as Chinese, French, Russian and English.

English has been the most popular foreign language of study since 1986, the year Vietnam launched a series of political and economic reforms (Innovation Policy) to improve its economy. Vietnam changed its "centrally-planned economy" (that focused only on the country) into an "open door market economy", where international trade is made possible and speaking English is highly valued (Son 2011). Vietnam became a member of the Association of Southeast Asian Nations (ASEAN) in 1995 and the World Trade Organization (WTO) in 2006. Vietnam has also attracted the attention of foreign direct investment (FDI) (Son 2011) and this has drawn a large number of foreigners and investors to Vietnam. 
It has created more opportunities to access higher paying jobs for the Vietnamese people, but it also requires communication in English. Consequently, English as a Foreign Language (EFL) classes have been packed with students and professionals like doctors, engineers, government officials, diplomats, police and army officers (Kam 2004). The need for fluent English speakers has increased significantly, but in reality, the numbers are still fairly low.

This has been attributed to the way that Vietnamese students study, which focuses only on grammar and vocabulary (Peterson 2014). The English examinations in schools further exacerbate the situation, testing only reading and writing and not speaking and listening. The students and teachers aim to achieve high grades in the exams because, for the students, the certificate is more important than speaking competence, and for the teachers, the number of students passing the course reflects their teaching abilities (Tuyet 2013). It is possible that some of these students with high grades cannot communicate well in real life (Pham 2007).

In order to promote and enhance the quality of English language teaching and learning in Vietnam, Vice-Prime Minister Nguyen Thien Nhan approved a 12-year national plan for English in 2008. The national plan is titled "Teaching and Learning Foreign Languages in the National Formal Educational system in the Period of 2008-2020” (Van 2011). The objective of this Project 2020 is to ensure that students are able to use English or other foreign languages in their studies, daily correspondences, and work by 2020 (Toan 2013).

Even though the government of Vietnam recognizes the importance of developing English language competency, especially in the area of speaking, the steps to realizing this goal are more difficult than they sound. The reasons lie in the teaching methods used, and the teacher-centred model of education.

The major obstacle to achieve English speaking competency is the method used in teaching and testing. Most students learn English to pass the national examinations in which listening and speaking English are not components. To pass the national grammar-based and norm- referenced examinations requires the students to have a sufficiently good knowledge of the grammar and vocabulary of the target language, thus communicative needs are not their obvious motivation (Canh 2001). Even under a new national education program, many teachers continue to apply the traditional grammar-translation method, which focuses on reading and writing (Canh and Bernard 2009, Tomlinson and Bao 2004, 
Canh 2002). The Ministry of Education and Training's (MOET) curriculum is also exambased, meaning it tests grammar, reading and translation, all of which can be easily done on written exams. Students can emerge from years of schooling speaking little to no English. Thus, the curriculum aiming for better-speaking competence is focusing more on the reading and writing competence (Ferraris, Martel, and Vignollet 2011).

Another setback to improving the speaking competence of Vietnamese students is the influence of Confucianism, a deep-rooted philosophical or religious way of thinking (Canh 1999, Son 2011, Lim 2003). In Confucianism, the teacher is always correct and the students should passively receive the information and not ask questions unless asked to do so (Canh 1999). It is considered impolite if students disrupt, question or argue with their teacher, and the students may lose 'face', a form of perception and respect others give to them (Son 2011). Thus, Vietnamese students tend to be quieter and be less opinionated than their Western counterparts (Lim 2003). This learning environment is not conducive to speaking, let alone developing speaking competence.

Developing speaking competence should be one of the primary goals of English language teaching in Vietnamese schools. To achieve this goal, it is best to start at the earlier possible period in the student's life, i.e., primary school. Primary school students are more receptive to learning new things, acquire language the quickest, and have more years in school to study English. In the next section, the status of English language teaching in Vietnamese primary schools will be examined in more detail as well as the development of English language teaching.

\subsection{The English language teaching in primary schools in Vietnam}

Since the 1990s, English has been taught in a pilot program at language centres and some primary schools in cities like Hanoi and Ho Chi Minh City (Nguyen 2007). In 1996, English became an elective subject starting from Grade 3 (8 years of age), with two 40minute periods per week (Nguyen 2011). These schools received sufficient teaching resources and support from the parents, but speaking competence was not achieved.

Seeing the need to improve the current system, the MOET publicized the aims of teaching English in primary schools and the policies to realize these aims (MOET 2003). The three aims were: 
1. "Forming basic English communicative skills in listening, speaking, reading, and writing for students to be able to communicate in English at schools, at home and familiar social environments.

2. Providing students with a fundamental knowledge of English to gain a primary understanding of the country, people and culture of some English speaking countries.

3. Building positive attitudes to English, and better understanding and love for Vietnamese through learning. Furthermore, student's intelligence, personality and learning method will have also been gradually formed.”

The MOET launched an English curriculum that gave the numbers of words that the students must learn: Grade 3, 120-140 words; Grade 4, 140-160 words; and Grade 5, 180 200 words (Nguyen 2011). The government set the aim of students communicating in English in various settings, and the solution was to learn vocabulary.

The vocabulary curriculum led to the use of various inappropriate textbooks for Vietnamese students. There is a debate on whether or not teachers should use English textbooks. Some teachers have complained that the textbooks have a boring style and are less than useful as a source for classroom teaching, while others have a more positive attitude (Harmer 2007). Textbooks are useful guidelines for both the teachers and students, while others demonstrated the danger of being restricted to a particular textbook and the lack of practice teachers end up with, in terms of preparing materials and instruction (Ander 2015). However, in the context of Vietnam, textbooks are basically used for almost every curriculum. According to (Harmer 2007), English teachers can use textbooks to take advantage of quality materials with a detailed syllabus for grammar, appropriate vocabulary, practice, pronunciation focus, and exercises. Moreover, some textbooks include a teachers' book which assist the teachers with procedures and the implementation of new ideas. This advantage saves much time for teachers in comparison with preparing the materials and instruction by themselves. Furthermore, from the point of the students, textbooks provide a grammatical and fundamental framework that assumes the common needs of learners, as well as enabling them to study topics in advance (Hedge 2008) or revise previous topics, and consequently keep track of their own progress. Thus, selecting suitable textbooks is an important key to implementing the goals of a curriculum, as well as the education's goals. 
As seen in Table 1, the most widely used English textbook from the school years 19992000 to 2010-2011 was “Let’s Go” (Educational Publishing House). Thai (2005) criticized the textbooks for being ambiguous, unappealing, lacking games and pronunciation exercises, and the attached cassette tapes were poor and insufficient in numbers. He did, however, praise the topics for vocabulary and the grammar was consistent. Moon (2005), on behalf of the British Council, also reiterates Thai's opinions that the focus and types of activities in the textbooks were not appropriate for students.

The "Let's Go" series is no longer published, and was replaced by the "Let's Learn English” series. "Let’s Learn English” comes with three books, a teacher's guide, and a workbook. This series was written by Vietnamese authors, ${ }^{4}$ and published by the Educational Publishing House of Vietnam, Panpac Education in Singapore, and the British Council in Vietnam.

\footnotetext{
${ }^{4}$ Nguyen Quoc Tuan Phan Ha Dao Ngoc Loc and Do Thi Ngoc Hien
} 
Table 1. The number of school teachers and students from the school years 1999-2000 to 2010-2011 (Thai 2005).

\begin{tabular}{|c|c|c|c|c|c|c|}
\hline No. & Province & Classes* & Schools** & Students*** & Teachers & $\begin{array}{l}\text { Publisher and } \\
\text { Material }\end{array}$ \\
\hline 1 & Hanoi & 3286 & 262 & 113,713 & 828 & $\begin{array}{l}\text { Educational Publishing } \\
\text { House: Let's Go }\end{array}$ \\
\hline 2 & Hai Phong & 4041 & 121 & 128,431 & 89 & $\begin{array}{l}\text { Educational Publishing } \\
\text { House, and Centre for } \\
\text { Educational Technology }\end{array}$ \\
\hline 3 & Nam Dinh & 1086 & $106 / 293$ & 36,647 & 199 & $\begin{array}{l}\text { Educational Publishing } \\
\text { House }\end{array}$ \\
\hline 4 & Thai Binh & 3250 & 292 & 98,294 & 486 & $\begin{array}{l}\text { Educational Publishing } \\
\text { House }\end{array}$ \\
\hline 5 & Phu Tho & $946 / 5088$ & $170 / 299$ & $23,640 / 119,031$ & 106 & - \\
\hline 6 & $\begin{array}{l}\text { Quang } \\
\text { Ninh }\end{array}$ & 96 & $31 / 156$ & 3750 & 34 & $\begin{array}{l}\text { Educational Publishing } \\
\text { House Let's Go }\end{array}$ \\
\hline 7 & $\begin{array}{l}\text { Quang } \\
\text { Binh }\end{array}$ & 320 & 53 & 12,505 & 57 & $\begin{array}{l}\text { Educational Publishing } \\
\text { House }\end{array}$ \\
\hline 8 & Da Nang & $1555 / 2017$ & $94 / 95$ & $54,091 / 67,656$ & - & $\begin{array}{l}\text { Educational Publishing } \\
\text { House }\end{array}$ \\
\hline 9 & $\begin{array}{l}\text { Quang } \\
\text { Ngai }\end{array}$ & 273 & $61 / 230$ & 23,889 & 95 & - \\
\hline 10 & Khanh Hoa & $237 / 3758$ & $36 / 182$ & $8102 / 113,783$ & - & $\begin{array}{l}\text { Centre for Educational } \\
\text { Technology: Let's Go }\end{array}$ \\
\hline 11 & Lam Dong & $590 / 2583$ & $42 / 266$ & 19,840 & - & Let's Go \\
\hline 12 & $\begin{array}{l}\text { Binh } \\
\text { Duong }\end{array}$ & 1425 & 125 & 42,815 & 192 & Let's Go \\
\hline 13 & Dong Nai & $1231 / 4471$ & $90 / 300$ & 43,418 & 138 & $\begin{array}{l}\text { Centre for Educational } \\
\text { Technology, and } \\
\text { Educational Publishing } \\
\text { House: Let's Go }\end{array}$ \\
\hline 14 & Dong Thap & $2343 / 5726$ & $306 / 306$ & $72,893 / 153,368$ & 326 & $\begin{array}{l}\text { Educational Publishing } \\
\text { House }\end{array}$ \\
\hline 15 & Tien Giang & 531 & 60 & 18,478 & 58 & Let's Go \\
\hline
\end{tabular}

\footnotetext{
* Number of classes teaching this English pilot program over the total number of classes in the school.

** Number of schools implementing this program over the total number of schools in the province.

*** Number of students who were taught English by this program over the total number of students in the province.
} 
Despite the previous setbacks, the MOET issued the national plan "Teaching and Learning Foreign Languages in the National Formal Educational System in the Period of 20082020” in 2008 (Ngoc 2014). According to the latest MOET directive, issued in August 2010, the curriculum encompasses the following guidelines:

- The need for teaching English at the primary level;

- The principles for developing the curriculum;

- The objectives, teaching contents, recommended methodology, evaluation and prerequisite requirements for the implementation; and

- Specific directions for teaching contents for each grade.

(Nguyen 2011, 231)

The school year 2010-2011 saw major changes in the primary school curriculum. English was to be taught as a compulsory subject from Grades 3 to 5, for a total of 420 periods (140 periods per grade). The curriculum was designed so that the primary school students would reach the A1 level in the Common European Framework of Reference (CEFR) for Languages (Nguyen 2011). The CEFR provides a detailed recipe for leading instructors and curriculum developers to nurture the cognitive development and enhanced language skills in accordance with the generally accepted theories of language teaching (Thornbury 2006). This reference framework is widely used in different countries for various languages and is taken into consideration when developing and selecting textbooks for the different required levels.

The definition of the A1 level in the CEFR is shown in Table 2. The A1 level puts more emphasis on speaking and listening than reading and writing skills. Although in Vietnam, the exams almost never test speaking skills, so the students inherently focus more on grammar and vocabulary.

To supplement the new curriculum, the government defined the first official English textbook for primary school students. The series, “Let’s Learn English” was replaced by “Tiếng Anh 1, 2, 3” (English 1, 2, 3), which adopts a learner-centred and communicative approach, with a straightforward textbook structure and many listening and speaking activities. Eventually, "English 3, 4, 5” were published and used immediately. Table 3 consists of an example of the book map for Unit 1 and Unit 2 of "English 4". The content 
and the requirements of each lesson are very clear and focus on the communicative competence $^{5}$ of the A1 level in the CEFR.

Table 2. The criteria for the A1 level in the European Framework of Reference for Languages (Council for Cultural Co-operation 2009, 24-26). ${ }^{6}$

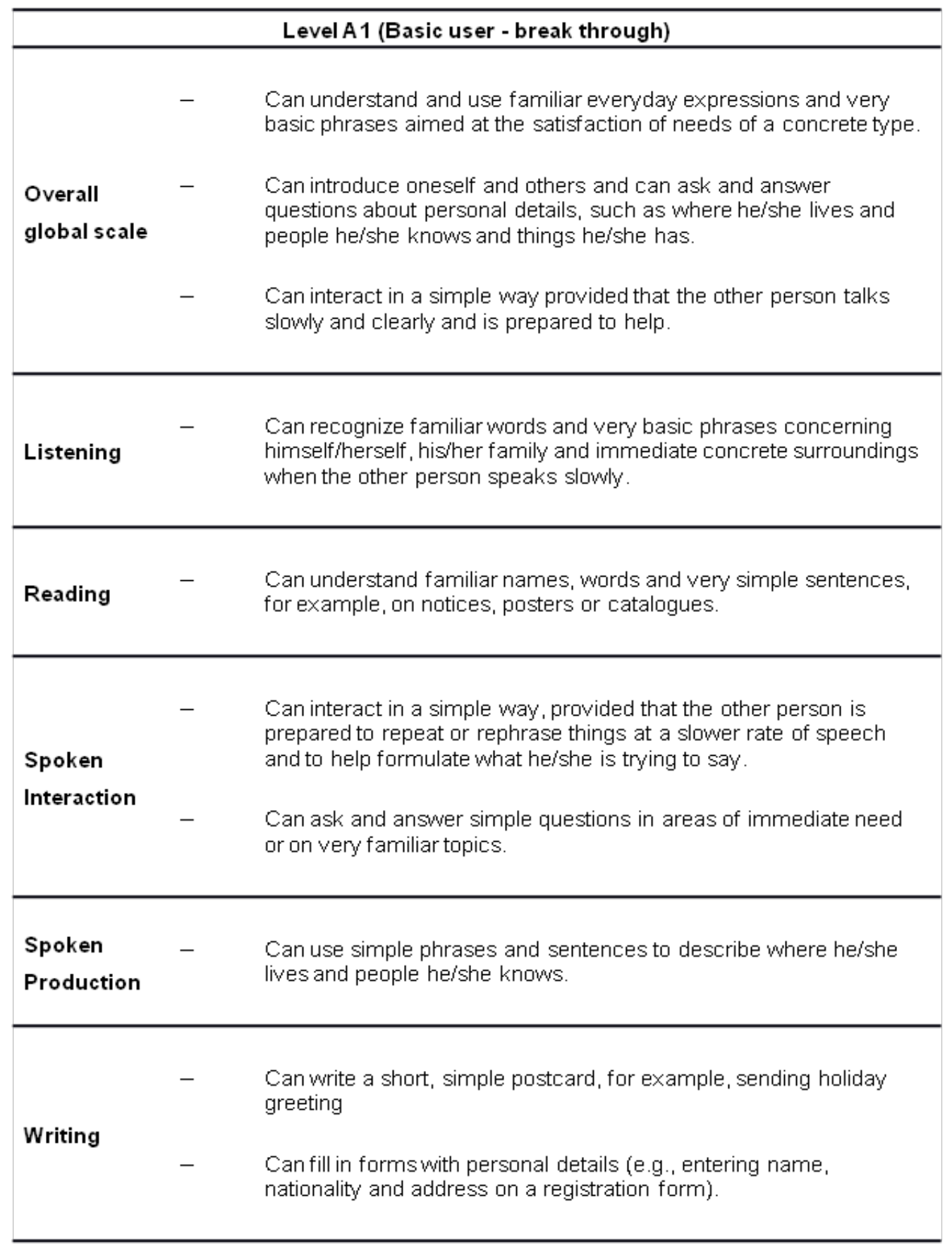

\footnotetext{
${ }^{5}$ The communicative approach will be discussed more thoroughly in the Communicative Language Teaching chapter. It refers to the ability to understand and to communicate effectively in authentic social and school environments.

6 “Common European Framework of Reference for Languages: Learning Teaching Assessment” was published by the Cambridge University Press.
} 
Table 3. An example of a book map from an English textbook, “English 4” (Van et al. 2010)

\begin{tabular}{|c|c|c|c|}
\hline \multicolumn{4}{|c|}{ Me and My Friends } \\
\hline \multicolumn{4}{|c|}{ Unit 1. Good Moming. How Are You? (Page 6) } \\
\hline $\begin{array}{l}\text { Competences } \\
\text { - Greeting someone formally } \\
\text { - Giving answers to the } \\
\text { question How are you? }\end{array}$ & $\begin{array}{l}\text { Sentence Patterns } \\
\text { - Good morning, Miss Hien. } \\
\text { - How are you? } \\
\text { - I'm fine, thank you. }\end{array}$ & $\begin{array}{l}\text { Vocabulary } \\
\text { morning, afternoon, } \\
\text { evening } \\
\text { bored, well, happy, OK }\end{array}$ & $\begin{array}{l}\text { Phonics } \\
\text { morning } \\
\text { afternoon }\end{array}$ \\
\hline \multicolumn{4}{|l|}{ Unit 2. My New Friends (Page 12) } \\
\hline $\begin{array}{l}\text { Competences } \\
\text { - Asking and answering } \\
\text { questions about where } \\
\text { someone is from } \\
\text { - Stating one's own nationality } \\
\text { or nationality of others } \\
\text { - Asking for and giving the full } \\
\text { name of a pupil/person }\end{array}$ & $\begin{array}{l}\text { Sentence Patterns } \\
\text { - Where are you from? } \\
\circ \text { I'm from England. } \\
\circ \text { I'm Vietnamese. } \\
\text { - What's his full name? } \\
\circ \text { Tom Green. }\end{array}$ & $\begin{array}{l}\text { Vocabulary } \\
\text { England, English } \\
\text { America, American } \\
\text { Australia, Australian } \\
\text { Viet Nam, Vietnamese } \\
\text { China, Chinese } \\
\text { Japan, Japanese }\end{array}$ & $\begin{array}{l}\text { Phonics } \\
\text { Vietnamese }\end{array}$ \\
\hline
\end{tabular}

In order for the country and the citizens to continuously improve their livelihood, it is paramount that the Vietnamese people can speak English fluently. The government recognizes that there must be a revolution in English language teaching because there is a more pressing need to acquire fluency in speaking and not accuracy in writing (Wright 2002). The government has made countless educational reforms in the last three decades. Not all the reforms have led to the desired outcome of competent English speakers, but the latest reform has brought about a standard goal and a uniform textbook and number of hours of English language learning across the nation. Although it is too early to foresee the outcomes, the changes are likely to be more successful than in the past, because they make use of a proven, well-researched approach, the Communicative Language Teaching Methodology. 


\section{Chapter 4: Communicative Language Teaching (CLT)}

Due to the importance of the English language, and the demand for teachers, a good command of English is necessary to satisfy the market demands. In the 1960s, English was taught using grammar-based, translation-based, or repetition-based methods (now known as traditional language teaching). By the 1970s, a new approach was introduced, focusing on what the traditional approach lacked most, which is speaking the language proficiently. The new approach, known as Communicative Language Teaching (CLT), aims to teach language for the purposes of communication. In this chapter, the traditional and CLT methods will firstly be compared and contrasted, and then the advantages and disadvantages of both methods will be discussed. Afterward, a brief history of CLT, the evolution of the theory and the research and practice of CLT will be provided in order to see why CLT is important and necessary for the students' developing communicative competences, especially in speaking proficiency.

\subsection{Traditional language teaching methods}

The 'traditional language teaching approach' is an umbrella term for language teaching methods developed before the 1970s. This term refers to some kind of teacher-centered instruction. The most commonly used methods were the grammar-translation, direct and

audio-lingual methods. These methods were used for most of the $19^{\text {th }}$ century to teach modern foreign languages (Richards and Rodgers 2001).

As early as the seventeenth century, the grammar-translation method was the way languages were taught in schools. This approach focuses on analyzing and studying the grammatical rules of a language by translating to and from one's mother tongue and the target language (Widdowson and Howatt 2004). Using grammar and vocabulary accurately is central to the grammar-translation approach (Larsen-Freeman and Anderson 2011). Teaching English at a primary school in Vietnam, where so far - despite a recent language policy, according to the teaching of English mainly according to traditional teaching methods and social forms (grammar-translation method, focus on literacy, frontal teaching) is taught - to be aligned with the communicative approach.

The grammar-translation method is an academic exercise, using grammar to learn the target language, rather than an exercise to assist the learners in using the language (Cook 
2013). The teachers give instructions, explain conceptual problems and discuss the particular grammatical structure in the mother tongue. Typically, the teachers present the rules of one grammatical instance and then illustrate its use through repetition in reading, writing and translating. The text is often accompanied by a list of new vocabulary. In the grammar-translation method, repetition and the textbooks are essential for student to learn.

As unimaginative as it sounds, however, the grammar-translation method has achieved a remarkable success. Wahba, Taha and England (2013) observed that millions of people had successfully learned the second language to a high degree of proficiency using this method. However, students could be more involved in the coursework instead of simply following the textbook and make corrections afterward. Therefore, the direct method was created as a consequence of the grammar-translation method (Hinkel 2011).

The direct method focuses on the written language, of which grammar and vocabulary are taught inductively by means of direct translations. Rather than analyzing and explaining grammar rules, students are encouraged to communicate freely and use grammar naturally. In this approach, all teaching is done using the target language. The teachers may employ visual aids and pantomime to clarify concepts and vocabulary. The learners speak in the target language and speak as if they are in real life scenarios. This approach is often referred to as the natural or oral method (Wahba, Taha, and England 2013).Although the direct method focuses more on listening and speaking than its predecessor, it does have its own limitations. Brown (1994) wrote that the direct method "did not take well in public schools where the constraints of budget, classroom size, time and teacher background (native speakers or native-like fluency) made such a method difficult to use”. It ignores reading and writing activities, rarely teaches vocabulary and grammar is not taught systematically. Hence, by the early twentieth century, the direct method's popularity began to wane and the audio-lingual method (ALM) was created to tackle some of the weaknesses of the direct method.

The ALM is based on the operant conditioning learning model developed by psychologist Burrhus Frederic Skinner, where the best way to reinforce/reduce behavior is by modifying the consequences (McLeod 2007). For example, if the learner is rewarded for correctly producing the sound, then he/she is more likely to produce the same sound in the future.

The ALM believes that repetition increases the likelihood of producing correct sounds and sentences. The learners listen and repeat the phrase until they are able to do so naturally. They are first given said phrases in the subject-verb-prepositional format. After learning 
these concepts, they will be able to add or remove words to make novel sentences. The ALM believes that learning a language is about acquiring the appropriate or right linguistic habits, and it uses drills to form good language habits (Singh 2008).

However, in this model, the teacher directly controls the students' behavior: he/she provides a model as well as reinforces correct responses (Larsen-Freeman and Anderson 2011). Moreover, grammatical skills are neither taught nor reinforced.

In summary, the traditional understanding of teaching is that the teacher is the focal point of class activities and handles the responsibility of all teaching activities. Teachers utilize the same teaching methodologies of teaching regardless of the age, understanding level, or grades of pupils mainly basing on reading and memorizing textbooks. In addition, there are no supplementary activities to help students understand and visualize the content of a lesson. During class time teachers read text aloud and involve students in a process of repeating the text. This ideal can be found in the study by Menon, G (2008). The author found that the traditional learning environment consists of "discipline, listening, obeying, repeating and reproducing”.

The main aim of this method is to help students finish their textbook is their ultimate goal and to finish textbook is commonly considered a success among teachers.

Key features of traditional methods of teaching are listed :

- Teachers are at the center of all activities;

- Teachers work a lot;

- Teacher accomplishes all activities;

- Teacher work a lot and transfer the knowledge to the students;

- Teachers just teach textbooks;

- The lessons are just prepared in accordance with the syllabus of the textbooks;

- Students are afraid of entering the class since the class environment is dreadful and teachers act like dictators;

- Students learn but forget soon;

- The classroom is arranged in a manner that has all students seated in a row and faced toward the board;

- During the class, students are quiet, calm, and concentrated on the teacher;

- The students sit passively listen and receive information as communicated by the teacher;

Therefore, teaching English as a foreign language is a more monotonous process whereby teaching is reduced to recital and word by word translation of English to the native language Vietnamese. Instead of coaching and leading students to cognitively understand the overarching message of the lesson, teachers make the students read, repeat, and 
memorize. As a result of this type of traditional teaching, many students even finished several years of learning English, but they still have difficulty in introducing themselves in English.

However, according to Carrasquillo (1994), in English as foreign language courses, it is important that learners have the opportunity to talk and to practice what they have learned in the classroom. The sooner the students realize that language habits drive from custom and usage rather than from logic, the sooner they will get down to the serious business of mastering a new set of language skills. As a general rule, we may say that the teacher should do no more than $25 \%$ of the talking in the class and that students should be permitted to do $75 \%$ of the talking through multiple relevant activities created by their teachers.

As a response, the CLT method was developed to address the previously mentioned disadvantages of the grammar-translation method, the direct method, and ALM).

\subsection{Communicative Language Teaching}

Due to the shortcomings of the traditional language teaching methods, it was necessary to develop a new approach to meet the growing demand for proficient English speakers. The approach should be realistic enough with the whole language in order to help students know how to communicate using the correct social language, gestures or expressions (Galloway 1993). This approach is known as CLT. It is mainly based on competence and performance, which is explained as a language in mind or knowledge of the language. However there is the production of certain meaningful sets of words and sounds that are the actual use of language which suggests performance (Chomsky 1965). The terms were later merged and broadened by Hymes (1972) and Campbell and Wales (1970) as communicative competence, which formulated in deliberate. That contrasts with Chomsky's more abstract notion of "linguistic competence", as a system of neurologically deep-wired rules (Chomsky 1965). Hymes argued that communicative competence stressed the social context of language acquisition. For example, like "a normal child acquires knowledge of sentences, not only as grammatical but also as appropriate. He or she acquires competence as to when to speak, when not, and as to what you talk about with whom, when, where, in what manner” (Hymes 1971). Thus, “a communicative approach to language teaching would include not only knowledge of the language-internal aspects of a language-its pronunciation, vocabulary, and grammar but also an understanding of the appropriate use of a language in different social contexts” (McDonald 2011,33)

CLT developed simultaneously in the early 1970s in Europe and the United States, and it quickly spread around the world (Spada 2007, Savignon, 2005). CLT has since garnered 
the support of many researchers (Littlewood 1981, Canale 1983, Rivers 1987, O’Malley and Chamot 1990, Cook 1991, Richards and Rodgers 2001), and it has been regarded as one of the ideal teaching approaches in the area of foreign and second language education in the past three decades.

CLT is based on the sociolinguistic theory that was introduced in the late 1960s (Richards and Rodgers 2001). Since its conception, the CLT approach has gradually become a prominent language teaching method and a successor, in some instances, to the grammartranslation method and the audio-lingual method (Warschauer and Kern 2000).

CLT emphasizes meaning and communication aiming at improving the learner's communicative competence. Communicative competence is the capacity to work in a communicative setting, i.e., in a dynamic exchange in which linguistic competence must adapt itself to the total information input, both linguistic and paralinguistic, of one or more of the interlocutors (Savignon 1972,. Canale and Swain (1980) later defined communicative competence as comprising of four areas: linguistic competence, sociolinguistic competence, strategic competence and discourse competence. Since its inception by Hymes (1972), the theoretical and practical approaches to the concept have increased significantly. Hotwatt (1984) distinguished two versions of CLT known as the "weak version" and the "strong version". The weak version emphasizes the significance of allowing learners to use English for communication, while the strong one believes that language is picked up through such communication. In other words, in the strong version, the learners learn English by using it.

Furthermore, Morrow (1981) has provided some guiding principles behind the use of communicative activities as language teaching and learning techniques, which are as follows:

1 - “Know what you are doing”.

This principle reminds that every part of the lesson should focus on tasks which motivate the student to perform in the target language. For example, in teaching speaking, the task could be asking someone about their family. It is important that both the teacher and students have to answer the following questions throughout the lesson: "Why am I teaching this?”, “Why am I learning this” and “For what?”. Every lesson should end by showing the learners what they can do which they could not at the beginning of the lesson so that student will realize and be more motivated for the next time of learning. An 
example of this principle is the technique of role-playing. This part of CLT promotes holistic learning as well because students have opportunities to connect school with the outside world, thus they understand the purpose of learning process but not only try to drill the exercises

2 - “The whole is more than the sum of its parts".

Learning is a lifelong process and communication is the same. Communication is dynamic and "cannot easily be analyzed into its various components without its nature being destroyed in the process” (Gupta 2004, 73). For example, the teacher may teach the students the various forms of greeting but it may be that the student cannot use all of them appropriately in a given situation. However, they may later use them in different situations and at different times.

3 - "The processes are as important as the forms".

To develop the abilities of the students in communicating in the foreign language, the information gap, choice and feedback are three important processes of communication which should be applied to the teaching and learning processes. These processes are described in detail in the paragraphs below.

4-“To learn it, do it”.

Only by practicing communicative activities will students learn to communicate. The role of the teacher thus changes, and they no longer dominate the learning process all of the time, but they provide all the help for the students to play an active role in their own learning.

5 - “Mistakes are not always mistakes”.

Making mistakes is inevitable during the learning process, however, the teacher should be flexible enough to treat mistakes differently depending on the time and situation. As Richard $(2006,13)$ recommended, “be tolerant of learners’ errors as they indicate that the learner is building up his or her communicative competence”.

CLT combines the functional and structural aspects of language. The functional aspect of language varies with the situation in which the communication is taking place. For example, an academic lecture is different from a wedding toast. The structural aspect of the language also varies if the communication is verbal or written formal or informal. For example, the language in a report is different from daily conversations. 
In CLT, the various language skills (reading, writing, etc.) are integrated into the lessons. Thus, through CLT, the learners are expected to master a foreign language, not only in speaking but in the other areas as well.

CLT believes that the objective of learning a language is for communicating with others, which is more important than following grammatical arrangements. The main aim is to help learners having the skills and knowledge for interpreting or using the given language in different contexts or situation. The aims of the CLT's pedagogical model can be described by six keywords: learner-centred, cooperative (collaborative), interactive, integrated, content-centred and task-based.

Unlike the teacher-centred model of traditional language teaching methods, CLT is learnercentred. In this approach, the learners are the active members in the learning process, and the teacher's participation is minimal. The student is a mediator "between the self, the learning process, and the object of learning”, and a joint mediator between oneself and others (Breen and Candlin 1980, 110). In the learner-centred approach of CLT, the learners are assigned various roles and, therefore, are constantly engaged in their learning.

Another aspect of CLT is that the activities are cooperative. Students usually carry out these activities in small groups ( $\mathrm{Hu}$ 2005). Working in a group helps to minimize the amount of time each student spends to learn and negotiate meaning. When the students cooperate, they also interact. This aspect can help students further developing their ability to working in bigger groups. They might be more actively to involve in the learning process and to share their ideas with others.

CLT activities are also designed to be interactive because the purpose of language is for communication, as a motivation for learning the language (Hamid and Baldauf 2008). Interaction compels the students to focus systematically on the structural and functional aspects of language (D. Gupta 2004). Therefore, CLT helps advance the students' grammar competence in the target language by increasing their communicative competence. That is, what is a more meaningful way to use a language than through social interaction? In CLT, Richards and Rodgers (2001) found communication involves integrating the various language skills.

Furthermore, the activities are designed to encourage the students to use authentic and meaningful language (content-centred), and not merely as mechanical patterns for 
practicing the language. To simulate real-life situations, authentic materials play an important role in CLT (Hui-Chun 2003). Authentic materials include newspaper articles, live TV or radio broadcasts, menus and literary texts.

Regarding grammar in CLT, Thompson $(1996,11)$ suggested learner should learn a new language in a comprehensible context in order to understand the meaning. After that, they pay more attention to the grammatical forms to convey the meaning. With guidance from the teacher, the students do most of the discussing tasks to get a better knowledge of the language. CLT is not concerned with the grammatical rules of the language and "how to form grammatical sentences but to know when, where and to whom to use these sentences in a speech community” (Richards 1985, Hymes 1972). Grammatical rules are not neglected in the communicative approach, but more emphasis is given to the use of language for the communicating the meaning than the learning of structures, forms, and vocabulary.

In addition, Richards (2006) presented a set of ten core assumptions or principles of Communicative Language Teaching as follow:

1- "Second language learning is facilitated when learners are engaged in interaction and meaningful communication

2- Effective classroom learning tasks and exercises provide opportunities for students to negotiate meaning, expand their language resources, notice how language is used, and take part in meaningful interpersonal exchange

3- Meaningful communication results from students processing content that is relevant, purposeful, interesting, and engaging.

4- Communication is a holistic process that often calls for the use of several languages skills or modalities.

5- Language learning is facilitated both by activities that involve inductive or discovery learning of underlying rules of language use and organization, as well as by those involving language analysis and reflection

6- Language learning is a gradual process that involves creative use of language, and trial 
and error. Although errors are normal product of learning, the ultimate goal of learning is to be able to use the new language both accurately and fluently.

7- Learners develop their own routes to language learning, progress at different rates, and have different needs and motivation for language learning

8- Successful language learning involves the use of effective learning and communication strategies

9- The role of teacher in the language classroom is that of a facilitator that creates a classroom climate conducive to language learning and provides opportunities for students to use and practice the language and to reflect on language use and language learning

10- The classroom is a community where learners learn through collaboration and sharing.”

(Richards 2006, 22)

As mentioned above, one of the important principles of CLT is "the processes are as important as the form”. In which 'Information gap' refers to a meaningful activity which takes places between students and a teacher, who can demonstrate the activities in advance. The information gap is one of the most fundamental in the whole area of communicative teaching. Any exercise or procedure which claims to engage the students in communication should be considered in the light of it, and one of the main jobs for the teacher is to set up situations where information gaps exist and motivate the students to join in them appropriately. 
Person A:

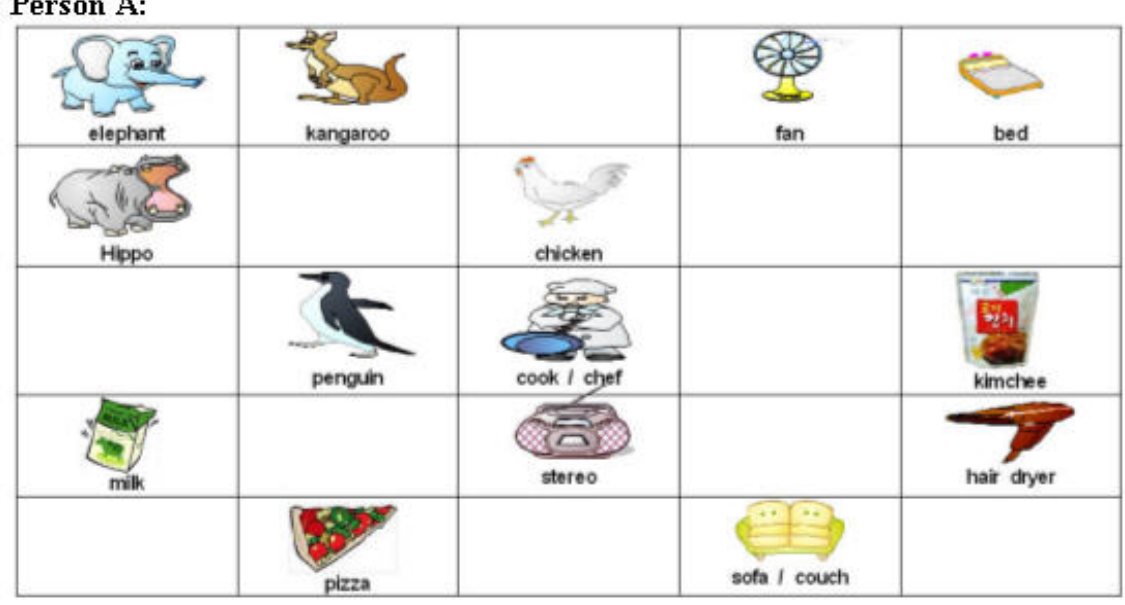

Person B:

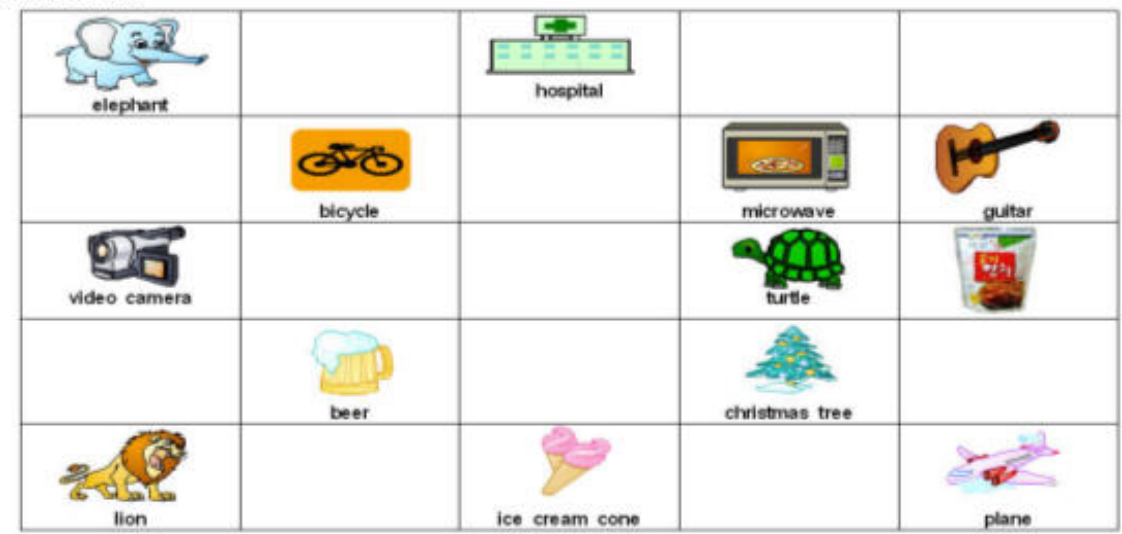

Figure 3. An example of an information gap activity. ${ }^{7}$ Person A and Person B must communicate to determine what is in their missing cells.

Larsen-Freeman (2000) points out that during a communicative exchange, the speaker decides what they will say and how they would say it. Therefore, communicative activities should create real situations where the learners can decide what to say and how to say it, irrespective of the task's requirements. The learner must have a 'choice' on what to say and how to say it, or else it would not be communication. This is another crucial characteristic of communication which, from the point of view of the speaker, means that he must choose what and how to say it. Doing so under time pressure is one problem foreign users often encounter, and it is an aspect of communicative ability which has hitherto been frequently overlooked in the classroom. A similar problem confronts the listener. The choice which is open for the speaker means that there is always doubt in the listener's mind about what is to come next. This means that an exercise where the speaker and

\footnotetext{
${ }^{7}$ http://ddeubel.edublogs.org/2010/09/18/the-1-communicative-language-teaching-activity/
} 
listener are controlled in their language use by the teacher fails to practice this aspect of communication.

The third, final process of communication is feedback. As is known, communication is defined as the interaction between a speaker and a listener. Therefore, the speaker will know whether or not they got their point across based on the 'feedback' from the listener. However, if the listener does not or cannot provide feedback, then the interaction is not communication.

In real life, one person communicates with another because they wish to, e.g., to invite him, to complain to him, to threaten him or to reassure him, and this aim will be on their mind all the time they are speaking. What a person says to the other person will be designed to reach that aim, and what the other person says to them will be judged. In other words, what you say depends on what they have just told you (though this is obviously very important), but also on what you want to get out of the conversation. The strategies and tactics involved in using language in this way are of fundamental importance in communication, and again they are omitted in a method which fails to provide practice in using a language for real purposes.

All CLT activities have a gap of information between the speakers, a choice of what and how to say something, and a feedback component from the listener. Taken together, the three processes outlined above seem central to the development of any procedure for teaching the communicative use of a language. The role of the teacher is to choose the right activities for the purposes of the lesson or lesson plan.

\section{The CLT Procedure}

The communicative approach can be used for any language skill and level or any type of instructional material and classroom activity. Finocchiaro and Brumfit (1983) offered the instructional outline for teaching a foreign language to secondary school students. According to the authors, the lesson should begin with a motivation and discussion of the situation. This stage familiarizes the students with the communicative activity that they will do later on and gives them an opportunity to prepare beforehand. The communicative activity is presented, and the students are given some time to practice. After the activity, the teacher and students discuss the situation and similar personal experiences. The students study the dialogue in the communicative activity to discover the language rule(s). After the rule is well understood, the students can engage in the more unstructured 
communicative activity. The teacher can then review the students' homework and evaluate their learning.

1. "Presentation of a brief dialog or several mini-dialogs, preceded by a motivation (relating the dialog situation[s] to the learners' probable community experience) and a discussion of the function and situation - people, roles setting, and the informality or formality of the language which the function and situation demand. (At beginning levels where all the learners understand the same native language, the motivation can well be given in their native tongue).

2. Oral practice of each utterance of the dialog segment to be presented that day (entire class repetition half-class groups individuals) generally preceded by your model. If mini-dialogs are used, engage in the similar practice.

3. Questions and answers based on the dialog topic(s) and situation itself. (Inverted wh or or questions.)

4. Questions and answers related to the students' personal experiences but centered around the dialog theme.

5. Study one of the basic communicative expressions in the dialog or one of the structures which exemplify the function. You will wish to give several additional examples of the communicative use of the expression or structure of familiar vocabulary in unambiguous utterances or mini-dialogs (using pictures, simple real objects, or dramatization) to clarify the meaning of the expression or structure...

6. Learner discovery of generalizations or rules underlying the functional expression or structure. This should include at least four points: its oral and written forms (the elements of which it is composed, e.g., "How about + verb + ing?”); its position in the utterance; its formality or informality in the utterance; and in the case of a structure its grammatical function and meaning...

7. Oral recognition interpretative activities (two to five depending on the learning level the language knowledge of the students and related factors).

8. Oral production - proceeding from guided to freer communication activities.

9. Copying of the dialog or mini-dialogs or modules if they are not in the class text.

10. Sampling of the written homework assignment, if given.

11. Evaluation of learning (oral only), e.g., "How would you ask your friend to ? And how would you ask me to ?" "

(Finocchiaro and Brumfit 1983, 107-108)

\section{Instructional materials of CLT}

There is a wide range of materials that support CLT. According to Richards and Rodgers (2001), there are three kinds of materials: text-based materials, task-based materials, and realia which are designed for the CLT classroom to undertake the role of promoting the communicative goals of language teaching and learning.

There are numerous text-based materials (textbooks) that were intended to guide and supplement CLT. As seen in Figure 4, the book map shows the competence, sentence patterns, vocabulary and phonics that are covered in the units. Text-based materials are a well-written guidance for teachers who want to implement CLT in their classrooms. The 
teacher has to plan the activities which should be suitable for each lesson, and which can be the best for them to deal with the competence in each unit. For example, an information gap activity can be used to remind students about the vocabulary of weekdays, as in Figure 4.

\begin{tabular}{|c|c|c|c|}
\hline \multicolumn{4}{|c|}{ Unit 8. My School Timetable Page 54} \\
\hline $\begin{array}{l}\text { Competences } \\
\text { - Asking and answering } \\
\text { questions about days of } \\
\text { the week } \\
\text { - Asking and answering } \\
\text { questions about school } \\
\text { timetables, using frequency } \\
\text { expressions }\end{array}$ & $\begin{array}{l}\text { Sentence Patterns } \\
\text { - What day is it today? } \\
\text { - It's Monday. } \\
\text { - How often have you got English? } \\
\text { - Four times a week. }\end{array}$ & $\begin{array}{l}\text { Vocabulary } \\
\text { Monday, Tuesday, } \\
\text { Wednesday, Thursday, } \\
\text { Friday, Saturday, } \\
\text { Sunday, } \\
\text { once a week, twice a } \\
\text { week, three time a } \\
\text { week, ... }\end{array}$ & $\begin{array}{l}\text { Phonics } \\
\text { Monday } \\
\text { Thursday }\end{array}$ \\
\hline \multicolumn{4}{|c|}{ Unit 9. In My Classroom Page 60} \\
\hline $\begin{array}{l}\text { Competences } \\
\text { - Asking and answering } \\
\text { questions about } \\
\text { classroom objects } \\
\text { - Asking and answering } \\
\text { questions about the quantities } \\
\text { of the classroom objects }\end{array}$ & $\begin{array}{l}\text { Sentence Patterns } \\
\text { What is it? - It's a new clock. } \\
\text { What are they? - They're benches. } \\
\text { How many books are there in your } \\
\text { schoolbag? } \\
\text { - Ten books. }\end{array}$ & $\begin{array}{l}\text { Vocabulary } \\
\text { board, painting, clock, } \\
\text { cupboard, map, bench } \\
\text { numbers to } 100 \\
\text { in, on, at }\end{array}$ & $\begin{array}{l}\text { Phonics } \\
\text { pens } \\
\text { books }\end{array}$ \\
\hline
\end{tabular}

Figure 4. Sample unit outline from Book map - English 4.

Task-based learning is an overall approach to language learning that views the 'tasks' that learners do as central to the learning process. The learning procedure is viewed as an arrangement of open assignments that are straightforwardly connected to curricular objectives.Task-based materials are games, role-plays, simulations and communication activities that support the CLT classroom. Task-based materials can be exercise handbooks, cue cards, and interaction booklets (see Figure 5). 


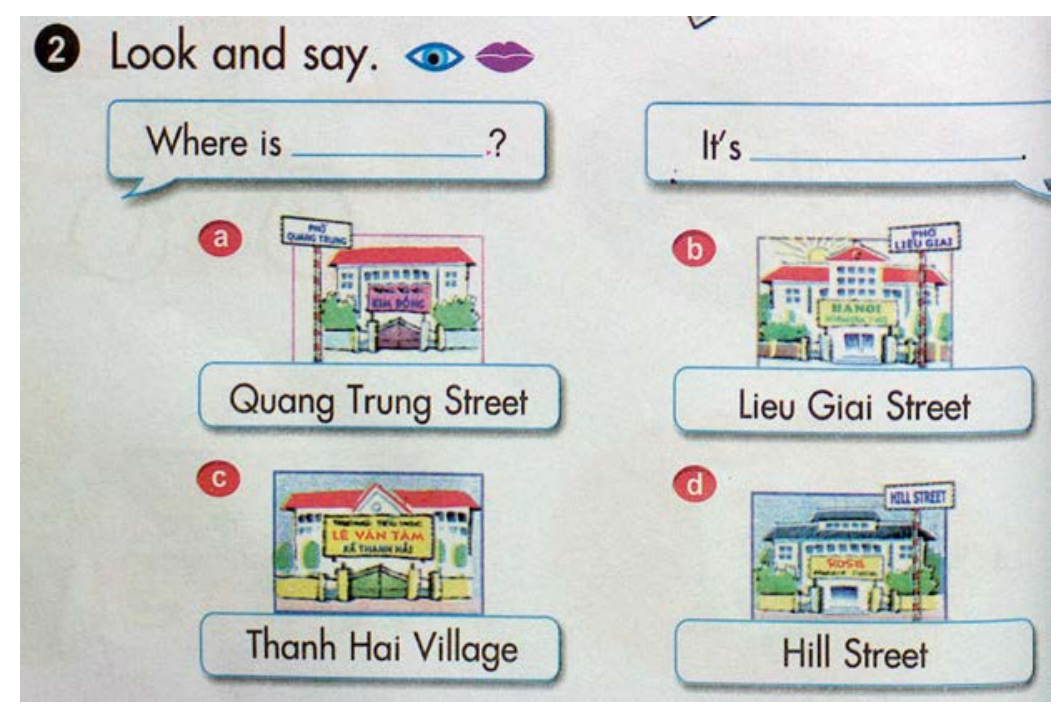

Figure 5. An example of a task-based material. The students are instructed to complete the sentence based on the pictures given (English 4).

This activity can be more meaningful than using the grammar-translation method. Students can role play like two people meeting on the street and asking about the way to get somewhere.

Realia are authentic materials taken from real life. Proponents of CLT have maintained the importance of realia in the foreign language classroom because real-life materials are shown to help students to be aware of the language easier and to create motivation much better. Realia includes signs, magazines, advertisements, newspapers, pictures and symbols (see Figure 6). The authentic materials allow the students to develop strategies for comprehending the language used by native speakers (Hui-Chun 2003). Authentic materials present the students with the language as it is, rather than the language as it is written to be taught. Thus, authentic materials enable students to communicate 'authentically' (Larsen-Freeman 2000). Examples of role-playing scenarios might be: two students are asked to be a doctor and a patient in a hospital or a student to be a teacher while the rest are students. The assessment will be determined by the outcome of the task rather than the accuracy of the language forms.

In the end, students have to use the language spontaneously in situations outside the classroom (Brown 2001). Therefore, classroom tasks should prepare for the students by using authentic materials and similar experiences for communication in real life situations. 


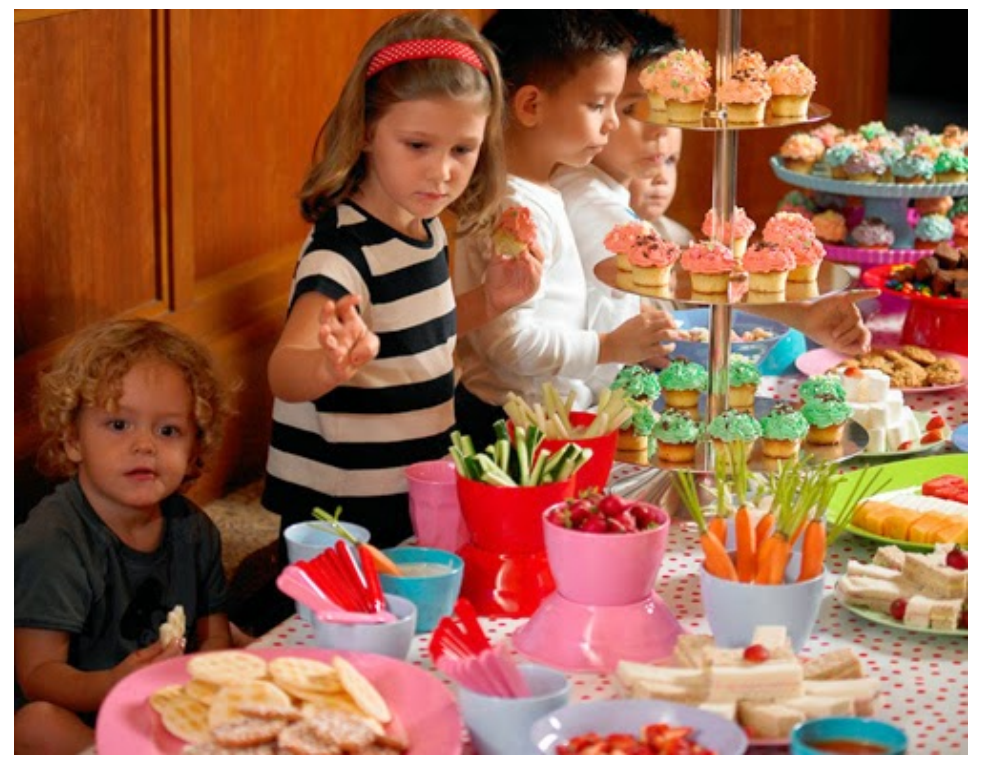

Figure 6. An example of a realia. Students are instructed to describe the situation, people, etc., in the picture.

By using authentic pictures, students can guess the place, the reason and the participants in the photograph. They are easy to describe and even they can imagine their own picture in the same situation.

\subsubsection{Roles of the teacher and learner}

In different methods of teaching, the roles of the teachers and students in the teaching and learning processes are different. In the traditional method, the teachers are a source of knowledge and the learners are passive receivers (Kuzu 2008). It is so called as the “teacher-dominated interaction” (Broughton 1994, 22) which puts the responsibility for the teaching and learning mainly on the teacher. It is believed that if the students are present in the lessons and listen to the teachers' explanations and examples, they will be able to use the knowledge. Alternatively, in communicative language teaching, the roles of the teachers and students have changed. The roles of the learners are very different from those found in traditional classrooms since students are parts of the communicative activities in the classroom. Similarly, the teachers are not only facilitators offering the stimulus and experience that this language learning process requires, but they also sometimes need to be an independent participant in the group (Boumova 2008). Students are encouraged to take responsibility for their own language skill development and to gain confidence in their language learning. Teachers can support the students' learning by offering communicative 
activities, guiding them in how to use learning strategies, the available tools and resources, and instruction on how to reflect on their own learning. Compared to traditional teaching methods, in CLT the teacher does not use the chalk-talk lecture method anymore but give the students the chance to do most of the talking. Breen and Candlin 1980 found that the main roles of the teacher in CLT is to "facilitate the communication process within participants and act as an important participant in the learning-teaching group”(Breen and Candlin 1980, 99).

In CLT, the teacher is not a model of communication and is not solely there to help the students make error-free sentences. The teacher must still answer questions, monitor the students' performances, and make note of their errors (Memari 2013). Brown 2001 mentioned the teacher's role is to guide the learners, and not that of an all-knowing knowledge provider The teacher has gained more roles and is supposed to be a supportive character, while the students have also gained more roles and are more active.

Breen and Candlin $(1980,166)$ illustrated that the role of the learner in CLT as a negotiator in the learning process. In addition, they have responsibility of negotiation within the group during the class procedure and activities. Regarding the teacher role, they need to relinquish control of the learning process to the learners since in CLT error correction is perceived as a hindrance to the language learning process (Heller 2010). The model ignores errors that might arise, especially during the initial stages of teaching and learning. Feedback on the students' performances is provided in that the learners subconsciously test hypotheses of the target language. Through this model, the students' fluency is not hampered, which gives them the opportunity for communication.

In summary, Badger and Yan (2008) believed that the CLT approach refers to the learners' ability to use the language, but not only the knowledge of that language. A detailed description of CLT is shown in Table 4. 
Table 4. A description of CLT (Badger and Yan 2008).

\begin{tabular}{|c|c|}
\hline Features & Focus \\
\hline Pedagogical orientation & $\begin{array}{l}\text { - Balanced attention to the four language skills. } \\
\text { - Focus on students' ability to use the second } \\
\text { language. }\end{array}$ \\
\hline Instructional content and presentation & $\begin{array}{l}\text { - Use of the second language in conducting a } \\
\text { - lesson. } \\
\text { - Inductive teaching of grammar. } \\
\text { - Teaching of communicative functions. } \\
\text { - } \quad \text { Use of open-ended questions. }\end{array}$ \\
\hline Language practice activities & $\begin{array}{l}\text { - } \text { Teacher-student interaction in the second } \\
\text { language. } \\
\text { - Games and activities resembling real world } \\
\text { tasks. } \\
\text { - Constant exposure to new language input. } \\
\text { - Communication in the second language among } \\
\text { - } \text { students. } \\
\text { - } \text { Integrated practice in the four language skills. } \\
\text { - Listening and speaking about various topics. }\end{array}$ \\
\hline Teacher and learner roles & $\begin{array}{l}\text { - } \quad \text { Pair and small group work. } \\
\text { - } \quad \text { Peer feedback and evaluation. }\end{array}$ \\
\hline Learning materials & $\begin{array}{l}\text { - } \text { Teacher-developed materials. } \\
\text { - Authentic materials. } \\
\text { - } \quad \text { Ability to use the second language. }\end{array}$ \\
\hline
\end{tabular}

As we can see in Table 4, CLT method covers a wide range of aspect in teaching such as pedagogical orientation, instructional content, and presentation, language practice activities, the roles of teacher and learner and teaching materials. The main idea is to develop four language skills, to encourage working in groups of the learners, and to use the foreign language as the second language in daily communication. Therefore, the interaction 
between teacher and learner is more frequency leading to an increase of the willingness to use the language of the learning out of the classroom.

Bill Flick relied on ten indicators to compare the communicative language teaching with three other traditional methods (Table 5). There are similar to three traditional teaching methods such as focus more on teacher role, lack of concerning students' motivation, focus more on grammar and structure. Those aspects are very different compared to the communicative language teaching that favors of the social context purpose in learning English, student roles and their motivation, and covers four language skills. These findings are in line with the study by Badger and Yan (2008). 
Table 5. Comparison of the three traditional foreign language teaching methods with communicative language teaching (Dr Bill Flick, Director of ESL at Auburn). ${ }^{8}$

\begin{tabular}{|c|c|c|c|c|}
\hline & \multicolumn{3}{|c|}{ Traditional Language Teaching } & \multirow{2}{*}{$\begin{array}{l}\text { Communicative } \\
\text { Language Teaching }\end{array}$} \\
\hline & Grammar-translation & Direct method & Audio-lingual method & \\
\hline Goals & $\begin{array}{l}\text { Read materials, } \\
\text { develop critical } \\
\text { thinking, learn } \\
\text { grammar and } \\
\text { vocabulary }\end{array}$ & $\begin{array}{l}\text { Communicate by } \\
\text { thinking and } \\
\text { associating directly } \\
\text { in the second } \\
\text { language }\end{array}$ & $\begin{array}{l}\text { Communicate } \\
\text { automatically by learning } \\
\text { new habits }\end{array}$ & $\begin{array}{l}\text { Communicate in social } \\
\text { context appropriately and get } \\
\text { the right purpose of learning } \\
\text { English }\end{array}$ \\
\hline $\begin{array}{l}\text { Role of the } \\
\text { teacher }\end{array}$ & Authority & $\begin{array}{l}\text { Teacher is centre } \\
\text { and directs }\end{array}$ & Teacher-centered & $\begin{array}{l}\text { Facilitator/advisor/manager/ev } \\
\text { aluator/co-communicator }\end{array}$ \\
\hline $\begin{array}{l}\text { Role of the } \\
\text { student }\end{array}$ & $\begin{array}{l}\text { Learn from the } \\
\text { teacher }\end{array}$ & $\begin{array}{l}\text { Follow what teacher } \\
\text { says }\end{array}$ & Imitate the teacher & Active communicator \\
\hline $\begin{array}{l}\text { Student-teacher } \\
\text { interaction }\end{array}$ & $\begin{array}{l}\text { Teacher first, then } \\
\text { students }\end{array}$ & $\begin{array}{l}\text { Both initiate } \\
\text { interaction, and } \\
\text { student to student }\end{array}$ & $\begin{array}{l}\text { Teacher directs and the } \\
\text { student is in drill }\end{array}$ & $\begin{array}{l}\text { Teacher designs tasks for } \\
\text { student to communicate }\end{array}$ \\
\hline $\begin{array}{l}\text { Student's } \\
\text { motivation }\end{array}$ & Not applicable & No concern & No concern & Be motivated \\
\hline Focus & $\begin{array}{l}\text { Vocabulary and } \\
\text { grammar }\end{array}$ & $\begin{array}{l}\text { Mostly vocabulary, } \\
\text { grammar and } \\
\text { communication }\end{array}$ & Structure is important & $\begin{array}{l}\text { Accomplish communication } \\
\text { purposes in studying English }\end{array}$ \\
\hline Language skills & Reading and writing & Not applicable & $\begin{array}{l}\text { Listening, speaking, } \\
\text { reading, and writing }\end{array}$ & $\begin{array}{l}\text { Reading, writing, and more } \\
\text { listening and speaking }\end{array}$ \\
\hline $\begin{array}{l}\text { The mother } \\
\text { language use }\end{array}$ & Two-way translation & Not used & Avoiding & Generally not used \\
\hline $\begin{array}{l}\text { Evaluation of } \\
\text { language } \\
\text { learning }\end{array}$ & $\begin{array}{l}\text { Applying grammar } \\
\text { rules in written } \\
\text { translation }\end{array}$ & $\begin{array}{l}\text { How they use } \\
\text { language in an } \\
\text { interview }\end{array}$ & Testing for accuracy & $\begin{array}{l}\text { Communicative tests on } \\
\text { fluency and accuracy }\end{array}$ \\
\hline $\begin{array}{l}\text { Treatment of } \\
\text { errors }\end{array}$ & $\begin{array}{l}\text { Teacher supplies } \\
\text { correct answer }\end{array}$ & Self-correction & $\begin{array}{l}\text { Avoid errors by over- } \\
\text { learning }\end{array}$ & $\begin{array}{l}\text { No error correction unless it } \\
\text { interfered with communication }\end{array}$ \\
\hline
\end{tabular}

\footnotetext{
${ }^{8}$ http://www.auburn.edu/ nunnath/engl6240/principl.html
} 


\section{Chapter 5: Speaking Competence}

In communicative language teaching, speaking is the means as well as the goal of learning. In order to achieve competence in speaking, it is important to define what makes someone a good speaker with a high speaking competence. In this chapter, speaking competence and its sub-competences will be defined by their attributes and intentions. Finally, the characteristics of a successful speaking class, how to develop a speaking competence classroom, and the difficulties of implementing these will be discussed.

\subsection{Speaking}

Speaking is an oral form of communication, and one of the four language skills, alongside reading, writing and listening. Brown (2004) defined speaking as imitative, responsive, interactive, interpersonal and extensive. A good speaker is able to imitate a word, phrase or a sentence (imitative). They are able to use a limited amount of grammar, phrases, lexicon or phonology correctly. This includes prosody, such as intonation, stress, rhythm, juncture and intensive ability. The speaker can respond to a very short conversation, greetings, small talk, simple requests, comments, and the like (responsive). They can interact with others by exchanging specific information or maintaining social relationships (interactive). Being able to maintain social relationships with the transmission of facts and information is also considered as a good speaking skill (interpersonal). Finally, a good speaker is able to speak extensively without, or with limited, interaction with the listener, e.g., speeches, presentations, and stories (Akhyak and Indramawan 2013). Thus, speaking is one of the four language skills, and arguably one of the most complicated ones.

In addition, how the information is conveyed (i.e., the form and meaning) depends on the purpose, context, culture, and participants involved (Burns and Joyce 1997). For example, when giving an uninterrupted oral presentation, it is a monologue; when interacting with other speakers, then it is a dialogue. There are social and cultural norms (i.e., non-verbal components) involved in a dialogue, such as a turn-taking, the rate of speech, the length of pause between the speakers, and the relative roles of the participants. These overt and sometimes covert rules must be learned before a mastery of speaking is possible. 
Speaking helps express needs, exchange important information, develop social closeness and fulfill social etiquette. The message must be clear for the transaction or exchange of information, but the precise meaning is sometimes not required during interactions or relationship building.

According to Richards (2006), speaking has three types of function. Firstly, "talk as interaction”, which refers to the conversation, and depicts interactions that serve a primarily social function.

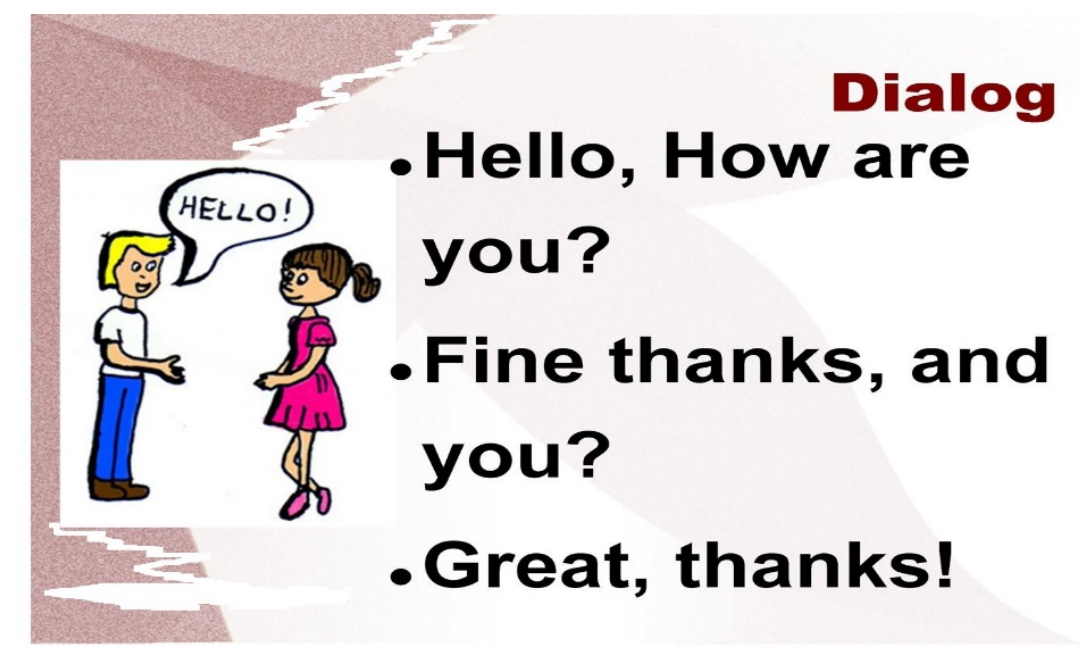

Figure 7: An example of a dialogue exercise from a textbook

Secondly, "talk as a transaction" refers to situations where the focus is on what is said or done (Richards 2006). It has been stated that "In this type of function students and teachers usually focus on meaning or on talking their way to understand” (Jones 1996, 14). The central focus is not on the participants and how they interact socially with others. Talk as the transaction is differentiated into two types (Burns 1998). The first one focuses on giving and receiving information, and where the participants focus on what is being said or done. Information is successfully communicated or understood is more important than accuracy. Examples of this technique might be asking for directions or asking the time, which does not put accuracy as a priority but the priorities are the goals of communication, whether or not the direction is shown or the time is known. The second type of "talk as a transaction” is a transaction which focuses on obtaining goods or services, for example, calling for a taxi or checking into a hotel. Generally, to acquire "talk as a transaction", some skills should be involved, such as: explaining or describing something; asking questions; making comparisons; agreeing and disagreeing, etc. 
The third type of "talk as performance” refers to talks which transmit information before an audience, for example, giving a lecture, public announcements, and report presentation. Jones (1996) identified some features of "talk as performance":

"[O]ften have identifiable generic structures of the language and in more predictable ... Because less textual support, the speaker must include all necessary information in the text - hence the importance of topic as well as textual knowledge. And while meaning is still important there will be more emphasis on form and accuracy.”

(Jones 1996, 14)

Richards (2006) adds that "talk as performance" is in the type of monolog as opposed to exchange and is frequently a conspicuous arrangement (e.g., a lecture, a presentation) and has a tendency to be nearer to the composed dialect than conversational dialect. The impacts on the listeners are the key to evaluate the effectiveness of talk as performance. That is the greatest difference between "talk as performance" and the two other types of functions. There are some skills which should be remembered while using talk as performance: utilizing a fitting configuration, displaying data in a proper arrangement, keeping up people's engagement, employing correct articulation and language structures, making an impact on the group of participants by utilizing suitable vocabulary and using a fitting opening and close.

Hence, speaking is considered a highly complex, cognitive skill. It requires a variety of controlled and automatic processes, such as listening, the cognitive processing of information, thinking of a correct response in that context and society and the mechanical production of coherent sounds (Hastoyo 2010).

It is important to identify the demands of the curriculum or the students and teachers themselves to design speaking activities or instructional material.

\subsection{Speaking competence}

If speaking is an oral form of communication, then speaking competence is one's capability to use the language appropriately and correctly to achieve the goals of communication (Hunsaker 2000). Apart from the ability and power to do what is needed, competence also entails knowledge, motivation, and skills (Kempe and Holroyd 2013). This point of view is similar to that of Spitzberg and Cupach (1984), who identify the necessary components of competence, including knowledge, motivation, skills, and 
outcomes. In other words, speaking competence is the ability to use the correct words (vocabulary), in the correct order (grammar), with the correct pronunciation, and in the appropriate context with the social norms and cultural rules (Burkart 1998). Thus, in this study, speaking competence is divided into five speaking sub-competences: grammatical competence; discourse competence; pragmatic competence; fluency; and motivation and attitude. These cover all of the aspects of the knowledge of effective and appropriate speaking patterns, the ways of using that knowledge to speak in various contexts, and the motivation to reflect on the process with a positive attitude.

\subsection{Speaking sub-competence}

To make things simpler, researchers have divided speaking competence into five speaking sub-competences: grammatical, discourse, pragmatic, fluency, motivation and attitudes. Although it is not a main sub-competent in the conversational model, fluency is included as the fourth sub-competence in the present study, because the goal of the study is to also improve fluency along with speaking competence.

'Grammatical competence' is defined in the CEF as follows: "May be defined as knowledge of, and ability to use, the grammatical resources of a language ... Grammatical competence is the ability to understand and express meaning by producing and recognizing well-formed phrases and sentences in accordance with these principles (as opposed to memorizing and reproducing them as fixed formulae)” (Council of Europe 2001, 112-113).

This means that an individual is using the language rules (e.g., grammar, vocabulary, and pronunciation) correctly in a speech (Riggenbach 1998):

- Grammar is the structure of the language. However, grammar in the written form and spoken form can be different. When writing, proper grammatical structures, and complete sentences are encouraged. When speaking, we tend to connect sentences with coordinators, such as "and" or "but", or by pausing shortly and saying them one after the other. Therefore, a competent A1 speaker can use simple sentence structure and repetitions, even if the sentences are not as eloquent as the written form (Hughes 2002, Louma 2004).

- Vocabulary is the list of new words. When words are used correctly, it implies he/she knows the correct definition and the usage of the word, much like native speakers (Luoma 2004, 24). 
- Pronunciation is about producing the correct sounds, intonation, and rhythm (Morely 1996, Florez 1998, Cornbleet and Carter 2001).

o Sounds come in vowels, consonants, and consonant groups. Changes in pronunciation may occur due to linking and assimilation, such as on the house /an ðə 'haus/ becomes /an nə 'haus/.

o Intonation is the changes in pitch, such as rising and falling pitch. For example, yes or no questions end with rising pitch, while statements end with a falling pitch.

o Rhythm is the beat of a sentence, due to the placement of stresses within a word or group of words. Stresses have set positions in a word, but stresses within words can change depending on the meaning. For example, there are seven meanings to the sentence, "I never said she stole my money", depending on which word is emphasized (see Figure 8).

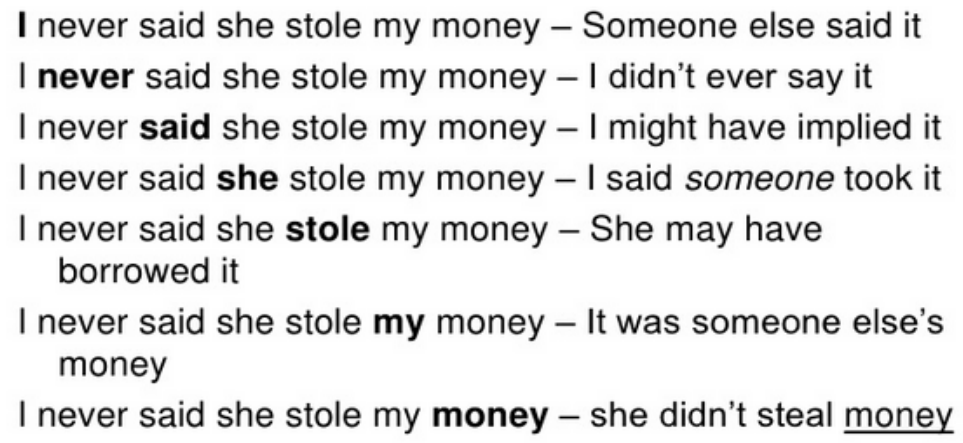

Figure 8. The seven meanings of the sentence "I never said she stole my money" ${ }^{9}$ due to which word is stressed. The stressed word (in bold) and the sentence is on the left and the meaning is on the right.

'Discourse competence' is a sub-competence of speaking, and is the learning of how to deliver and grasp oral or composed messages in the methods of talking/composing and tuning in/perusing separately. It requires knowing how to consolidate dialect structures into a durable and cognizant oral or composed content of various types. This means that the person can structure digressions from the current conversation coherently. Thus, discourse competence manages the arrangments of words, expressions, and sentences so as to make sense of discussions, addresses, verse, email messages, daily paper articles, and so forth. A

\footnotetext{
${ }^{9}$ http://www.slideshare.net/rcaroe/social-media-for-business-training-course
} 
person uses appropriate references to allude to people and objects (Foster 2001), and the discourse markers to signify informational relations or conversational relations. Informational discourse markers signal the introduction, a shift, or a summary of the topic. Conversational discourse markers, like "well” and "now", keep the conversation coherent (Young 2002). There is a logical sequence of the things being said, and the speaker is easy to follow (Louwerse and Mitchel 2003).

Another sub-competence of speaking competence is 'pragmatic competence', which is the “appropriateness" of a conversation (Cornbleet and Carter 2001, Pohl 2004). The appropriateness of a conversation is dependent on what the function of the conversation is, its social and cultural context. Thus, pragmatic competence is divided into functional competence and sociolinguistic competence (Pohl 2004):

Sociolinguistic competence, in contrast, means the knowledge of how one should speak in different situations and to different people (e.g., formal or informal). Depending on the relationship between the speaker and listener, we are expected to be more polite the more distant we are, and vice versa (Nattinger and DeCarrico 1992, Yoshida 2003).

In addition, we often ascribe the term 'fluency', to speaking competence. Fluency is the quality of speaking where the words and thoughts flow, run, or pour "from your mouth in a gentle stream”. It depends upon one's ability to facilitate (with fillers, lexical phrases, or an ellipsis) and compensate (with self-correction, rephrasing or repeating) a continuous and rapid conversation (Widdowson 1998, Segaowitz 2000). Competency in speaking means that the person is able to speak the language spontaneously or without interruptions.

Another speaking sub-competence mentioned in this study is 'motivation and attitude', which is different from the speaking skills. As we know, to be able to communicate to a certain degree in any language, the individual needs to have knowledge of the grammar, vocabulary, and pronunciation of the language (Burkart 1998). As more time is spent studying the language, knowledge of that language increases. Armed with more knowledge, the person's speaking or speaking competence will gradually increase. The increased speaking competence is not indefinite, and it depends on other factors, such as skills. Once an individual has some knowledge of the English language, their speaking competence will not improve unless they practice often to improve their speaking. The amount of practice that the learners do depends on their level of motivation. Motivation is the drive to initiate actions (Dornyei 1998), and it is considered an important element of 
language learning (Spolsky 2000). The more motivated the students are, the higher the probability that they will learn the new language (Lennartsson 2008). For example, if you are living in a foreign country and no one speaks your native language, then there is a strong motivation for you to learn the new language. Whatever difficult conditions or situations they may encounter, if the learners are motivated to improve their English language performances, then they will do many great things inside and outside the classroom. Motivation breaks the limitations and distractions on the road to become a successful English speaker.

Motivation is a notion used to explain the success or failure of a student (Chalak and Kassaian 2010). It can be classified as intrinsic or extrinsic motivation. Intrinsic motivation is about doing a task that is rewarding in and by itself (Deci and Ryan 2000). Extrinsic motivation, on the other hand, is about doing a task for the sake of a reward at the end or for "something other than an interest” (Dickson 1995, 196).

It has been argued that "Motivation is not something that a learner has, or does not have, but rather something that varies from one moment to the next, depending on the learning context or task” (Ellis 1997, 76). The levels of intrinsic and extrinsic motivation, however, do vary according to the context, time, and within the same individual. Motivation should be thought of as a continuum of the intrinsic, extrinsic and "a-"motivational (lack of motivation) (Deci and Ryan 2000).

On this spectrum, intrinsic motivation depends mostly on oneself (Standage, Duda, and Ntoumanis 2005), and is closely associated with one's desire to be competent in the task. For example, a study was performed by Lepper, Greene, and Nisbett (1973) on a group of kindergarten students' motivation for drawing. In high intrinsic motivation students, once the act is paired with a reward (i.e., or extrinsic motivation), then the act of drawing decreased. Therefore, opportunities that are rewarding without reward can increase intrinsic motivation while the lack of opportunities can decrease intrinsic motivation. Motivation is related to attitudes because they involve one's goals, beliefs, perceptions, and expectations.

Attitude is about the perception of oneself, others and cultures (Brown 2000). Since attitudes can be positive or negative, it is clear that one's attitude towards a foreign language is instrumental in whether or not a person can reach a stage of speaking competency. 
Positive attitudes towards the foreign language and its speakers tend to increase the likelihood of learning that language (Brown 2000). Hence, if students are curious about the countries or the people speaking the language, then they may be more motivated to learn the language (Noels et al. 2003).

Negative attitudes towards the foreign language or group of people can inhibit learning, especially when they originally had a strong will to learn (Ellis 1997). Negative attitudes may arise when there is a negative bias against the speakers, a lack of interest in learning, or other difficulties in the classroom (Ellis 1997).

Nevertheless, a person's attitudes may change with experience. Positive experiences, such as recognition and applause, can facilitate and reinforce positive attitudes. On the other hand, experiences like excessive correction or criticism can impede language learning. It is the job of the teachers to foster positive attitudes in students towards the language they are teaching.

\subsection{The importance of acquiring speaking competence}

Speaking competence is one of the essential factors behind appropriate and effective communication (Trumbull and Pacheco 2005). Speaking competence is a positive feedback cycle: the learners possess some language skills and are able to enhance their competence in communication, and their increased competence in communication helps them improve their speaking skills. Thus, improving speaking competence will enhance the learners' communication skills.

Apart from improving their communication skills, speaking competence also improves other areas of the competences, such as listening, perceiving, critical and symbolic thinking, cultural sensitivity and interpersonal communication. Speaking competence is correlated with the listening and perception competences. In a conversation, a person not only has to be able to speak but must be able to listen and interpret the information as well. Hence, enhancing one's speaking competence inevitably improves one's competence in listening and understanding the information too.

Another form of speaking is asking questions, and asking good questions demonstrates critical thinking. Even if the students are able to think critically, without speaking competence and the ability to make the other person understand the question, then a 'good' question is only a typical or confusing question. 
During the development of speaking competence, students usually acquire other skills as well, such as symbolic thinking. Symbolic thinking is important because words are just symbols for the actual person, object, emotion, etc. Furthermore, many languages have their own idioms and slangs, and they are usually not taught in schools. When a learner is able to use the words, idioms, and slang correctly, then they are an exceptionally competent speaker.

Speaking competence also helps to develop a person's cultural awareness and sensitivity to diversity. The acceptance and usage of certain words are dependent on a person's understanding of socially acceptable behaviors (Trumbull and Pacheco 2005). Thus, it is essential to learn about the norms, values, and ethics of the cultures associated with the language. Once we know the norms and rules of another culture, we are made aware of the differences or similarities between the two cultures.

Another purpose of communication is to develop social closeness because any social relationship requires communication. Developing speaking competence is important for improving interpersonal relationships because it may help improve one's knowledge, expectations, and conventions of the social norms of that type of relationship. As mentioned earlier, the social and cultural aspects of language are an important part of speaking competence.

Speaking competence also helps the students in their future. Any job requires a certain degree of communication and competent speakers are usually viewed as capable leaders because faulty grammar, vocabulary or pronunciation is hard for others to understand. Thus, speaking competence is usually associated with quicker promotions and better opportunities. English-speaking competence has also been viewed as a bridge between developed and developing countries. Luckily, speaking competence can occur at any stage of a person's life or career.

In short, speaking competence is extremely important in developing communication skills and other cognitive abilities. The question is which factors define or enhance speaking competence?

\subsection{How to develop competence in speaking}

After learning about the advantages of having speaking competence, the next question that should be asked is how to develop competency in speaking. For students to learn, acquire and enhance speaking competence, practice is essential during the early years of their 
development (Islami 2012). Without practice, speaking competence can never develop and good speaking competence may deteriorate over time.

In addition, Bahrani and Soltani (2012) believed that the simplest method to develop speaking competence is to balance the language input, structure output, and communicative output. In a foreign language classroom, the teacher's monologue, and reading and listening activities are very important. They may be the only source of language input for the students if they have limited opportunity to practice the language outside the classroom. Language input comes in two forms: content-oriented and formoriented inputs. Content-oriented input encompasses information, like a lecture or an abstract from an academic report, while the form-oriented input encompasses the ways the learner uses the language and the assistance provided by the teacher or other sources. In most cases, language input gives the students an opportunity and the materials they need to start learning the language.

After language input from the teacher or source, there must be an output from the students. The output can be choosing the right form, acquiring the right information or producing a result (such as creating a video). The output requirement should not be difficult in relation to the students' level, or not too easy that their motivation will decrease.

When the response is about choosing the right form, then it is a structured output. There are usually many ways to phrase the correct response, but these options might require the learners to adopt a structure or form that they just learned. Teachers and textbooks often use the structured output exercise to link the presentation and the execution of the lesson plan. Structured output presents the newly introduced language item in activities where it is repeated and practiced (Dundar 2013).

The communicative output is about the student acquiring the right information and delivering the message to the listener. There is an information gap between the speakers and listeners and the students must close this information gap. The learners may use the material that was just presented, or they may use any language they already know because language is viewed as a tool and not the final product. To communicate the right information, it doesn't matter if the student is using the new or already known language item.

\subsection{Characteristics of a successful speaking classroom}

There are a couple of key features of a successful English speaking classroom: instructions are given in English, even participation, high motivation, an acceptable level of language 
and confident and talkative learners (Ur 2002). In a speaking classroom, the teacher gives instructions in English rather than the local language. The teacher's instructions may be the only significant source of target language input (Nunan 1991). Nunan (1991) states that when the teacher's use of English increases, the students' use of English proportionally increases.

A successful speaking classroom means that the learners should have a high Englishspeaking competence. As mentioned earlier, practice is essential to developing speaking competence. The learners need to practice their English by talking more often. However, in almost all cases, the teachers spend more time talking than the learners. As a response, a period should be allotted to class activities that give the learners the opportunity to practice and express themselves.

In addition, the activity or teacher should give each participant a chance to speak. During good speaking activities, classroom discussions are not dominated by a few talkative members and the participation is evenly distributed among all members. In the ideal situation, the learners are highly motivated and eager to speak. As mentioned in Section 4.5, students with a high intrinsic motivation are more likely to succeed. Intrinsic motivation is learning for the sake of learning because the process itself is enjoyable for the learner (Lepper and Hodell 1989). To cultivate intrinsic motivation in an English language classroom, Brown (2007) recommended that teachers should help their students understand that they are involved in their own learning processes and goals. Once the students are more involved, then they are interested in the topics being discussed and have something to talk about.

In a successful speaking activity, learners are able to express themselves at a level that is easy to comprehend, relevant and acceptable. The students should interact mostly with each other rather than with the teacher (Richards and Rodgers 2001). This requires the students to be confident, motivated and positive towards their studies (Liu 2007, Scharle and Szabo 2000).

\subsection{Problems with achieving speaking competence in English language classrooms}

In the ideal situation, every EFL class should be a speaking classroom; however, this is often not the case. Research has shown that issues arise from both the teachers (overuse of the mother tongue, speaking too much and not having enough time for English speaking 
activities) and the students (having nothing to say, feelings of inhibition and rarely participating) (Ur 2002).

In a classroom where the teacher and most of the learners speak the same mother tongue, then they often use their mother tongue instead of the foreign language. Although it feels natural and is easier to speak in the local language, it is counterproductive in teaching and learning a foreign language, because everyone will overly rely on translation (Zhenhui 2001), and students should understand how crucial it is to use English as often as possible in the classroom (Son 2011). Therefore, teachers should always give instructions in English and the use of the mother tongue should be limited.

Apart from not using the local language in a foreign language class, the teacher should not be the sole speaker in the classroom. Littlewood, Liu, and Yu (1996) stated that if teachers speak more often in class, then there is little time for students to improve their communication skills. If the teacher speaks more often, then the students are basically being deprived of the chance to improve their speaking skills.

If not enough time is spent on speaking activities, then the students cannot improve their speaking skills. Not all students may have time to speak, or they are put in an uncomfortable position to answer the question spontaneously. If more time is given to speaking activities, then the students can discuss the answers in small groups or pairs, come up with more ideas and organize them before answering.

Some factors affecting the speaking competence of a classroom stem from the learners. The learners might feel inhibited when they try to communicate in a foreign language classroom. For example, they might be shy, concerned about making mistakes, being criticized or losing face. Unlike reading, listening and writing activities, speaking requires that the learners have an adequate amount of exposure to an audience.

Even if the learners are not reserved, they often state that they have no idea about what to say (Willis 2007). The learners may not be able to come up with something original if the answers are limited. If they have no idea of what to say, then they are not motivated to speak.

In addition, when speaking activities are just open discussions with only one learner talking at a time, then it is practically impossible for every member of a large class to participate equally. In these situations, dominant learners tend to speak more than those who speak very little or not at all. 
In regards to the current study, all of the above-mentioned factors will be addressed in consideration of primary school student's speaking competence. The teacher should give instructions in the foreign language, spend a minimal amount of time talking and allocate more time to speaking activities. To best assist the students' engagement in speaking activities, teachers should use the appropriate communicative activities that are tailored to the students' interests, needs and choices (Stribling 2003, Holt 2001). The next part of this study is to determine whether or not the suggested technique (i.e., drama) is suitable for the students and can improve their speaking competence. 


\section{Chapter 6: Drama Activities in EFL Classrooms}

“If a learner of English asked you 'What is a blind person?', you might simply reply, 'A blind person cannot see', and this would probably satisfy him intellectually. But if you replied, 'Shut your eyes and try to find your pen on the desk in front of you', you would be involving him in the actual experience of being blind, and would thus satisfy him not only intellectually, but emotionally as well, and possibly inspire in him feelings of empathy with all blind people. He would be more likely to remember the meaning of the word as a result of this moment of direct experience” (Wessels 1987, 7). This, in oversimplified terms, is one of the precise functions of drama.

Drama has been used to teach a language since the Middle Ages (Sam 1990) and is used to teach EFL today. The use of drama in EFL classes does adhere to the principles of CLT. According to Belliveau and Kim (2013, 6): "Drama in the language classroom is ultimately indispensable because it offers a lens for learners to use their imagination. It draws upon students' abilities to imitate and express themselves and if well handled, it should arouse interest and foster personal development. Drama encourages adaptability, fluency, and communicative competence”. Language is put in context, learners are given the experiences of success in real-life situations and armed with the confidence for confronting the world outside the classroom (Davies 1990). CLT and drama share a common aim to create situations for learners to be fluent in the language (i.e., achieve speaking competence). This chapter begins with an introduction to drama in general, and its roles in education and in foreign language classes will also be discussed. This section will also introduce drama activities, how they are implemented, and discuss the role of the teacher.

\subsection{Introduction to drama}

The word 'drama' (dran in Greek means “to do”) originally refers to a performance on stage. Shakespeare's “All the world's a stage, and all the men and women merely players” is exceptionally fitting in our discussion of drama (“As you like it”, William Shakespeare, Act II, Scene VII). We all start life with the role of a son or daughter, and some people have additional roles as the brother or sister, husband or wife, and father or mother. Some people may have multiple roles at the same time. Thus, we are all 'actors' in a sense. 
However, drama is no longer limited to a performance on stage but can be identified as a means of communication or any activities with an element of creativity (Hubbard 1986).

Drama is a form of communication because it integrates both the verbal and non-verbal components of conveying information, and it often entails the interaction between two or more participants (Anderson 2010). Drama engages both the mind (intellectually) and the body (physically), which are necessary for learning and speaking a new language (Huang 2008). Drama is sometimes a dialogue between two or more actors, like in a real conversation. Thus, Bolton (1993) stated that drama is language itself.

Drama is also an activity that involves creativity. For example, a child feigning illness so as not to go to school, a marriage rehearsal and a practice for a presentation are all examples of drama. As long as we did something that required some creativity, then we have utilized drama at one point or another in our lives.

Drama is more commonplace than some people previously believed, and it has been used in education for many years (McCaslin 1998). As put forward by most scholars, drama most often appears in the classroom as a process rather than a product of learning (Chiang and Schallert 2012).

For the purpose of this study, drama is defined as any activity where the participants have to portray themselves or another person in a given situation. Drama is a form of expression that utilizes verbal expressions, gestures, imagination and memory (Holden 1981).

\subsection{Drama in Education (DIE)}

Drama in education (DIE) is drama activity or exercise that is carried out for educational aims. It is necessary to note that the aims of DIE and drama in ELT are different. Drama in schools can take on several forms: an examinable "subject in its own right" "away of learning about the world" and "a way of learning life skill”. Some activities or exercises include role-playing, improvisation, simulation, language games and warm-ups (O’Toole 1992, 1-2). For example, DIE has been applied in history classes, when acting a scene from a conflict in the royal family, and in biology classes, when acting out how the organelles of a cell function (Phillips 2000, Billíková and Kissová 2013). Due to the popularity of DIE, it has been called by many names, such as educational drama, creative dramatic, process drama, and drama for understanding (Bolton 1993).

The principle of DIE is that the best way to study is through playing games (Gabriella 2013). Students find drama activities very entertaining and motivating because they are 
flexible (Heller 2010) and give them the freedom to create stories or perform in the stories as they wish. DIE, like playing games, is fun, enjoyable and memorable in the long run.

To summarize the value of drama in education, Sam (1990) listed eight main values which he had collected from other educators and researchers:

1- Maley and Duff (1978) expressed that drama is an educational objective which not only releases imagination and energy but also encourages students to exercise their sensitivity and imagination. Thus, drama makes learning become more realistic and meaningful (Fernandez and Coil 1986).

2- Drama is considered as an educational tool when fostering the social, intellectual and the linguistic development of the child (Dougill 1987); centring around language development, personal awareness, group co-operation, sensory awareness, and imaginative growth (Early and Tarlington 1982).

3- Drama increases motivation and provides the incentive to work hard (Mordecai 1985). The activities using drama tend to be purposeful. The students see the need to communicate and concentrate on how to go about a task since drama provides them with a meaningful context.

4- When working in groups, drama creates a need to complete the task, then fosters a sense of responsibility and co-operation among the students (Early and Tarlington 1982, Mordecai 1985). Thus, the students develop a sense of self-worth as they work together.

5- Drama activities expend the students' energies and encourage the shy and uncooperative students to participate. This is because drama has a therapeutic effect which can help solve emotional and behavioral problems (Stern 1980).

6- The students' sensitivities and imaginations are encouraged during drama activities (Fernandez and Coil 1986). They have the opportunity to put their feet into other's shoes and to experience feelings which are different from their own. For example, in role-play, a student is given a role as a mother whose son is very naughty. She will understand the feelings, the emotion which that mother has to suffer. This role develops a sense of empathy in the student. Thus, it is said that drama develops moral and social qualities in students.

7- Drama helps the teacher to understand the needs of the students when they express themselves during drama activities (Mordecai 1985). The teacher can then better plan 
effective strategies to meet the needs of the learning and teaching processes, from the teacher's point of view and for the students as well.

8- Drama is an art form (Valgemaee 1981) which facilitates communication and provides an appropriate psycholinguistic climate for language learning. From this point of view, drama heightens self-esteem, motivation, spontaneity, and increases the capacity for empathy, and lowers sensitivity to rejection (Stern 1980).

\subsection{The benefits of drama activities in EFL classrooms}

Scholars and educators have recommended using drama in teaching a foreign language. Indeed, this approach has attracted the attention of many practitioners, such as: Stern (1980); Maley and Duff (1978); Kao and O’Neil (1998); Liu (2002); Almond (2005); Taylor and Warner (2006); Dörnyei (2005, 2007); Cheng (2007); Anderson, Hughes, and Manuel (2008); Ulas (2008); Dupont (2010); Kurowski (2011); Even (2011); and Wisna (2015). DIE has garnered so much attention in foreign language teaching because of the insufficiencies of the traditional language teaching approaches.

Learners from the traditional language teaching approach are always afraid of speaking in and out of the classroom. These learners hardly get a chance to interact with their fellow students or the teacher in the foreign language, and with native speakers outside the classroom. Therefore, students from the traditional teaching approach find it very difficult to attain fluency and confidence when speaking in the foreign language (Janudom and Wasanasomsithi 2009). From this perspective, DIE is an attractive alternative, because drama is considered as “communication between people” (Via 1987, 110). It integrates the verbal and non-verbal components of an experience (Bolton 1993), very much like language. Even if the students have a limited amount of vocabulary, they can use gestures and body language to compensate and express the content. These verbal and non-verbal components make learning a new language much easier and more interesting (Armstrong 2009).

Maley and Duff defined dramatic activities in a language classroom as activities which "give the student an opportunity to use his or her own personality in creating the material on which part of the language class is to be based. These activities draw on the natural ability of every person to imitate, mimic and express himself or herself through gesture. They draw too, on the student's imagination and memory, and natural capacity to bring to life parts of his or her past experience that might never otherwise emerge. They are 
dramatic because they arouse our interest, which they do by drawing on the unpredictable power generated when one person is brought together with others. Each student brings a different life, a different background into the class. We would like students to be able to use this when working with others” (Maley and Duff 1991, 6)

There are four advantages of using drama in language teaching:

1. "The achievement of meaningful fluent interaction in the target language.

2. The assimilation of phonetic and prosodic features in a contextualized and interactive manner.

3. The fully contextualized acquisition of new vocabulary and expression.

4. A sense of confidence in the learner's ability to learn the target language.”

(Hewgill, Noro, and Poulton 2004, 229)

Drama is viewed as effective in teaching speaking competence because it puts the learner in the centre; increases one's imagination, creativity, and motivation; provides real-life situations for the learners to practice; builds confidence and reduces anxiety, and is a different learning method.

As mentioned in Chapter 3, the learner-centred and not the teacher-centred is the better model of teaching. The learner-centred model focuses on the needs of the students and allocates more time for them to speak, while the teacher-centred model focuses on the teacher and almost all of the time the teacher talks exclusively. Drama is learner-centred, because it requires active cooperation from the learners and the outcomes greatly depend on the learners themselves (Fleming 2006).

The strength of using drama to facilitate language learning is its ability to encourage imagination and creativity (Athiemoolam 2004). Imagination and creativity utilize more areas of the brain, thus making learning more effective and memory recalls more efficient by coding the language with more cues. ${ }^{10}$ Therefore, using drama techniques may open up different opportunities for students to be more imaginative and creative.

Motivation is essential for learning, and it is true for learning a foreign language. Learners are more intrinsically motivated to do activities that stimulate their imagination and creativity, such as drama activities (Dodson 2002, Miccoli 2003). Drama motivates the students because learning English is entertaining (Su 2005). It can create the space for

\footnotetext{
${ }^{10}$ http://www.human-memory.net/processes_recall.html
} 
students to argue, discuss, ask and answer materials (Winston 2013). The learners are motivated to do the drama activities because they are imaginative, creative, and educational experiences for the participants (Adlard, Ottway, and Procter-Legg 2012).

In addition, drama allows the teacher and students to deal with real-life problems in a protective environment, hence facilitating learning by acquiring real knowledge and experience (Heathcote 1995). As Heathcote noted in her study, their experience and knowledge affected their actions (Heathcote 1995). So, drama activities are like rehearsals to prepare the students for their future social roles and everyday lives. They can help the students obtain the relevant qualities to improve their performances in any professions and roles. The opportunity to experience real-life situations gives the students the confidence necessary for tackling real-life situations beyond the classroom.

Most students will participate in drama activities, even if they are initially not confident (Barrett and Johnson 2011). The participants in Barrett and Johnson's study liked the activities because they were enjoyable and a good chance to speak more naturally, not like lists of vocabulary and worksheets (Barrett and Johnson 2011). Drama activities require courage to express oneself in front of one's classmates, and this courage and confidence can be transferred to real life. Drama can also reduce anxiety in a second language class. In a drama-oriented ESL classroom in Hong Kong, Fung (2005) found that most of the students have a low level of anxiety, while a small number of the students seldom felt anxious. He found that role-playing also helped decrease the learners' anxiety. Therefore, it can be concluded that drama can raise the confidence and reduce the anxiety of students when they learn English as a foreign language.

Drama helps students learn about conflict resolution as well as improve their interpersonal relationships. Since drama activities are interactive and require cooperation between the participants, the students learn how to deal with each other and solve conflicts if they do arise. Davies and Pearse (2000) asserted that drama immerses students in a social milieu and creates the necessary experiences for learning and dealing with other people, which are very important in language learning (Ntelioglou 2011). Language learning is easier if it is built on rapport with other students (Bang 2003).

Drama can be used to teach students with different learning styles and levels of understanding. Some people may prefer to learn by reading, drawing, or acting out scenes from a story. When we act, we use verbal and non-verbal cues, such as facial expressions 
and body movements. Using non-verbal cues helps us to understand the images and the stories more deeply. The verbal and non-verbal components of drama allow the participants to conceptualize, organize, and recall the teacher's instructions in a different way to the verbal one.

The non-verbal component of drama and communication also involves ideas and feelings (Barbu 2007). Miming activities like “Mime a Monster”, "Who am I?” and "What am I telling you" helps students to integrate ideas and feelings into a form of communication. We hardly ever notice that we are communicating with ideas and feelings, because we are improvising in our native language (Dora To et al. 2011). In the case of a foreign language, we are conscious and aware of this process, and we realize that the transition of thoughts into linguistic expression is more difficult.

Through drama, students acquire new vocabulary and expression in the appropriate context. For example, in a "at the hospital” simulation, a student pretending to be a doctor may write down "one spoonful of tequila” as a remedy for coughing. While other students do not know the meaning of tequila, after the teacher explained the meaning of the phrase, the students learned the new phrase from a different culture (Farmer 2007).

Through drama, students are able to integrate their competencies in listening, speaking and writing in English in ESL or EFL classes. Firstly, they will learn the fundamentals of English syntax through drama strategies (i.e., drama games of language)). These strategies encourage negotiation, understanding, and creativity. Then they will learn about idioms and sounds. Over time, when they have acquired knowledge of the language and practice it frequently, they will be able to speak the language fluently and accurately.

There are many benefits of using drama in EFL classes. Drama uses the learner-centred approach to teaching and provides a real language environment (i.e., expressions, conversations, emotions, and ideas) for the students (Gomez 2010). In a typical English class, students may feel bored due to the tediousness and monotony of the material. In drama, students have increased exposure to content outside of the normal school curriculum, which they find is more engaging because the activities are different. The goal of DIE is that teaching is both entertaining and educational.

Drama provides the context and needs to listen and speak the foreign language comprehensively. For example, when the students have to enact meeting an English speaking person for the first time, they have to listen carefully and introduce themselves 
properly. Equipped with the experience, it may motivate the learner to practice talking to a native English speaker in the real world. When there is the experience of speaking the foreign language and a need later arises, then the motivation of the students in using that language should also increase.

After all the discussion of the different drama activities and the benefits of using DIE in foreign language teaching, the major challenge is to decide which one is appropriate for what level. Hoecherl-Alden (2006) suggested that role-play, simulations and improvisation are the most popular activities in the classroom because they only require the user's imagination and cost very little to implement. A more detailed analysis of the three activities is provided below.

\subsubsection{Role-play}

Role-play is the act of pretending to be an imaginary or real person in a given situation. For example, role-play can be a dramatic play, interviews or storytelling. Due to the nature of role-playing, it is the most common drama activity used in language teaching, and in this study, because it helps to develop the various speaking sub-competences and interpersonal skills of the learners.

Role-play can help develop grammatical competence and discourse competence because the grammar and discourse markers used in the script provide a written record for the students to study and use. For example, the first line in "Peppa Pig learns about Number" is “I'm Peppa Pig. This is my little brother George Pig. This is Mommy Pig, and this is Daddy Pig.” The students learn about the present tense and the way to introduce someone and yourself. The students can read, imitate and hone their grammatical and discourse competences through role-playing.

Role-play helps develop pragmatic competence because it provides a context for communication to the learners (Kodotchigova 2001). For example, students may be asked to role-play family scenes, school situations or playground incidents using the new vocabulary they learned in their classroom. After role-playing in different social and cultural scenarios, the students are more prepared when they encounter similar real-life situations and develop better pragmatic competence.

The students' fluency also improves with role-plays, because they practice the same lines from a script or speak freely about anything they want. Therefore, role-play helps students communicate fluently in the target language. 
Role-play is a good activity to develop the students' strategic competence, because, the students do not have a script to follow, and they would have to develop strategies to overcome words that they do not know. Role-play is an excellent experience for the students to test and refine their speaking performances in these situations.

Role-play is also good for improving the attitudes and increasing the motivation of the learners. Role-play is fun and requires a lot of creativity from the learners. With each positive role-playing experience, the students develop positive attitudes as well. Something that is fun is motivation enough for the learners too.

Role-play can help develop the interpersonal skills of the learners because to role-play successfully, they need to accept their roles and interact with the other role-players (Palmer 2001). For example, the learners may role-play a classroom scene, and they must interact with the 'teacher' and 'students' accordingly. Role-play is good for developing the interpersonal skills of students who are normally reluctant or too anxious to speak in the target language (Harmer 1983). People become better at interacting with others from experience and role-play helps the students by giving them such experiences.

Role-play is much more effective than when telling the students "to simply repeat a given dialogue in pair” (Nunan 1990, 68). Role-play provides the context for communication, motivation, and the opportunity to develop the interpersonal skills of the learners. By engaging students in real communication, it helps them to be proficient in sharing information and negotiating meaning (Richards and Rodgers 2001), which are precursors to the speaking sub-competences.

\subsubsection{Simulation}

"In a very real sense, a simulation is like a strawberry. It has to be tasted to be appreciated" (Jones 1982, 7). Buckingham (2003, 79) defined simulation as "a form of role-play: it involves putting students into the position of media procedures, albeit in an essentially fictional way”. The terms 'simulation' and 'role-play' have been used interchangeably. Simulations are broader than role-play, but it may include some elements of role-play. Simulations are usually longer and more complex than role-plays.

Simulations are ideal for EFL classrooms because they provide students with the opportunity to speak fluently in a plausible scenario (Hyland 2009). For example, the learners can pretend to be teachers at a meeting where they discuss and decide that students should have Saturdays off. The participants use their own life experience when solving the 
problem. They respond to the task, solve the problem, analyze it, speculate, discuss, judge and evaluate it (Billíková and Kissová 2013).

According to Billíková and Kissová (2013, 55), there are many reasons for using simulations in a foreign language classroom:

- "It lowers anxiety and breaks the ice in communicating in a foreign language;

- It increases students' talking time and decrease teacher’s talking time;

- It practices all language skills;

- It brings reality of characters, setting, problems, and a real need to communicate;

- It encourages thinking, creativity and motivation;

- It provides opportunities to practice fluency and accuracy in context;

- It promotes the development of the interpersonal relations and social skills.”

Therefore, like role-play, simulations can develop the speaking competence of students in terms of their grammatical competence. When they read the scripts and imitate them in role play, they can remember the grammatical points, e.g., they role-play the conversation of asking the direction, they will remember the words for asking directions and the structures of asking questions, like: “How to get...”or “Could you please show me...”. Through role-play, students acquire discourse competence when they learn from the scripts how the sentences combine together and practice them; pragmatic competence, when they know how to make sentences meaningful and how to begin and end a conversation; fluency, when they have practiced often; and attitudes and motivation when they enjoy the simulations and the experiences reinforce positive attitudes and motivation.

\subsubsection{Improvisation}

Improvisation is an activity that is not rehearsed and is, therefore, spontaneous. Students must speak, act and move without much preparation, much like in real life conversations. For example, we all improvise when we encounter a new situation, such as arriving in a new country. However, we can transfer some past experiences or knowledge so as to know how to react in a certain situation.

Improvisation is recommended for students, especially primary school students (Farmer 2007) because it is very simple and engaging. According to Billíková and Kissová (2013), the simplest improvisation is to use a common object and show how else it can be used in real life. For example, the teacher can ask the students to stand in a circle around a single chair, and then to imagine it as anything but a chair. The students are asked to go to the middle and show how the novel object is to be used by miming and sounds, such as 
pushing the chair like a pram or playing it like a guitar. It is the task for the rest of the class to guess what this object is. Improvisation is ideal for younger students because there are no rules and they can be creative.

Improvisation is also very good for older students because it helps the students overcome or reduce anxiety, and become fluent in speaking English (Haas Dyson 2010). Some students may initially be scared of thinking and performing on the stage, but with practice, it prepares the students by training them to think and react quickly, especially when speaking English in real life situations because it is also spontaneous. Improvisation is in contrast to other speaking activities in the classroom, where students normally have some time (even a few minutes) to prepare when speaking English in the classroom.

In the improvisation activity called “Alphabet Improvisation”, students are instructed to work in pairs and decide who they are, and what they are. They act out the dialogue without preparation. The first line of their scene must start with the letter $\mathrm{A}$, and so on until the letter $\mathrm{Z}$ is the beginning of the last sentence. For example: “Are you coming?”; "Before lunch, sure.”, “Can you come before 11 h30 ?”, etc.

Improvisation is beneficial to the developing of grammar competence, discourse competence, pragmatic competence, fluency and motivation, and attitudes. It helps to raise the learners' knowledge of grammar competence, when they want to make a sentence; of discourse competence, when they want to follow the previous sentences coherently; of pragmatic competence, when they want to make sentences logically and meaningful in connection with others; of fluency, when they are asked to speak spontaneously without preparation; of motivation and attitudes, when they finish they have good feelings towards themselves that motivate them to do the next tasks.

In summary, drama in education is a respite from the usual textbook and blackboard methods. Drama offers students the opportunities to study in an authentic situation freely and creatively; to mingle and act out different roles in a less formal environment; to motivate their mental and physical bodies; to bring them to the outside world; to visualize the language in the scripts. Therefore, they can acquire grammatical competence, discourse competence, pragmatic competence, fluency and positive motivation and attitudes towards speaking and learning English as a foreign language. The next section will examine the advantages of drama activities in the EFL classroom. 


\subsection{Role of the teacher}

Despite its rich potential, drama as a classroom method brings a number of challenges for the teacher. It involves moving away from familiar structures and routines which feel safe into approaches which are more open-ended and unpredictable. With younger learners, the enthusiasm and exuberance produced by engaging in drama can turn into problems of discipline. With older learners, there may be problems of inhibition and embarrassment. Despite the enormous potential for drama to motivate and engage the participants, in practice the drama can sometimes be flat and fail to inspire. In the context of teaching a second language, the possibilities are inevitably limited by the fluency and language facility of the learners. These comments are not meant to be negative but to offer a realistic view of the challenges involved in using drama in the language classroom. Unlike the traditional form of teaching, where the teachers often talk while the students only listen, Royka (2002) notes that drama makes the teacher a listener and observer. The teacher can easily identify the needs of the students by observing the way the students act and show their feelings during drama activities.

According to Luyegu (2011), some teachers are afraid and lack confidence in using drama activities in their classes in Vietnam. The teachers are worried about strategies they can employ or organize, and how to build authority when carrying out drama activities. Persuading them to reverse the traditional teaching style can be difficult. If the mechanisms can be put in place to assist teachers in understanding the effectiveness of drama activities, it will be easier to integrate such activities into their methodologies.

They should be clear about their roles and the relationship between them and the students. Teachers should make the students lead the drama activities by guiding and directing the students' actions. It is important for the teacher to give clear and not very detailed instructions to their students, and ensure that students understand the activities to be carried out. Messinger (2010) asserted that as soon as teachers have a command of drama activities, planning and preparing actual lessons will be easy for them. Mages (2008) emphasized the following constraint for teachers: in proper drama activities, teachers should not take the major role in the class activitíe.

Despite the fact that the use of drama in the classroom is not a new concept, it has experienced a surge in popularity in recent years due to the support of educational research. Educators who use drama in the class have realized that it is a very successful method, and 
have communicated their findings to the rest of the world. In the following chapter, the reasons for, and how to apply, drama in EFL classes will be discussed.

An increasing number of research studies have confirmed my experience that teachers and their pedagogical choices play a significant role in student learning (Darling-Hammond 1998, Evans 2006, Joyce et al. 2000, Mortimore 1999). This has been aptly summarized as: "What teachers know and do is one of the most important influences on what students learn” (Darling-Hammond 1998, 9). Giroux and McLaren (1996) view teachers as transformative intellectuals. I concur with Giroux (1988), who argued that teachers should not be reduced to being technicians carrying out the latest directives and objectives decided by experts far removed from the everyday realities of the classroom. Sonia Nieto, cited in Cummins' “Negotiating Identities” (2001), talks about the potential impact of individual teachers. Nieto explains that “teachers' attitudes and behaviors can make an astonishing difference in student learning” (Cummins 2001, 21). Teaching to the test often leaves little room for creativity, originality, and reflection on the part of the teachers as well as the students (Anderson and Grinsenberg 1998, McNeil 2000, Pennington 2004). Teachers are often given prepackaged curricula that tell them what they should teach word by word. Critical pedagogues argue that the ability of teachers to become transformative educationists resides in their resistance to becoming merely 'technicists' who are confined to simply being transmitters of knowledge (Giroux 1988, Giroux and McLaren 1996, Ntelioglou 2012). 


\section{Chapter 7: The Implementation of Drama in the Communicative Approach}

\subsection{Communicative Language Teaching in Practice}

Due to the importance of English nowadays and the need to teach students better English, EFL teachers in many Asian countries have realized the advantages of CLT and have been eager to study about this new method (Pham 2005). Most of the recent English language curricula developed in Asian specifies CLT as the expected methodology.

Vietnam was one the countries that implemented CLT in the 1990s and had unexpected results (Ellis 1994). When Vietnam adopted CLT, it marked the start of a paradigm shift that led to a number of reforms in how to teach a second language and it has quickly garnered attention in Vietnam. (Gebhard 2006). However, this method that has been transferred from the Western English-speaking countries to the contexts of developing nations is seen as problematic due to the conflicts with the social, cultural and physical conditions of the recipient countries (Holliday 1994, Pennycook 1989). For example, in Vietnam, if students learning English have no immediate need to use English in the classroom or outside the classroom, then they all tend to use their mother tongue, Vietnamese.

The principle of doing CLT tasks in the classroom that are applicable to the world outside the classroom is not valid in Vietnam. The main reasons are that it is not an Englishspeaking country, and Vietnamese students rarely have a real need to communicate in English outside the classroom. Additionally, the use of authentic materials, meaning authentic to native speakers of English, can also be problematic in the Vietnamese setting. Kramsch and Sullivan (1996) argued that what is authentic in London might not be authentic in Hanoi. The authors showed that Western values are reflected not only in the principles of CLT but also in common CLT classroom activities and practices, such as in pairs and grouping works and in information gap activities. Working in pairs or in groups assumes that the students have the freedom of choice and equality to choose whom to talk with, and what to talk about and that they have equal power relationships with others in the class or in their pairs or groups. Similarly, 
information gap activities also imply that people are equal in the classroom, since at some point during the activities each student knows something that others (or even the teacher) may not know. The underlying message of these activities, Sullivan (2000) concluded, was that unequal, hierarchical relationships are not conducive to communicative teaching and learning.

The lack of teaching facilities, the large class sizes, the influence of Confucianism and the traditional examination system also impede the Vietnamese teachers' abilities to do communicative tasks in their classrooms. Therefore, despite the apparent popularity of CLT, numerous English teachers and students have not changed their concept of effective language instruction, nor their practices in the classroom. As a result, English is not commonly used in Vietnam in communication.

CLT has not received widespread support in China, and the traditional approach is still dominant in many classrooms today (Hu 2001). There are a number of reasons mentioned in the studies by Badger and Yan (2008) and Pham (2005) for these failures in some Asian countries, and in Vietnam and China in particular. It will further discuss in this chapter in order to find the possible solutions.

Pham (2005) pointed out six reasons why CLT had failed to be applied successfully in Vietnam:

1. Vietnamese people rarely use English outside the classroom. Many Vietnamese people choose to use Vietnamese when given a choice. They see their native language as an intermediate and prefer to use it rather than English when interacting with others outside the classroom. Hence, the people lack the motivation to speak English when they are outside of the classroom.

2. Influence of Confucianism on the Vietnamese culture of teaching and learning. The teachings of Confucianism have a great impact on Vietnamese culture. Hence, the teachers and textbooks are the major forms of English input. Again, there is the lack of exposure of the students to the English language.

3. The teaching method needs to be relevant and suitable for the Vietnamese culture. The teaching materials come from mostly English-speaking countries, which may not be ideal for teaching English in Vietnam. CLT activities like role-plays, simulations and storytelling are new to the Vietnamese culture and completely 
opposite to the passive learning styles of the students and the conservative beliefs of Vietnamese teachers.

4. The resources are simple. The resources in the classroom usually consist of only a blackboard and textbooks.

5. There are too many students per class. Vietnamese classrooms can be up to 50 to 70 students, which make any methodological innovation difficult to implement (Kam 2004). The shortage of English teachers has also increased, which may have contributed to the large class sizes (Nguyen 2004). According to her, more time is needed for the non-academic activities related to administrative and organizational procedures and to the management and control of discipline in large classes. The relationship between class sizes and learning outcomes is clear: "Reductions in the quantity of learning opportunities constrain teachers from achieving the necessary pace, depth and breadth of curriculum coverage as class size increases” (Al-Jarf 2006: 24).

6. The traditional, grammar-based examination system. In most circumstances, the examinations test linguistic competence and not communicative competence. This is due to there being are no listening and speaking components in the exams, from the primary to the university level. Examinations demoralize the learners; and when the exams are at stake, the English classrooms are consistently grammar-oriented and not communicative-oriented (Roth and Aberson 2010).

7. Another reason why CLT is not widely used in some Asian countries is that of the beliefs of the teachers. Studies have shown that the ultimate failure of CLT innovation in English language teaching is often due to teachers' perceptions about the usefulness and feasibility of CLT practices (e.g.Li 1998). Many teachers, for instance, teachers in China claim that it takes longer to prepare and to guide the students on how to do and how to study for the activities (Hu 2002). Vietnamese teachers shared the same views, some have said that it took a lot of effort to include CLT in their lessons. Another said that it was not necessary because it only emphasized: "open-ended discussion activities”, while others have said it was impossible because there would be an “absence of grammar” (Richards 2006: 16). For these reasons, changing the teachers' beliefs and choosing suitable techniques that would help to effectively improve speaking competence is of the most importance. 


\section{Overcoming the shortcomings of CLT}

To address some of the difficulties in implementing CLT in Vietnamese classrooms, changes must be made in the syllabus and textbooks, and in the roles of the teachers and students. More importantly, adaptions to the version of CLT should be made to adjust to the day-to-day realities in a developing non-English-speaking country like Vietnam, who has a particular traditional culture as a result of its long Confucian heritage.

The syllabus should be designed with a special focus on communication (Karim 2004). Chowdhury and Farooqui (2008) suggested that instead of a syllabus based on structural complexity (e.g., easy to complex, known to unknown), the CLT syllabus should be determined by functions, themes, meanings or tasks. It emphasizes exposure to the target language through large input and output from the students. Changing the syllabus to focus more on communication can maximize the opportunities to interact and to negotiate between teachers and learners, and among the learners themselves (Lomicka and Lord 2011). Drama is suggested to be used as a method in this case.

To overcome the shortcomings in Vietnam, it is necessary to realize a change in the teacher's role, since the teachers and their choice of methods of teaching play a significant role in student learning (Darling-Hammond 1998, Evans 2006, Joyce et al. 2000). Teachers should bear in mind that "their attitudes and behaviours can make an astonishing difference in student learning” (Sonia 2001, 21); and that teaching to the test often leaves little room for creativity, originality, and reflection on the part of the teachers as well as the students (Anderson and Grinsenberg 1998, Pennington 2004).However, to change the beliefs and behaviors of teachers and students take time, particularly in education, thus "new ideas need a great deal of work by practicing teacher for these ideas to be translated into everyday teaching routines” (Farrell and Jacobs 2010: 13)

In their study, Tomlinson and Bao (2004) found some discrepancies between the teachers' and students' views of the role of the teacher-student interaction in the English classroom in Vietnam. The teachers used a lecturing style in the classes, believing that their students should be passive and not be involved in classroom activities; while the students complained that their teachers talked too much, and were always the centre of attention in the class. Consequently, the students did not have time to speak or practice. The results also showed that the students wanted to be organized into groups to practice speaking. By 
highlighting the discrepancies between the teachers' and the students' perceptions of their relationship, the authors aimed to help Vietnamese legislators, researchers, and teachers to gain a better understanding of English language teaching.

For an overview of the traditional and communicative language teaching methods, see Table 4. There are many positive and negative aspects of the traditional language teaching methods and CLT in Vietnam. The challenges of implementing CLT in Vietnam include the education system, a lack of infrastructural facilities, and the teachers' misconceptions about the CLT method, the traditional examination system, socio-cultural factors and the large class sizes (Ferraris, Martel, and Vignollet 2011).

To address these challenges, the teachers should adopt a secure learning environment in which their participation in the learning process is minimal. That is, they should be facilitators and not mere providers of knowledge to the learners. CLT focuses on a collaborative form of learning in which the learners work in groups or pairs. The learners remain active participants during the entire learning process. In addition, error correction is considered obstructive and not supportive of the language learning process.

Furthermore, according to McDonald (2011:41), it has been found that the communicative approach has a better adaption to the teaching of spoken language, "particularly those instances of spoken language which take place in a clearly defined situation and with clear goals”. The use of drama in CLT was studied by Davies (1980). He found that drama can fill the gap between the classroom and actual life. Therefore, it leads to fluency, motivation, and confidence of the learners through multiple activities (e.g., good listening practice, learning of vocabulary, physical involvement like acting). In the same storyline, Barbee (2014) reviewed enrich literature on the second language (L2) learning and concluded that drama gives an advantage to both students and language teachers. For instance, students can gain virtual experience and appropriate language skills meanwhile teachers can also improve their teaching capacities. Students play an important role in process of learning through drama. The roles of teachers are to facilitate the communication process and to participate in the teamwork or to act a participant in drama activities. Recently, through an experiment in Brasil, Galante and Thomson (2016) examined that drama based instruction is better than the traditional communicative method in improving learners' fluency. 
Overall, there is a close relationship between drama and CLT. Moreover, the CLT approach is a possible way to develop the learner's speaking competence in an EFL classroom, and drama is a CLT method. Drama has been used for educational purposes for many decades. The question remains whether the drama technique actually develops the learner's speaking competence? Thus, the next section will explore whether or not drama techniques are suitable for developing the speaking competence of primary school students and how to implement and apply drama techniques in English lessons.

\subsection{Drama and children}

The question is why children? Are they too small to learn a foreign language? There are many debates around this question. However according to Lee (Chua 2005), "The younger one learns to speak a language, the more permanently it is remembered” (Chua 2005, 127). Lee shared his own experiences on this topic and drew his own recommendation: "The lesson is: learn it when young. So it is important to make the effort. Have the roots to sink into your mind and it will be a lifelong asset. It is something I have missed which I cannot recover now" (Chua 2005, 87). This is in agreement with McDonald (2011), who explained the reasons for children tending to learn languages relatively quickly and easily was because of three main points: motivation, opportunity and time. As McDonald (2011) argues, children are highly motivated to learn a language because language gives them the key to open an enormous world of many meaningful activities around them. They also receive an enormous amount of support and reinforcement in their first faltering attempts at an adult language and are continually encouraged and rewarded for their successes. Language brings children the opportunity to access a rich and patterned language environment. Thus, they are exposed to language and experience it as being linked to clear material and social contexts, in which language use is highly functional, and where many other modalities such as gaze, body language, and gesture reinforce the linguistic meanings being made. Gradually children are exposed to the sheer amount of language over the periods of time in which they can listen to others talking and try out the new language themselves. Therefore, seemingly trivial play activities, such as nursery rhymes, language games can be the reinforce key of their language development (McDonald 2011: 69)

In China, there is a common problem among language teachers that they prefer teaching English by focusing on grammar rather than on speaking. They believe that to learn a foreign language, grammar is the most important factor to learn first (Hu 2002). However, a child, when learning their mother language, learns words or sentences by listening and 
repeating, and eventually, they are able to speak or express most of the things relating to the area of their knowledge without knowing the rules of grammar. Children only start learning the rules of grammar in grades 2 or 3. Therefore, learning a foreign language should follow the same process. Children should be placed in a similar context to when they are learning their mother language. Thus, the environment should be natural, with authentic materials, as well as being in accordance with the characteristics of their growth.

According to Vernon (2010), there is a strong link between pretend play and language development. Drama immerses the students in real life situations through challenging and enjoyable activities: “Through drama, students became a part of the learning process rather than mere observers or inactive receptacles of the rich experience of learning; in this way their learning was deeper, more sustained, and infinitely more complex” (Wilhelm and Edmiston 1998, 1). Through such activities, the students see that the language is vivid, flexible and colorful. In the same line, Vernon (2010) found that the learning process is effective for children if they can learn through play.

Drama provides authentic materials when learners practice their speaking, and creates a situation for them to learn how to cooperate, tolerate and be empathetic while promoting active learning. Drama activities help at-risk children (called low-level learners) the most (Schiller 2008). Drama in English language classes explores the students' potential to learn and improve their performances by imitating the way characters do this in the play (Dressman 2007). Language and the learning process are visualized and contextualized through drama activities so that children find it easy to get the meanings and memorize them by referring to their own experiences, feelings, attitudes, ideas, and life situation (Hoyt 1992).

Acknowledging the effectiveness of drama in education, most preschool or kindergarten and primary school classrooms use drama as a useful tool to develop the students' language and personalities. In drama activities, the students can 'be' someone else, so they are more likely to try new things without the fear of making mistakes or receiving punishment. Since they created the situations themselves, they are more likely to accept the results of their performances.

It is often said that "Drama is doing”, and children love doing, playing and acting out scenes from stories or from real life. Even adults act and direct themselves when 
rehearsing the language and script for certain situations. We act in situations like buying and selling, weddings, etc. Therefore, we are the directors and actors/actresses of our lives. Drama is basically a rehearsal for the children for the situations they will encounter in the future (Phillips 2000). Thus, they are attracted to drama. Drama adds positive emotions, feelings and motivation to their study of English. Drama and children are really a wonderful combination, in which children can play, explore new things, learn about the language and learn how to speak in a competent way.

\subsection{How drama techniques fulfill each speaking sub-competence}

As mentioned in Chapter 5, speaking competence in this study is defined as a combination of the five sub-competences: grammatical, discourse, pragmatic, fluency, and attitudes and motivation.

\subsubsection{Grammatical competence}

"Language requires that we understand each other [...]As in English, you can speak with different accents, but if the grammar is correct, it can be understood” (Chua 2005, 67)As mentioned, grammatical competence means that the individual's grammar, vocabulary, and pronunciation are used correctly when speaking (Riggenbach 1998).

Drama is an excellent method to teach grammar because it is more exciting than, and different to, the traditional, duller textbook method. Young learners are generally slow to learn the structures of grammar because grammar is not obvious. However in drama, according to Stewing and Buege (1994) “nouns, verbs, adjectives, and adverbs are better understood when children physically act them out in the sequential order found in basic sentences". This means that by acting out, by being in roles, the students practice speaking sentences one-to-one and from time to time, and they can understand how the grammatical structures are created. The students learn grammar in a simulated reality of a play, and per

the discussion about drama and memory, it is more lasting than reading from a piece of paper.

To gain grammatical competency, it is necessary to have a variety of vocabulary to make sense of sentences. Young students can learn new words easier because words have meanings. However, there are some young learners who find it difficult to memorize new vocabulary items because of differing learning styles and different dominant parts of their intelligence (Demircioğlu 2010). In drama, however, the students do not learn the vocabulary in isolation. When a student has read, practiced and dramatized a scene using 
the words, they are not likely going to forget them. Additionally, movement and pantomime in drama can help develop the student's vocabulary, since they can experience the feelings and meanings of the words (Demircioğlu 2010). It would be different if the words are memorized purely for a vocabulary test. Using drama to teach English helps to improve one’s understanding and memory of a word and to learn vocabulary.

In addition, drama is an excellent tool for students to practice the pronunciation of words in an integrated way and to improve their vocal delivery (Goodwin 2001). Due to the communicative nature of drama activities, the learners can easily practice all aspects of English pronunciation, from phonemes to intonation to stress. For example, in a vowel production activity, students are asked to stand up and start walking around the room. As they are walking, they produce a vowel sound for one minute, and another in the next, such as from “оoo" to "aaa”. Learners can also use drama activities "to warm up their voices and improve their projection, enunciation, and overall vocal delivery" (Advance Consulting for Education 2014) ${ }^{11}$. Drama teaches the learners how to properly pronounce their words and to speak up so that they become better speakers.

While mentioning drama and grammatical competence, it would be remiss to not mention Even's (2011) theory of drama grammar. Based on the principles of drama pedagogy, the structures of drama grammar employ procedures from the performing art expressions, including subjective, passionate, social, handy and kinaesthetic learning measures:

"The concepts of drama grammar subscribes to the same tenets as drama pedagogy - its claim to holistic learning and its clear alignment with the dramatic arts. Drama grammar is both content and skill oriented. Through techniques from the performing arts, grammar is put onto the classroom stage, and the fictionality of the dramatic context serves as a secure environment for learners to try out combinations of words, gestures, and movements in collaborative efforts to drive the action forward. Learners' cognitive, social, practical and kinesthetic potentials are brought to the forefront, and the 'freedom of being somebody else' (quoted in Even 2003, 340) affords new perspectives and can be a highly effective outlet for creativity and imagination.” (Even 2011, 307)

As mentioned, since the 1990s drama has been regarded as a consistent methodological continuation of the communicative approach, and drama grammar "takes the communicative orientation one step further into post method, making additional use of

\footnotetext{
${ }^{11}$ https://www.youtube.com/watch?v=aCcdJD2j1Mg
} 
techniques that direct learners' conscious attention to specific linguistic structures during carefully orchestrated phases” ( Even 2011, 307).

Students are often scared or inhibited about speaking up in class, due to the fear of making mistakes about grammar. Drama is a solution to this problem because it creates a classroom environment where words are fun, and being error-free is not a priority (Thornbury 2002).

\subsubsection{Discourse competence}

Discourse competence means that the speaker can structure digressions from the current conversation coherently. Something is coherent if there is a logical flow in the sequence of events, or it fulfills the reader's or listener's expectations. The good ways to learn how to structure a discourse are through written texts and conversations.

Narratives in stories sometimes utilize a flashback to offer an exposition of the current situation, and they utilize the discourse markers to keep the story coherent. If the learners are immersed in such a narrative, like in a role-play, then they have the first-hand experience of how the variety of cohesive devices (e.g., and, so, but) are used. For example, the students can role-play as a teacher (Student A) and student (Student B) talking about the summer vacation:

Student A: Good morning, Laura.

Student B: Good morning, Ms. Nguyen.

Student A: What did you do over the summer break?

Student B: My family and I went to the beach.

Student A: What did you do at the beach?

Student B: It was raining most of the time, so we didn't get to do much. It was much better a few years ago when the weather was nicer.

Learners can also learn how to practice structuring a discourse in a normal conversation. Some drama activities require the learner to converse with another learner, and it is an excellent opportunity to learn from the other person how to structure a digression and to learn by doing it. In an activity called "Cut and Paste", the teacher prepares a short story with many dialogues. The teacher tells the students about the story first and then asks the students to work in pairs to put the fragmented story back in order and to act it out. "Cut 
and Paste" is a good activity that shows the learners how the sentences are linked together, and they learn with another person and by acting it out.

By using authentic materials, drama can make students aware of the structure or lexicon of the language system. Once the students are aware of the concept of coherence, it will be easier for them to improvise a story and to manage the conversation effectively.

\subsubsection{Pragmatic competence}

Pragmatic competence means that one knows what is appropriate to say in a conversation (Cornbleet and Carter 2001, Pohl 2004). For example, if two students separately ask a native English speaker to borrow their pen, the native speaker would likely respond more favorably to the request of "Could I borrow your pen”, rather than "Borrow your pen”. The preference of the native speaker is due to the fact that the first request is more appropriate than the second.

Drama activities, such as role-playing and simulations, let the students take on different social roles and participate in different events. Drama activities provide students with the chance to practice a wide variety of pragmatic skills that they need in social situations outside the classroom.

\subsubsection{Fluency}

Fluency means that the person speaks the language continuously and with little to no interruptions. Learners can improve their fluency through drama because certain activities are repeatedly rehearsed, and practice improves fluency. In a theatrical play, for example, the students listen, read and repeat their lines. By repetition, they are able to say the lines with increasing fluency. Moreover, playing enables learners to overcome their rational and emotional barriers, so they can speak freely and confidently express what they want to. The learners feel at ease and safe when there are a facilitator and a group of like-minded people. Therefore, speaking gradually improves fluency.

\subsubsection{Attitude and Motivation}

A positive attitude and intrinsic motivation are essential to the success of the students' English speaking competences. Drama activities are good tools to ensure that all the students experience success during their learning process, hence facilitating motivation and a positive attitude. 
The students' experiences of success or failure impact on their motivation. If the students repeatedly fail, even when they worked really hard, they are more likely to develop a negative attitude. Drama activities are wonderful in this case because they can handle mixed abilities in the same task. A bigger role can be given to a better student (to keep them motivated), while a simpler role can be given to a lower level student (to avoid making it too challenging). With drama, and the appropriate play and roles, every student can experience success.

It has been argued, in support of creating a positive classroom environment: "If students experience the classroom as a caring, supportive place where there is a sense of belonging and everyone is valued and respected, they will tend to participate more fully in the process of learning” (Pandey 2005, 87). Drama lessons can satisfy these feelings because all students are involved in their roles; therefore, each role is important in a play and cannot be compared with others. Students can develop a sense of belonging, which is difficult to achieve in traditional classroom settings.

Drama helps the students by making them more self-confident when using the language. Each student, shy or talkative, is given a role in the play or activity. They can initially speak through the disguises of the costumes. They will garner more positive attitudes towards learning English and will become better speakers over time. Once they are exposed to the situation, the students will be more motivated to speak in similar real-life situations.

\subsection{Implementation of drama activities in the EFL classroom}

Billíková and Kissová (2013) suggested three methods for incorporating drama into a foreign language classroom: drama-based activities, drama-based lesson plans, and performances on stage. In this section, the researcher will examine each method to see how they develop speaking competence and analyze their advantages and disadvantages.

\subsubsection{Drama-based activities}

Drama-based activities are activities that are based on removing negative effective elements from the class, such as fear and anxiety. There are some drama-based activities that are suggested specifically for primary school students, as seen in Figure 9 (Phillips 2000, Farmer 2007). Some examples include "getting started”, “songs, rhymes, and chants" and "developing skills" activities. The idea of drama-based activities is that the 
fear of using the foreign language will disappear when the students get used to the activities.

In general, getting started activities are like warm-ups and ice-breakers, which energize the students and 'break the ice'. They involve the revision of vocabulary through emotions, body language (e.g., miming) and sometimes listening skills. A detailed description of each getting started an activity and its focus are provided in Table 6. Getting started is an excellent drama-based activity to use at the beginning of an English class.

After the students are sufficiently warmed up, they can participate in songs, rhymes and chanting activities. These activities teach stress, adjectives, etc., through rhythm and body movements. Table 7 provides a list of some activities and their description and focus. Songs, rhymes, and chants are good for engaging the students, because they are out of their seats, and the activities are repetitive and fun.

Once the students have established a foundation of the necessary English skills, the teachers can build on these skills in developing the skills drama-based activities. Examples are shown in Table 8. The developing skills activities are characterized by spontaneity, improvisation, speaking and observing. These activities are ideal for tapping into the imaginative and creative parts of the student's minds and reinforcing the basic skill the teachers want to develop.
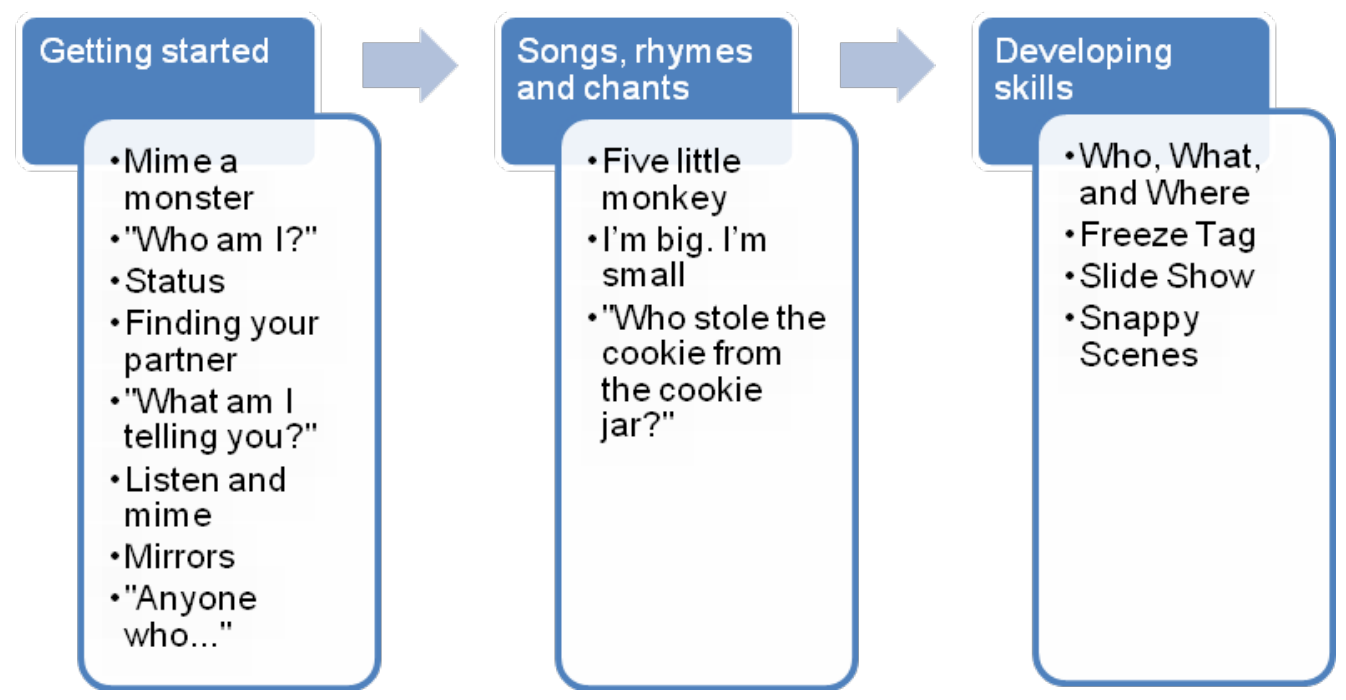

Figure 9. Examples of drama-based activities for primary school students (Phillips 2000, Farmer 2007). 
Table 6. Detailed description and focus of “Getting started” activities (Phillips 2000,

Farmer 2007).

\begin{tabular}{|c|c|c|}
\hline Activity & Description & Focus \\
\hline Mime a monster & $\begin{array}{l}\text { Children work in pairs or in groups. } \\
\text { The teacher describes a monster and the children } \\
\text { create with their bodies. }\end{array}$ & $\begin{array}{l}\text { Introducing mime; vocabulary of } \\
\text { parts of the body }\end{array}$ \\
\hline "Who am I?" & $\begin{array}{l}\text { The children work in pairs to mime the characters } \\
\text { on a particular page in their book. } \\
\text { Each pair performs to the rest of the class, who } \\
\text { then guess the characters. }\end{array}$ & $\begin{array}{l}\text { Revision through mime; working in } \\
\text { pairs/co-operation; } \\
\text { encouraging children to revise the } \\
\text { language in the textbook }\end{array}$ \\
\hline Status & $\begin{array}{l}\text { The children work in pairs to mime a word from a } \\
\text { "word family". For example, pencil, pen and } \\
\text { pencil case. } \\
\text { They perform to their classmates, who then guess } \\
\text { what it is. }\end{array}$ & $\begin{array}{l}\text { Revision of vocabulary using } \\
\text { mime; working in pairs; } \\
\text { stimulating imagination and } \\
\text { creativity }\end{array}$ \\
\hline $\begin{array}{l}\text { Finding your } \\
\text { partner }\end{array}$ & $\begin{array}{l}\text { The children work on short dialogues ( } 2-4 \text { lines) } \\
\text { that they have been studying, and are given a } \\
\text { card that tells them how they feel. } \\
\text { They talk to others in the class, trying to find } \\
\text { another person who feels the same way as they } \\
\text { do. }\end{array}$ & $\begin{array}{l}\text { Practising vocabulary of feelings } \\
\text { and showing emotions with voices, } \\
\text { faces and bodies; learning a } \\
\text { dialogue through non-verbal } \\
\text { communication }\end{array}$ \\
\hline $\begin{array}{l}\text { "What am I } \\
\text { telling you?" }\end{array}$ & $\begin{array}{l}\text { Two children mime a sentence and the other } \\
\text { children guess what the sentence is. }\end{array}$ & $\begin{array}{l}\text { Practicing performance; revising } \\
\text { language from previous lessons }\end{array}$ \\
\hline $\begin{array}{l}\text { Listen and } \\
\text { mime }\end{array}$ & $\begin{array}{l}\text { The children listen to a story, and act out certain } \\
\text { words they hear. } \\
\text { For example, enormous: starting above your head, } \\
\text { trace a big circle with your hands; elephant: wave } \\
\text { an arm in front of your nose like an elephant's } \\
\text { trunk (Phillips 2000: 19). }\end{array}$ & $\begin{array}{l}\text { Listening to a story for a specific } \\
\text { words and phrases }\end{array}$ \\
\hline Mirrors & $\begin{array}{l}\text { Children work in pairs and can be done to music. } \\
\text { One person is just himself/herself, while the other } \\
\text { person is the "mirrors image", carefully copying } \\
\text { everything done by the real person. } \\
\text { For example, student A extends her left arm, } \\
\text { student B should extend her right arm. After a } \\
\text { few minutes the roles are reversed. }\end{array}$ & $\begin{array}{l}\text { Listening to recount a sequence of } \\
\text { action }\end{array}$ \\
\hline $\begin{array}{l}\text { "Anyone } \\
\text { who..." }\end{array}$ & $\begin{array}{l}\text { Children sit in chairs in a circle, apart from one } \\
\text { person (the caller) who stands in the centre. } \\
\text { He calls out a category beginning with "Anyone } \\
\text { who...", such as "Anyone who is wearing orange" } \\
\text { and "Anyone who gets up at } 6 \text { am". } \\
\text { The rest of the class sit around and hearing the } \\
\text { called out category, anyone wearing the colour } \\
\text { orange must move to a different chair while the } \\
\text { caller tries to sit on one of the empty seats. } \\
\text { The person who gets no chair afterward will } \\
\text { become a caller and so on. }\end{array}$ & $\begin{array}{l}\text { Concentration; ice-breaker, } \\
\text { energiser }\end{array}$ \\
\hline
\end{tabular}


Table 7. Detailed description and focus of "Songs, rhymes and chants" activities (Phillips 2000, Farmer 2007).

\begin{tabular}{|c|c|c|}
\hline Activity & Description & Focus \\
\hline $\begin{array}{l}\text { Five little } \\
\text { monkeys }\end{array}$ & $\begin{array}{l}\text { The children say and act out a traditional rhyme. } \\
\text { Example: "Five little monkeys jumping on the bed. One } \\
\text { fell off and bumped his head. Mummy called the } \\
\text { doctor and the doctor said. No more monkey } \\
\text { jumping on the bed." }\end{array}$ & $\begin{array}{l}\text { Co-operation and acting } \\
\text { out a traditional rhyme } \\
\text { rhythm; total physical } \\
\text { response }\end{array}$ \\
\hline $\begin{array}{l}\text { l'm big. I'm } \\
\text { small }\end{array}$ & $\begin{array}{l}\text { The children act out a poem: } \\
\text { I'm big } \\
\text { I'm small } \\
\text { I'm short } \\
\text { I'm tall } \\
\text { l'm happy } \\
\text { I'm sad... }\end{array}$ & $\begin{array}{l}\text { Practising adjectives: big, } \\
\text { small, tall, short, happy, } \\
\text { unhappy, sad, bored; } \\
\text { encouraging children to } \\
\text { associate adjectives with } \\
\text { movement and work on } \\
\text { group dynamics }\end{array}$ \\
\hline $\begin{array}{l}\text { "Who stole the } \\
\text { cookie from } \\
\text { the cookie } \\
\text { jar?" }\end{array}$ & $\begin{array}{l}\text { The children learn a traditional chant with a question, } \\
\text { answer verse and chorus. } \\
\text { Then they add actions to it. } \\
\text { Finally, they suggest new word and actions for their } \\
\text { own version. } \\
\text { Example: (read with stress and rhythm) } \\
\text { All: Who stole the cookie from the cookie jar? } \\
\text { Teacher: Maria stole the cookie from the cookie jar. } \\
\text { Maria: Who, me? } \\
\text { Teacher: Yes, you } \\
\text { Maria: Not me! } \\
\text { Teacher: Then who? } \\
\text { All: Who stole the cookie from the cookie jar? } \\
\text { Maria: (names another child) }\end{array}$ & $\begin{array}{l}\text { Practising the stress and } \\
\text { rhythm of spoken English; } \\
\text { taking part in a simple } \\
\text { question and answer } \\
\text { exchange; listening for the } \\
\text { key words in a text }\end{array}$ \\
\hline
\end{tabular}


Table 8. Detailed description and focus of “Developing skills” activities. (Phillips 2000,

Farmer 2007).

\begin{tabular}{|c|c|c|}
\hline Activity & Description & Focus \\
\hline $\begin{array}{l}\text { Who, What, } \\
\text { and Where }\end{array}$ & $\begin{array}{l}\text { Divide the children into pairs labelled " } \mathrm{A} \text { " and " } \mathrm{B} \text { ". } \\
\text { The aim is to improvise a three-line scene and to establish the "Who", } \\
\text { "What" and "Where" as quickly as possible. } \\
\text { Who is in the scene and what is their relationship to one another? } \\
\text { What are the characters doing? } \\
\text { Where is the scene taking place? } \\
\text { " } \mathrm{A} \text { " initiates the scene and speaks first. " } \mathrm{B} \text { " must work out what situation } \\
\text { " } \mathrm{A} \text { " is setting up and respond verbally in character. } \\
\text { Finally " } \mathrm{A} \text { " ends the scene with a third line } \\
\text { The idea is not to plan the scene in advance, so as soon " } \mathrm{A} \text { " has an idea } \\
\text { the improvisation can start. }\end{array}$ & $\begin{array}{l}\text { Spontaneity, } \\
\text { speaking and } \\
\text { listening }\end{array}$ \\
\hline Freeze Tag & $\begin{array}{l}\text { Two children ("A" and "B") improvise a simple scene that involves a } \\
\text { physical activity, such as painting a room. } \\
\text { Not long after the scene has started, the facilitator shouts "freeze" and } \\
\text { both actors hold their positions. } \\
\text { "C } \mathrm{C} \text { steps forward and tags "A/B" on the shoulder. "A/B" leaves the scene } \\
\text { and "C takes over the pose and position. } \\
{ }^{\circ} \mathrm{C} \text { " restarts and creates a completely different situation. }\end{array}$ & $\begin{array}{l}\text { Improvisation, } \\
\text { spontaneity and } \\
\text { co-operation }\end{array}$ \\
\hline Slide Show & $\begin{array}{l}\text { Ask each group to prepare a presentation on a particular theme. One of } \\
\text { them will be the presenter and the others will "be" the slide show. } \\
\text { The presenter has an imaginary remote-control that he presses to show } \\
\text { the next slide. } \\
\text { As the presenter goes through the speech, the other group members } \\
\text { have to jump into position to make a tableau each time the remote- } \\
\text { control is pressed. } \\
\text { This should not be too thoroughly rehearsed as the element of surprise } \\
\text { makes the presentation more entertaining. } \\
\text { The ideas should be developed both by the presenter and the actors } \\
\text { making the slides, who can add visual ideas to carry the story along } \\
\text { (e.g. a vacation slide show). }\end{array}$ & $\begin{array}{l}\text { Mime and verbal } \\
\text { communication }\end{array}$ \\
\hline $\begin{array}{l}\text { Snappy } \\
\text { Scenes }\end{array}$ & $\begin{array}{l}\text { The children stand in a circle. } \\
\text { Anyone can begin by choosing to act as an object or character. That } \\
\text { person steps into the center and says "I am a..." } \\
\text { One by one the other players step in, each naming and making a related } \\
\text { object or character. } \\
\text { Example: } \\
\text { A: I am a car } \\
\text { B: I am a mechanic } \\
\text { C: I am a spanner } \\
\text { This continues until you are happy with the number of people in the } \\
\text { tableau. At this point you can say "Whoosh" to clear the stage and a } \\
\text { new sequence can begin. }\end{array}$ & $\begin{array}{l}\text { Spontaneity and } \\
\text { observation }\end{array}$ \\
\hline
\end{tabular}

\subsubsection{Drama-based lesson plans}

A drama-based plan consists of four stages: warm-up, pre-drama, drama and calm-down. The warm-up and cool-down stages are to bring the noise and energy levels to acceptable levels. New vocabulary, structures, and functions are taught in the pre-drama stage and used in context in the drama stage. As there are four stages in a drama-based lesson plan, 
there are varying levels of effectiveness. Daniela and Tim (2000) created the terms of “strong approach” and “weak approach” in relation to drama-based lesson planning in EFL classroom.

The strong approach to drama-based lesson plans incorporates a distinctive educational philosophy implied in drama: a learner-centred, democratic and humanistic approach. Drama becomes the frame for teaching and learning. Language is learned and acquired through active use in a meaningful, "as if” situation. The strong approach determines the structure of the lesson and the four different parts form a clearly coherent unit. The weak approach to drama-based lesson plans utilizes drama techniques in a more conventional teaching situation, where the teacher follows the pattern of presentation-practiceproduction. Drama is used in the warm-up, dialogue practice or reading activities. This drama approach can be found in many resource books, for example, Alan Maley and Alan Duff's “Drama Techniques in Language Learning: A Resource Book of Communication Activities for Language Teachers”; Sarah Philipps' “Drama with Children: Resource Books for Teachers”; John Dougill's "Drama Activities for Language Learning”; and Bernie Warren’s “Drama Games: Drama and Group Activities for Leaders Working With People of All Ages and Abilities”. They contain various drama activities and ideas that may be useful for a language teacher and can serve as stepping stones towards a more structural drama approach. However, because the content of a drama-based lesson plan must respect the learners’ proficiency level (Billíková and Kissová 2013), the weak drama approach is better for primary school students, because it requires less English skills.

The warm-up activities aim to warm students up, prepare them for active participation, increase their concentration levels, establish trust and prepare the learners vocally and physically for the drama-based activities, for example, "Breaking the ice", "Mime a monster”, "Who am I?” or “Finding your partner”. Warm-up activities are usually done in a circle, because it feels more inclusive and everyone can see each other.

The pre-drama stage aims to teach specific vocabulary, grammar structures or language functions. They are presented and practiced. The learners' imaginations are enhanced and their expectations and commitment are raised. Learners usually work in small groups or in pairs. Teachers can use different objects, posters, letters, photos or texts in order to create a meaningful context. 
In the drama stage, the performances can be done right after each other, so as to save and reduce time. The focuses are on fluency and grammatically and socially proper language, since the main aim is to develop the speaking competences of the language learners.

The calming-down stage is intended to calm the learners down and bring them back to their normal voices and energy levels. The calming down is followed by reflection, which is a crucial part of the lesson. Learners reveal their feelings and express their opinions about their learning experiences, either through a written internal monologue or a class discussion.

Depending on the different curricula, time frames, contents and language levels of the learners, the teacher should adjust the above structure to accomplish the aims of the lesson. The full structure of a drama-based lesson plan is seen in Table 9. The explanations and descriptions from Billíková and Kissová (2013) are helpful for those who want to use drama techniques in their lesson plans. 
Table 9. The four stages of a drama-based lesson plan (Billíková and Kissová 2013).

\begin{tabular}{|c|c|c|c|}
\hline Stage & Description & Teacher's Roles & Examples \\
\hline Warm-ups & $\begin{array}{l}\text { Introduced after opening } \\
\text { the lesson ( } 2-7 \text { minutes). } \\
\text { Movement is great to } \\
\text { energize the class and } \\
\text { wake up the learners' } \\
\text { bodies and senses. }\end{array}$ & $\begin{array}{l}\text { Teacher is a leader and a } \\
\text { manager during this } \\
\text { stage. }\end{array}$ & $\begin{array}{l}\text { Nonverbal activities: clapping, } \\
\text { sending silent signals, walking in } \\
\text { space, etc. } \\
\text { Simple verbal activities: word } \\
\text { chains, greeting activities, tongue } \\
\text { twisters, etc. }\end{array}$ \\
\hline Pre-Drama & $\begin{array}{l}\text { A preparation stage } \\
\text { where the topic of a } \\
\text { lesson is introduced (10- } \\
15 \text { minutes). }\end{array}$ & $\begin{array}{l}\text { Teacher is a facilitator, not } \\
\text { a doer, but he/she is still } \\
\text { quite dominant during this } \\
\text { stage. } \\
\text { He/she should ensure that } \\
\text { the learners are doing the } \\
\text { task properly. }\end{array}$ & $\begin{array}{l}\text { Miming, still image, setting, } \\
\text { characters, dramatic hook, choral, } \\
\text { individual drills, chants, story } \\
\text { elicitation, and short } \\
\text { improvisations. }\end{array}$ \\
\hline Drama & $\begin{array}{l}\text { The most productive } \\
\text { stage. The learners } \\
\text { prepare, rehearse and } \\
\text { perform to the class (15- } \\
30 \text { minutes). }\end{array}$ & $\begin{array}{l}\text { Teacher is an observer } \\
\text { and encourager. } \\
\text { Learners are responsible } \\
\text { for their work, by means } \\
\text { of their performances. }\end{array}$ & $\begin{array}{l}\text { Different alternatives of } \\
\text { improvisations, simulations, role- } \\
\text { plays, dialogues, rehearsed plays, } \\
\text { still images, etc. }\end{array}$ \\
\hline $\begin{array}{l}\text { Calming } \\
\text { down }\end{array}$ & $\begin{array}{l}\text { The final and most } \\
\text { critical stage of drama- } \\
\text { based lesson plan. } \\
\text { Learners will be "left" at } \\
\text { a high emotional and } \\
\text { voice level without this } \\
\text { stage. }\end{array}$ & $\begin{array}{l}\text { Teachers and learners } \\
\text { should share their } \\
\text { experience from the } \\
\text { lesson, such as } \\
\text { difficulties, critical } \\
\text { evaluation and feedback. }\end{array}$ & $\begin{array}{l}\text { Relaxation activities (music), hot- } \\
\text { seating, writing (letters, news, } \\
\text { reports, journals, diary entries, } \\
\text { dialogues, finishing a story), } \\
\text { writing-in-role, drawing, creating } \\
\text { poster, jigsaw reading, etc. }\end{array}$ \\
\hline
\end{tabular}

\subsubsection{Performances on the stage}

There is usually not enough time or space for stage performances during English lessons. Performances on the stage are recommended for "English clubs" or "extra-curricular days”, where simple, short and funny plays can be staged by the child actors and actresses. The supportive audience can help encourage the children to act and role-play. Therefore, short plays can be performed at school events or class meetings.

There are many possibilities of including the performative character of a dramatic text into teaching, e.g., by watching a recorded theatre productions or a film based on a play, by 
imagining it being performed on stage while reading and interpreting it, or through the students acting it out.

Performance or theatre is an excellent approach to developing speaking competence in the EFL classroom. These approaches are effective if the students are expected to eventually stage a performance. This form of drama must be made appropriate to the grade level. It is dependent on which and how the strategy is utilized to make it work for the students (Fonseca and Arnold 2004).

According to Torgeson (2001), Miller (2009) and Mellou (1996), a ‘dramatic play' refers to all types of pretend play, like symbolic, imagination, fantasy, make-believe, socio-dramatic and role-play. A dramatic play is a type of play where students receive and act out roles. ${ }^{12}$ The students are engrossed in a play that fits their needs and interests, while the teacher is designing a space, and providing costume pieces, structures and props. An example of such a drama is "Let Us Pretend", which is important for kindergarten to Grade 1 students (Williams and Lutes 2010). A dramatic play is a child-oriented activity and includes imitation, simulation, role-play, interpersonal interaction and verbal communication. These elements of a dramatic play can be helpful in a primary school students' language learning process (McCullough 2000).

In conclusion, drama directly involves the students (Bas 2008). It arouses the students' interests and builds their personalities (Luyegu 2011). Students who are interested in a learning activity generally perform better than those who are not. The conventional teaching system is often focused on the textbook and the teacher, but in drama, the focus is on the students. Drama is seen as a teaching tool that puts the student's interests first.

The use of drama is essential in the foreign language classroom because it offers students an opportunity to use their imaginations and enhances their ability to imitate and articulate information. During a drama activity, the students are expected to use their previous experiences to fit into and understand their roles, and to give responses just like in reading and writing. It offers the students an effective way to master a language. Through drama, students are encouraged to modify their communicative competency and fluency.

\footnotetext{
12 http://www.earlychildhoodnews.com/earlychildhood/article_view.aspx?ArticleID=751
} 
The suggestions by Billíková and Kissová (2013) about how to apply drama in a lesson plan were used in this study, and implemented in two main phases: drama-based lesson plans and performances on stage.

During the first phase, drama-based activities were used in the drama-based lesson plan, with the aim of creating a space for learning by playing and being involving in the lesson. The structures of the drama-based lesson plan are described in more detail in Chapter 8 and Appendix C.

In the second phase, the performance on the stage helps the students to acquire grammatical competence, discourse competence and pragmatic competency through the scripts, but also lets the students practice speaking and to be a character in a simulated play. Furthermore, the performance on the stage might raise their motivation levels.

In the next chapter, the methodology will explain, in considerably more detail, how the drama-lesson plan was designed to meet the need for developing speaking competence through drama activities. 
Table 10. The percentages for each Item in the Attitudes and Motivation test.

\begin{tabular}{|c|c|c|c|c|c|c|c|c|c|c|c|c|}
\hline \multirow{3}{*}{ Items } & \multicolumn{6}{|c|}{ Control group } & \multicolumn{6}{|c|}{ Experimental group } \\
\hline & \multirow{2}{*}{\multicolumn{3}{|c|}{$\begin{array}{l}\text { Pre-intervention (\%) } \\
\text { Agree Disagree No idea }\end{array}$}} & \multicolumn{3}{|c|}{ Post-intervention (\%) } & \multicolumn{3}{|c|}{ Pre-intervention (\%) } & \multicolumn{3}{|c|}{ Post-intervention (\%) } \\
\hline & & & & Agree & Disagre & No idea & Agree & Disagree & No idea & Agree & Disagree & No idea \\
\hline $\begin{array}{l}\text { 1. Interest in } \\
\text { Foreign } \\
\text { languages }\end{array}$ & 50 & 50 & 0 & 57.65 & 42.35 & 0 & 48.82 & 51.18 & 0 & 82.35 & 12.94 & 0 \\
\hline $\begin{array}{l}\text { 2. Parental } \\
\text { Encouragement }\end{array}$ & 41.91 & 58.09 & 0 & 41.91 & 58.09 & 0 & 42.65 & 57.35 & 0 & 46.32 & 53.68 & 0 \\
\hline $\begin{array}{l}\text { 3. Motivational } \\
\text { intensity }\end{array}$ & 42.35 & 57.65 & 0 & 42.35 & 57.65 & 0 & 41.76 & 58.24 & 0 & 74.12 & 25.88 & 0 \\
\hline $\begin{array}{l}\text { 4. English class } \\
\text { anxiety }\end{array}$ & 45.29 & 54.71 & 0 & 48.24 & 51.76 & 0 & 43.53 & 56.47 & 0 & 74.71 & 25.29 & 0 \\
\hline $\begin{array}{l}\text { 5. English } \\
\text { teacher } \\
\text { evaluation }\end{array}$ & 47.06 & 50 & 0 & 50 & 50 & 0 & 47.06 & 52.94 & 0 & 93.53 & 6.47 & 0 \\
\hline $\begin{array}{l}\text { 6. Attitudes } \\
\text { towards } \\
\text { leaming } \\
\text { English }\end{array}$ & 48.82 & 51.18 & 0 & 52.94 & 47.06 & 0 & 49.41 & 50.59 & 0 & 91.76 & 8.24 & 0 \\
\hline \begin{tabular}{|l|}
7. Attitudes \\
towards \\
English- \\
speaking \\
people
\end{tabular} & 28.68 & 33.82 & 37.5 & 32.35 & 30.15 & 37.5 & 29.41 & 36.03 & 34.56 & 51.47 & 13.97 & 34.56 \\
\hline $\begin{array}{l}\text { 8. Integrative } \\
\text { orientation }\end{array}$ & 39.71 & 60.29 & 0 & 52.94 & 47.06 & 0 & 36.76 & 63.24 & 0 & 89.71 & 10.29 & 0 \\
\hline $\begin{array}{l}\text { 9. Desire to } \\
\text { leam English }\end{array}$ & 48.82 & 51.18 & 0 & 50 & 50 & 0 & 49.41 & 50.59 & 0 & 87.65 & 12.35 & 0 \\
\hline $\begin{array}{l}\text { 10. English } \\
\text { course } \\
\text { evaluation }\end{array}$ & 36.47 & 63.53 & 0 & 39.41 & 60.59 & 0 & 38.24 & 61.76 & 0 & 85.88 & 14.12 & 0 \\
\hline $\begin{array}{l}\text { 11. English use } \\
\text { anxiety }\end{array}$ & 27.06 & 72.94 & 0 & 27.65 & 72.35 & 0 & 26.47 & 73.53 & 0 & 64.71 & 35.29 & 0 \\
\hline \begin{tabular}{|l|}
12. \\
Instrumental \\
orientation
\end{tabular} & 51.52 & 48.48 & 0 & 63.24 & 36.76 & 0 & 50 & 50 & 0 & 82.35 & 17.65 & 0 \\
\hline
\end{tabular}


Table 11. T-tests for the Attitudes and Motivation Items, comparing the control and experimental groups pre- and post-intervention (i.e. lesson plan).

Asterisk $(*)$ denotes a significant difference at $\mathrm{p}<0.05$ and N/A means not applicable.

\begin{tabular}{|c|c|c|c|c|}
\hline \multirow{3}{*}{ Item Number } & \multicolumn{4}{|c|}{$\underline{\text { P-values }}$} \\
\hline & \multicolumn{2}{|c|}{ Control vs. Experimental } & \multicolumn{2}{|c|}{ Pre-intervention vs. Post-intervention } \\
\hline & Pre-intervention & Post-intervention & Control & Experimental \\
\hline 1 & 0.804 & $<0.001 *$ & 0.19 & $<0.001^{*}$ \\
\hline 2 & 0.928 & 0.6 & 1 & 0.600 \\
\hline 3 & 0.933 & $<0.001^{*}$ & 1 & $0.002 *$ \\
\hline 4 & 0.778 & $<0.001^{*}$ & 0.637 & $<0.001 *$ \\
\hline 5 & 1.000 & $<0.001^{*}$ & 0.496 & $<0.001 *$ \\
\hline 6 & 0.935 & $<0.001^{*}$ & 0.589 & $<0.001 *$ \\
\hline 7 & N/A & N/A & N/A & $\mathrm{N} / \mathrm{A}$ \\
\hline 8 & 0.367 & $0.002 *$ & 0.122 & $0.004^{4} *$ \\
\hline 9 & 0.950 & $<0.001^{*}$ & 0.9 & $0.002 *$ \\
\hline 10 & 0.658 & $<0.001 *$ & 0.461 & $<0.001 *$ \\
\hline 11 & 0.845 & $<0.001 *$ & 0.85 & $<0.001 *$ \\
\hline 12 & 1.000 & $0.03 *$ & 0.281 & $0.001 *$ \\
\hline
\end{tabular}

The advantages of a performance on stage are that it involves the whole group, incorporates movement and carefully planned language usage to create the best speaking practice for real life. By watching the episode and reading the scripts during the pre-performance, the students learn the grammar rules and discourse markers, imitate correct pronunciation, memorize new words about numbers and games, and learn how to make coherent and meaningful sentences. During the performance, the students have the opportunity to act and exhibit what they have prepared. Therefore, they were excited and motivated. The applause from the audience is also another extrinsic motivation factor. After the performance, the students evaluated themselves and realized what their strong and weak points were. If they did well in the performance, they will be motivated for the next performance. If not, they will draw from the experience of this lesson to make the next performance even better. 


\section{Chapter 8: Research Methodology}

To develop the speaking competences of primary school students in Vietnam, it is essential to gain a theoretical overview of the education system in which the study is taking place and to review the sample and population of the study. Therefore, in this chapter, the details of the institutional context and the population will be presented. Afterwards, the research design and formulas used in this study will also be explained.

\subsection{The institutional context}

This research study was carried out in Truong Thinh Primary School in the town of Phu Tho province, Vietnam. Phu Tho (with an area of $64 \mathrm{~km}^{2}$ ) is a township in the Phu Tho province, which is $100 \mathrm{~km}$ far from the capital of Hanoi. In 2013, the town had a population of 91,650 inhabitants. Phu Tho town lies between forestry hills and the Red River, where the past is mixed with the modern. In 1968, Phu Tho town became the center of Phu Tho province, the provincial training and education centre, and a bridge between the northwest and the northern delta.

In addition, Phu Tho is famous for its history and culture where the first King of Vietnam lived thousand years agour. Local officials said, there is an increasing number of tourists, including foreigners go and visit. English environment is expected to widely open in this area. It will create more opportunities for students and people speaking English and job offers. Moreover, we also observed there have been several English centers with foreign teachers offer English classes for students at any level in the province. 
Study Area
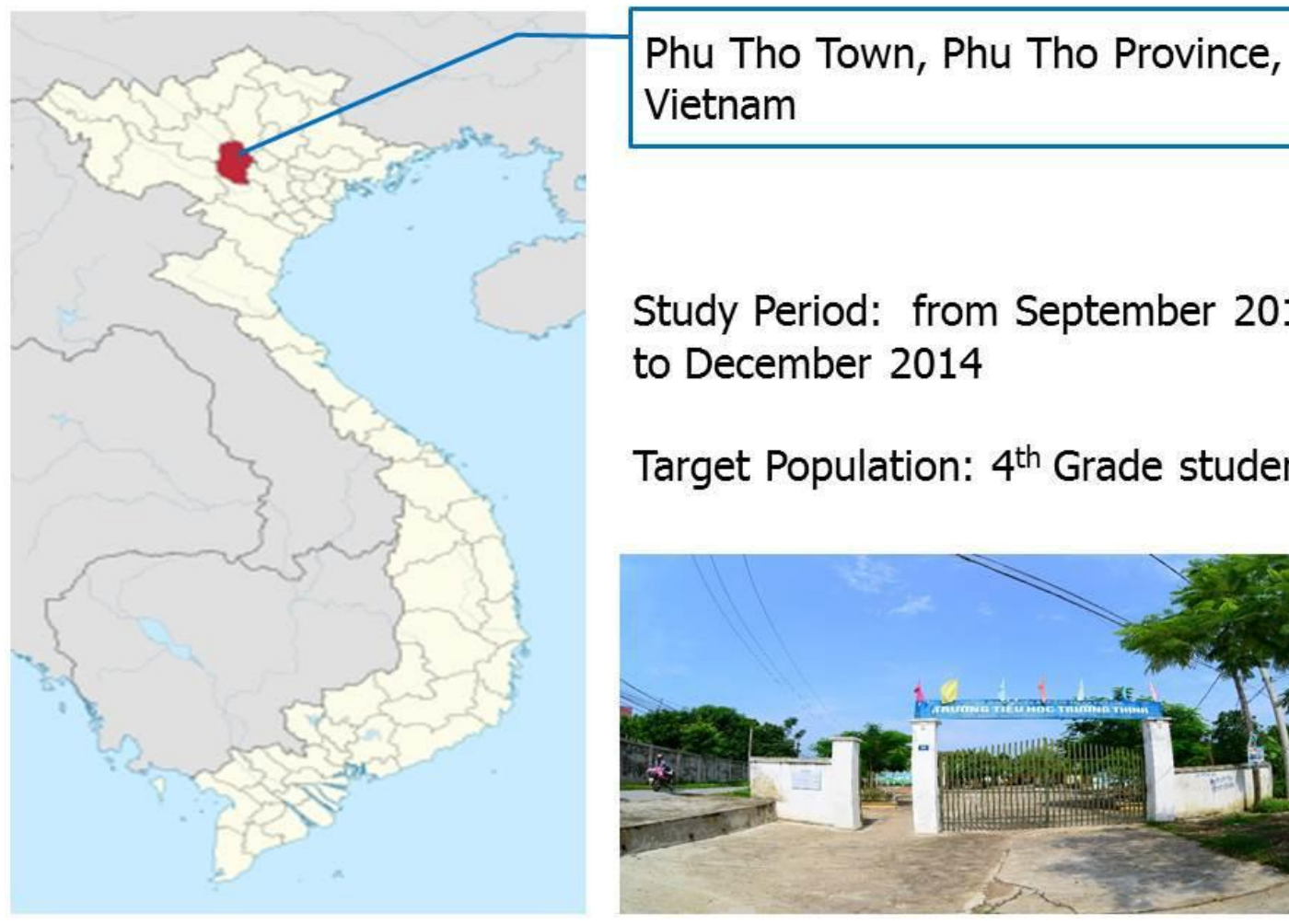

Study Period: from September 2014 to December 2014

Target Population: $4^{\text {th }}$ Grade students

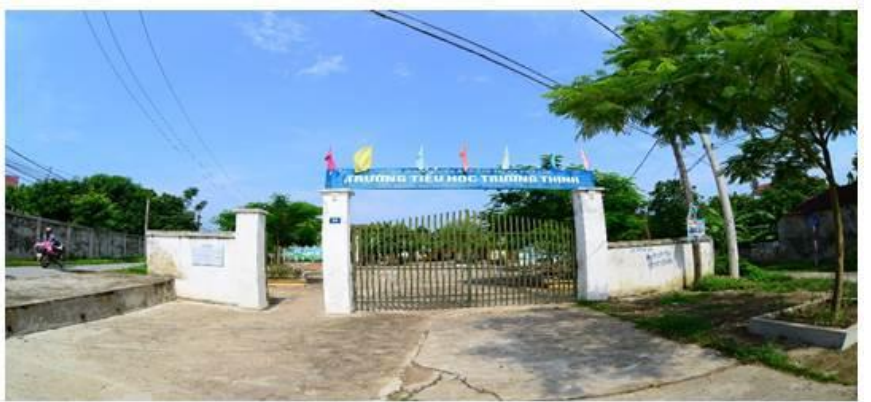

Figure 10. Location of the Truong Trinh primary school

Truong Thinh is one of the five wards in Phu Tho town, which has an area of $2446.5 \mathrm{~m}^{2}$, and where the majority of the local people are farmers (PSO 2014). We purposely selected the Truong Thinh primary school for conducting an experiment. The school was established in 1982 to educate a large number of students, aged 6 to 11 years old (Grade 1 to Grade 5). This school was selected from the six primary schools in Phu Tho town because it represents a typical government-run Vietnamese rural primary school.

In line with the National Curriculum requirements, English is compulsory up from Grade 3, with two periods of 45 minutes per week. After Grade 5, students have to reach the A1.1 level in communicative competence, as specified in the Common European Framework of Reference (CEFR).

However, in almost all primary schools in Vietnam, the students are typically expected to be good at doing the written English tests rather than being good at oral communication. Therefore, the drama method in ELT seemed to be very strange to both the teachers and 
students. This is true in rural areas like Phu Tho town, where English only recently appeared as a subject at school and is not used anymore outside the classroom. Thus, in this research, the researcher tried to give an overview of the drama method to both the teachers and students in the primary school. The researcher had to ask for permission from local authorities for doing experiment since they do not know very well what is the drama based method of teaching English. In addition, she also explained the method to English teachers in order to get their support. Some of them were not willing to change the traditional method of teaching (grammar-based). After explaining the purpose of the study, the experiment was conducted at the school.

During the four months of the experimental study, the researcher designed a lesson plan that uses drama techniques, so at the end of the experiment, it can be seen whether or not drama techniques can develop the speaking competence of the primary school students in Truong Thinh Primary School.

\subsection{Population and sample}

Truong Thinh Primary School has 180 primary school students in the school year 20142015, and they were partitioned into eight classes. The researcher randomly chose to sample one class, which consisted of 34 students. They were divided equally into two groups: a control group and an experimental group. The two groups were to learn EFL as usual, with all the settings the same, but the methods of instruction were different. The control group received 4 months of regular instruction by using the traditional method of teaching, while the experimental group received 4 months of drama-based instructions.

The average age in both groups was eleven. They have been studying English as a foreign language since Grade 3. The students have two 40-minutes classroom periods of English language per week. When the period of the experiment was over, the test of speaking competence was again administered to both groups and the questionnaires about motivation and attitudes were given to both groups to measure the changes in their levels.

\subsection{Research design}

The procedure for the study was as follows: 


\begin{tabular}{|l|l|}
\hline P Speaking competence test \\
• Attitudes and motivation questionnaire \\
\hline Pre-test
\end{tabular}

Figure 11. The experimental outline.

Firstly, the participants were selected randomly at the site. The informed consents were then delivered and obtained from the participants and the participants' parents or guardians. The procedure then followed a number of steps:

- The researcher observed the students in the classroom and recorded field notes regarding the students’ English speaking competences.

- The pre-questionnaire was administered to participants to report on their motivation and attitudes.

- The pre-test was administered to see the levels of the primary school students' speaking competences. 
- The participants participated in the drama-based instructional program. The researcher took notes of her observation after each drama-based lesson.

- The post-questionnaire and post-test were administered to the participants to report on their speaking competence levels, in terms of their knowledge, skills, motivation, and attitudes.

- Observe the class of both groups of students in order to determine the differences between the two methods of teaching.

The empirical research method was chosen for this research study. Empirical research is implemented by observing and measuring the phenomena and knowledge that were derived from the actual experience. In other words, it is "a plan for assigning experimental units to treatment levels and the statistical analysis associated with the plan” (Kirk 1995,1). In this design, there are two groups: the experimental (E) and control (C) groups. The experimental group received a treatment called the "drama-based lesson plan”, while the control group received regular instruction, called the "non-drama-based lesson plan” (both groups were assessed on a pre-treatment measure (i.e., pre-test), then the treatments were administered, before the post-treatment effect was measured (i.e., post-test) (Gay 2006). Figure 12 illustrates the experimental design.

The control group received regular instruction from the classroom teacher. The regular instruction was described as the traditional approach, with an emphasis on grammar and the grammar-translation method. On the other hand, the drama-based program was taught by the researcher, ${ }^{13}$ who is more familiar with the knowledge and theory of drama activities. The researcher did not rely on the textbook but used the drama-based program, which was explained in more detail in Chapter 7.

To find the baseline speaking competence level, checks of the primary school students' speaking competences were administered at the beginning of the study (i.e., pre-test: $\mathrm{C}_{1}$ or $\mathrm{E}_{1}$; and questionnaire ). The baseline was compared to the student's speaking competences (i.e., post-test: $\mathrm{C}_{2}$ or $\mathrm{E}_{2 \text { : }}$ and questionnaire) measured at the end of the four months of instruction, in order to determine any changes in the mean scores and in the change of attitude and motivation (see Table 10 for a schematic representation).

\footnotetext{
${ }^{13}$ The limitations were discussed in the last chapter
} 
Table 12. The pre- and post-test control and experimental group design.

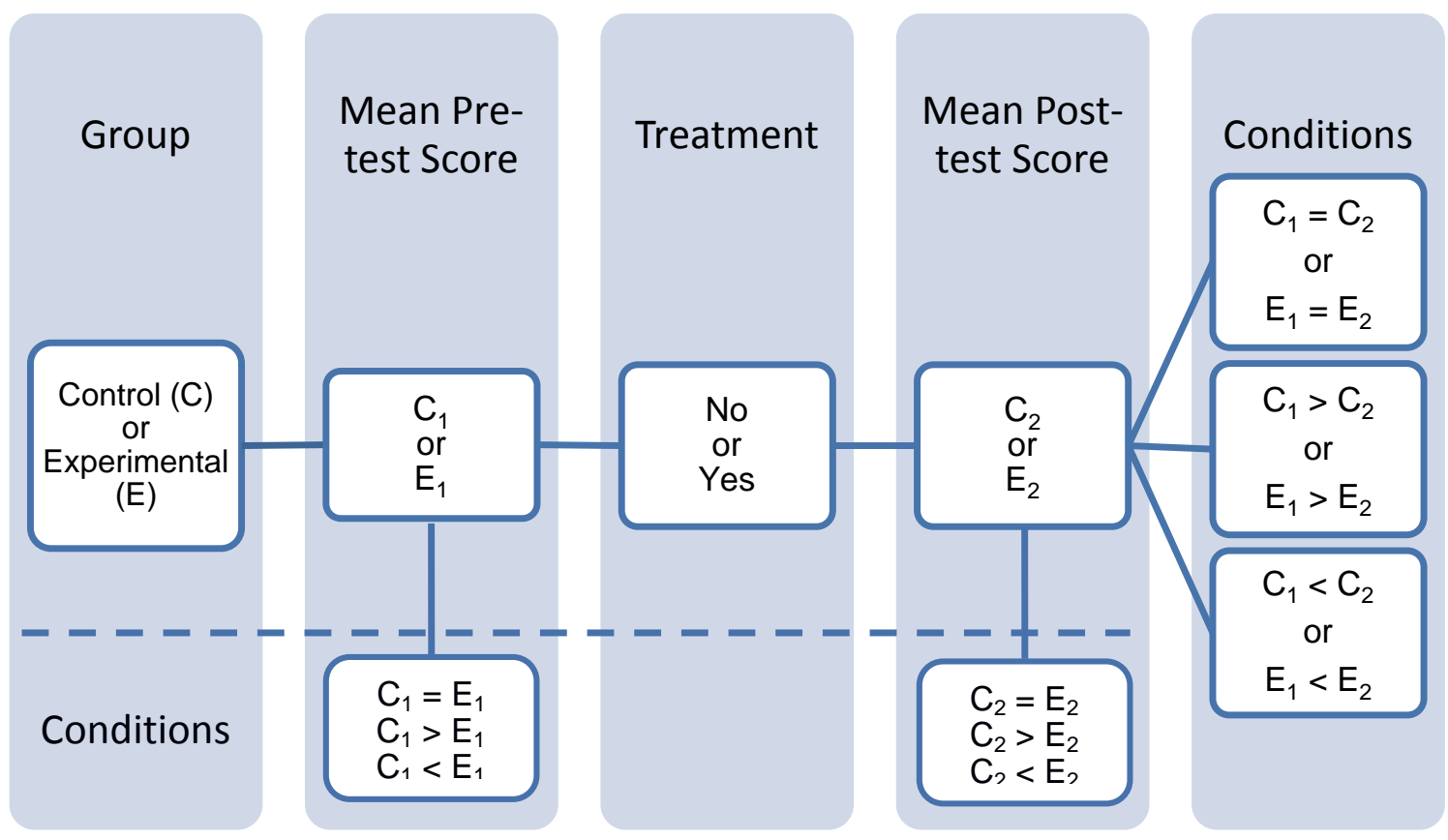

As a result, several conditions were possible, involving the mean scores within each group (Table 12). If the mean pre-test score was equal to the mean post-test score (i.e., $\mathrm{C}_{1}=\mathrm{C}_{2}$ or $E_{1}=E_{2}$ ), then there was no change in speaking competence after the study. If the mean pretest score was greater than the mean post-test score (i.e., $C_{1}>C_{2}$ or $E_{1}>E_{2}$ ), then there was a decrease in speaking competence after four months. The other condition was when the mean pre-test score was less than the mean post-test score (i.e., $\mathrm{C}_{1}<\mathrm{C}_{2}$ or $\mathrm{E}_{1}<\mathrm{E}_{2}$ ), then there was an increase in speaking competence. Since the only independent variable is the drama-based lesson plan treatment, then no change in the speaking competence levels meant that the lesson plan made no difference, a decrease meant that it possibly deteriorated speaking competence levels, and an increase meant that it may be beneficial for speaking competence levels. It was also possible to compare the speaking competence levels between the two groups (see Table 13). When the mean pre-test or post-test scores were equal between the two groups (i.e., $C_{1}=E_{1}$ or $C_{2}=E_{2}$ ), then both groups were at comparable speaking competence levels at the beginning or at the end of the study, respectively. When the control group's score was greater than the experimental group (i.e., $C_{1}>E_{1}$ or $C_{2}>E_{2}$ ), then the control group had a higher speaking competence level than the experimental group at the pre-test or post-test, respectively. When the experimental group's score was greater than the control group (i.e., $\mathrm{C}_{1}<\mathrm{E}_{1}$ or $\mathrm{C}_{2}<\mathrm{E}_{2}$ ), then the experimental group had a higher speaking competence level than the control group at the 
pre-test or post-test, respectively. It was important to compare both of the groups' mean pre-test scores, because if they were not equal, then it would be difficult to delineate the effect of the independent variable. Since the drama-based lesson plan was the only independent variable, then the differences in the post-test scores can be linked to the drama-based lesson plan.

Table 13. Speaking competence analysis.

\begin{tabular}{|c|c|}
\hline Condition & Conclusion \\
\hline \multicolumn{2}{|l|}{ Pre-test $=$ Post-test } \\
\hline $\mathrm{C}_{1}=\mathrm{C}_{2}$ & No change \\
\hline \multicolumn{2}{|l|}{$\mathrm{E}_{1}=\mathrm{E}_{2}$} \\
\hline \multicolumn{2}{|l|}{ Pre-test $>$ Post-test } \\
\hline $\mathrm{C}_{1}>\mathrm{C}_{2}$ & Speaking competence decreased \\
\hline \multicolumn{2}{|l|}{$\mathrm{E}_{1}>\mathrm{E}_{2}$} \\
\hline \multicolumn{2}{|l|}{ Pre-test $<$ Post-test } \\
\hline $\mathrm{C}_{1}<\mathrm{C}_{2}$ & Speaking competence improved \\
\hline \multicolumn{2}{|l|}{$\mathrm{E}_{1}<\mathrm{E}_{2}$} \\
\hline \multicolumn{2}{|l|}{ Control = Experimental } \\
\hline $\mathrm{C}_{1}=\mathrm{E}_{1}$ & Speaking competence equal \\
\hline \multicolumn{2}{|l|}{$\mathrm{C}_{2}=\mathrm{E}_{2}$} \\
\hline \multicolumn{2}{|l|}{ Control > Experiemntal } \\
\hline $\mathrm{C}_{1}>\mathrm{E}_{1}$ & Speaking competence better in control group \\
\hline \multicolumn{2}{|l|}{$\mathrm{C}_{2}>\mathrm{E}_{2}$} \\
\hline \multicolumn{2}{|l|}{ Control < Experimental } \\
\hline $\mathrm{C}_{1}<\mathrm{E}_{1}$ & Speaking competence better than experimental group \\
\hline $\mathrm{C}_{2}<\mathrm{E}_{2}$ & \\
\hline
\end{tabular}




\subsection{Tools for the data collection}

\subsubsection{Pre- and post-speaking tests to measure the primary school students' speaking competence}

The objective of the pre- and post-speaking tests is to determine if the students' speaking competences are at the A1 level of the European Framework of Reference for Languages (see Section 3.3). When they are at the A1 speaking level, the students should be able to interact with others in the target language, despite their limited vocabulary. However, despite trying to find previous studies about the speaking competence test for the A1level, it made no sense. It appears that not many countries have a particular speaking test for the A1 level in their national curricula of foreign languages, except for Greece. Moreover, in Greece the pre- and post-speaking tests were adapted from the Greek National Foreign Languages Curriculum Sub-project 2:2007-2013 for the A1 speaking level. These models of speaking test were selected because of the success which Greek education had made in their progress of English language teaching and learning in comparison with others. More importantly, this curriculum was verified by the Greek national examination and it has really worked during the time that it has been administered.

The pre- and post-speaking test consisted of three activities: interviewing; talking about a theme; and making a conversation (see Table 14). The students were tested individually and in pairs by two examiners, the English teacher of Truong Thinh Primary School and the researcher. It took approximately 10-15 minutes for every two students.

The first activity was an interview. The purpose of this interview was for the examiners to get to know the participants and to make the oral exam feel more pleasant. The examiner alternated between the two students and asked at least five pre-defined questions for each student. The whole interview typically took 3 minutes to complete. The "Interview" activity was the ideal first activity to introduce and to get to know the participants.

The second activity was to talk about a theme, which involved a set of thematically-linked pictures. For example, the students were asked to describe people and things in the pictures, talk about what they see in one or more of the pictures or talk about something that happened. The examiner asked ten questions related to the pictures within 3-5 minutes. In the "Talking about a theme" activity, the students were asked to identify or provide a simple description of the pictures. 
The third activity was about making a conversation with a stranger. The examiners asked the students to pretend to be two strangers, who are meeting each other for the first time. The conversation took 3-5 minutes. In the "Making a conversation" activity, the students had to make a conversation using what they have learned, showcasing their creativity, vocabulary and speaking competence in this activity.

In this study, the pre-speaking test determined whether or not both groups were at the same level prior to the implementation of the proposed lesson plan. The post-speaking test measured the effectiveness of the proposed lesson plan in developing the students' speaking competences.

Table 14. The three activities of the pre- and post-speaking tests. Adapted from the Greek National Foreign Languages Curriculum Sub-project 2:2007-2013 for the A1 speaking level.

\begin{tabular}{|l|l|}
\hline \multicolumn{1}{|c|}{ Activity } & \multicolumn{1}{c|}{ Content } \\
\hline Interview & $\begin{array}{l}\text { Greeting, small talk, giving personal information, expressing } \\
\text { likes/dislikes, habits and hobbies. }\end{array}$ \\
\hline Talking about a theme & $\begin{array}{l}\text { Describing the pictures, people, places or something in the handouts } \\
\text { or worksheets }\end{array}$ \\
\hline Making a conversation & Greeting, asking and answering questions, exchanging information. \\
\hline
\end{tabular}

In order to minimize individual variations in the scoring of the participants, the two examiners evaluated the students separately. The examiners filled in the speaking competence evaluation forms in Table 13 and Table E.1 in Appendix A. The forms consisted of the name of the examiners, scoring sheet, and sample parts of the students' pre- and post-speaking tests.

The evaluation forms were adapted from Torky (2006) and the Greek National Foreign Languages Curriculum Subproject 2:2007-2013 for the A1 speaking level. They were designed based on the characteristics of speaking competence in terms of grammatical competence, discourse competence, pragmatic competence, and fluency (see Chapter 4). Speaking competence, in terms of attitude and motivation, were measured by the results of 
the questionnaires before and after the intervention, which is described in the next section. Each competence or sub-competence was given a score from 0 (poor) to 5 (good). For the questionnaires on attitude and motivation, the results were collected and analyzed differently and separately to the results of pre and post-tests.

\subsubsection{Proposed lesson plan using drama techniques to develop the speaking competence of the experimental group (Intervention)}

The drama-based program consisted of two main phases: the drama-based lesson plan and a performance on the stage.

The aim of the lesson plan was to develop the speaking competence of the primary school students by engaging them in drama activities. By the end of the study the students would be able to:

- Use basic spoken grammatical rules correctly;

- Use a simple, relevant, adequate and appropriate range of vocabulary and collocations;

- Demonstrate clear pronunciation and intonation;

- Structure discourse coherently by using references as well as discourse markers correctly;

- Interact and manage simple conversation effectively to encourage the speaker to continue speaking;

- Show understanding;

- Take turns adequately;

- Speak fluently at a simple level for a basic user; and

- Speak English in and beyond an English language classroom.

The contents of the lesson plan consisted of six units and eighteen lessons. 
Table 155. The six units of the drama-based lesson plan, their associated targeted competence and examples.

\begin{tabular}{|c|c|c|c|}
\hline Unit & Competences & Sentence Pattern & Vocabulary \\
\hline Unit 1 & $\begin{array}{l}\text { - Greeting someone formally } \\
\text { - Giving answer to the } \\
\text { question, How are you? }\end{array}$ & $\begin{array}{l}\text { Good morning, Miss } \\
\text { Hien } \\
\text { How are you? } \\
\text { - I'm fine, thank you. }\end{array}$ & $\begin{array}{l}\text { Morning, afternoon, } \\
\text { evening, bored, well, } \\
\text { happy, ok }\end{array}$ \\
\hline Unit 2 & $\begin{array}{l}\text { - Asking and answering } \\
\text { questions about where } \\
\text { someone is from } \\
\text { - Stating one's own } \\
\text { nationality }\end{array}$ & $\begin{array}{l}\text { Where are you from? } \\
\text { - I'm from England } \\
\text { - I'm Vietnamese } \\
\text { What's his full name? } \\
\text { - Tom Green }\end{array}$ & $\begin{array}{l}\text { England, English, } \\
\text { America, American, } \\
\text { Australia, Australian, } \\
\text { Vietnam-Vietnamese, } \\
\text { China-Chinese, Japan- } \\
\text { Japanese }\end{array}$ \\
\hline Unit 3 & $\begin{array}{l}\text { - Asking and answering } \\
\text { questions about when } \\
\text { someone's birthday is } \\
\text { - Asking and answering } \\
\text { questions about dates }\end{array}$ & $\begin{array}{l}\text { When's your birthday } \\
\text { - It's in May } \\
\text { What's the date today? } \\
\text { - It's the fifth of October }\end{array}$ & $\begin{array}{l}\text { January, February, ... } \\
\text { Ordinal number (first, } \\
\text { second, third, etc.) } \\
\text { Birthday, date, today }\end{array}$ \\
\hline Unit 4 & $\begin{array}{l}\text { - Asking and answering } \\
\text { questions about what } \\
\text { someone can do } \\
\text { - Asking and answering } \\
\text { questions about abilities }\end{array}$ & $\begin{array}{l}\text { What can you do? } \\
\text { + I can dance. } \\
\text { Can you play } \\
\text { badminton? } \\
\text { + Yes, I can/ No, I can't. }\end{array}$ & $\begin{array}{l}\text { Swim, draw, ride a } \\
\text { bike, play the piano, } \\
\text { use a computer, } \\
\text { dance, play } \\
\text { badminton }\end{array}$ \\
\hline Unit 5 & $\begin{array}{l}\text { - Expressing what someone } \\
\text { likes doing } \\
\text { - Asking and answering } \\
\text { questions about someone's } \\
\text { hobbies }\end{array}$ & $\begin{array}{l}\text { I like dancing. } \\
\text { What is your hobby? } \\
\text { - Dancing. }\end{array}$ & $\begin{array}{l}\text { Hobby, music, music } \\
\text { club }\end{array}$ \\
\hline Unit 6 & $\begin{array}{l}\text { - Asking and answering } \\
\text { questions about where a } \\
\text { school is } \\
\text { - Asking and answering } \\
\text { questions about what class/ } \\
\text { grade someone is in }\end{array}$ & $\begin{array}{l}\text { Where is Trang An } \\
\text { School? } \\
\text { - It's on Nguyen Du } \\
\text { Street. } \\
\text { What class/grade are you } \\
\text { in? } \\
\text { - I'm in 4C. }\end{array}$ & $\begin{array}{l}\text { Street, village, grade, } \\
\text { class, address }\end{array}$ \\
\hline
\end{tabular}

For a detailed look at each unit and lesson plan, see Appendix C. All six units belonged to the themes of "Me and My friend" and "Me and My School”, which are already in the curriculum. The units are: 1) Good morning. How are you?; 2) My new friends; 3) My birthday; 4) Things I can do; 5) Our hobbies, and 6) My school. No particular unit that focused only on speaking was favored in both groups because the researcher wanted to explore whether the current curriculum can develop speaking competence. The drama techniques were infused into the six units of the lesson plan for the experimental group. 
The lessons were further enforced with drama-based lesson plans. Drama-based lesson plans consist of four parts: warm up, pre-drama, drama and the calming down stage.

The first stage, the warm-up, aimed to warm the students up, be more active and be eager to participate in the next activities of the lesson. The warm-up stage consisted of games, non-verbal activities and greeting activities, which were used for these goals. There were many drama-based activities for getting started or for energizing the students (e.g., who am I, finding your partner, mime a monster and name games) and for developing speaking skills (e.g., who-what-where, freeze tag, slide show, and snappy scenes). These activities are suitable for waking-up and getting the learners warmer, with both nonverbal activities like clapping, sending silent signals, etc., and the simple verbal activities like word chains and greet activities. These activities, with their own focus on introducing, mime, working in pairs, practicing vocabulary, practicing performance, etc., are really helping to develop the speaking competence of the primary school students while they are playing-learning.

The next stage is the pre-drama stage, where the topic of the lesson was introduced with specific vocabulary, grammar structures, and language functions. Some drama activities that were used were miming, still images, settings, characters, dramatic hooks, choral, individual drills, story elicitation and short improvisations.

During the drama stage, the learners prepared, rehearsed and performed short improvisations to the other students. The students were guided and helped by the teacher/researcher to perform using materials from the textbook or curriculum. The short improvisations were mostly students role-playing dialogues from their textbook and making some dialogues by themselves.

Lastly, in the calming down stage, the students participated in the class discussions and expressed their opinions about learning through drama. Some drama activities that were used were relaxation activities (i.e., music), writing cards, finishing short stories and making dialogues.

In this study, the proposed lesson plan from Unit 1 to Unit 6 was designed with the communicative approach combining Drama activities as follows: 


\section{UNIT 1: GOOD MORNING. HOW ARE YOU?}

\section{Lesson 1}

\section{Aims:}

- By the end of the lesson, students will be able to:

o Know the way to greet formally.

o Give an answer to the question: How are you?

o Practice listening and speaking skills.

\section{Language contents:}

- Vocabulary: morning, afternoon, evening and night.

- Structure: Good

- Phonics: morning and afternoon.

III. Teaching aids:

- Teaching plan, English 4, workbook, pictures, chalk, board, and crayons.

\section{Procedures:}

\begin{tabular}{|c|c|c|c|}
\hline Time & Teacher's Actions & Arrangement & $\begin{array}{c}\text { Student's } \\
\text { Action }\end{array}$ \\
\hline $\begin{array}{l}\text { Warm- } \\
\text { up } \\
\text { (5m') }\end{array}$ & $\begin{array}{l}\text { Drama activity: The Name Game } \\
\text { - } \quad \text { Ask students to stand in a circle. } \\
\text { - The teacher will say her name out loud and } \\
\text { one foreign country that she likes. } \\
\text { - Continuing with the group member on her } \\
\text { right, have each student say her/his name and } \\
\text { name one country. } \\
\text { - Once everyone has called out names, a new } \\
\text { round begins. }\end{array}$ & In a big circle & $\begin{array}{l}\text { Play the } \\
\text { game }\end{array}$ \\
\hline $\begin{array}{l}\text { Pre- } \\
\text { Drama } \\
\text { (15m') }\end{array}$ & $\begin{array}{l}\text { Pre-teach new vocabulary and structures } \\
\text { - Greetings: Good + morning/ afternoon } \\
\text { /evening / night/ bye. }\end{array}$ & Plenum & \\
\hline
\end{tabular}




\begin{tabular}{|c|c|c|c|}
\hline & $\begin{array}{l}\text { - Adjectives: bored, well, happy and ok. } \\
\text { 1. Look, listen and repeat } \\
\text { - Ask students to look at the picture in the book } \\
\text { (Figure 1, page 6) and ask: } \\
\text { they in the picture? } \\
\text { Where are they? } \\
\text { - Ask students listen and repeat after the tape. } \\
\text { - Role play: Divide the class into pairs to repeat } \\
\text { 2. Look and say } \\
\text { - Ask students to look at the pictures to know } \\
\text { that if you greet someone in the morning, you } \\
\text { say: good morning and so on. } \\
\text { - Ask students to fill in the blanks with the } \\
\text { given words in each picture. }\end{array}$ & & $\begin{array}{l}\text { Good..., } \\
\text { Name. }\end{array}$ \\
\hline $\begin{array}{l}\text { Drama } \\
\text { (20m') }\end{array}$ & $\begin{array}{l}\text { 3. Talk } \\
\text { - Ask students to look at the pictures in the } \\
\text { book (Figures 3, pages 7) and role play with } \\
\text { the pictures in Tasks 1-3. } \\
\text { Call some pairs to act out. } \\
\text { Drama activities: Imagination } \\
\text { - Ask students to stand up, close their eyes and } \\
\text { walk around the classroom, imagining that } \\
\text { they are at a school festival. } \\
\text { - Listening to the teacher saying: "Stop. Greet } \\
\text { the nearest person”. } \\
\text { After } 2 \text { minutes of talking, the teacher asks } \\
\text { students to close their eyes and walk again. } \\
\text { - Teacher says, "Stop to greet and talk to the } \\
\text { nearest person about what is their name and } \\
\text { their mother/father's name." }\end{array}$ & $\begin{array}{l}\text { In pairs } \\
\text { Big circle and } \\
\text { walk around }\end{array}$ & $\begin{array}{l}\text { Do the } \\
\text { tas }\end{array}$ \\
\hline
\end{tabular}




\begin{tabular}{|c|c|c|c|}
\hline & $\begin{array}{l}\text { 4. Listen and tick } \\
\text { - Students present the situations in the pictures } \\
\text { before listening (Figures 4, pages 7). } \\
\text { - } \quad \text { Let students guess by role-playing. } \\
\text { - } \quad \text { Ask students to listen to the tape and check. }\end{array}$ & In pairs & $\begin{array}{l}\text { Answers: } \\
\text { 1.Good } \\
\text { morning; } \\
\text { 2. Good } \\
\text { evening }\end{array}$ \\
\hline $\begin{array}{c}\text { Calming } \\
\text { down } \\
\text { (5m') }\end{array}$ & $\begin{array}{l}\text { Drama game: Greetings } \\
\text { • } \quad \text { Provide two words of greeting: “Hello” and } \\
\text { "Bye”. } \\
\text { • Have the players walk around the room and } \\
\text { greet each other with the first word + one } \\
\text { person's name and reply with the second word } \\
\text { + the other's name. } \\
\text { - Students can shake hands or hug others if they } \\
\text { like. } \\
\text { - For example, “Hello, Mai” and "Bye, Nam.” } \\
\text { Provide two other words: “Good morning” } \\
\text { and “Good bye”. }\end{array}$ & $\begin{array}{l}\text { Big circle and } \\
\text { walk around }\end{array}$ & \\
\hline
\end{tabular}

\section{Teachers comment}

\section{Self-evaluation}




\section{UNIT 1: GOOD MORNING. HOW ARE YOU?}

\section{Lesson 2}

\section{I/ $\underline{\text { Aims: }}$}

By the end of the lesson, students will be able to:

- Correctly pronounce “ng' and “n”.

- Listen and read for specific information.

- Practice listening, writing and reading skills.

\section{II/ Language contents:}

* Vocabulary: morning, afternoon, evening, night

* Structure: Good

\section{III/ Teaching aids:}

Teaching plan, English 4, workbook, pictures, chalk, board, and crayons.

\section{IV/ Procedures:}

\begin{tabular}{|c|l|c|c|}
\hline Time & \multicolumn{1}{|c|}{ Teacher's Actions } & Arrangement & $\begin{array}{c}\text { Studen } \\
\text { t's } \\
\text { Action }\end{array}$ \\
\hline up & $\begin{array}{l}\text { Wm') } \\
\text { Ask students to sit in their place and name each } \\
\text { student with one letter of the alphabet. The teacher } \\
\text { and class sing the song ABC. When they start } \\
\text { singing with letter A, the student's name that is A } \\
\text { will stand up and so on until the song is finished and } \\
\text { all students are stood up. Then sing one more time } \\
\text { and at the end all students will sit down. } \\
\text { Prepare the tape for the music and let students stand } \\
\text { in a circle so that they can see each other and dance. }\end{array}$ & Plenum & \\
\hline
\end{tabular}




\begin{tabular}{|c|c|c|}
\hline & $\begin{array}{l}\text { JJ “Come on, let's sing.” } \\
\text { “Okay!” } \\
\text { “Hello!” [Wave your right hand.] } \\
\text { "Hello!” [Wave your left hand.] } \\
\text { "Hello, how are you?” [Wave your right hand, then } \\
\text { gesture towards someone else, placing your arms in } \\
\text { front of you in an "And you?" kind of gesture.] } \\
\text { (Repeat) } \\
\text { "I'm good!” [One thumb up!] } \\
\text { I'm great! [Two thumbs up!] } \\
\text { I'm wonderful! [Jump in the air!] } \\
\text { (Repeat) } \\
\text { Hello! } \\
\text { Hello! } \\
\text { Hello, how are you? } \\
\text { (Repeat) } \\
\text { I'm tired. [Slouch your shoulders and sigh.] } \\
\text { ('m hungry. [Rub your tummy.] } \\
\text { (Rello, hollo good. [One thumb down!] } \\
\text { Hello! }\end{array}$ & \\
\hline $\begin{array}{c}\text { Pre- } \\
\text { Drama } \\
\text { (15m') }\end{array}$ & $\begin{array}{l}\text { 1. Listen and repeat } \\
\text { - Ask students to look at the pictures in the book and } \\
\text { describe the pictures (Figure 1, pages } 8 \text { ). } \\
\text { Morning: }\end{array}$ & Plenum \\
\hline
\end{tabular}




\begin{tabular}{|c|c|c|c|}
\hline & $\begin{array}{l}\text { Good morning, Miss Hien. } \\
\text { Good morning, Nga. } \\
\text { Good afternoon, Miss Hien. } \\
\text { Good afternoon, Linda. } \\
\text { - Ask students to role-play in pairs to correct the } \\
\text { pronoun with different times. } \\
\text { 2. Listen and number } \\
\text { - Ask students to look at } 4 \text { pictures in the book and } \\
\text { guess the conversation scripts (Figure 2, pages } 8 \text { ). } \\
\text { - Ask students to role-play with each picture to } \\
\text { practice greetings. } \\
\text { - Then play the video tape and ask students to listen } \\
3 \text { times. } \\
\text { - Check and give the answer: }\end{array}$ & & $\begin{array}{c}\text { Answers } \\
\text { a-1; b- } \\
\text { 3; c-4; } \\
\text { d-2 }\end{array}$ \\
\hline $\begin{array}{l}\text { Drama } \\
\left(20 m^{\prime}\right)\end{array}$ & $\begin{array}{l}\text { 3. Read and tick } \\
\text { - Ask students to look at } 4 \text { pictures in the book } \\
\text { before reading (Figure 3, pages 9). } \\
\text { - Teacher reads aloud. } \\
\text { - Ask students listen and repeat. } \\
\text { - Ask students to read in pairs. } \\
\text { - Call some pairs to read aloud. } \\
\text { - Correct the pronoun. } \\
\text { - Tick and check. } \\
\text { Answer:1-a ; 2-b }\end{array}$ & In pairs & \\
\hline
\end{tabular}




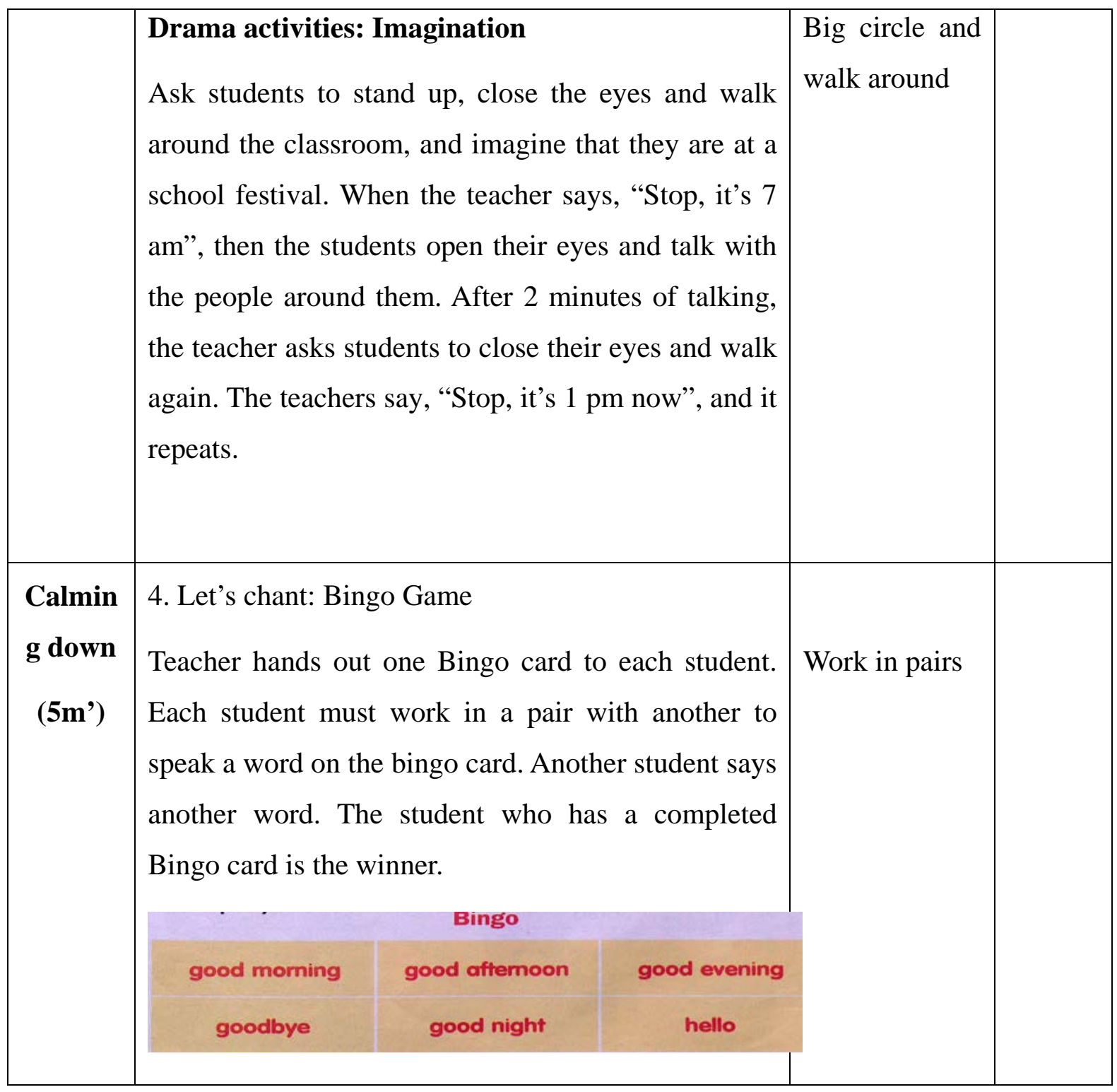

\section{V/ Teachers comment}

\section{VI/ Self-evaluation}




\section{UNIT 1: GOOD MORNING. HOW ARE YOU?}

\section{Lesson 3}

\section{I/ $\underline{\text { Aims: }}$}

By the end of the lesson, students will be able to:

- Give answers to the question: "How are you?"

- Practice writing, listening and speaking skills.

\section{II/ Language contents:}

* Vocabulary: bored, well and happy.

* Pronunciation: morning, afternoon

* Structure: How are you? - I’m

\section{III/ Teaching aids}

Teaching plan, English 4, workbook, pictures, chalk, board, and crayons.

\section{IV/ Procedures:}

\begin{tabular}{|c|c|c|c|}
\hline Time & Teacher's Actions & Arrangement & $\begin{array}{c}\text { Student's } \\
\text { Actions }\end{array}$ \\
\hline $\begin{array}{c}\text { Warm- } \\
\text { up } \\
\text { (5m’) }\end{array}$ & $\begin{array}{l}\text { 1.Warmup: Sing aloud twice. } \\
\text { T: Good morning, students. } \\
\text { T: How are you? } \\
\text { T: I'm fine, thanks. Let's study a new lesson. }\end{array}$ & Plenum & $\begin{array}{l}\text { S: Good } \\
\text { morning, } \\
\text { teacher. } \\
\text { S: We are } \\
\text { fine, } \\
\text { thank } \\
\text { you. And } \\
\text { you? } \\
\text { s: Yes! }\end{array}$ \\
\hline $\begin{array}{c}\text { Pre- } \\
\text { Drama }\end{array}$ & $\begin{array}{l}\text { 2. New lesson } \\
\text { a. Listen and repeat }\end{array}$ & & \\
\hline
\end{tabular}




\begin{tabular}{|c|c|c|}
\hline (15m') & $\begin{array}{l}\text { - Ask students to look at the picture of Mr. Robot } \\
\text { and Tom. } \\
\text { - Ask students listen to the tape and repeat. } \\
\text { - Ask students to read in pairs and correct the } \\
\text { pronoun. } \\
\text { b. Look and say } \\
\text { Look at the picture and guess how he/she is } \\
\qquad \text { Bored } \\
\quad \text { Well } \\
\text { Practices: How are you? } \\
\text { I'm bored } \\
\text { Look at the pictures for more vocabulary }\end{array}$ & $\begin{array}{l}\text { Plenum } \\
\text { Work in pairs } \\
\text { Work in pair }\end{array}$ \\
\hline $\begin{array}{l}\text { Drama } \\
\text { (20m') }\end{array}$ & $\begin{array}{l}\text { c. Write } \\
\text { - Ask students to look at the picture and complete. } \\
\text { • Good evening, Mr. Brown. } \\
\text { Good evening, Mrs. Brown. } \\
\text { - Good afternoon, Mrs. Brown. } \\
\text { Good afternoon, Mrs. Green. } \\
\text { d. Let's chant } \\
\text { Let students listen to the tapes and repeat. }\end{array}$ & \\
\hline $\begin{array}{c}\text { Calming } \\
\text { down } \\
\left(5 \mathrm{~m}^{\prime}\right)\end{array}$ & $\begin{array}{l}\text { - Sing the song: page } 11 \\
\text { Good night, good night, Mummy. } \\
\text { Good night, good night, Daddy. } \\
\text { Good night, good night, Mary }\end{array}$ & \\
\hline
\end{tabular}




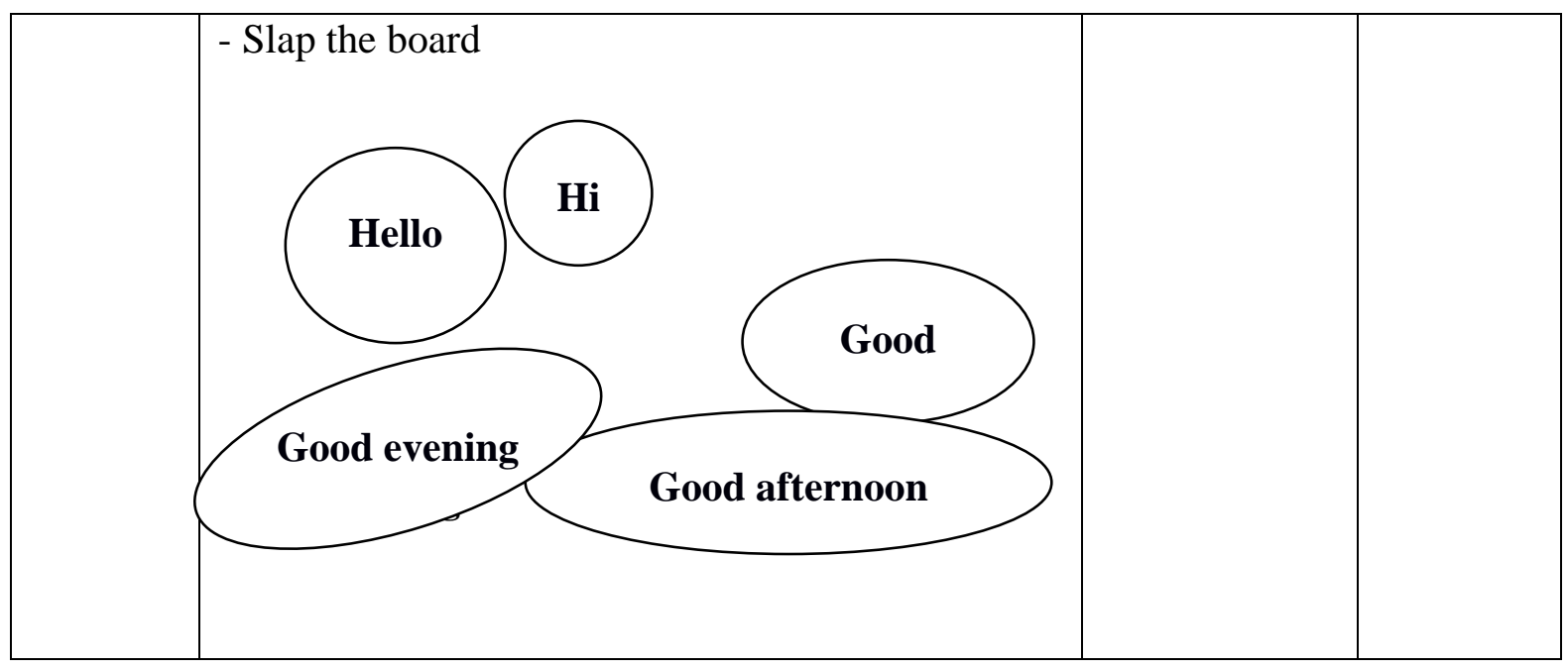

IV/ Teachers comment

\section{V/ Self-evaluation}




\section{UNIT 2: MY NEW FRIENDS}

\section{Lesson 1}

\section{I/ $\underline{\text { Aims: }}$}

By the end of the lesson, students will be able to:

- Ask and answer where someone is from.

- Practice listening and speaking skills.

\section{II/ Language contents:}

* Vocabulary: Japan, America, Australia, England, from and where.

* Pronunciation: Vietnamese

* Structure: Review the way to introduce oneself.

\section{III/ Teaching aids:}

Teaching plan, English 4, workbook, pictures, chalk, board, and crayons.

\section{IV/ Procedures:}

\begin{tabular}{|c|c|c|c|}
\hline Time & Content / Learning's Activity & Arrangement & Material \\
\hline $\begin{array}{c}\text { Warm- } \\
\text { up } \\
\text { (5m’) }\end{array}$ & $\begin{array}{l}\text { Mirrors: } \\
\text { Children work in pairs and dance to the music. One } \\
\text { child is just himself/herself while the other child is } \\
\text { the "mirror's image" (carefully copy everything } \\
\text { done by the real person). For example. Student A } \\
\text { raises his left hand up, Student B who is the mirror } \\
\text { image must raise his right hand up too. }\end{array}$ & Work in pairs & \\
\hline $\begin{array}{c}\text { Pre- } \\
\text { Drama } \\
\text { (15m’) }\end{array}$ & $\begin{array}{l}\text { 1. Look, listen and repeat } \\
\text { - Ask students to look at the picture and answer: } \\
\text { Who are they in the picture? } \\
\text { What are they talking about? } \\
\text { - Ask students to listen and repeat. }\end{array}$ & plenum & \\
\hline
\end{tabular}




\begin{tabular}{|c|c|c|}
\hline & $\begin{array}{l}\text { b. Look and say } \\
\text { - New words: } \\
\text { Japan America England } \\
\text { Singapore Australia China } \\
\text { - Note: } \quad \text { Where are you from? } \\
\text { I am from Viet Nam } \\
\text { - Ask students to work in pairs and act. }\end{array}$ & $\begin{array}{l}\text { Work in pairs } \\
\text { Work in pairs }\end{array}$ \\
\hline $\begin{array}{l}\text { Drama } \\
\left(20 m^{\prime}\right)\end{array}$ & $\begin{array}{l}\text { c. Talk } \\
\text { - Ask students to work in pairs and practice: } \\
\text { Ask students to make a similar dialogue. } \\
\text { - Call some pairs to act out } \\
\text { - Correct the pronoun. } \\
\text { d. Listen and tick } \\
\text { - Let students look at } 4 \text { pictures and think about the } \\
\text { situation (Figure } 3 \text {, page 13). } \\
\text { - Guess and make conversation about each picture. } \\
\text {-Then listen } 3 \text { times and check. } \\
\text { Answer:1-b; 2- b }\end{array}$ & $\begin{array}{l}\text { Plenum } \\
\text { Work in pairs } \\
\text { and change } \\
\text { partners }\end{array}$ \\
\hline $\begin{array}{c}\text { Calming } \\
\text { down } \\
\text { (5m') }\end{array}$ & $\begin{array}{l}\text { Miming: } \\
\text { Students role-play newcomers who come from } \\
\text { different countries. One by one, they introduce } \\
\text { themselves and show the typical actions of their } \\
\text { own country. }\end{array}$ & Big circle \\
\hline
\end{tabular}

\section{IV/ Teachers comment}




\section{V/ Self-evaluation}




\section{UNIT 2: MY NEW FRIENDS}

\section{Lesson 2}

\section{I/ $\underline{\text { Aims: }}$}

By the end of the lesson, students will be able to:

- Correctly pronounce “ese”.

- Say what nationality they are or what nationality the others are.

- Practice listening, writing and reading skills.

\section{II/ Language contents:}

* Vocabulary: Vietnam-Vietnamese, America-American, Japan-Japanese, AustraliaAustralian, China-Chinese and international.

* Structure: I’m

\section{III/ Teaching aids:}

Teaching plan, English 4, workbook, pictures, chalk, board, and crayons.

\section{IV/ Procedures:}

\begin{tabular}{|c|c|c|c|c|}
\hline Time & \multicolumn{2}{|c|}{ Content / Learning's Activity } & Arrangement & Material \\
\hline $\begin{array}{l}\text { Warm- } \\
\text { up } \\
\text { (5m’) }\end{array}$ & \multicolumn{2}{|c|}{$\begin{array}{l}\text { Guide me: } \\
\text { Students play in pairs, one of them will be a "blind" person who } \\
\text { has a handkerchief tied around their eyes. The other student } \\
\text { guides them through obstacles in the classroom (e.g., chairs and } \\
\text { tables). Note that they are instructed to be careful in case the } \\
\text { blindfolded person falls and gets hurt. }\end{array}$} & Work in pairs. & \\
\hline \multirow[t]{2}{*}{$\begin{array}{l}\text { Pre- } \\
\text { Drama } \\
\text { (15m') }\end{array}$} & \multicolumn{2}{|c|}{$\begin{array}{l}\text { Look, listen and repeat } \\
\text { - Ask students to look at the picture, listen and repeat. } \\
\text { New words: }\end{array}$} & \multirow[t]{2}{*}{ Plenum } & \\
\hline & Country & Nationality & & \\
\hline
\end{tabular}




\begin{tabular}{|c|c|c|c|c|}
\hline & \multicolumn{3}{|c|}{$\begin{array}{l}\text { - Practice with the structure: } \\
\qquad \text { I am Vietnamese. } \\
\qquad \text { She is Japanese } \\
\text { - } \text { The ball activity: } \\
\text { - } \text { Ask one student to begin with "My name is...I come } \\
\text { from...I am....”, then they throw the ball to another } \\
\text { student. This student with the ball continues speaking } \\
\text { with repeated words from the previous one, such as: } \\
\text { "His name is...He comes from. He is...”, and then } \\
\text { introduce himself/herself. }\end{array}$} & Big circle \\
\hline $\begin{array}{l}\text { Drama } \\
\left(20 m^{\prime}\right)\end{array}$ & & $\begin{array}{l}\text { ten and num } \\
\text { t students loo } \\
\text { e their own c } \\
\text { ut these pictur } \\
\text { sten } 3 \text { times a } \\
\text { wer:1-a ; 2-b; } \\
\text { ead and circle } \\
\text { k students to } \\
\text { ll some stude } \\
\text { rrect the pron }\end{array}$ & $\begin{array}{l}\text { he blanks and guess the nationality. Then } \\
\text { sation asking and answering the question } \\
\text { igure 2, page 14). } \\
\text { eck. } \\
\text { 4-c } \\
\text { and repeat. } \\
\text { read aloud. }\end{array}$ & \\
\hline
\end{tabular}




\begin{tabular}{|c|c|c|}
\hline & $\begin{array}{l}\text { - Circle the right answer. } \\
\begin{aligned} \text { Answer: } 1 \text {. Japan } & \text { 3. Tokyo } \\
\text { 2. Ten } & \text { 4. Swimming }\end{aligned}\end{array}$ & \\
\hline $\begin{array}{l}\text { Calming } \\
\text { down } \\
\text { (5m') }\end{array}$ & $\begin{array}{l}\text { Let's play: Jumble the letters } \\
\text { The teacher prepares some cards with the words for countries } \\
\text { and nationalities mixed up. Then ask the student to answer as } \\
\text { quick as possible. } \\
\text { Vietnam-Vietnamese } \\
\text { Japan-Japanese } \\
\text { China-Chinese } \\
\text { America-American } \\
\text { England-English }\end{array}$ & Big circle \\
\hline
\end{tabular}

\section{V/ Teachers comment}

\section{VI/ Self-evaluation}




\section{UNIT 2: MY NEW FRIENDS}

\section{Lesson 3}

\section{I/ $\underline{\text { Aims: }}$}

By the end of the lesson, students will be able to:

- Ask and give the full name of a person.

- Practice writing, listening and speaking skills.

\section{II/ Language contents:}

* Vocabulary: full

* Pronunciation

* Structure: How do you spell your name?

\section{III/ Teaching aids:}

Teaching plan, English 4, workbook, pictures, chalk, board, and crayons.

\section{IV/ Procedures:}

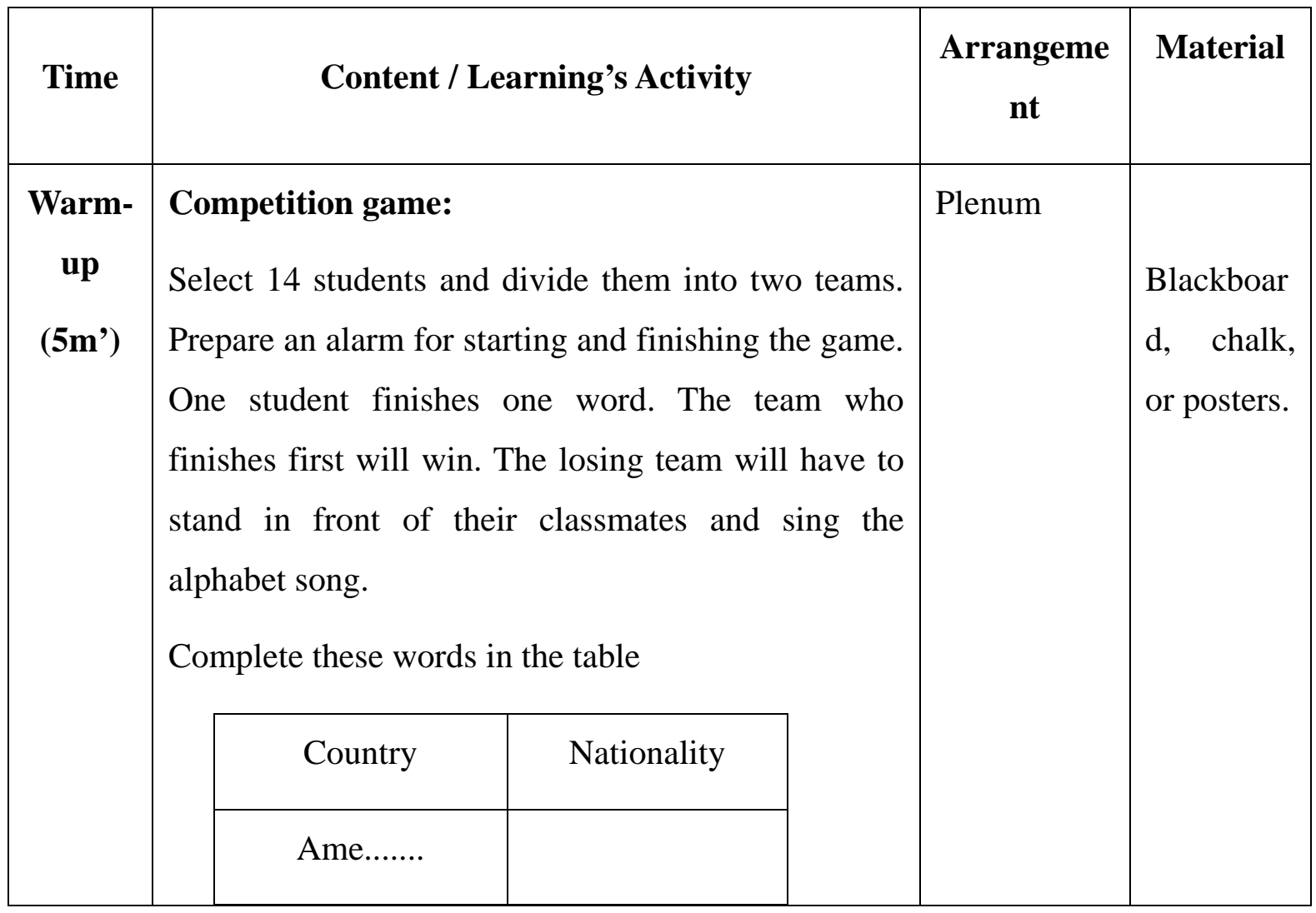




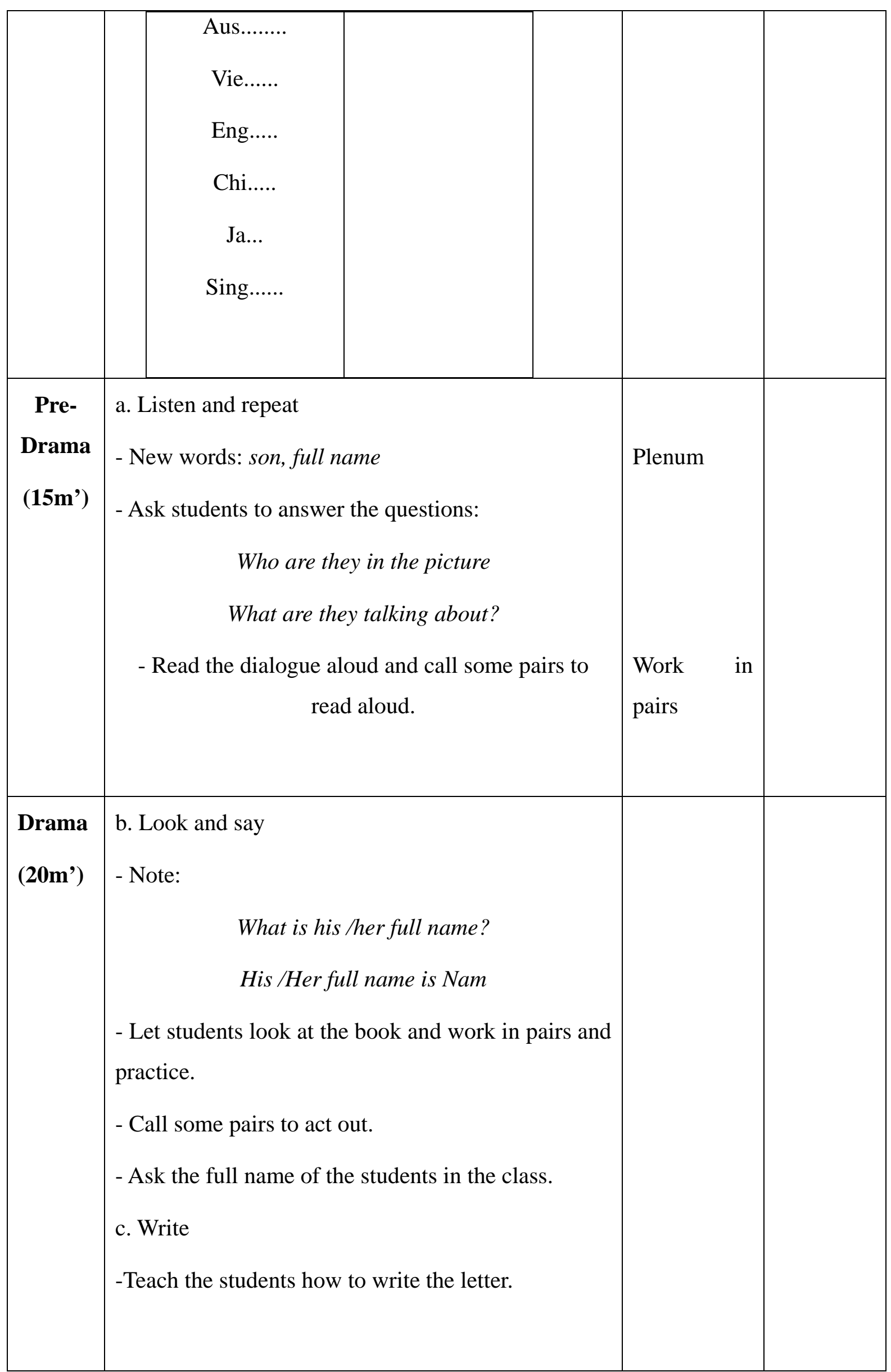




\begin{tabular}{|c|c|c|}
\hline & $\begin{array}{l}\text { Dear Lan, } \\
\text { My name is Nam. } \\
\text { I'm from Vietnam. I am Vietnamese. } \\
\text { I'm ....... years old. } \\
\text { I like football. } \\
\text { Sincerely, } \\
\text { Nam } \\
\text { - Let students write and call them to read aloud and } \\
\text { correct. }\end{array}$ & \\
\hline $\begin{array}{c}\text { Calmin } \\
\text { g down } \\
\text { (5m') }\end{array}$ & $\begin{array}{l}\text { d. Let's sing } \\
\text { Sing after the tape. } \\
\text { Ask students to role-play as Tony Black and spell } \\
\text { it. } \\
\text { What's your full name? } \\
\text { What's your full name? } \\
\text { Tony Black. } \\
\text { Tony Black. } \\
\text { How do you spell it? } \\
\text { How do you spell it? } \\
\text { lon't know. } \\
\text { Do you know? }\end{array}$ & Big circle \\
\hline
\end{tabular}

\section{IV/ Teachers comment}

\section{V/ Self-evaluation}




\section{UNIT 3: MY BIRTHDAY}

\section{Lesson 1}

\section{I/ $\underline{\text { Aims: }}$}

By the end of the lesson, students will be able to:

- Ask and answer when someone’s birthday is.

- Practice listening and speaking skills.

\section{II/ Language contents:}

* Vocabulary: twelve months, ordinal numbers.

* Pronunciation

* Structure: When's your birthday? - It's in

\section{III/ Teaching aids:}

Teaching plan, English 4, workbook, pictures, chalk, board, and crayons.

\section{IV/ Procedures:}

\begin{tabular}{|c|l|l|}
\hline Time & \multicolumn{1}{|c|}{ Content / Learning's Activity } & Arrangement \\
\hline Warm- & $\begin{array}{l}\text { The Wind Blows } \\
\text { Put chairs in a circle. Turn one chair to face out. Choose someone to } \\
\text { (5m') }\end{array}$ & $\begin{array}{l}\text { stand in the middle. The teacher goes first and says: } \\
\text { “ The wind blows for........... } \\
\text { Everyone who is born in April; } \\
\text { everyone who is born in September; } \\
\text { everyone who has a birthday party next month, etc. } \\
\text { If the statement applies to a pupil, they must get up and change } \\
\text { places. The caller finds a seat. The last pupil left standing becomes } \\
\text { the new caller. No-one can change places with the person sitting next } \\
\text { to them. }\end{array}$ \\
\hline
\end{tabular}




\begin{tabular}{|c|c|c|}
\hline $\begin{array}{c}\text { Pre- } \\
\text { Drama } \\
\text { (10m') }\end{array}$ & \multicolumn{2}{|c|}{$\begin{array}{l}\text { a. Look, listen and repeat } \\
\text { - Ask students to look at the picture and describe what is going on in } \\
\text { the picture- Ask students to listen and repeat. } \\
\text { - Listen and repeat after the tape. } \\
\text { - Call some pairs to read aloud. }\end{array}$} \\
\hline $\begin{array}{l}\text { Drama } \\
\left(25 m^{\prime}\right)\end{array}$ & $\begin{array}{l}\text { b. Look and say } \\
\text { - New words: } \\
\text { January May } \\
\text { February June } \\
\text { March July } \\
\text { April } \\
\text { - Note: When is your } \\
\text { - Ask students to look } \\
\text { - Work in pairs to mal } \\
\text { - Call some pairs to a } \\
\text { - Sing the song, Mon } \\
\text { January, February, Ma } \\
\text { May, June, July, Augu } \\
\text { September, October, I } \\
\text { c. Talk } \\
\text { - Let students work } \\
\text { students in the class. } \\
\text { - Call some pairs to a } \\
\text { - Correct the pronoun } \\
\text { - Instruct students to l }\end{array}$ & $\begin{array}{l}\text { September } \\
\text { October } \\
\text { November } \\
\text { December } \\
\text { day? It's in May } \\
\text { at. book and work in pairs to practice. } \\
\text { t. } \\
\text { April } \\
\text { tonger, and December. }\end{array}$ \\
\hline
\end{tabular}




\begin{tabular}{|c|l|l|}
\hline & $\begin{array}{l}\text { - Guessing. } \\
\text { - Listen } 3 \text { times and check. } \\
\text { Answer:1-a ; 2- b }\end{array}$ & \\
\hline Calming & "Anyone who...” activity: & Big circle \\
$\mathbf{( 5 m})$ & $\begin{array}{l}\text { Students sit in chairs in a big circle. The caller will be in the centre. } \\
\text { "Anyone who is born in April?" Students born in April must stand up } \\
\text { and move to another empty chair while the caller tries to sit on one of } \\
\text { the empty chairs. The person who has no chair will be the caller and } \\
\text { so on. }\end{array}$ & Bategory beginning with "Anyone who...", such as \\
\hline
\end{tabular}

\section{IV/ Teachers comment}

\section{V/ Self-evaluation}




\section{UNIT 3: MY BIRTHDAY}

\section{Lesson 2}

\section{I/ $\underline{\text { Aims: }}$}

By the end of the lesson, students will be able to:

- Ask and answer when someone’s birthday is.

- Practice listening and speaking skills.

\section{II/ Language contents:}

* Structure: Revision of the structures: When's your birthday?

\section{III/ Teaching aids:}

Teaching plan, English 4, workbook, pictures, chalk, board and crayons.

\section{IV/ Procedures:}

\begin{tabular}{|c|l|c|c|}
\hline Time & \multicolumn{1}{|c|}{ Content / Learning's Activity } & Arrangement & Material \\
Warm- & - Slap the board \\
(5m') & $\begin{array}{l}\text { Select two teams, each team has three students. Two members } \\
\text { will be in a competition to find out which team will arrange the } \\
\text { months in the correct order of time first. }\end{array}$ & $\begin{array}{l}\text { Cards of } \\
\text { months }\end{array}$ \\
\hline
\end{tabular}




\begin{tabular}{|c|c|}
\hline $\begin{array}{l}\text { Drama } \\
\text { (15m') }\end{array}$ & $\begin{array}{l}\text { - Look at the book and read aloud. } \\
\text { - Let students listen to the tapes. } \\
\text { - Call some students to read and correct the pronoun. } \\
\text { - Ask students if they know which months belong to which } \\
\text { season, then teach them how to pronoun the words. }\end{array}$ \\
\hline $\begin{array}{l}\text { Drama } \\
\text { (20m’) }\end{array}$ & $\begin{array}{l}\text { b. Listen and numbers } \\
\text { - Ask students to look at } 4 \text { pictures in the book, say the months } \\
\text { in the calendars (Figure 2, page 20). } \\
\text { - Guessing the number before listening. } \\
\text { - Let students listen to the tape } 3 \text { times. } \\
\text { Check. } \\
\text { c. Read and number } \\
\text { - Ask students to read the dialogue aloud } \\
\text { - Read in pairs } \\
\text { - Number the sentences } \\
\text { Correct the mistakes } \\
\text { Answer: a-3; b-1; c-4; d-2 } \\
\text { Role play: Birthday party. } \\
\text { Auestions about the months and the days. } \\
\text { Wxample: } \\
\text { party for the birthday. } \\
\text { Retings: in a birthday party of one student in that group. } \\
\text { Reptember. And you? }\end{array}$ \\
\hline
\end{tabular}




\begin{tabular}{|c|l|l|l|}
\hline & $\begin{array}{l}\text { A: My birthday is in September, too. } \\
\text { C: Oh, it is nice. We have two birthday parties in September. } \\
\text { D: My birthday is in September, too. } \\
\text { A: We will have a very big birthday party in September } \\
\ldots \text { and so on. }\end{array}$ & & \\
\hline Calming & $\begin{array}{l}\text { d. Let's sing } \\
\text { Imagine the classroom is a birthday party and one student is the } \\
\text { owner of the party. The classmates sing the song, “Happy } \\
\text { Birthday", replacing the name of the owner. Then, change } \\
\text { another owner, unit all four or five students are mentioned in the } \\
\text { song. }\end{array}$ & & \\
\hline
\end{tabular}

\section{IV/ Teachers comment}

\section{V/ Self-evaluation}




\section{UNIT 3: MY BIRTHDAY}

\section{Lesson 3}

\section{I/ $\underline{\text { Aims: }}$}

By the end of the lesson, students will be able to:

- Ask and answer the date.

- Practice writing, listening and speaking skills.

\section{II/ Language contents:}

* Vocabulary: ordinal numbers.

* Structure: What's the date today? - It's + ordinal numbers + of + month.

\section{III/ Teaching aids:}

Teaching plan, English 4, workbook, pictures, chalk, board, and crayons.

\section{IV/ Procedures:}

\begin{tabular}{|c|c|c|c|}
\hline Time & Content / Learning's Activity & Arrangement & Material \\
\hline $\begin{array}{c}\text { Warm- } \\
\text { up } \\
\text { (5m') }\end{array}$ & $\begin{array}{l}\text { - Date game: } \\
\text { Ask students in go in order according to a date. When the } \\
\text { teacher calls one date, the person who is that date must stand up } \\
\text { and introduce himself. } \\
\text { For example Teacher: the first of October } \\
\qquad \text { A student: It's me. My name is... I am } 11 \text { years } \\
\text { old. }\end{array}$ & Big circle & \\
\hline $\begin{array}{c}\text { Pre- } \\
\text { Drama } \\
\text { (15m’) }\end{array}$ & $\begin{array}{l}\text { a. Listen and repeat } \\
\text { - Ask students to look at the picture and answer: } \\
\text { How many people are there in the picture? } \\
\text { Who are they? }\end{array}$ & & \\
\hline
\end{tabular}




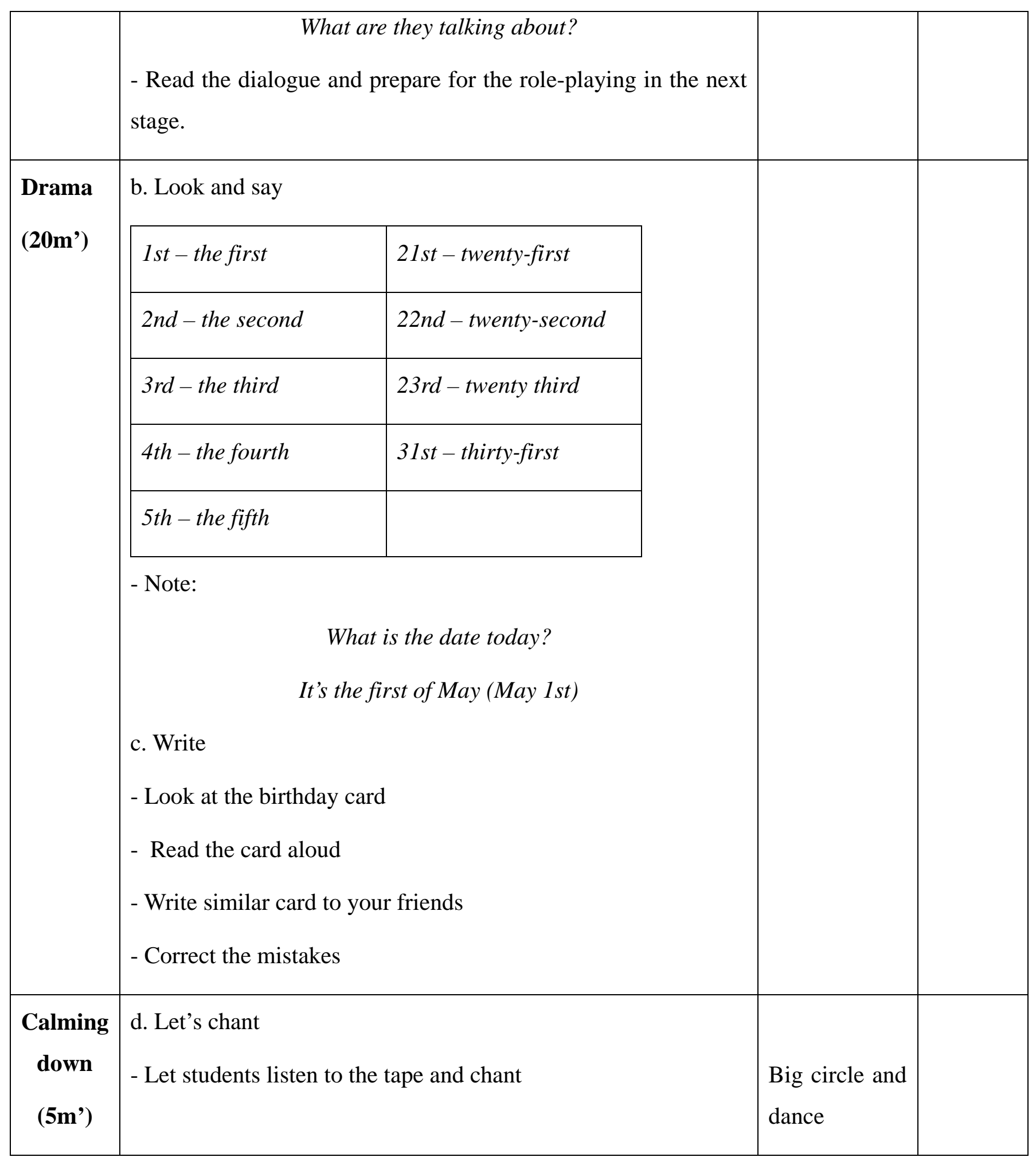

IV/ Teachers comment

\section{V/ Self-evaluation}




\section{UNIT 4: THINGS I CAN DO}

\section{Lesson 1}

\section{I/ $\underline{\text { Aims: }}$}

By the end of the lesson, students will be able to:

- Ask and answer about what they can do.

- Practice listening and speaking skills.

\section{II/ Language contents:}

* Vocabulary: use, speak, piano, ride, bike, dance

* Structure: What can you do?

$$
\text { - I can }
$$

\section{III/ Teaching aids:}

Teaching plan, English 4, workbook, pictures, chalk, board, crayons.

\section{IV/ Procedures:}

\begin{tabular}{|c|c|c|c|}
\hline Time & Content / Learning's Activity & Arrangement & Material \\
\hline $\begin{array}{c}\text { Warm- } \\
\text { up } \\
\text { (5m’) }\end{array}$ & $\begin{array}{l}\text { "I like "activity: } \\
\text { The teacher and students stand up in a big circle. The teacher } \\
\text { begins by saying "My name is...I am...years old. I come } \\
\text { from... and I like...." The next student will have to repeat the } \\
\text { name and what the previous person likes and introduces } \\
\text { himself. For example: "She is A, she likes...I am...I am...years } \\
\text { old. I come from...I like..." and so on until all students have a } \\
\text { chance to speak. }\end{array}$ & Big circle & \\
\hline $\begin{array}{c}\text { Pre- } \\
\text { Drama } \\
\text { (10m') }\end{array}$ & $\begin{array}{l}\text { a. Look, listen and repeat } \\
\text { - Look at the picture and answer: } \\
\text { How many students are there in the picture? }\end{array}$ & & \\
\hline
\end{tabular}




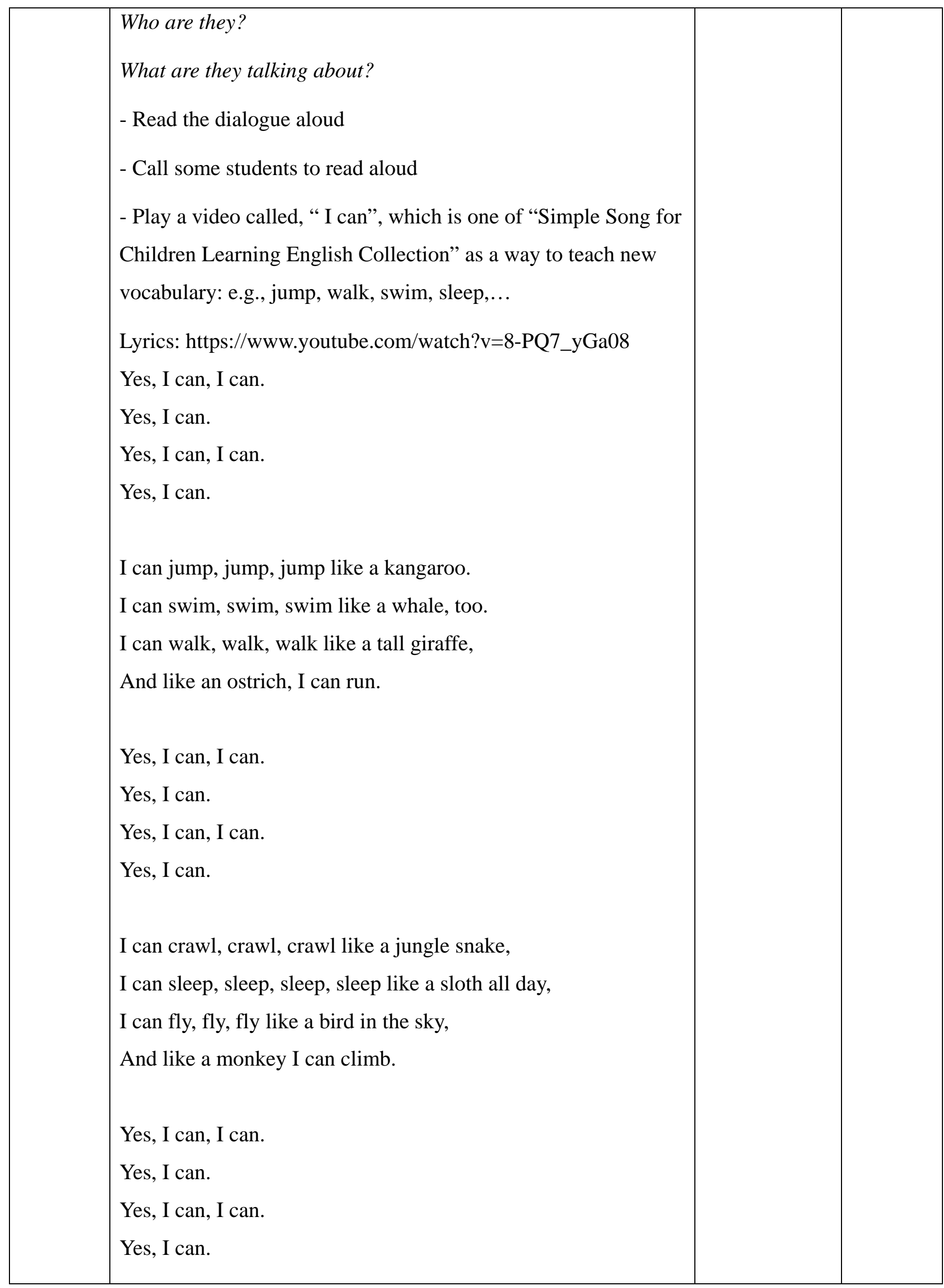




\begin{tabular}{|c|c|c|c|}
\hline & & $\begin{array}{l}\text { b. Look and say } \\
\text { New words: } \\
\text { Draw Play the piano } \\
\text { Dance Speak English } \\
\text { Use } \\
\text { Ride a bike } \\
\text { Let students work in pairs and practice } \\
\text { c. Talk } \\
\text { - Look at the picture and practice: ask and answer questions } \\
\text { about your partners } \\
\text { Answer: a-3; b-1; c-2; d-4 } \\
\text { - Listen to the tape } 3 \text { time then check } \\
\text { - Look at the pictures, guess the number } \\
\text { - Then ask about your friends, what he or she can do } \\
\text { disten and number }\end{array}$ \\
\hline & & $\begin{array}{l}\text { Calming } \\
\text { down } \\
\text { (5m') }\end{array}$ & $\begin{array}{l}\text { Sing along } \\
\text { Ask students to stand up in a big circle. While singing the song, } \\
\text { "I can", do the actions of the words mentioned in the song. }\end{array}$ \\
\hline
\end{tabular}

IV/ Teachers comment

\section{V/ Self-evaluation}




\section{UNIT 4: THINGS I CAN DO}

\section{Lesson 2}

\section{I/ $\underline{\text { Aims: }}$}

By the end of the lesson, students will be able to:

- Say what they can do or what they can’t do.

- Practice listening, writing and reading skills.

\section{II/ Language contents:}

* Vocabulary: can’t

* Structure: I can

\section{I can’t}

\section{III/ Teaching aids:}

Teaching plan, English 4, workbook, pictures, chalk, board, crayons....

\section{IV/ Procedures:}

\begin{tabular}{|c|c|c|c|}
\hline Time & Content / Learning's Activity & Arrangement & Material \\
\hline $\begin{array}{c}\text { Warm- } \\
\text { up } \\
\text { (5m’) }\end{array}$ & $\begin{array}{l}\text { - Freeze/Do } \\
\text { Ask students to spread out around the space. When the teacher } \\
\text { gives the "Freeze" signal, they are silent and freeze. When the } \\
\text { teacher says to do something, they pretend doing that. For } \\
\text { example: "ride a bike". } \\
\text { Ride a bike Fly } \\
\text { Sing the song Swim } \\
\text { Speak English Write } \\
\text { Draw a picture Lay eggs } \\
\text { Play the piano/ chess/ badminton... } \\
\text { Dance }\end{array}$ & & \\
\hline
\end{tabular}




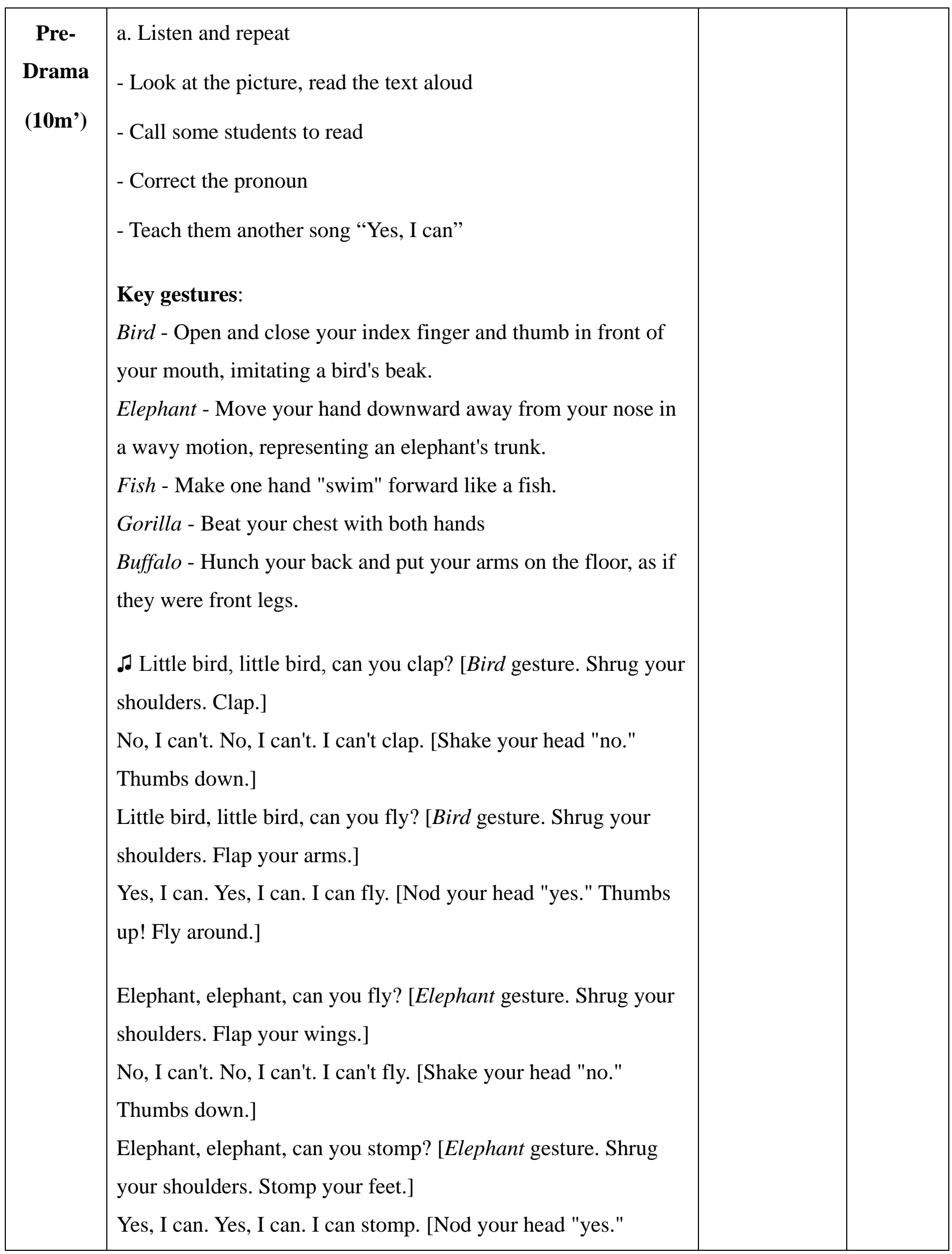


Thumbs up! Stomp around.]

Little fish, little fish, can you stomp? [Fish gesture. Shrug your shoulders. Stomp your feet.]

No, I can't. No, I can't. I can't stomp. [Shake your head "no."

Thumbs down.]

Little fish, little fish, can you swim? [Fish gesture. Shrug your shoulders. Swim.]

Yes, I can. Yes, I can. I can swim. [Nod your head "yes."

Thumbs up! Swim around.]

Gorilla, gorilla, can you swim? [Gorilla gesture. Shrug your shoulders. Swim.]

No, I can't. No, I can't. I can't swim. [Shake your head "no."

Thumbs down.]

Gorilla, gorilla, can you climb? [Gorilla gesture. Shrug your shoulders. Climb.]

Yes, I can. Yes, I can. I can climb. [Nod your head "yes."

Thumbs up! Climb around.]

Buffalo, Buffalo, can you climb? [Buffalo gesture. Shrug your shoulders. Climb.]

No, I can't. No, I can't. I can't climb. [Shake your head "no."

Thumbs down.]

Buffalo, Buffalo, can you run? [Buffalo gesture. Shrug your shoulders. Run.]

Yes, I can. Yes, I can. I can run. [Nod your head "yes." Thumbs up! Run around.]

Boy and girls, boys and girls, can you sing? [Point to boys and girls. Shrug your shoulders. Sing.]

Yes, we can. Yes, we can. We can sing. [Nod your head "yes".

Thumbs up! Sing.]

Boys and girls, boys and girls, can you dance? [Point to boys and girls. Shrug your shoulders. Dance.] 


\begin{tabular}{|c|c|}
\hline & $\begin{array}{l}\text { Yes, we can. Yes, we can. We can dance. [Nod your head "yes." } \\
\text { Thumbs up! Dance.] } \\
\text { We can sing. We can dance. Yes, we can. [Sing and dance. } \\
\text { Thumbs up!] } \\
\text { We can sing. We can dance. Yes, we can. } \\
\text { Yes, we can. Yes, we can. Yes, we can. } \\
\text { Yes, we can. Yes, we can. Yes, we can. } \\
\text { Yes, we can. Yes, we can. Yes, we can. } \delta\end{array}$ \\
\hline $\begin{array}{l}\text { Drama } \\
\text { (25m’) }\end{array}$ & $\begin{array}{l}\text { b. Listen and tick } \\
\text { - Look at the pictures in the book } \\
\text { - Describe the pictures } \\
\text { a. He can ride a bike. } \\
\text { b. He can't ride a bike. } \\
\text { c. She can play the piano. } \\
\text { d. She can't play the piano. } \\
\text { - Guess and then listen to the tape } \\
\text { - Correct and give answers: 1-a; 2-b } \\
\text { c. Read and complete } \\
\text { - Ask students to look at the pictures in the book } \\
\text { - Check } \\
\text { - Complete who can do or can’t do things } \\
\text { - Read the text aloud, some students read } \\
\text { - } 2 \text {. Quan } \\
\text { - }\end{array}$ \\
\hline
\end{tabular}


Calming d. Let's play: Guessing games

down Games: It can fly in the sky, but It can't swim. What is it?

(5m') It's a bird.

IV/ Teachers comment

\section{V/ $\underline{\text { Self-evaluation }}$}




\section{UNIT 4: THINGS I CAN DO}

\section{Lesson 3}

\section{I/ $\underline{\text { Aims: }}$}

By the end of the lesson, students will be able to:

- Ask and answer what they can do with a yes/no question.

- Practice writing, listening and speaking skills.

\section{II/ Language contents:}

* Structure: Can you____ ?

Yes, I can. / No, I can’t.

\section{III/ Teaching aids:}

Teaching plan, English 4, workbook, pictures, chalk, board, and crayons.

\section{IV/ Procedures:}

\begin{tabular}{|c|l|l|l|}
\hline Time & \multicolumn{1}{|c|}{ Content / Learning's Activity } & Arrangement & Material \\
\hline $\begin{array}{c}\text { Warm- } \\
\mathbf{( 5 m} \text { ') }\end{array}$ & Warm students up by singing the song "Yes, I can” and action. & Big circle & \\
\hline $\begin{array}{c}\text { Pre- } \\
\text { Drama }\end{array}$ & $\begin{array}{l}\text { a. Listen and repeat } \\
\text { - Look at the picture, read the text aloud }\end{array}$ & $\begin{array}{l}\text { - Call some students to read } \\
\text { - Correct the pronoun } \\
\text {-Mime game: } \\
\text { Ask students to play in pairs. Each pair has 10 flashcards of } \\
\text { actions. One of two students will mime by actions so that the } \\
\text { other can guess what that action is and then try to make a }\end{array}$ & \\
\hline
\end{tabular}




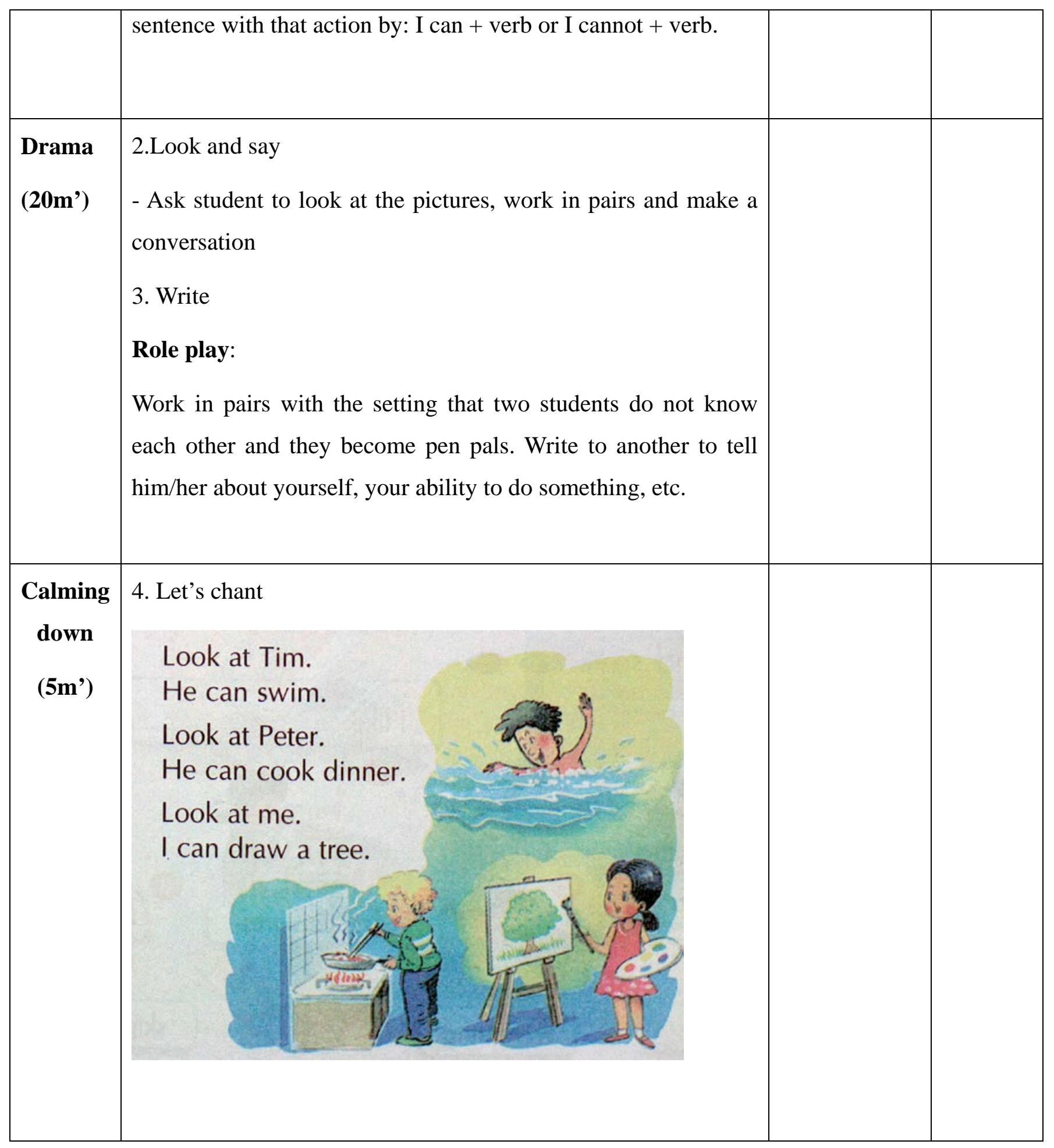

\section{IV/ Teachers comment}

\section{V/ Self-evaluation}




\section{UNIT 5: OUR HOBBIES}

\section{Lesson 1}

\section{I/ $\underline{\text { Aims: }}$}

By the end of the lesson, students will be able to:

- Say something about what they like doing.

- Practice listening and speaking skills.

\section{II/ Language contents:}

* Vocabulary: V-ing

* Structure: I like

\section{III/ Teaching aids:}

Teaching plan, English 4, workbook, pictures, chalk, board, crayons....

\section{IV/ Procedures:}

\begin{tabular}{|c|c|c|c|}
\hline Time & Content / Learning's Activity & Arrangement & Material \\
\hline $\begin{array}{c}\text { Warm- } \\
\text { up } \\
\text { (5m’) }\end{array}$ & $\begin{array}{l}\text { Ask the student to play the game: walking around. } \\
\text { Ask students to walk around freely in the } \\
\text { classroom. When teacher says "stop" and "talk", } \\
\text { students must find a partner to greet and talk about } \\
\text { whatever they want. After } 1 \text { minute, the teacher } \\
\text { says "Stop, close your eyes and think about as } \\
\text { many verbs as you know". Then the teacher says } \\
\text { "stop" and "talk". Let students talk freely within 1- } \\
2 \text { minutes. }\end{array}$ & & \\
\hline $\begin{array}{c}\text { Pre- } \\
\text { Drama } \\
\text { (10m') }\end{array}$ & $\begin{array}{l}\text { a. Look, listen and repeat } \\
\text { - Ask students to look at the book and answer } \\
\text { Who are they in the picture? } \\
\text { - Read the dialogue aloud }\end{array}$ & & \\
\hline
\end{tabular}




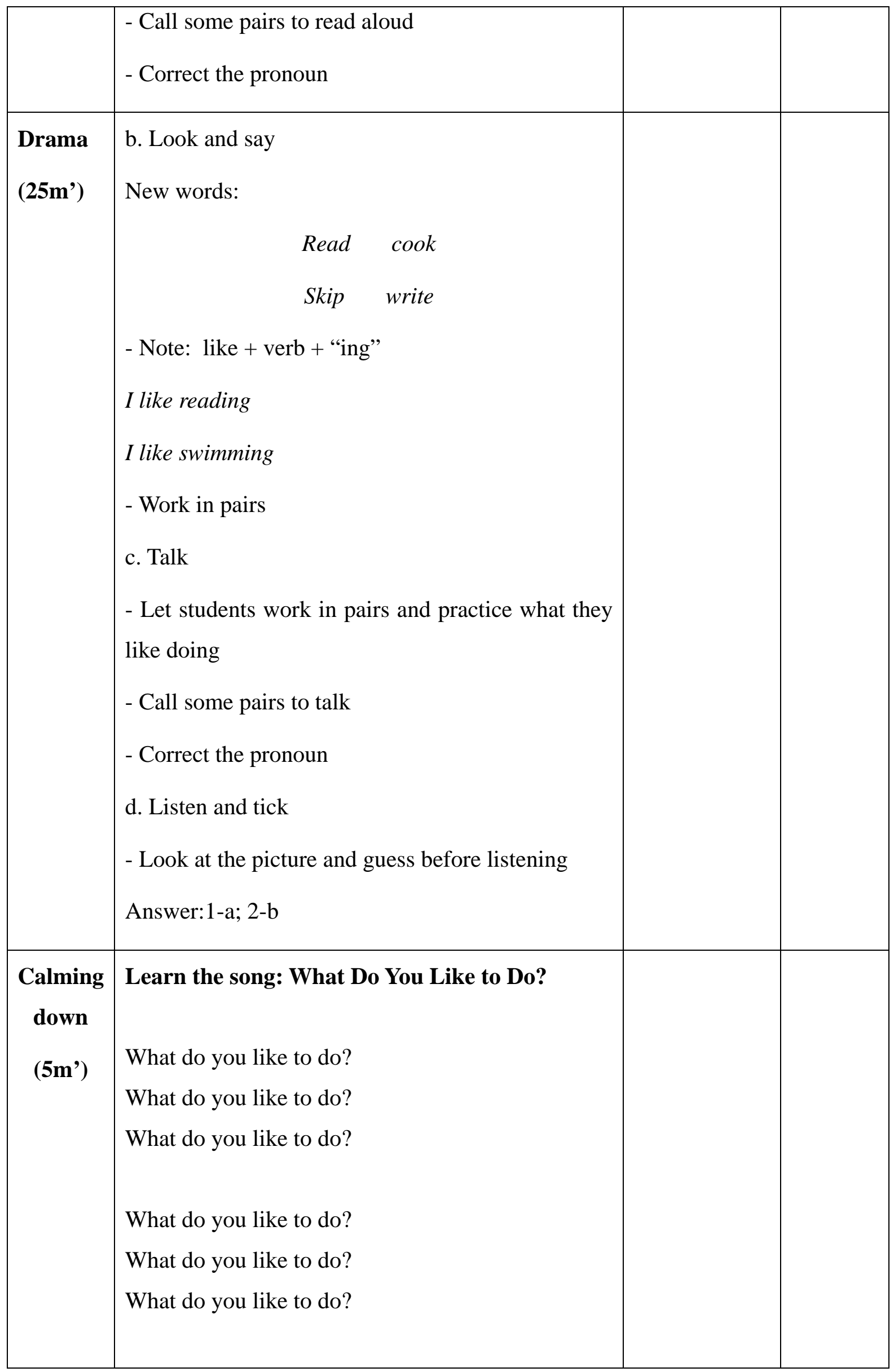




\begin{tabular}{|l|l|l|}
\hline Ride a bike. & \\
Watch TV. & & \\
Dance. & Climb a tree. \\
Speak English. & $\begin{array}{l}\text { Read a book. } \\
\text { Swim. }\end{array}$ & \\
What do you like to do? & What do you like to do? \\
What do you like to do? & \\
What do you like to do? & \\
What do you like to do? & & \\
What do you like to do? & & \\
\end{tabular}

\section{V/ Teachers comment}

\section{VI/ Self-evaluation}




\section{UNIT 5: OUR HOBBIES}

\section{Lesson 2}

\section{I/ $\underline{\text { Aims: }}$}

By the end of the lesson, students will be able to:

- Ask and answer what they like doing with yes/no questions.

- Practice listening, writing and reading skills.

\section{II/ Language contents:}

* Vocabulary: exciting, boring

* Structure: Do you like

Yes, I do. / No, I don’t.

\section{III/ Teaching aids:}

Teaching plan, English 4, workbook, pictures, chalk, board, and crayons.

\section{IV/ Procedures:}

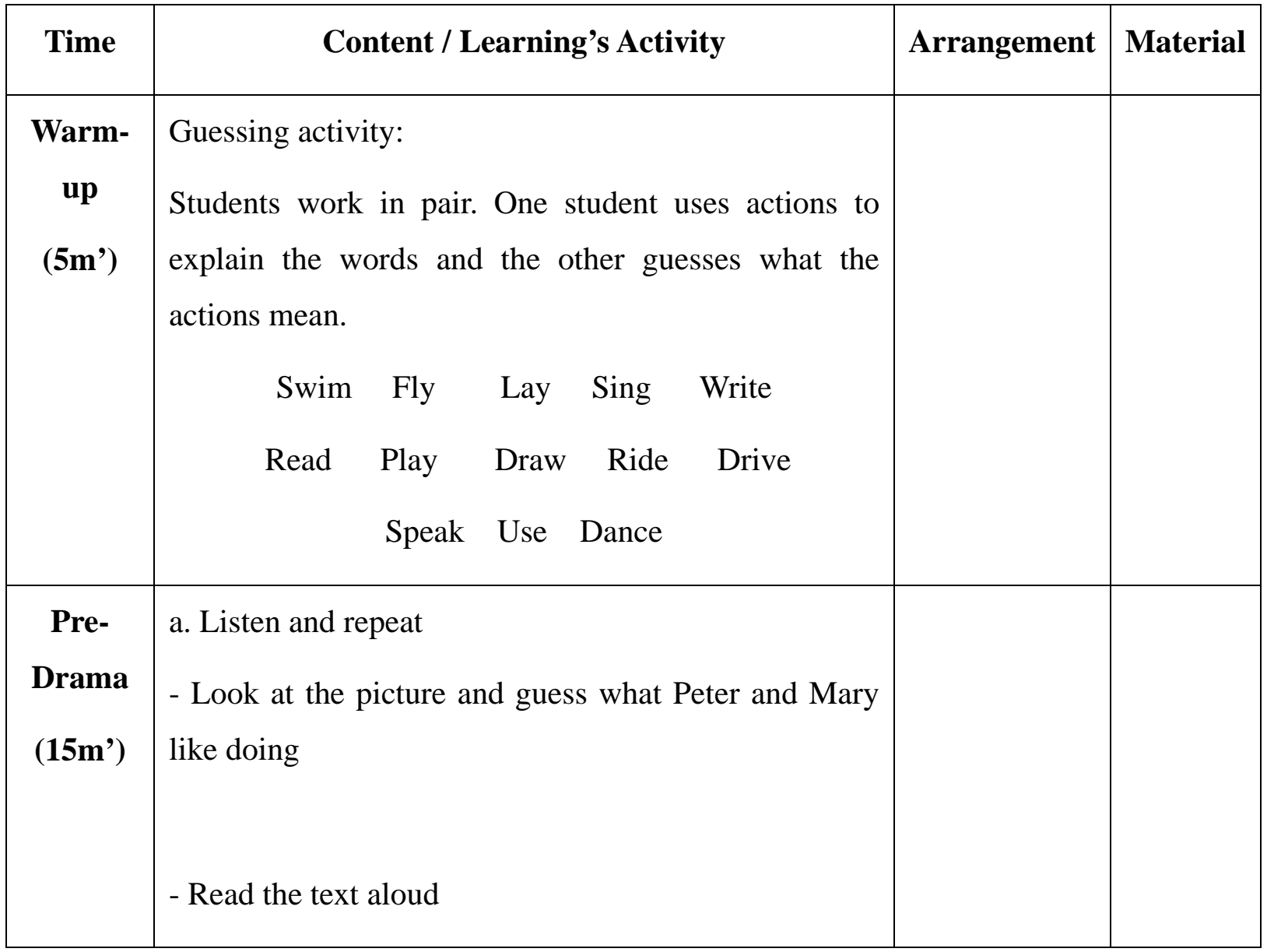




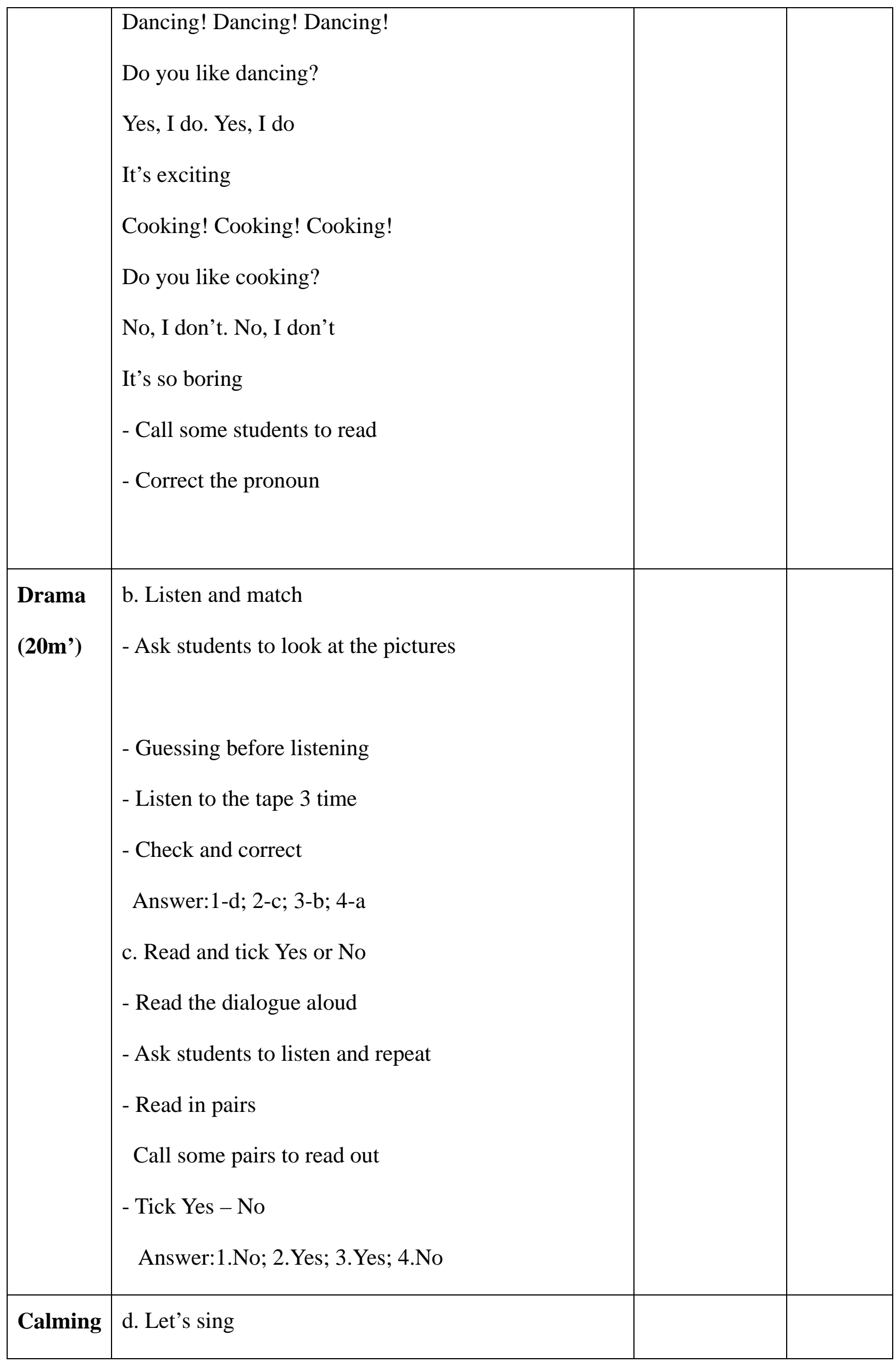




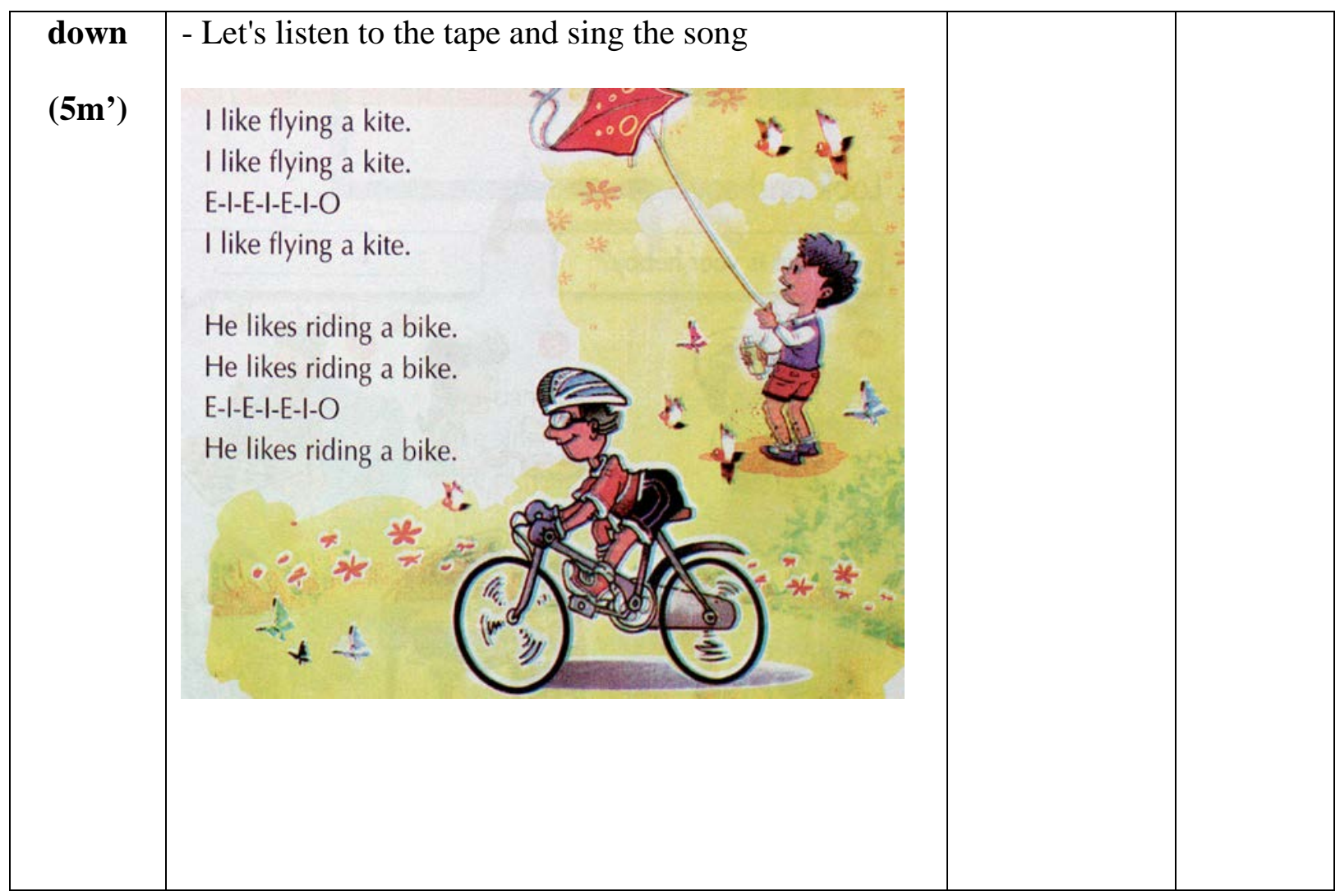

\section{IV/ Teachers comment}

\section{V/ Self-evaluation}




\section{UNIT 5: OUR HOBBIES}

\section{Lesson 3}

\section{I/ Aims:}

By the end of the lesson, students will be able to:

- Ask and answer what their hobbies are.

- Practice writing, listening and speaking skills.

\section{II/ Language contents:}

* Structure: What's your hobby?

My hobby is

\section{III/ Teaching aids:}

Teaching plan, English 4, workbook, pictures, chalk, board, and crayons.

\section{IV/ Procedures:}

\begin{tabular}{|c|c|c|c|}
\hline Time & Content / Learning's Activity & Arrangement & Material \\
\hline $\begin{array}{c}\text { Warm- } \\
\text { up } \\
\text { (5m') }\end{array}$ & $\begin{array}{l}\text { 1.Warm up: } \\
\text { - Play game: } \\
\text { Call } 3 \text { groups of students to go to the board, each group has to } \\
\text { write the words of verbs in } 4 \text { minutes. The fastest group is the } \\
\text { winner. }\end{array}$ & & \\
\hline $\begin{array}{c}\text { Pre- } \\
\text { Drama } \\
\text { (15m’) }\end{array}$ & $\begin{array}{l}\text { a. Listen and repeat } \\
\text { - Look at the picture and answer the questions } \\
\text { Who are they in the picture? } \\
\text { What are they talking about? } \\
\text { - Read the dialogue aloud } \\
\text { - Read in pairs } \\
\text { - Call some pairs to read, correct the pronoun }\end{array}$ & & \\
\hline
\end{tabular}




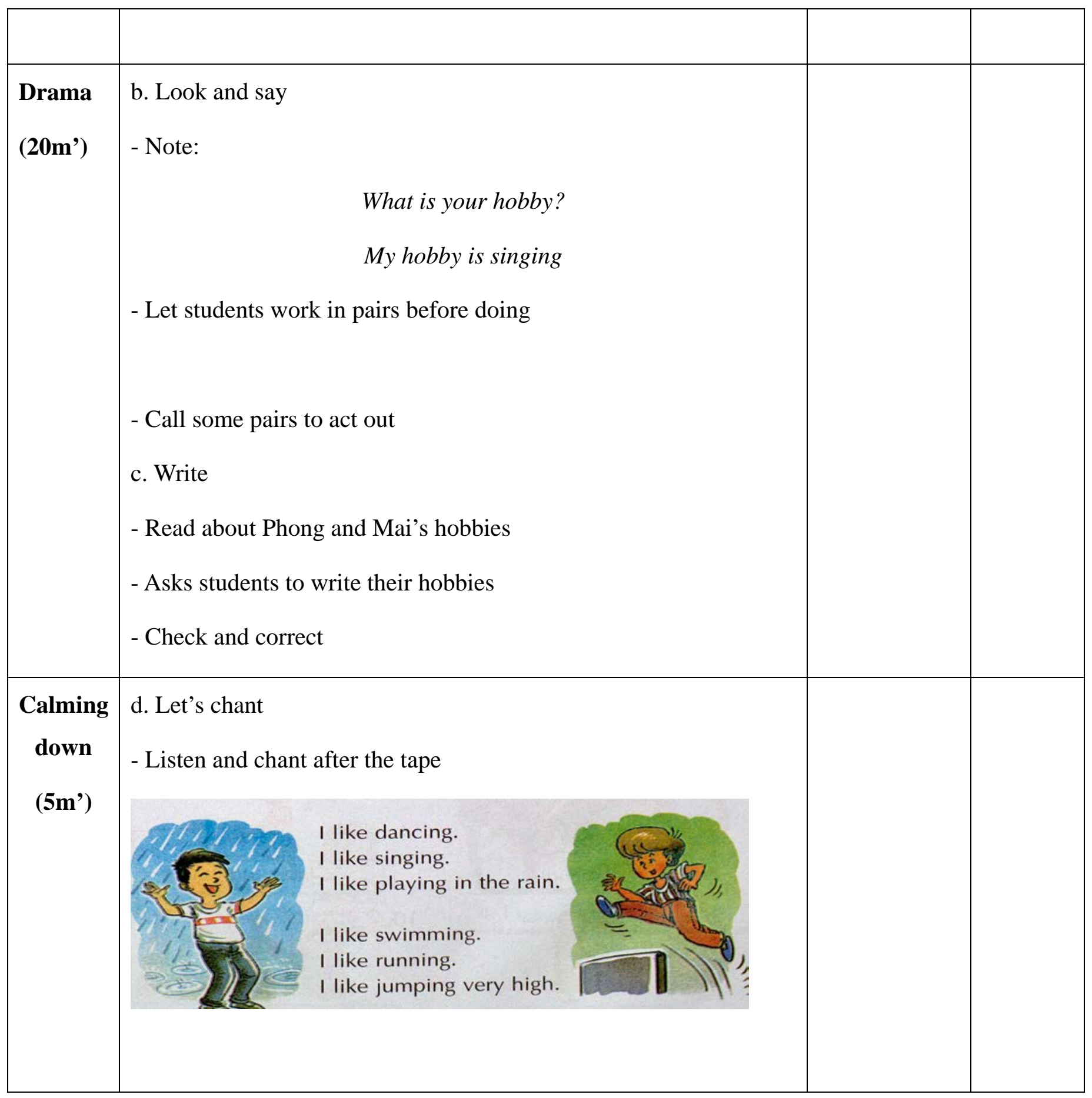

IV/ Teachers comment

\section{V/ Self-evaluation}




\section{UNIT 6: MY SCHOOL}

\section{Lesson 1}

\section{I/ Aims:}

By the end of the lesson, students will be able to:

- Asking and answering questions about where a school is.

- Practice listening, speaking skills and do exercises in the book.

\section{II/ Teaching aids:}

Teaching plan, English 4, workbook, pictures, chalk, board, and crayons.

\section{III/ Procedures:}

\begin{tabular}{|c|c|c|c|}
\hline Time & Content / Learning's Activity & Arrangement & Material \\
\hline $\begin{array}{c}\text { Warm- } \\
\text { up } \\
\text { (5m') }\end{array}$ & $\begin{array}{l}\text { Waking students up with the song “This is the way” } \\
\text { This is the way we wake ourselves, } \\
\text { Wake ourselves, wake ourselves. } \\
\text { This is the way we wake ourselves, } \\
\text { So early in the morning. } \\
\text { This is the way we brush our teeth, } \\
\text { Brush our teeth, brush our teeth. } \\
\text { This is the way we brush our teeth, } \\
\text { So early in the morning. } \\
\text { This is the way we wash our face, } \\
\text { Wash our face, wash our face. } \\
\text { This is the way we wash our face, } \\
\text { So early in the morning. } \\
\text { This is the way we put on our clothes, } \\
\text { Put on our clothes, put on our clothes. } \\
\text { This is the way we put on our clothes, } \\
\text { So early in the morning. }\end{array}$ & & \\
\hline
\end{tabular}




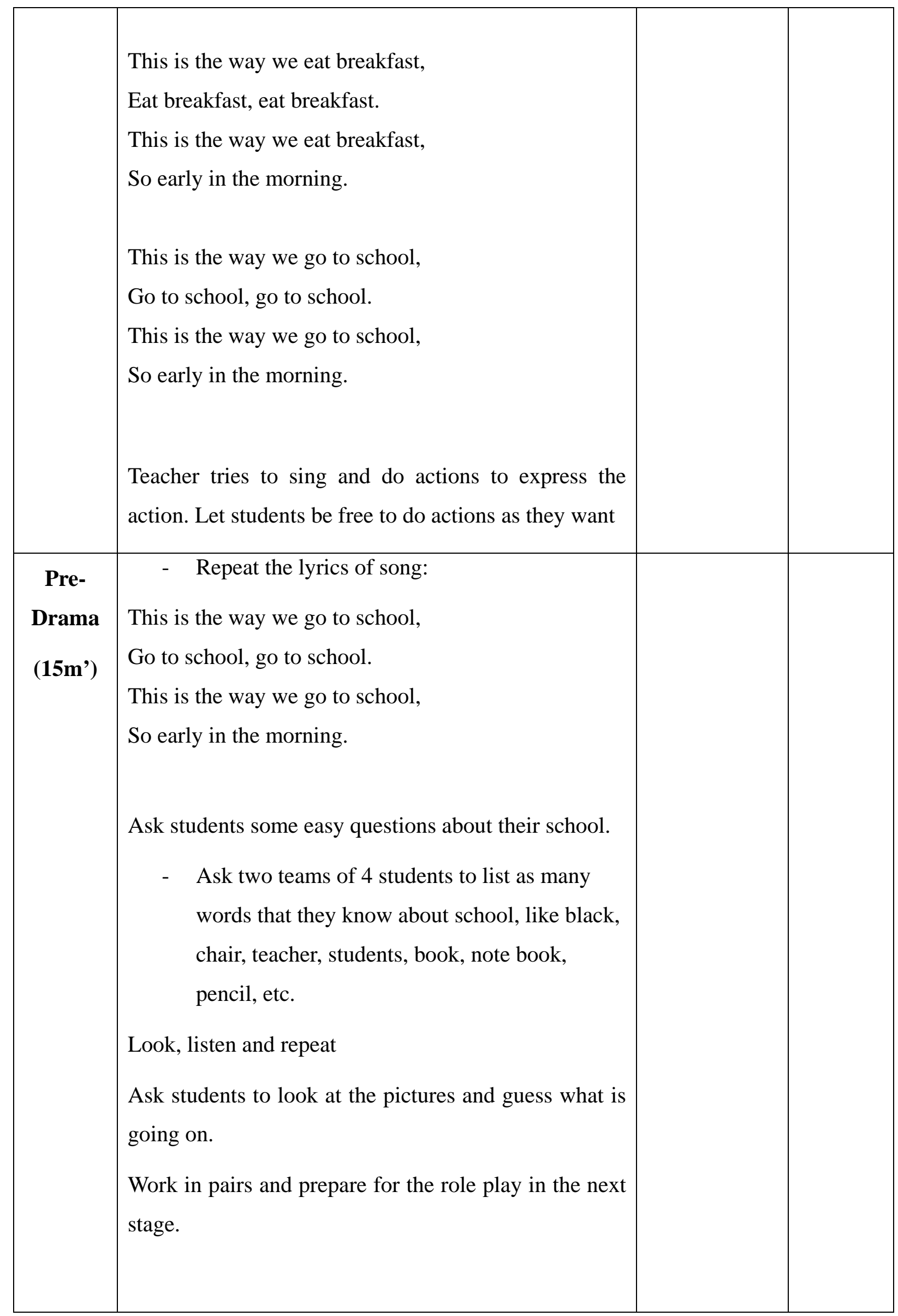




\begin{tabular}{|c|c|c|}
\hline $\begin{array}{l}\text { Drama } \\
\left(20 m^{\prime}\right)\end{array}$ & 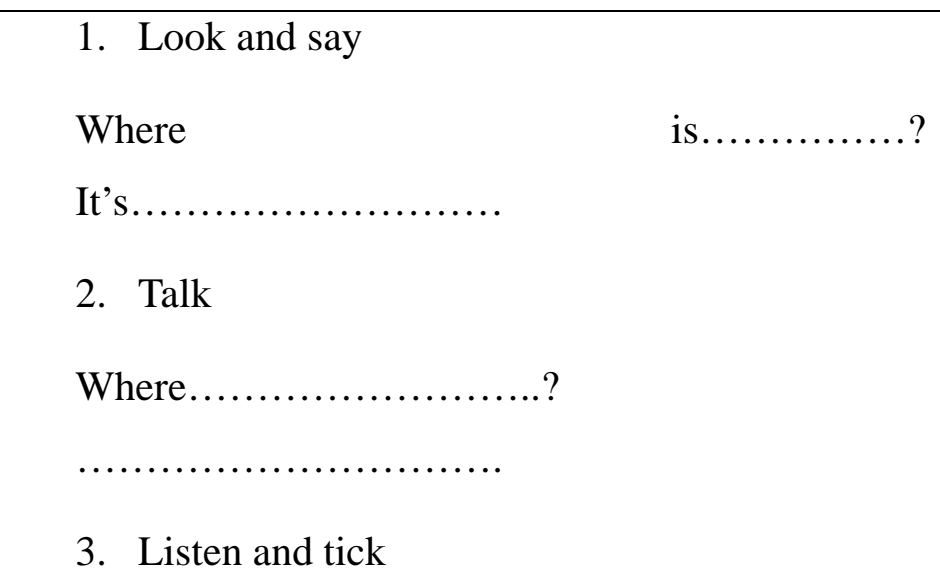 & \\
\hline $\begin{array}{c}\text { Calming } \\
\text { down } \\
\text { (5m') }\end{array}$ & $\begin{array}{l}\text { Look who came to school today! } \\
\text { (tune: Mary had a little lamb) } \\
\text { Look who came to school today, } \\
\text { School today, school today } \\
\text { Look who came to school today, } \\
\text {--------------(student's name) did. } \\
\text { One by one, students get up and dance as others say } \\
\text { his name and clap. Repeat until all the children's } \\
\text { names, including the teacher’s name, have been } \\
\text { called. }\end{array}$ & Big circle \\
\hline
\end{tabular}

\section{IV/ Teachers comment}

\section{V/ Self-evaluation}




\section{UNIT 6: MY SCHOOL}

\section{Lesson 2}

\section{I/ $\underline{\text { Aims: }}$}

By the end of the lesson, students will be able to:

- Talking about where a school is.

- $\quad$ Practice listening and reading skills and do exercises in the book.

\section{II/ Teaching aids:}

Teaching plan, English 4, workbook, pictures, chalk, board and crayons.

\section{III/ Procedures:}

\begin{tabular}{|c|c|c|c|}
\hline Time & Content / Learning's Activity & $\begin{array}{c}\text { Arrangemen } \\
\mathbf{t}\end{array}$ & $\begin{array}{c}\text { Materia } \\
\text { l }\end{array}$ \\
\hline $\begin{array}{c}\text { Warm- } \\
\text { up } \\
\text { (5m') }\end{array}$ & $\begin{array}{l}\text { Human Bingo: } \\
\text { Each student is given a sheet of paper like a bingo card. } \\
\text { Each box contains a phrase relating to age, hobbies, } \\
\text { interests, school or other personal information. A time- } \\
\text { limit is given and everyone asks each other questions to } \\
\text { find someone who fits one of the categories, and then } \\
\text { asks the person to write their names in the box. The } \\
\text { winner is the first student to have a signature in every } \\
\text { box or who gathered the most names within the time- } \\
\text { limit. }\end{array}$ & & \\
\hline $\begin{array}{c}\text { Pre- } \\
\text { Drama } \\
\text { (15m') }\end{array}$ & $\begin{array}{l}\text { 1. Listen and repeat } \\
\text { Ask students to look at the pictures and guess } \\
\text { Work in pairs, read aloud } \\
\text { Listen and repeat }\end{array}$ & & \\
\hline
\end{tabular}




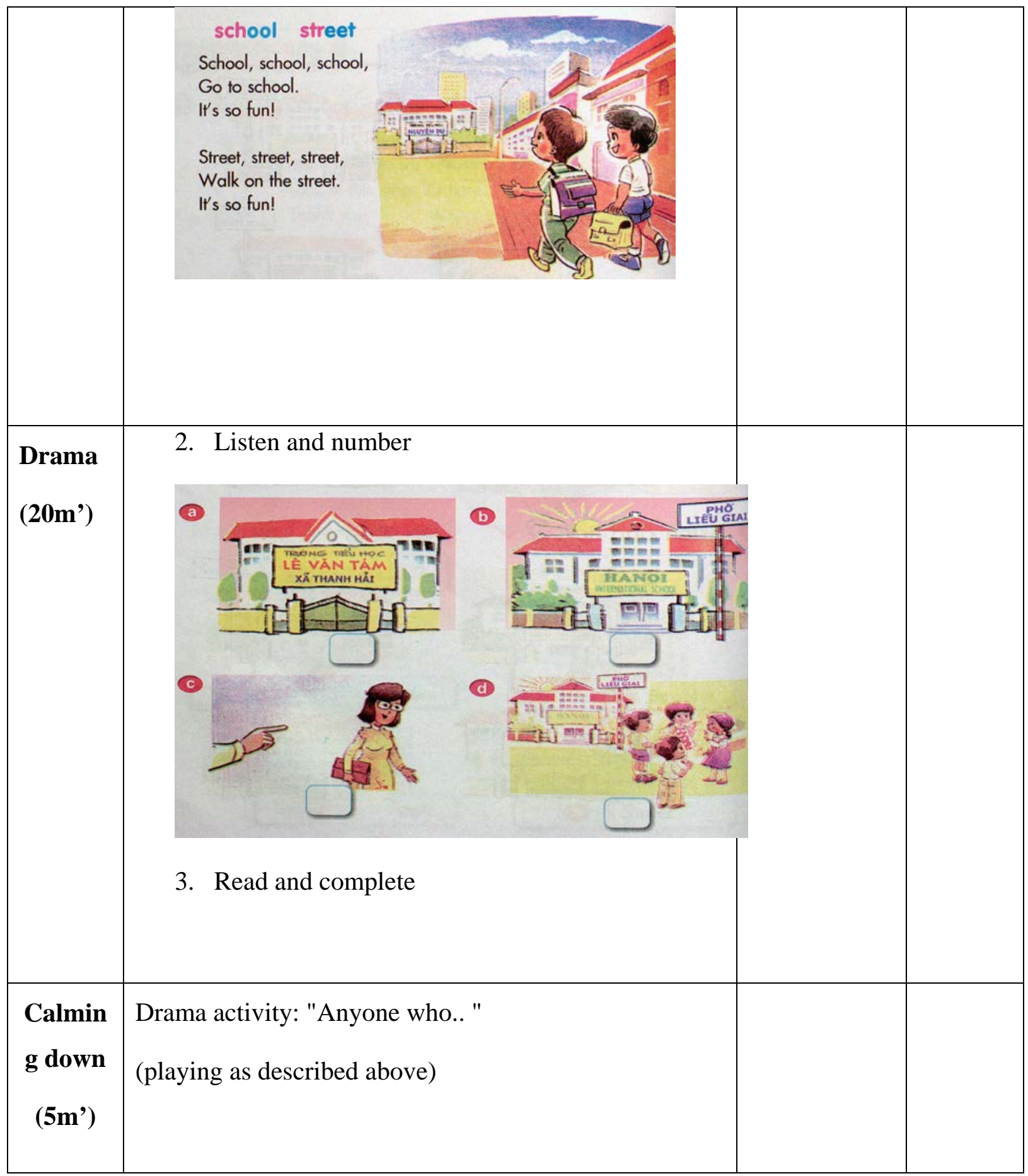

\section{IV/ Teachers comment}

\section{V/ Self-evaluation}




\section{UNIT 6: MY SCHOOL}

\section{Lesson 3}

\section{I/ $\underline{\text { Aims: }}$}

By the end of the lesson, students will be able to:

- Ask and answer questions about what class or grade someone is in.

- $\quad$ Practice listening, speaking and writing skills and do exercises in the book.

\section{II/ Teaching aids:}

Teaching plan, English 4, workbook, pictures, chalk, board and crayons.

\section{III/ Procedures:}

\begin{tabular}{|c|c|c|c|}
\hline Time & Content / Learning's Activity & Arrangement & Material \\
\hline $\begin{array}{c}\text { Warm- } \\
\text { up } \\
\text { (5m’) }\end{array}$ & $\begin{array}{l}\text { Thought Tracking 9: } \\
\text { Students speak aloud the thoughts of their character in } \\
\text { a still image. } \\
\text { Students are frozen and are thinking about school, } \\
\text { classroom, etc, and then the teacher will tap them on } \\
\text { the shoulder and then they have to speak aloud the } \\
\text { thoughts or feelings at that time. For example: "I am } \\
\text { feeling worried", "worried", "and happy”, "scared”, } \\
\text { etc. }\end{array}$ & Big circle & \\
\hline $\begin{array}{c}\text { Pre- } \\
\text { Drama } \\
\text { (15m') }\end{array}$ & $\begin{array}{l}\text { 1. Listen and repeat } \\
\text { Look at the book and answer } \\
\qquad \text { Who are they? } \\
\qquad \text { What are they talking about? } \\
\text { Listen and repeat after the tape } \\
\text { Read in pairs }\end{array}$ & & \\
\hline
\end{tabular}




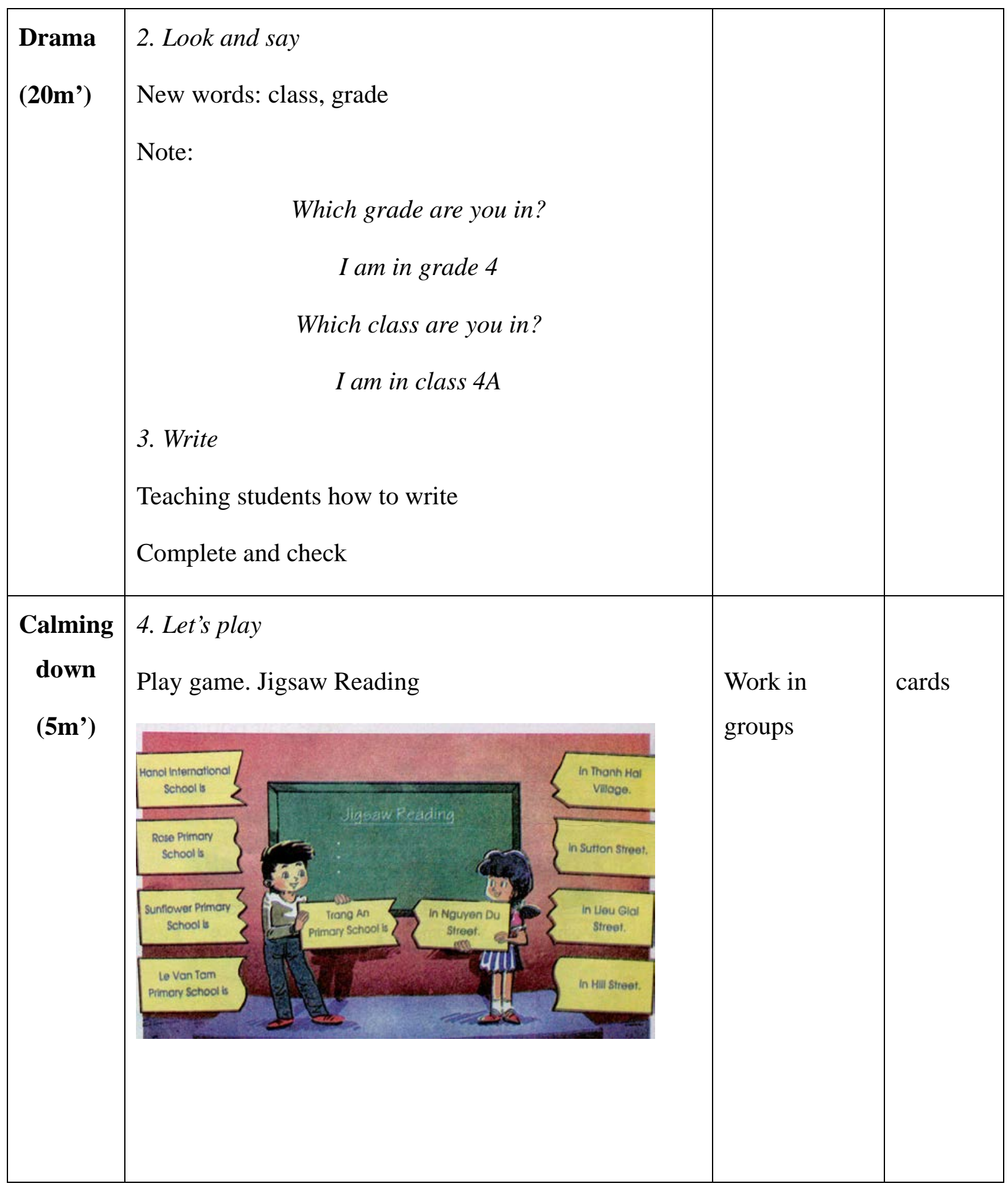

\section{IV/ Teachers comment}

\section{V/ Self-evaluation}


Example of non-drama based lesson plan (Unit 1 and 6)

\section{UNIT 1: GOOD MORNING, HOW ARE YOU?}

Lesson 1 (Reference: English Textbook for grade 3)

\section{Objectives:}

- By the end of this lesson, students will be able to answer the question, "How are you?"

- Develop writing and reading skills

\section{Language focus:}

- Vocabulary: morning, afternoon, evening and night, how, thank, thanks, fine, and

- Sentence patterns:

- Good morning/afternoon,...

- How are you?

- I'm fine, thank you. And you?

- I'm fine, thanks.

\section{Teaching method:}

- Techniques:

- Work in pairs and individually

- Work in groups and discuss

\section{Teaching aids:}

- Teacher's aids: audio, stickers, puppets, flashcards

- Students' aids: book, notebook, workbook

\section{Procedures:}

\subsection{Warm up}

- Ask students to find names in the crossword.

- Time: 5 minutes

- Arrangement: T-WC, in pairs, T-whole

- Example:

\begin{tabular}{|l|l|l|l|l|l|l|l|}
\hline L & A & N & A & B & C & D & E \\
\hline A & V & D & E & F & M & U & F \\
\hline B & X & P & L & R & L & T & G \\
\hline C & Z & H & M & W & I & S & H \\
\hline D & T & O & N & Y & N & Q & I \\
\hline
\end{tabular}




\begin{tabular}{|l|l|l|l|l|l|l|l|}
\hline E & Y & N & O & P & D & P & J \\
\hline F & H & G & I & J & A & O & K \\
\hline U & X & Y & Z & N & A & M & L \\
\hline V & T & X & Q & P & O & N & M \\
\hline
\end{tabular}

- Answers: Lan, Phong, Tony, Nam, Linda.

- Ask students work in pairs:

o Student 1: Hello. I'm Nam.

o Student 2: Hi, Nam. I'm Tom.

\subsection{New Lesson}

- Time:

- Arrangement: In pairs and whole class

\subsubsection{Look, listen and repeat}

- Ask students to identify the characters in the picture on page 18 and what they are saying.

- Set the scene: "You are going to review and learn some phrases used for greetings." Use two puppets to illustrate the situation.

- Explain the situation and the use of the titles Mr, Mrs, and Miss.

- Play the recording and ask students to listen to the tape twice.

- Teacher asks students to listen and repeat two times.

- Hold up the specific character puppets in the air and point to each character. Ask the whole class to say the appropriate line in the dialogue.

- Have the whole class repeat all the phrases a few times to reinforce their pronunciation.

- Note:

o Children do not tend to ask each other, "How are you?” (It is something adults ask each other and ask children, but not a child to another child).

o Thanks is an informal expression of thank you.

\subsubsection{Look and say}

- Time:

- Arrangement: In pairs and whole class

- Have students look at the picture A on page 18.

- Ask them to identify the characters in the pictures and recall the phrases for greeting.

- Point to picture A and ask students to guess what each character should say. Fill in the speech bubbles with the phrases provided by the students and have the students repeat the lines a few times.

- Teacher models the dialogue.

- Assign a pair to pretend to be Tom and Mrs. Lan in picture A Mrs. Lan: How are you, Tom?

Tom: I'm fine, thank you. And you?

Mrs. Lan: Fine, thanks. 
- Have one repeat Mrs. Lan’s part, the other Tom’s part. Then have the pair swap their roles.

- Repeat the step with a few more pairs.

- Ask students to act out the dialogue using picture A and B.

- Monitor the activity, check the pronunciation (e.g. sound, assimilation of sound and intonation) and offer help when necessary.

- Call on some pairs to perform the task in the front of the class. Others observe and comment.

- Have the whole class repeat all the phrases to reinforce their pronunciation.

\subsubsection{Talk}

- Have students look at the pictures on page 19 and identify the characters in the pictures.

- Recall the titles Mr., Mrs., Miss.

- Point to picture A, and ask students to guess what the characters should say.

- Fill in the speech bubbles with the phrases provided by the students

A: How are you?

B: I'm fine, thank you. And you?

A: Fine, thanks.

- Have students to repeat the lines in the bubbles a few times before letting them practice freely. Use the characters in their books to practice or role play the greeting phrases.

- Have students work in pairs to practice the greeting.

- Monitor the activity and offer help when necessary or correct typical pronunciation errors.

- Call on a pair to demonstrate in the front of the class.

- Have the whole class repeat all the phrases to reinforce their pronunciation.

\section{Summary and Homework:}

- Encourage students to prepare for Unit 3 - Lesson 2. 


\section{UNIT 1: GOOD MORNING, HOW ARE YOU?}

Lesson 2 (Reference: English Textbook for grade 3)

\section{Objectives:}

- By the end of this lesson, students will be able to greet each other.

- Develop listening, reading, and writing skills.

\section{Language focus:}

- Phonics: hello, thanks

- Vocabulary: how, thank, thanks, fine, and.

- Sentence patterns:

- How are you?

- I'm fine, thank you. And you?

- I'm fine, thanks.

\section{Teaching methods:}

- Communicative method

- Techniques:

- Work in pairs

- Work individually

- Work in groups and discuss

\section{Teaching aids:}

- Teacher's aids: pictures, word cards, audio, puppets, and flashcards.

- Student's aids: book, notebook, and workbook.

\section{Procedures:}

\subsection{Warm up}

- Let's students chant ( L2 - 4)

- Play the recording

\subsection{New lesson}

\subsubsection{Listen and repeat}

- Have students open the book to page 14, and look at the words spoken by Linda and Nam. Notice the letters colored differently in both words.

- Set the scene: "You are going to learn how to produce the sound of the letter "l" in the word, "hello", and "an" in the word, "thanks".

- Produce the sound "l" and "n" a few times.

- Teach the new phrase, "How do you spell the + name?”. Show them how to spell Nam, Linda, and other names.

- Play the recording so students can listen while they read the chant in their books.

- Call on a group of six: three of them to repeat each line of the chant, and the other three to clap out the syllables.

- Have students practice the chant in groups and clap the syllables.

- Monitor the activity and offer help when necessary or correct typical pronunciation errors.

- Call on a group to recite the chant, while the others clap the syllables.

- Ask a few questions to check students' comprehension of the language. 
- Have the whole class recite the chant to reinforce their pronunciation.

\subsubsection{Listen and tick}

- Have students look at pictures 1a, 1b, 2a, 2b, and 2d on page 20.

- Identify the characters and their relationship.

- Set the scene: "You are going to listen to the recording. Match the information you hear to the pictures and tick the box in the corner of the correct picture."

- Play the recording so students can listen while they look at the pictures in their books.

- Play the recording for students to listen and tick the correct pictures.

- Play the recording for students to check their answers.

- Have students work in pairs to trade their answers for correction.

- Ask questions to test students' comprehension of the recording.

- Transcript

1. Nam: Hello, Mr. Loc. How are you?

Mr. Loc: I'm fine, thank you. And you, Nam?

Nam: I'm fine. Thank you, Mr. Loc.

2. Tom: Hi, Mary. How are you?

Mary: Hi, Tom. I'm fine, thanks.

Answers: 1 - b: 2 - a.

\subsubsection{Read and match}

- Ask students to identify the characters in the pictures on page 21.

- Set the scene: "You are going to read the dialogues and match each of them with the right picture."

- Ask students to read the dialogues and to match the sentence with the appropriate picture.

- Monitor the activity and offer help if necessary.

- Have students work in pairs to trade their answers for correction.

- Call on some students to report their answers, while the others listen and comment.

- Ask a few questions to check the students' comprehension of the sentences.

- Have the whole class read each line of the dialogue to reinforce their pronunciation.

- Answers: 1 - b; 2 - a

\section{Summary and Homework:}

- Students learned how to greet and greeting phrases, like “How are you?”, “fine”, "thank you”, "thanks", “and you?”

- Produce the sound of the letter "l” in hello and "an" in thanks

- Students recite the chant and clap to the syllables on page 20 of the Student Book at home. 


\section{UNIT 1: GOOD MORNING, HOW ARE YOU?}

Lesson 3 (Reference: English Textbook for grade 3)

\section{Objectives:}

- By the end of this lesson, students will be able to greet each other using the language they have learned.

- Develop speaking and listening skills

\section{Languages focus:}

- Vocabulary: how, thank, thanks, fine, and

- Sentence patterns:

- How are you?

I'm fine, thank you. And you?

I'm fine, thanks.

\section{Teaching methods:}

- Communicative method.

- Techniques:

- Work in pairs

- Work in groups and discuss

- Ask and answer

\section{Teaching aids:}

- Teacher's aids: pictures, word cards, audio, puppets, and flashcards

- Students' aids: book, notebook, and workbook

\section{Procedures:}

\subsection{Warm up}

Let students chant in two groups.

\subsection{New Lesson}

\subsubsection{Listen and repeat}

- Have students look at page 22 and identify the characters in the picture.

- Ask a few questions to check students' comprehension of the dialogue.

- Set the scene: "We are going to review the greeting phrases that we have learned in the previous lesson."

- Play the recording so students can listen while they read the text and practice the dialgoue.

- Play the recording again so students can repeat the dialogue a few times.

\subsubsection{Look and say}

- Have students look at the pictures a-d on page 22

- Elicit the characters in the pictures and their names.

- Tell them to guess and respond to the first character. Fill in the speech bubbles with the phrases provided by the students.

- Have students repeat a few times. 
- Teacher models the dialogue.

- Assign a pair to pretend to be Linda and Miss Hien to act out the dialogue.

- Repeat the previous step, but have the pair swap their parts.

- Have the whole class repeat all the phrases.

- Ask students to practice in pairs.

- Monitor the activity, check the pronunciation (e.g. sound, assimilation of sound and intonation) and offer help if necessary.

- Call on some pairs to perform the task at the front of the class. The others observe and comment.

- Have the whole class repeat the question and answer in unison to reinforce their pronunciation.

\subsubsection{Write}

- Get students to identify the characters in the pictures on page 23.

- Ask them to talk about the situation in each picture.

- Tell students that they are going to read and get information to write the missing words in the dialogue using those from the top of the page.

- Students read silently and complete the sentences.

- Monitor the activity and offer help if necessary.

- Have students work in pairs to trade their answers for correction.

- Ask some students to read their answers out loud to the class. The others listen and give comments.

- Answers:
a.Hi
b. How
c. Thank
d. Thanks

- Ask some questions to ensure students' comprehension of the written text.

- Have the whole class read each line of the dialogues in unison to reinforce their pronunciation.

\section{Summary:}

- Students learned how to ask, “How do you spell your name?”, answer questions about their name and to spell simple names.

\section{Homework:}

- Students spell their own names and the names of their family members at home. 


\section{UNIT 6: MY SCHOOL}

Lesson 1 (Reference: English Textbook for grade 3)

\section{Objectives:}

- By the end of this lesson, students will be able to introduce their school.

- Develop speaking skill.

\section{Languages focus:}

- Vocabulary: primary school, it

- Sentence Patterns: It’s Thang Long Primary School.

\section{Teaching methods:}

- Communicative approach.

- Techniques:

- Ask and answer individually

- Work in pairs or groups

\section{Teaching aids:}

- Teacher's aids: student's and teacher's book, flashcards, pictures, tape, cassette, and puppets

- Students' aids: books, notebooks, and workbooks

\section{Procedures:}

\subsection{Warm up}

- Let students listen and sing the rhyme of "My friends" on page 25.

\subsection{New Lesson}

\subsubsection{Look, listen and repeat}

- Ask students to identify the characters in the picture on page 42 and what they are saying.

- Set the scene: "You are going to listen to Mai talking to Tony about her school." (Use two character puppets to present the situation)

- Explain the new words, like "primary school".

- Play the recording so students can listen while they read the lines and practice the dialgoue. Correct pronunciation error(s) if necessary.

- Ask some questions to check students' comprehension of the language.

- Have the whole class repeat all the lines of the dialogue in unison to reinforce their pronunciation.

- Note: yeah $=$ yes.

\subsubsection{Look and say}

- Have students look at the pictures a-d on page 42.

- Ask them to identify the names of these schools in the pictures.

- Use a poster to teach them how to say the names of the schools (use the back-up building technique to teach the phrases)

- Ask students to repeat each name a few times.

- Have students to point to each picture and say the name again. 
- Model: Students pretend to be students at the school in the picture. Point to the picture and have them repeat.

o E.g. "It's Kim Dong Primary School."

- Repeat the previous steps for the other pictures.

- Ask students to practice saying, using a-d in their books.

- Monitor the activity and offer help. Correct pronunciation error(s) if necessary.

- Call on some pairs to perform at the front of the class. The others observe and comment.

\subsubsection{Talk}

- Have students look at the pictures on page 43 and identify the names of the schools in the pictures.

- Point to picture a. Ask students what they should say to fill in the speech bubble.

- Fill in the speech bubble with the answer provided by the students. E.g. "It's Kim Dong Primary School.”

- Have students repeat the lines in the bubbles a few times before letting them practice or role play freely.

- Have students to work in pairs to practice.

- Monitor the activity and offer help if necessary. Correct typical pronunciation errors.

- Ask students a few questions to check students' comprehension of the language.

- Call on some volunteers to perform the task at the front of the class. The rest of the class will observe and comment.

\section{Summary:}

- Students have learned to say school names, using "It’s ... Primary School”.

\section{Homework:}

- Encourage students to practice drawing their school at home and say its name. 


\section{UNIT 6: MY SCHOOL}

Lesson 2 (Reference: English Textbook for grade 3)

\section{Objectives:}

- By the end of this lesson, students will be able to ask and answer questions about schools.

- Develop listening, reading and writing skills.

\section{Language focus:}

- Phonics: which, school

- Vocabulary: primary school, it, which, one

- Sentence Patterns:

- Which is your school? This one/That one.

\section{Teaching methods:}

- Communicative method.

- Techniques:

- Work in pairs and individually

- Ask and answer.

- Work in groups and discuss.

\section{Teaching aids:}

- Teacher's aids: pictures, word cards, extra board, tape, and cassette.

- Student's aids: book, notebook, and workbook.

\section{Procedures:}

\subsection{Warm up}

- Greet students and have them reply.

- Students show the drawings that they did at home to their classmates and talk about the school in the drawing using the language learned in Lesson 1.

\subsection{New lesson}

\subsubsection{Listen and repeat}

- Have students open to page 44, and draw their attention to the letters colored differently in the words

- Set the scene: "We are going to learn how to produce the sound of letters "ch" in the word which and "oo" in the word school".

- Produce the sound of the letters "ch" and "oo" a few times.

- Ask students to say what they think about when they hear the sounds.

- Play the recording for students to listen as they read the chant and clap to the rhythm:

Which is your school?

This one.

Which is your school?

That one. 
- Call on a group of six: three of them to repeat each line of the chant, and the other three clap to the rhythm.

- Have students practice reciting and clapping the chant in groups.

- Monitor the activity, offer help if necessary, correct typical pronunciation errors.

- Call on a group to recite the chant, while the others clap to the rhythm.

- Ask a few questions to check students' comprehension of the language.

- Have the whole class recite the chant to reinforce their pronunciation.

\subsubsection{Listen and tick}

- Have students look at pictures 1a, 1b, 2a, 2b, and 2d on page 44 and identify the names of these schools and say the names in English.

- Set the scene: "You are going to listen to the recording, match the information you hear to the correct pictures, and tick the box next to the correct pictures."

- Play the recording so students can listen while they look at the pictures in the books

- Play the recording again for students to listen and tick the correct pictures.

- Choose one or two students to share their answers with their classmates.

- Play the recording for students to check their answers.

- Have students trade their answers with another student for correction

- Ask some questions to ensure students' comprehension of the text.

- Transcript:

o A: This is my school

B: Which one?

A: That one. Thang Long Primary School.

B: Thang Long?

A: Yes. Thang Long Primary School.

o A: This is my school

B: Which one?

A: This one. Hoa Sen Primary School.

B: Hoa Sen?

A: Yes. Hoa Sen Primary School.

- Answers: 1 - b: 2 - a.

\subsubsection{Read and tick}

- Ask students to read the dialogue and look at a and b on page 45.

- Set the scene: "You are going to read the dialogue and use the information to tick off the correct picture."

- Ask a few questions to check students' comprehension of the language.

- Ask students to read the dialogues individually and do the task.

- Monitor the activity and offer help if necessary.

- Have students trade their answers with another student for correction

- Call on one student to report their answer. The others listen and comment.

- Have the whole class read each line of the dialogues in unison to reinforce their pronunciation

- Answers: b

\section{Summary:}

- Students learned how to ask and answer questions about schools using, "Which is your school?” - This/that one. 
- Produce the sound of the letters "ch" in which and "oo" in school.

\section{Homework:}

- Recite the rhyme, “This is the way we way to go to school” on page 45 at home. 


\section{UNIT 6: MY SCHOOL}

Lesson 3 (Reference: English Textbook for grade 3)

\section{Objectives:}

- By the end of this lesson, students will be able to ask and answer questions about the name of a school.

- Develop speaking and listening skills.

\section{Language focus:}

- Vocabulary: primary school, it, which, one

- Sentence Patterns:

- What school is it? - Park Primary School.

\section{Teaching methods:}

- Communicative method

- Techniques:

- Work in pairs

- Work in groups and discuss

- Ask and answer

\section{Teaching aids:}

- Teacher's aids: audio CD, pictures, poster, and flashcards.

- Students' aids: book, notebook, and workbook.

\section{Procedures:}

\subsection{Warm up}

- Let students sing the song on page 45 for fun.

\subsection{New Lesson}

\subsubsection{Listen and repeat}

- Have students look at the book on page 46 and identify the names of the school in the picture.

- Set the scene: "We are going to listen, ask and answer about the name of a school."

- Explain the question with "that". Compare and contrast the meaning of "which school" and "what school".

- Play the recording so students can listen while they read the poster.

- Play the recording again for students to repeat each line in the bubbles a few times.

- Ask a few questions to ensure students' comprehension of the language.

\subsubsection{Look and say}

- Have students look at a-d on page 46 and identify the name of the school in each picture.

- Have students point to each picture and repeat the name again.

- Teacher points to a and asks, "What school is it?" 
- Ask students what they should say to answer the question.

- Fill in the bubbles with the correct answer provided by the students.

- Ask students to repeat the question and answers.

- Repeat the step with the other pictures, then have students repeat all the phrases a few times.

- Have students practice in pairs by asking and answering questions

- Monitor the activity, check the pronunciation (e.g. sound, assimilation of sound and intonation) and offer help if necessary.

- Call on some pairs to perform the task at the front of the class. Others observe and comment.

- Have the whole class repeat the question and answer in unison to reinforce their pronunciation.

\subsubsection{Write}

- Get students to identify the name of the school on page 47.

- Set the scene: "We are going to read and get the information to complete the missing word(s) in the dialogue."

- Students read silently and complete the sentences.

- Have students work in pairs to trade their answers for correction.

- Ask students to read the answers out loud to the class. The others listen and give comments.

- Answers:

a. Which

- b. One

- c. School

- Have the whole class read each line of the dialogue in unison to reinforce their pronunciation.

\section{Summary:}

- Students learned how to ask and answer questions about someone’s name using, "Is he/she ...?"

\section{Homework:}

- Encourage students to tell their parents the names of their friends. 
After 4 months of the traditional-based lesson plan (non-drama-based lesson plan), the control group students had to do exercises in the textbook only and no other activities.

From these two detailed lesson plans, an interesting comparison was made as in Table 16 below.

Table 166. Difference and similarities between two instructions

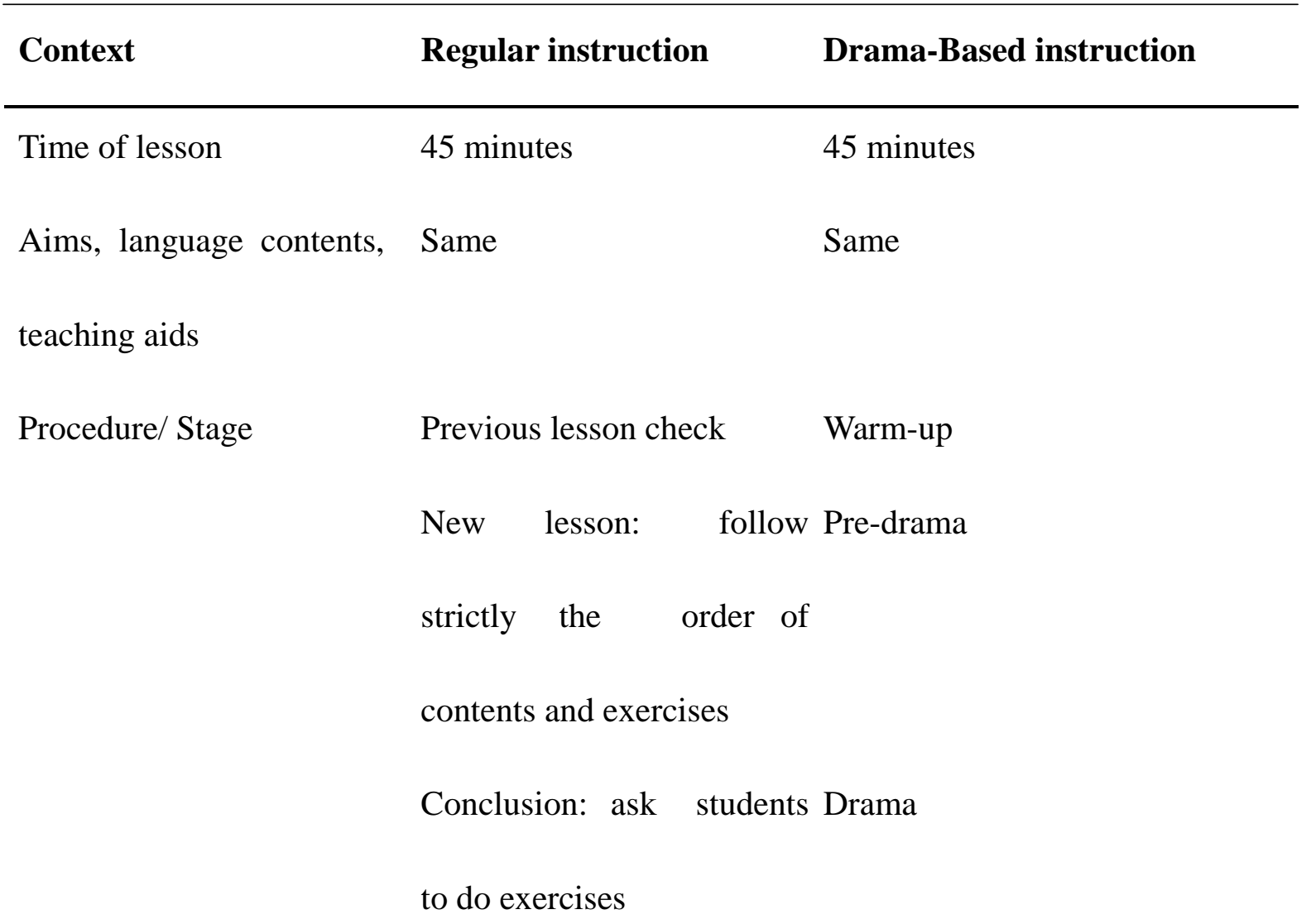

Calming down

Review Do all exercises in the Performance on stage: Peppa textbook Pig

$\begin{array}{lll}\text { Roles of teachers } & \text { Trainers } & \text { Facilitators/Moderators/Advisors }\end{array}$

Roles of students Passive learners Active learners/Organizers

Source illustration: Author

Table 16 illustrates the regular and drama-based instructions. The similarities of both instructions were the time of lesson 45 minutes for each and the aims, language contents, 
teaching aids were almost the same and were listed at the beginning of the teacher's lesson plan. The main aim is to help students achieving a lesson or a course given.

The differences were shown by the procedure and the review of each instruction. As our observation, the regular teacher teaches students followed three stages of the lesson. They were previous lesson check, a new lesson, and conclusion which strictly followed the numbering content in the textbook. In contrast, Drama-based instruction used drama activities to insert into each stage of the procedure. Drama activities helped students have more energy to start the new lesson at the warm-up stage. Students were involved with the new topic of the lesson at the pre-drama stage by the activities, such as song, chant, rhyme activities. When they have a basic background of the new lesson, the students have created the space for them to develop the language skills by drama activities, such as: where, when and what, etc.

At the end, at the calming down stage, teacher use again drama activities to bring the learners return the normal voice by the activities which help them to share their experience after the lesson. And then, when the students in the regular instruction were asked to review 6 lessons by doing all the exercises in the textbook, at the same time, the experimental students were given the scripts of Peppa Pig with a number as an exercise of performance on stage.

\subsubsection{Questionnaire to measure the attitudes and motivation of the primary school students towards English language learning before and after the intervention}

Speaking competence can be quantitatively measured by a speaking competence test, but the other important predictor of speaking competence, attitudes and motivation, cannot be measured by the same test. Therefore, the researcher used a questionnaire before and after the treatment period to measure the levels of attitudes and motivation of the students. The questionnaire, named “Attitudes and Motivation Test Battery (AMTB)”, was modified from Gardner's AMTB (1985), and was used by Chalak and Kassaian (2010, Wen (1997), Vaezi (2008) and Al-Tamimi and Shuib (2009) For example, Chalak and Kassaian (2010) used the questionnaire to study the motivation and attitudes of 108 students at the Islamic Azad University (Isfahan, Iran) towards English.

Wen (1997) designed a questionnaire based on Gardner's AMTB (1985) to look at the factors affecting the motivation of Asian and Asian-American students studying Chinese as a foreign language at the University of Houston, Texas. The total number of the students who 
participated in the study was 77, and they were of various origins: Vietnamese, Japanese, Korean, Indonesian and Malaysian. Fifty-three of the participants were taking the first-year Chinese class, and twenty-four a second-year Chinese class as part of their university study. All the participants were asked to complete the AMTB questionnaire twice, once at the beginning of the semester and again at the end of the semester. The students' responses to each motivation item in each class were calculated. Then ANOVA was used for each motivational variable to compare the students' motivation and attitudes among the three courses. Correlations were calculated between the students' motivation and their learning outcomes (their course-related scores). The findings of the study showed that motivated students studied frequently and effectively seized every chance to develop their language skills. The findings also revealed that there was a significant correlation between the students' motivation and their learning outcomes.

Vaezi (2008) investigated the effects of integrative and instrumental motivation on the achievement in English as a foreign language among Iranian undergraduate students whose major was not English. Vaezi chose 79 students, 41 females and 38 males, studying either in their first or second year at Berjand University in Iran. All of the 79 participants (average age 19) had studied English for about 8 years prior to the university. Vaezi created a 5-point instrumental and integrative motivation scale by modifying the Likert 7-point scale format of Gardner's AMTB (1985) and Clement et al. (1994). The points on the scale moved from 1 to 5 as strongly disagree, disagree, neutral, agree, and strongly agree. Vaezi used SPSS to analyze her data. She used a paired samples t-test to compare the two kinds of motivation. Vaezi calculated the mean scores of the students' responses to each item individually and the overall mean scores of their responses to the integrative and instrumental motives. Vaezi stated that the results indicated that students had positive orientations and attitudes towards English, and they were more instrumentally than integratively motivated to learn English. This indicates that there were significant differences between the mean scores of the two kinds of motivation.

All three above-mentioned studies investigated the same theme: motivation among learners of a foreign language (such as Chinese, English, etc.). They shared the same procedures and investigation process that the current study employs. Most of them used or modified a questionnaire based on Gardner’s AMTB (1985).

The present study is different from some of the above-mentioned studies, in that the target language is English as a foreign language, which is different from what it was in some of the 
reviewed studies, e.g., Chinese in Wen (1997). The present study is also different, in terms of the number of motivation items listed on the motivation questionnaire. It involved 14 motivational items, 7 instrumental and 7 integrative, whereas some of the reviewed studies involved a smaller number than that. The high instrumental motivation scores were mostly ascribed to the interest that the students had in taking advantage of learning English to accomplish practical benefits, such as getting a good job with a good salary and pursuing higher education. Based on this conclusion, the hypothesis of the present study was built, with the aim that similar results and parallel outcomes would be accordingly reached.

The participants were asked to pick one of the choices: agree, disagree and no idea. However, the sample and population of this study are primary students whose English levels are not enough to read and understand the whole of the original English questionnaire, so the researcher translated it into the Vietnamese language in order that the students can easily get the meaning by themselves (see Appendix B). The researcher also made a minor modification to Gardner $(1985 ; 2004)$ in order to make it more specific and be suitable for the context and the background of the participants in the study. For example, the researcher changed the statement "I wish I could read newspapers and magazines in many foreign languages" to "I wish I could read picture books in many foreign languages”.

\subsubsection{Class observation method}

Class observation plays a crucial role in aiming to identifying how well the teacher teaches. Teachers create a positive atmosphere for learning, to set up relevant activities in class, to give instructions and explanation, and to give feedback. In our study, the main purpose is to identify strengths and weaknesses of the teachers in order to improve their capacity in teaching. The observation is to "help narrow the gap between one's imagined view of teaching and what actually occurs in the classroom” (Richards \& Farrel 2005: 94).

Richards and Farrel (2005: 85) define peer observation as "a teacher or other observer closely watching and monitoring a language lesson or part of a lesson in order to gain an understanding of some aspect of teaching, learning or classroom interaction”. Peer observations can be beneficial for both the person being observed and the observer, if information is shared between the participants. The observer can provide helpful feedback to the teacher who was being observed. Therefore, consultation with the teacher was done before the lesson was made. In the pre-observation consultation, the researcher suggested which items she would like to have the observer focus on. However, according to Devos (2012), the peer-peer roles mean that the observation is not evaluative, meaning the observer should not 
be documenting the quality of the teaching, but rather objectively documenting what is happening in the classroom. As Zacharias (2012: 134) suggests, a general account where the observer writes down "whatever is going on when you are teaching". In this study, the observation process was done for each forty-five minutes lesson and recorded using handwritten notes. The study was conducted in two different classrooms with two different instructors. To avoid bias, the research asked for the support from another English teacher, who was not the instructor of the control group. The supporting teacher was allowed by the head of school. The instructor in the control group is called Teacher $\mathrm{C}$, and the researcher in the experimental group is called Teacher E; and the teacher who was appointed as an observer is called Teacher O.

Table 177. Classroom observation parameters for both classrooms:

\begin{tabular}{llllll}
\hline $\begin{array}{l}\text { Length of } \\
\text { Observation } \\
\text { Period }\end{array}$ & Group & Units & Observations/week & $\begin{array}{l}\text { Length of each } \\
\text { observation }\end{array}$ & $\begin{array}{l}\text { Total } \\
\text { time }\end{array}$ \\
\hline 4 weeks & C & 1 and 6 & Twice & 45 minutes & 6 hours \\
4 weeks & E & 1 and 6 & Twice & 45 minutes & 6 hours \\
\hline
\end{tabular}

During the observation, Teacher $\mathrm{O}$ focused on the following aspects/indicators:

- The activities and their effectiveness,

- The interactions of the students and teacher in the class,

- The procedures and materials the teacher used,

- The involvement of the students in the teaching and learning process,

- If speaking competence was shown by the students or not,

- The students' attitudes and motivation towards speaking and learning English in every lesson,

- Compare the speaking competence of each group to their performance in Unit 1 and Unit 6, and

- Compare their attitudes and motivation towards speaking and learning English in Unit 1 and Unit 6.

Table 18. General information about the teachers who were involved in the study:

\begin{tabular}{|c|c|c|c|}
\hline Name & Education Level & Experience in teaching & Duties \\
\hline Teacher C & Bachelor & 12 years & Group C's instructor \\
\hline Teacher E & Master & 6 years & Group E's instructor \\
\hline Teacher O & Bachelor & 15 years & Observser \\
\hline
\end{tabular}


The observation focused on some features as follows:

Table 19. Features of observation method

\begin{tabular}{|c|c|}
\hline Observation aspects & Note \\
\hline \multicolumn{2}{|l|}{ Lesson structure: } \\
\hline \multicolumn{2}{|l|}{ - The way the lesson opens } \\
\hline \multicolumn{2}{|l|}{ - The way the lesson develops } \\
\hline \multicolumn{2}{|l|}{ - The way the lesson ends } \\
\hline \multicolumn{2}{|l|}{ - The number of activities } \\
\hline \multicolumn{2}{|l|}{ - The links and transitions between activities } \\
\hline \multicolumn{2}{|l|}{ Classroom management strategies: } \\
\hline \multicolumn{2}{|l|}{ - Setting up groups } \\
\hline \multicolumn{2}{|l|}{ - Time management } \\
\hline \multicolumn{2}{|l|}{ Types of teaching activities: } \\
\hline \multicolumn{2}{|l|}{ - Teaching strategies } \\
\hline \multicolumn{2}{|l|}{ - Using of materials by the teacher } \\
\hline \multicolumn{2}{|l|}{ Teacher's use of the language: } \\
\hline \multicolumn{2}{|l|}{ - Use of instructional language } \\
\hline \multicolumn{2}{|l|}{ - Use of questions } \\
\hline \multicolumn{2}{|l|}{ - Feedback techniques } \\
\hline \multicolumn{2}{|l|}{ - Explanations of vocabulary and grammar } \\
\hline \multicolumn{2}{|l|}{ Student's use of language: } \\
\hline - Use of language in group work & \\
\hline
\end{tabular}




\begin{tabular}{|l|l|}
\hline - Use of mother tongue during class & \multicolumn{2}{|l|}{} \\
\hline - Problem with grammar & \\
\hline - Problem with pronunciation & \\
\hline Interaction of student in class: & \\
\hline - Time on task & \\
\hline - Questioning behaviors & \\
\hline - Student-to-student talking & \multicolumn{2}{|l|}{} \\
\hline Students' attitudes and motivation to learn, and speaking competence: \\
\hline - Students' attitudes & \\
\hline - Students' motivation & \\
\hline
\end{tabular}

\subsection{The research formula}

It is important to find out if the mean scores of the control and experimental groups are significantly different from each other. If there are significant differences after the implementation of the drama lesson plan, then the drama techniques have had a positive effect on the outcome.

The t-test assesses whether the means of the two groups are statistically different from each other before and after the normal curriculum or drama-based program. An independent samples t-test was employed to compare the means of a normally distributed dependent variable (i.e., speaking competence) for the two independent groups ${ }^{14}$ (i.e., the control and experimental groups). This analysis is especially appropriate for the post-test-only two-group randomized experimental design.The SPSS software package was used to analyze the data of this study.

\footnotetext{
${ }^{14}$ http://www.ats.ucla.edu/stat/mult_pkg/faq/general/citingats.htm
} 


\section{Chapter 9: Results and Discussion}

\subsection{Results}

The aim of this study was to develop the speaking competence of Vietnamese primary school students by using drama in EFL classes. Speaking competence was measured by knowledge and skills test and an attitudes and motivation questionnaire. The knowledge and skills test evaluated the students' overall speaking competence in terms of their grammatical competence, discourse competence, pragmatic competence, and fluency. The questionnaire evaluated the students' speaking competence in terms of their attitudes and motivation. The speaking competence at the beginning and after the four months of the study period was compared to see if there were any changes in the drama group compared to the control group.

\subsubsection{The control and experimental groups started at the same level of speaking competence}

The primary school students from the control and experimental groups started at relatively equal levels of speaking competence. As seen in Table E.1 and Figure 12, there was no significant difference in the speaking competence between the control and experimental groups at the beginning of the study. There were no statistically significant differences between the two groups, either in their overall speaking competence or in any of the speaking sub-competences.

However, even if there were no significant differences between the two groups, the speaking competence scores were equally low. The overall speaking competence score was $23.76 \pm$ 4.63 out of 50 (47.52\%) in the control group, and $24.00 \pm 4.23$ out of 50 (48.00\%) in the experimental group. The highest speaking sub-competence score was in grammatical competence, with a mean score of $7.41 \pm 1.33$ out of 15 (46.67\%) in the control group, and $7.71 \pm 0.85$ out of $15(51.40 \%)$ in the experimental group. On the other hand, the lowest speaking sub-competence score was in fluency, where the control group scored $1.82 \pm 0.73$ out of 5 (36.40\%) and the experimental group scored $1.94 \pm 0.83$ out of 5 (38.8\%). 


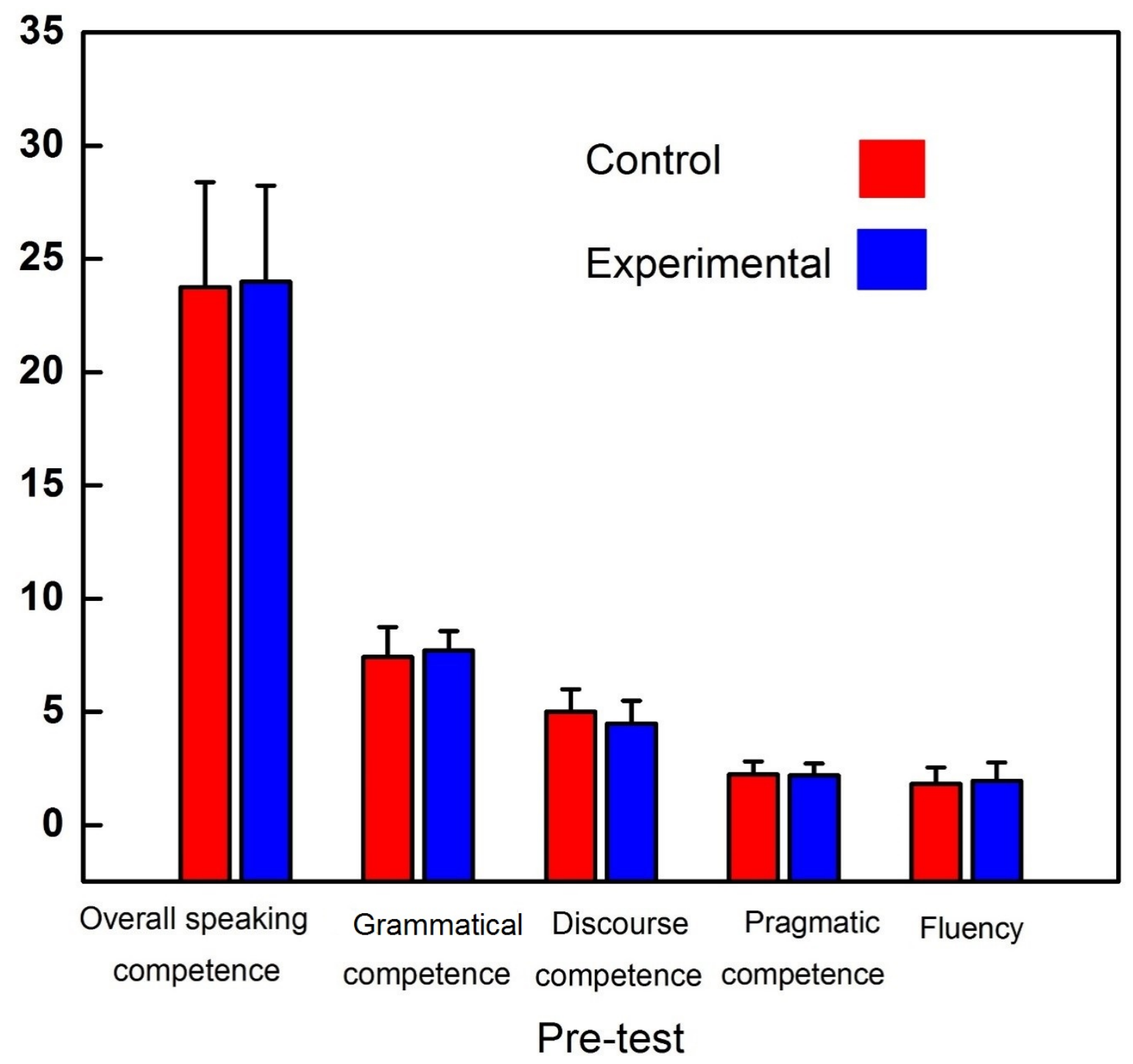

Figure 12. The mean pre-test scores and standard deviations of the overall speaking competences and sub-competences of the control and experimental groups.

Overall speaking competence is the total score of the three activities in terms of the four subcompetences.

Grammatical competence is the individual's ability to use grammar, vocabulary, and pronunciation properly in a speech (Riggenbach 1998). Most of the students in this study answered the task questions using incorrect grammar, with limited vocabulary and wrong pronunciation.

Grammar is the structure of the language, which entails how clauses, phrases, and words are formed (Huddleston and Geoffrey 2002). The primary school students made consistent grammatical mistakes in verb conjugation and articles usage. For example, when asked, "What is your name?” during the interview Student \#12 answered, “My name H” (Line 139). The answer is missing the word "is", the conjugated form verb of "to be", and hence is 
grammatically incorrect. In the "Talking about a Theme” task, some students used the article “a” incorrectly. Student number 24 said, “It is a apple” (instead of “an”) (Line 401), and Student number 25 said, “This flower” (missing “is a”) (Line 402). This test revealed that most of the students often made more grammatical mistakes while speaking than in writing because they did not really understand how the words, phrases or clauses are formed and had no chance of practicing speaking using correct grammar.

Vocabulary is the words in an individual's repertoire. The EFL students also forgot or misunderstood many words they have already learned in Grade 3. In “Talking about a theme”, 12 out of 34 of the students (35.29\%) were unable to answer questions about numbers, seasons, countries and colors (Student numbers 1, 3, 6, 9 and 10 (control); 8, 22, 26, 27, 29 and 34 (experimental)). This result showed that most students did not have or use a relevant and appropriate range of words.

Pronunciation is the sounds, intonation, and rhythm of a language (Morely 1996, Florez 1998, Cornbleet and Carter 2001). The students often mispronounced English words. For example, Student number 4 pronounced the word, "worker" [/'w3:kə(r)/], as /w3:k (r)/; Student number 5 pronounced the word, “pupil” [/pju:pl/], as /pi'p/; Student \#13 said “three orange” instead of "three oranges". Almost all of the students pronounced "year" [/jiə(r)/] as /yet/, and forgot to pronounce the ending sound /s/, /z/ and /iz/ at the end of nouns. Pronunciation was seen as one of the most difficult aspects of speaking correctly for every student.

Discourse competence is the individual's ability to keep the conversation coherent, even after a digression (Van Dijk 1981). The primary school students frequently had trouble keeping the conversation going; they only passively answered the questions (Student numbers 1, 6, 7, 10, 12,14, 25 and 32) or saying nothing at all after the questions have been answered by their partner (Student numbers 1, 2, and 11 (control); 32 and 33 (experimental)). For example, when Student number 23 was asked, “Do you like to play tennis?”, the student answered, "Yes, it is", instead of “Yes, I do" (Line 350). Similarly, Student number 29 answered "His name is Huong” for the question, "What is your mother's name?" It was confirmed that the students did not recognize the key discourse markers nor did they fully understand what their partners said. Then in their turn, they had difficulty in managing the conversation and taking turns to speak.

Pragmatic competence is the individual's ability to speak in the appropriate social and cultural context (Cornbleet and Carter 2001, Pohl 2004). The mean scores of pragmatic competence in both groups were very low: $2.24 \pm 0.56$ in control and $2.18 \pm 0.53$ in experimental. Almost all of the students performed poorly on the test. When they did not understand nor remember 
what to say, they chose to be silent (Student numbers 6 and 7 (control); 20 and 21 (experimental). For example, the conversation of Pair number 10 of the experimental group in the "Making a conversation" activity was as follows:

Student A: Is your school new or old?

Student B: It's old.

Student A: Do you like your school?

Student B: Yes. I do

Student A: Are you friendly?

Student B: Yes. They are.

It appears that the last sentence does not fit the two previous sentences, and the response from Student B to the question, “Are you friendly?” is wrong. It is easy to see that the students often lacked the competence in selecting the words that were suitable for the context, and thus they were unclear or said inappropriate words to their partners.

Fluency is the individual's ability to speak spontaneously or without interruptions. In terms of fluency, 7 of the 34 students (20.58\%) (Student numbers 1, 8, 16 and 17 (control); 20, 28 and 29 (experimental) were described as "answer[ing] and [speaking] quite clear and confident”. Eight of the 34 students (79.41\%) could not speak spontaneously, saying filler words like “uhm”, “ah” or “emm” with long pauses (Student numbers 1, 6, 7, 10, 12, 14, 25, and 32). The rest of the students could ask questions or give answers, but they were very slow. Some students were slow to start, answer and ask questions (Student numbers 1, 6, 7, 10, 11, and 12). This result revealed that the students were often slow in speaking, with pauses and hesitations that made the conversation ineffective with their partners.

A comparison of the overall speaking competence and the speaking sub-competences affirmed that both groups were at the same level of speaking competence at the start of the study.

\subsubsection{There was a significant increase in the experimental group's speaking competence, compared to the control group, after implementing drama techniques into the lesson plan}

There was a significant increase in the speaking competences in the experimental group and not in the control group after implementing the drama-based program (see Figure 13 and Table E.2.). There was a statistically significant increase in the experimental group's overall 
speaking performances and in all four speaking sub-competences (grammatical competence, discourse competence, pragmatic competence, and fluency) when compared to the control group.

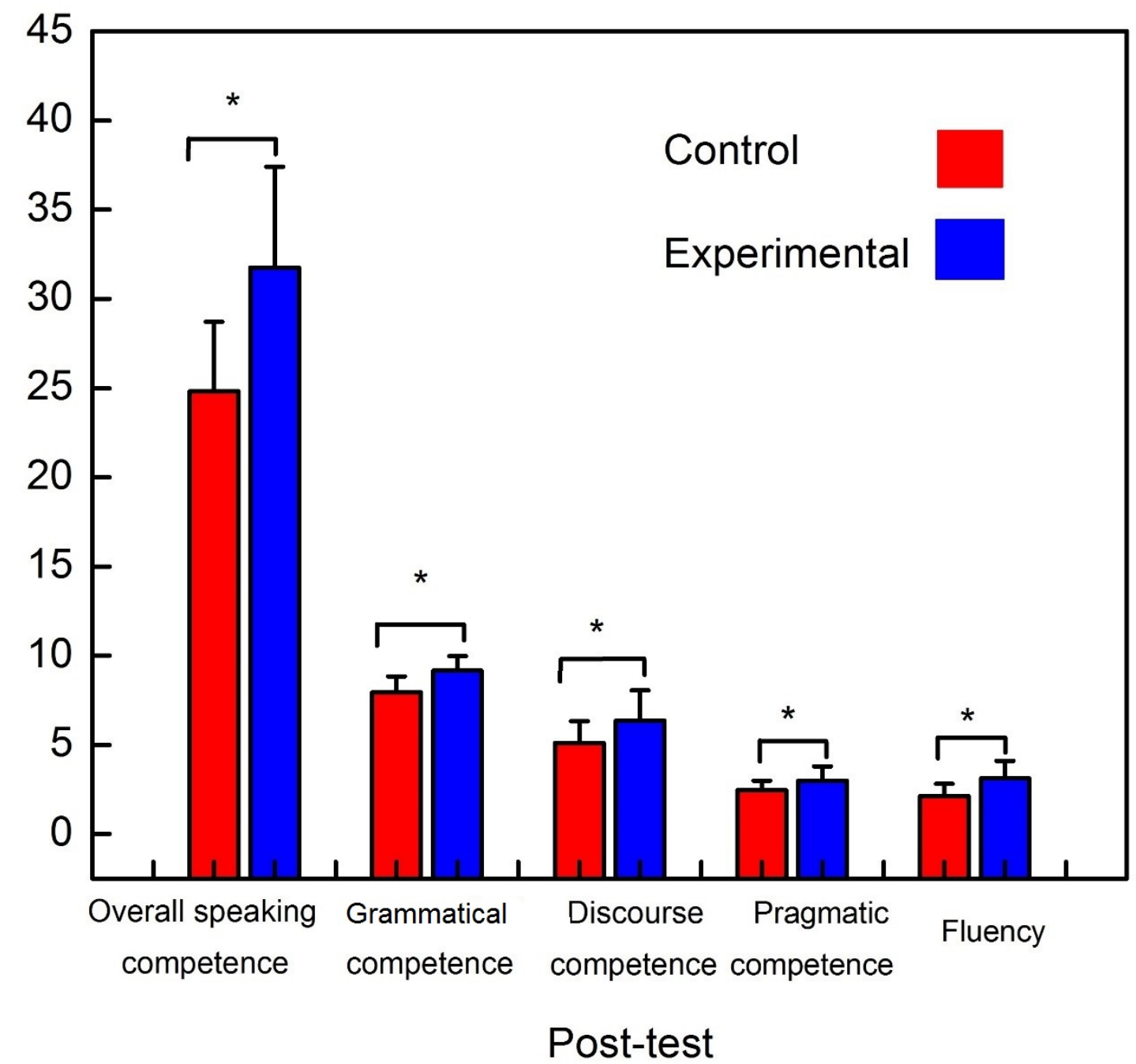

Figure 13. The mean post-test scores and standard deviations of the control group and experimental group in overall speaking performance and speaking sub-competences. An asterisk $(*)$ denotes a significant difference at $\mathrm{p}<0.05$. There are statistically significant results in the overall speaking competence $(\mathrm{p}<0.01)$, grammatical competence $(\mathrm{p}<0.01)$, discourse competence $(p<0.05)$, pragmatic competence $(p<0.05)$ and fluency $(p<0.01)$. 


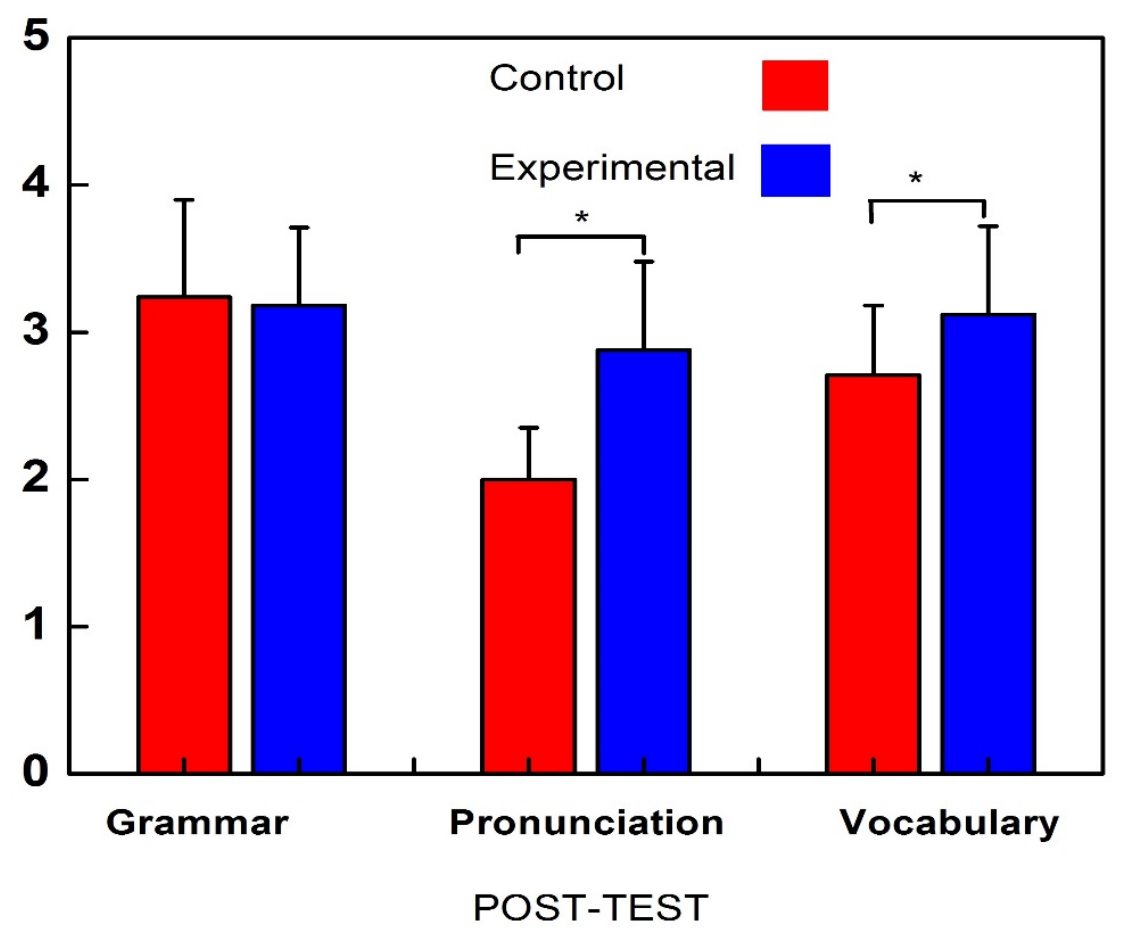

Figure 14. The mean post-test scores and standard deviations of the control group and experimental group in the grammatical sub-competences of grammar, pronunciation and vocabulary.

Asterisk $(*)$ denotes a significant difference at $\mathrm{p}<0.05$. There was a statistically significant result in pronunciation $(\mathrm{p}<0.01)$ and vocabulary $(\mathrm{p}<0.05)$.

The mean post-test score in overall speaking competence was $24.82 \pm 3.91$ out of 50 (49.64\%) in the control group, and $31.76 \pm 5.65$ out of 50 (63.52\%) in the experimental group (see Table E.2). The difference in mean scores between the control and experimental groups was statistically significant $(\mathrm{p}<0.01)$.

The mean post-test score in grammatical competence was $7.94 \pm 0.90$ out of 15 (52.90\%) in the control group, and $9.18 \pm 0.81$ out of 15 (61.20\%) in the experimental group. The difference in the mean scores between the control and experimental groups was statistically significant $(\mathrm{p}<0.01)$ During the post-tests, almost all of the students from both groups showed improvements in using the present tense, articles, and prepositions. For example, 4 students who forgot to use the verb "to be" in the pre-test remembered to use it in the post-test (Student numbers 1, 3, 17, and 18). Then, there was no significant difference in grammar between the control and experimental groups, which were $3.24 \pm 0.66$ and $3.18 \pm 0.53$ with $\mathrm{p}$ $=0.731$. However, there were statistically significant differences in pronunciation (mean $=$ $2.00 \pm 0.35$ and $2.88 \pm 0.6, \mathrm{p}<0.01$ ) and vocabulary (mean $=2.71 \pm 0.47$ and $3.12 \pm 0.6, \mathrm{p}<$ 0.05 ) between the two groups. 
The mean post-test score in discourse competence was $5.12 \pm 1.22$ out of 10 (51.20\%) in the control group, and $6.35 \pm 1.69$ out of 10 (63.50\%) in the experimental group. There was not a statistically significant difference $(\mathrm{p}=0.12)$. Students in both groups were remarked on as having "answered [questions with] correct grammar [and] with better pronunciation and more vocabulary” (Student numbers 1, 3, 10, 11, 12, 13, 14, 15, 18, 19, 22, 23, 26, 27, 28, 30 and 34). For example, almost all of the students answered the interview questions correctly with “to be” verbs, present tense, and articles: "What is your name? "How old are you?”, "How many people are in your family?”, “What is your mother's job?” etc. The students also correctly pronounced the words where they made mistakes in the last test: years, mother, worker, three, etc. The students also answered the questions with new vocabulary on colors, numbers, career, and schools. The students in the experimental group, compared to the control group, showed improvements in their discourse (coherency and cohesiveness) and conversational skills.

The mean post-test score in pragmatic competence was $2.47 \pm 0.51$ out of 5 (49.4\%) in the control group, and $3.00 \pm 0.79$ out of $5(60.00 \%)$ in the experimental group. There was a statistically significant difference of $p<0.05$.

The mean post-test score in fluency was $2.12 \pm 0.70$ out of 5 (42.4\%) in the control group, and $3.12 \pm 0.99$ out of $5(62.4 \%)$ in the experimental group. There was a statistically significant difference of $\mathrm{p}<0.01$. Many of the students in the experimental group spoke more fluently in the "Making a Conversation" task than in the control group. The experimental group's students spoke with fewer pauses and expressed sentences logically and correctly, while the control group's students spoke with more pauses, repeated sentences, and the sentences were difficult to understand. For example, in Pair number 3 of the control group (Line 915 - 919), Student number 6 asked an incomplete sentence about "How many people are there in your family", so Student number 7 was unable to understand and answer. In Pair number 10 of the experimental group (Line 1673-1687), Student numbers 20 and 21 were able to converse fluently and logically about the weather in Vietnam, features of the four seasons, and seasonal activities. The students in the experimental group could express themselves fluently, with less hesitation, while the students in the control group had pauses and silences in their conversations.

The results showed that the proposed drama-based program impacted on the experimental group's speaking performances in the post-test when compared to the control group, who only received regular instruction. 


\subsubsection{There was no significant improvement in the speaking competence of the control} group after 4 months of regular instruction, with the exception of grammar in the grammatical competence

The control group, who received 4 months of regular instruction, showed no improvement in their pre-test and post-test scores in all areas, with the exception of the grammatical competence’s grammar component (see Figure 15 and Table E.3.).

The mean pre-test score in the grammar of the grammatical competence was 2.47 and the mean post-test score was 3.23 (see Figure 16). There was a statistically significant difference of $\mathrm{p}<0.01$. The mean pre-test score in the grammatical sub-competence was 7.41 and the mean post-test score was 7.94 . There was no statistically significant difference at the $5 \%$ level. Even though the students were slow in speaking, their grammar was used correctly (e.g., Pair numbers 2, 3, 5, and 6).

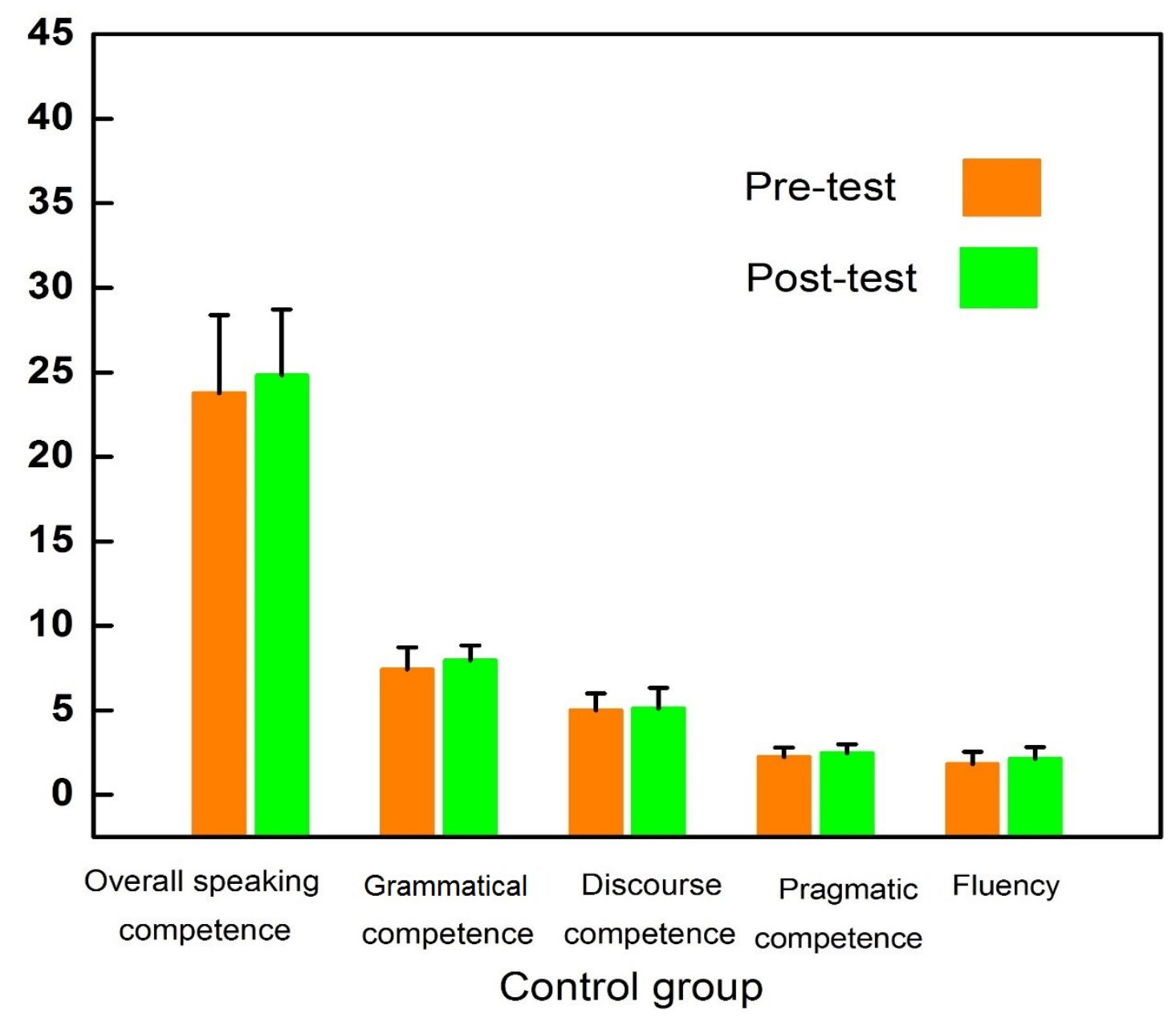

Figure 15. The mean scores and standard deviations of the control group comparing the pretest and post-test results for overall speaking and speaking sub-competences.

Asterisk $(*)$ denotes a significant difference at $\mathrm{p}<0.05$. 


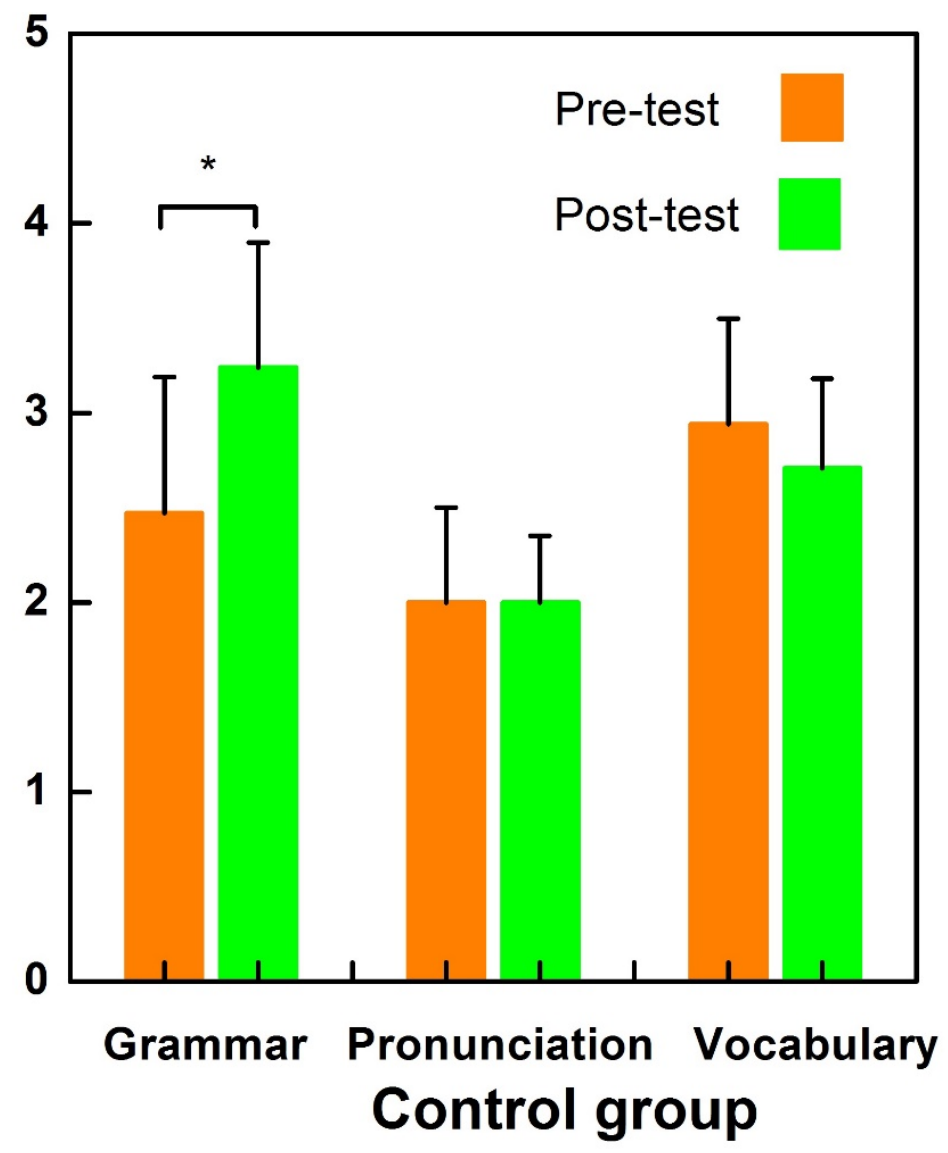

Figure 16. The mean scores and standard deviations of the control group in the pre-tests and post-tests in the grammatical sub-competences.

An asterisk $(*)$ denotes a significant difference at $\mathrm{p}<0.05$. There is a statistically significant result in grammar $(\mathrm{p}<0.01)$.

There was a trend of improvement in fluency in the control group's post-test scores compared to the pre-test scores, $2.12 \pm 0.70$ out of 5 (42.4\%) and $1.82 \pm 0.73$ out of 5 (36.4\%), respectively. However, the students were frequently pausing, and they made sentences sound unstructured. For example, when asked, “Do you like playing football?” Student number 11 repeated the question without answering (Line 119).

According to above-mentioned results, it is correct to say that the regular instruction (i.e., the traditional approach) had almost no effect on the speaking competence, except for the grammar.

\subsubsection{There were significant improvements in the speaking competence in the experimental group after using drama techniques}

As seen in Figure 17 and Table E.4, there were statistically significant increases in the overall speaking competence and in all four speaking sub-competences. The p-values were are less 
than 0.05 with $95 \%$ confidence interval, which indicated truly large significance differences in the pre-test and post-test scores.

The mean pre-test and post-test scores in the grammatical competence were $7.71 \pm 0.85$ and $9.18 \pm 0.81$. There was a statistically significant difference of $\mathrm{p}<0.01$. In other words, the grammatical competence of the experimental group improved after the treatment. The mean pre-test and post-test scores in the discourse competence were $4.47 \pm 1.01$ and $6.35 \pm 1.69$. There was a statistically significant difference of $p<0.01$. The experimental group's discourse competence improved after 4 months of the drama lesson plan.

The experimental group showed an improvement in the pragmatic competence after the treatment. The mean pre-test and post-test scores in the pragmatic competence were $2.18 \pm$ 0.53 and $3.00 \pm 0.79$. There was a statistically significant difference of $p<0.01$. The experimental group's fluency was significantly better after the 4 months of the drama lesson plan. The mean pre-test and post-test scores in fluency were $1.94 \pm 0.83$ and $3.12 \pm 0.99$. There was a statistically significant difference of $\mathrm{p}<0.01$.

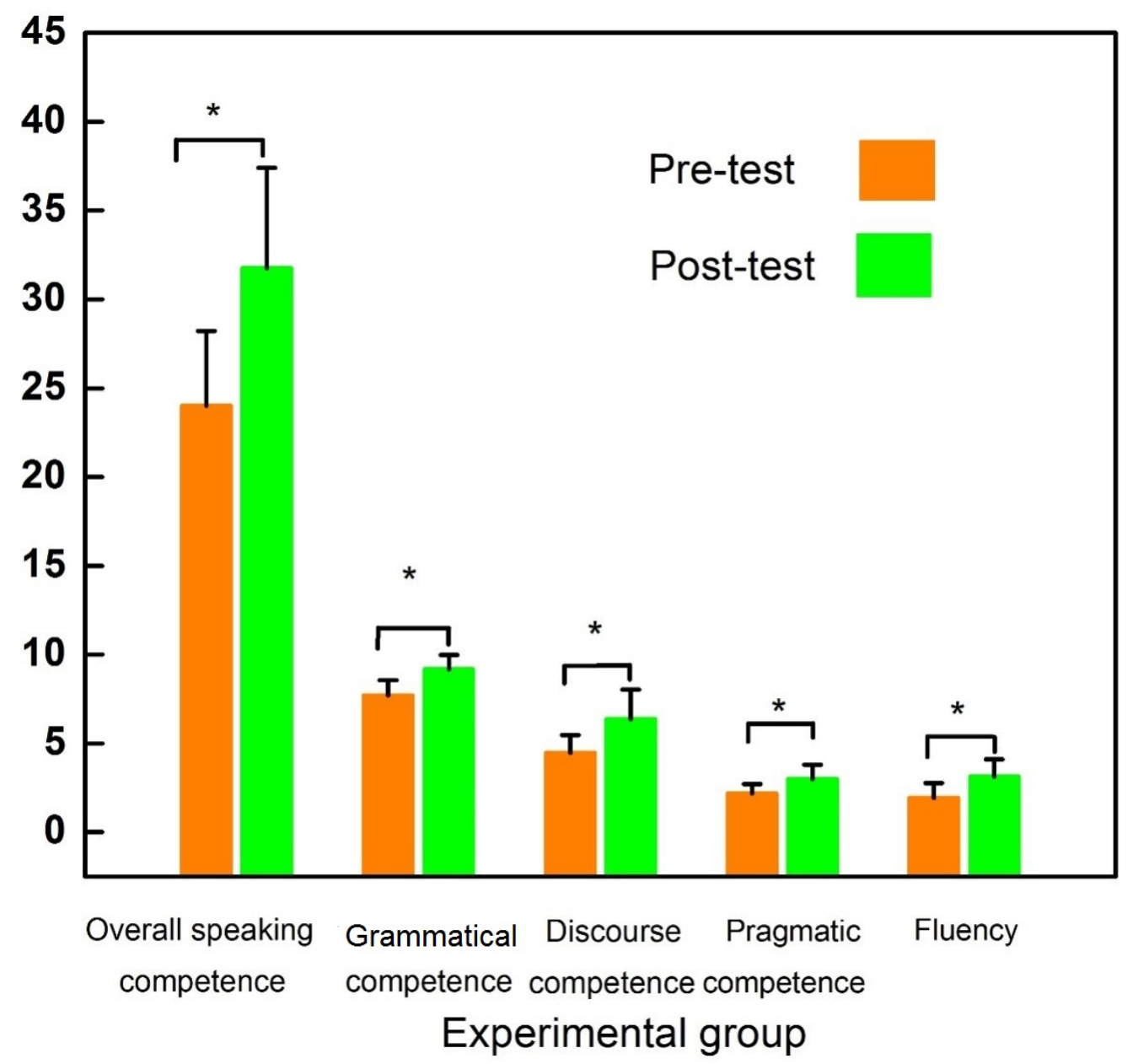

Figure 17. The mean scores and standard deviations of the experimental group in the pre-tests and post-tests in their overall speaking performance and speaking sub-competences. 
An asterisk $\left(^{*}\right)$ denotes a significant difference at $\mathrm{p}<0.05$. There were statistically significant results in the overall speaking competence $(p<0.01)$, grammatical competence $(p<0.01)$, discourse competence ( $\mathrm{p}<0.01)$, pragmatic competence $(\mathrm{p}<0.01)$ and fluency $(\mathrm{p}<0.01)$.

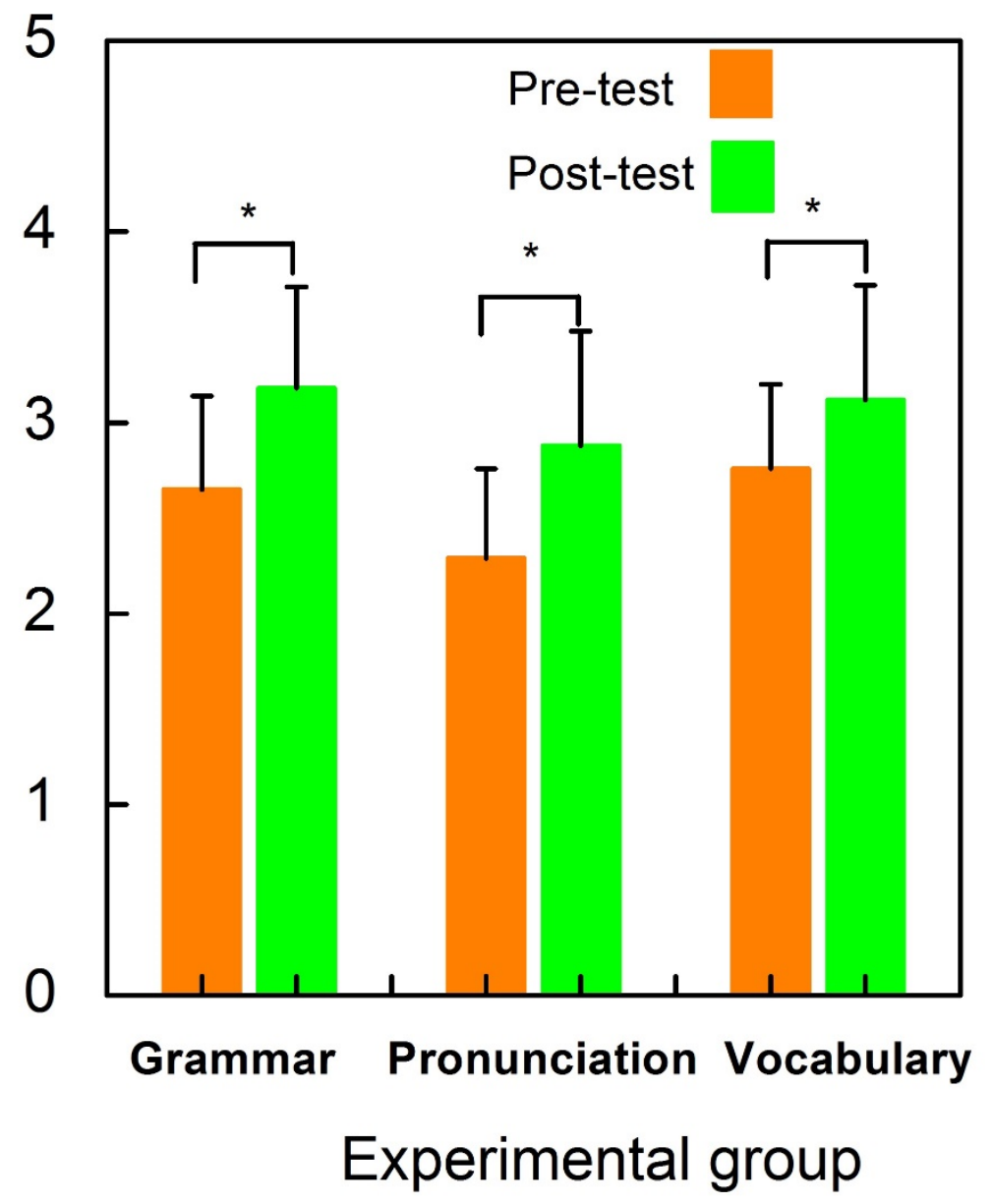

Figure 18. The mean scores and standard deviations of the experimental group in the pre-tests and post-tests in the grammatical sub-competences.

An asterisk $(*)$ denotes a significant difference at $\mathrm{p}<0.05$. There were statistically significant results in grammar ( $\mathrm{p}<0.01)$, pronunciation $(\mathrm{p}<0.01)$ and vocabulary $(\mathrm{p}<0.05)$.

\subsubsection{The control and experimental groups started with similar attitudes and motivation} levels

To investigate the control and experimental groups' attitudes and motivation towards learning English, a twelve-item questionnaire was administered before and after the implementation of the proposed lesson plan. The experimental group received the drama -based program (i.e., treatment), while the control group received regular instruction (i.e., without treatment). The students could choose either "Agree”, "Disagree”, or "Have no idea” about the Items in the 
questions. The percentages of the responses in each category are displayed in Table 14. The more agreeable the statement, the more positive are their attitudes and motivation, and vice versa.

To compare the development of the attitudes and motivation of both groups after the treatment stage, paired-sample tests were performed on all twelve items, either as control versus experimental or pre-treatment versus post-treatment for each group. The results are shown in Table 15, with a 95\% confidence level.

As seen in Table 15, the control and experimental groups had similar levels of attitudes and motivation prior to the treatment. There was no significant difference in any of the twelve items. All twelve items in the questionnaire got under $50 \%$ of the positive responses.

\subsubsection{There were statistically significant improvements in the attitudes and motivation in the experimental group after the treatment}

The students in the experimental group found more of the items in the questionnaire agreeable after the treatment. There were statistically significant differences in 10 of the 12 items (83.33\%), except for Item number 2 ("Parental encouragement”) and Item number 7 (“Attitudes towards English speaking people”). As mentioned above, the more agreeable the statements, the more positive were their attitudes and motivation. The reasons for these changes are discussed in the discussion section.

In Item Number 12 (“Instrumental orientation”), the positive response changed from 34 out of 68 responses (50\%) before the treatment to 56 out of 34 responses (82.35\%) after the treatment $(p<0.01)$. In Statement number 15 of Item number 12 ("Studying English is important because I will need it in the future”), only 8 out of 17 students (47.05\%) agree before the treatment and 15 out of 17 students (88.23\%) agree after the treatment.

However, the greatest changes occurred in Item Number 5, 6 and 9. In Item number 5 ("English teacher evaluation”), 80 out of 170 responses (47.06\%) rated the statement as true before the treatment, but 159 out of 170 responses (93.95\%) gave a positive response after the treatment $(\mathrm{p}<0.01)$. Of note, three statements in this item received $100 \%$ agreement from the experimental group students. These statements were:

Statement number 46: "My English teacher has a dynamic and interesting teaching style"; Statement number 78: "I would not prefer to have a different English teacher"; and

Statement number 89: "I really like my English teacher”. 
In Item Number 6 (“Attitudes toward learning English”), 84 out of 170 responses (49.41\%) rated the statement as true before the treatment, but 156 out of 170 responses (91.76\%) gave a positive response after the treatment $(\mathrm{p}<0.01)$.Meanwhile, in Item Number 9 ("Desire to learn English”), 84 out of 170 response (49.41\%) rated the statement as true before the treatment, but 149 out of 170 responses (87.75\%) gave a positive response after the treatment $(\mathrm{p}<0.01)$.

Significant changes in the attitudes and motivation only occurred after the study period in the experimental group and not in the control group. This suggests the effectiveness of the drama lesson plan in developing the motivation and attitudes of students towards English language learning in general.

\subsubsection{Similarly, the attitudes and motivation of the experimental group were statistically different from the control group post-treatment}

Since the experimental group showed an increase in attitudes and motivation after the treatment, while the control group remained unchanged, there were statistically significant differences between the control and experimental groups in all items. The only exception was Item Number 2 ("Parental encouragement”), which was almost the same (control: 41.91\% versus experimental: $46.32 \%$ positive response).

In conclusion, the significant changes in the motivation and attitudes of the experimental group after having the treatment confirmed that a drama-based program can develop the speaking competence in English. 
Table 20. The percentages for each Item in the Attitudes and Motivation test.

\begin{tabular}{|c|c|c|c|c|c|c|c|c|c|c|c|c|}
\hline \multirow{3}{*}{ Items } & \multicolumn{6}{|c|}{ Control group } & \multicolumn{6}{|c|}{ Experimental group } \\
\hline & \multicolumn{3}{|c|}{ Pre-intervention (\%) } & \multicolumn{3}{|c|}{ Post-intervention (\%) } & \multicolumn{3}{|c|}{ Pre-intervention (\%) } & \multicolumn{3}{|c|}{ Post-intervention (\%) } \\
\hline & Agree & Disagree & No idea & Agree & Disagree & No idea & Agree & Disagree & No idea & Agree & Disagree & No idea \\
\hline $\begin{array}{l}\text { 1. Interest in } \\
\text { Foreign } \\
\text { languages }\end{array}$ & 50 & 50 & 0 & 57.65 & 42.35 & 0 & 48.82 & 51.18 & 0 & 82.35 & 12.94 & 0 \\
\hline \begin{tabular}{|l|} 
2. Parental \\
Encouragement
\end{tabular} & 41.91 & 58.09 & 0 & 41.91 & 58.09 & 0 & 42.65 & 57.35 & 0 & 46.32 & 53.68 & 0 \\
\hline $\begin{array}{l}\text { 3. Motivational } \\
\text { intensity }\end{array}$ & 42.35 & 57.65 & 0 & 42.35 & 57.65 & 0 & 41.76 & 58.24 & 0 & 74.12 & 25.88 & 0 \\
\hline \begin{tabular}{|l|} 
4. English class \\
anxiety
\end{tabular} & 45.29 & 54.71 & 0 & 48.24 & 51.76 & 0 & 43.53 & 56.47 & 0 & 74.71 & 25.29 & 0 \\
\hline $\begin{array}{l}\text { 5. English } \\
\text { teacher } \\
\text { evaluation } \\
\end{array}$ & 47.06 & 50 & 0 & 50 & 50 & 0 & 47.06 & 52.94 & 0 & 93.53 & 6.47 & 0 \\
\hline \begin{tabular}{|l|} 
6. Attitudes \\
towards \\
leaming \\
English \\
\end{tabular} & 48.82 & 51.18 & 0 & 52.94 & 47.06 & 0 & 49.41 & 50.59 & 0 & 91.76 & 8.24 & 0 \\
\hline \begin{tabular}{|l} 
7.Attitudes \\
towards \\
English- \\
speaking \\
people
\end{tabular} & 28.68 & 33.82 & 37.5 & 32.35 & 30.15 & 37.5 & 29.41 & 36.03 & 34.56 & 51.47 & 13.97 & 34.56 \\
\hline $\begin{array}{l}\text { 8. Integrative } \\
\text { orientation }\end{array}$ & 39.71 & 60.29 & 0 & 52.94 & 47.06 & 0 & 36.76 & 63.24 & 0 & 89.71 & 10.29 & 0 \\
\hline $\begin{array}{l}\text { 9. Desire to } \\
\text { leam English }\end{array}$ & 48.82 & 51.18 & 0 & 50 & 50 & 0 & 49.41 & 50.59 & 0 & 87.65 & 12.35 & 0 \\
\hline $\begin{array}{l}\text { 10. English } \\
\text { course } \\
\text { evaluation } \\
\end{array}$ & 36.47 & 63.53 & 0 & 39.41 & 60.59 & 0 & 38.24 & 61.76 & 0 & 85.88 & 14.12 & 0 \\
\hline $\begin{array}{l}\text { 11. English use } \\
\text { anxiety }\end{array}$ & 27.06 & 72.94 & 0 & 27.65 & 72.35 & 0 & 26.47 & 73.53 & 0 & 64.71 & 35.29 & 0 \\
\hline $\begin{array}{l}12 . \\
\text { Instrumental } \\
\text { orientation }\end{array}$ & 51.52 & 48.48 & 0 & 63.24 & 36.76 & 0 & 50 & 50 & 0 & 82.35 & 17.65 & 0 \\
\hline
\end{tabular}


Table 21 . T-tests for the Attitudes and Motivation Items, comparing the control and experimental groups pre- and post-intervention (i.e. lesson plan)

\begin{tabular}{|c|c|c|c|c|}
\hline \multirow{3}{*}{ Item Number } & \multicolumn{4}{|c|}{$\underline{\text { P-values }}$} \\
\hline & \multicolumn{2}{|c|}{ Control vs. Experimental } & \multicolumn{2}{|c|}{ Pre-intervention vs. Post-intervention } \\
\hline & Pre-intervention & Post-intervention & Control & Experimental \\
\hline 1 & 0.804 & $<0.001^{*}$ & 0.19 & $<0.001^{*}$ \\
\hline 2 & 0.928 & 0.6 & 1 & 0.600 \\
\hline 3 & 0.933 & $<0.001^{*}$ & 1 & $0.002 *$ \\
\hline 4 & 0.778 & $<0.001^{*}$ & 0.637 & $<0.001 *$ \\
\hline 5 & 1.000 & $<0.001^{*}$ & 0.496 & $<0.001 *$ \\
\hline 6 & 0.935 & $<0.001^{*}$ & 0.589 & $<0.001 *$ \\
\hline 7 & N/A & N/A & N/A & N/A \\
\hline 8 & 0.367 & $0.002 *$ & 0.122 & $0.004^{4} *$ \\
\hline 9 & 0.950 & $<0.001 *$ & 0.9 & $0.002 *$ \\
\hline 10 & 0.658 & $<0.001 *$ & 0.461 & $<0.001^{*}$ \\
\hline 11 & 0.845 & $<0.001 *$ & 0.85 & $<0.001 *$ \\
\hline 12 & 1.000 & $0.03 *$ & 0.281 & $0.001 *$ \\
\hline
\end{tabular}

Asterisk (*) denotes a significant difference at $\mathrm{p}<0.05$ and N/A means not applicable.

The advantages of a performance on stage are that it involves the whole group, incorporates movement and carefully planned language usage to create the best speaking practice for real life. By watching the episode and reading the scripts during the pre-performance, the students learn the grammar rules and discourse markers, imitate correct pronunciation, memorize new words about numbers and games, and learn how to make coherent and meaningful sentences. During the performance, the students have the opportunity to act and exhibit what they have prepared. Therefore, they were excited and motivated. The applause from the audience is also another extrinsic motivation factor. After the performance, the students evaluated themselves and realized what their strong and weak points were. If they did well in the performance, they will be motivated for the next performance. If not, they will draw from the experience of this lesson to make the next performance even better. 


\subsubsection{The results of class observation supported the results of the speaking competence tests before and after the intervention of drama activities.}

From the observation notes collected from Teacher $\mathrm{O}$, it is clear which class used the traditional methods and which class used CLT.

Teacher O said, "Teacher E was moving away from traditional practices in terms of placing less emphasis on grammar, and both her students and herself were using more English. Meanwhile, Teacher $\mathrm{C}$ used repetition and emphasized a traditional view of error correction.”

In the class of Teacher E, students participated in different activities every lesson. Their classroom practices were more interactive and focused on speaking and communication among students and between students and teacher. For example Teacher E used more pair work and group work, songs, rhyme, recitation, drama games, role plays, simulation activities, learning through certain situations, body language/gestures to aid the students' understanding, and more attentiveness and positivity to the students.

As the result students who were taught in the communicative way have more motivation to learn, use, and practice English. As observerer, it is clearly to see that the atmosphere in the communicative class is very relaxing and exciting. The learners are more willingness to show their interest and to working in groups. To better understanding the method the comparisonbetween two classes was made from observation notes, as follow:

There are some crucial difference between the two classes in term of lesson structure, classroom management stratregies, teacher's use of language, student's use of language, interaction of student in class, as well as the attitudes and motivation of student.

Table 22: Comparision of observation notes between the traditional method and the communicative method

\begin{tabular}{|l|l|l|}
\hline \multicolumn{2}{|c|}{ Observation aspects } & \multicolumn{2}{l|}{ Traditional method } & Communicative method \\
\hline Lesson structure: & $\begin{array}{l}\text { Remember new words; } \\
\text { examination in short }\end{array}$ & Review previous lessons \\
\hline - The way the lesson opens & As curriculum & $\begin{array}{l}\text { As curriculum; more } \\
\text { interaction between } \\
\text { learners }\end{array}$ \\
\hline - The way the lesson develops & $\begin{array}{l}\text { Review last lesson; give } \\
\text { homework }\end{array}$ & $\begin{array}{l}\text { Review last lesson; take } \\
\text { home messages }\end{array}$ \\
\hline - The way the lesson ends & $\begin{array}{l}\text { Reading some text; task } \\
\text { discussion in group }\end{array}$ & $\begin{array}{l}\text { Drama; singing; acting; } \\
\text { discussion in a target } \\
\text { group }\end{array}$ \\
\hline - The number of activities &
\end{tabular}




\begin{tabular}{|c|c|c|}
\hline $\begin{array}{l}\text { - The links and transitions between } \\
\text { activities }\end{array}$ & No & Yes \\
\hline \multicolumn{3}{|l|}{ Classroom management strategies } \\
\hline - Setting up groups & General/whole group & Small group \\
\hline - Time management & As curriculum & As curriculum \\
\hline - Types of teaching activities & $\begin{array}{l}\text { Whole-class activities; } \\
\text { individual activities }\end{array}$ & Pair and group activities \\
\hline - Teaching strategies & Presenting tasks & $\begin{array}{l}\text { Teaching technique and } \\
\text { organizing practice; task- } \\
\text { relevant }\end{array}$ \\
\hline - Using of materials of teachers & Mainly rely on textbook & Using other resources \\
\hline \multicolumn{3}{|l|}{ Teacher's use of language } \\
\hline - Use of instructional language & $\begin{array}{l}\text { Mother tongue mainly } \\
\text { to explain }\end{array}$ & $\begin{array}{l}\text { Use more English to } \\
\text { explain }\end{array}$ \\
\hline - Use of questions & Yes/no questions & Open-ended questions \\
\hline - Feedback techniques & For the whole group & Individual feedbacks \\
\hline $\begin{array}{l}\text { - Explanations of vocabulary and } \\
\text { grammar }\end{array}$ & Clear & Clear \\
\hline \multicolumn{3}{|l|}{ Student's use of language } \\
\hline - Use of language in group work & $\begin{array}{l}\text { Group silence; speaking } \\
\text { permission as given } \\
\text { teacher }\end{array}$ & $\begin{array}{l}\text { Frequent; students use } \\
\text { foreign language to } \\
\text { explain situation }\end{array}$ \\
\hline - Use of mother tongue during class & More often & Less often \\
\hline - Problem with grammar & No & No \\
\hline - Problem with pronunciation & Yes & No \\
\hline \multicolumn{3}{|l|}{ Interaction of student in class } \\
\hline - Time on task & Short time & $\begin{array}{l}\text { Depends on student } \\
\text { activities in class }\end{array}$ \\
\hline - Questioning behaviors & $\begin{array}{l}\text { Few questions with } \\
\text { students }\end{array}$ & $\begin{array}{l}\text { More questions and } \\
\text { explanation }\end{array}$ \\
\hline - Student-to-student talk & Less often & More often \\
\hline
\end{tabular}


Students' attitudes and motivation to learn, and speaking competence

\begin{tabular}{|l|l|l|}
\hline - Students' attitudes & $\begin{array}{l}\text { They look stressed and } \\
\text { afraid of being called } \\
\text { by the teacher }\end{array}$ & $\begin{array}{l}\text { They are eager to join in } \\
\text { every activity that was } \\
\text { introduced by teacher }\end{array}$ \\
\hline - Students' motivation & $\begin{array}{l}\text { They almost didn't } \\
\text { have so much } \\
\text { motivation. They are } \\
\text { learning English, } \\
\text { because English is } \\
\text { compulsory at school. }\end{array}$ & $\begin{array}{l}\text { Their motivation was so } \\
\text { strong that they wanted to } \\
\text { learn every time the bell } \\
\text { rang at the end of the } \\
\text { lesson. }\end{array}$ \\
\hline
\end{tabular}

Source : Authors’ illustration

\subsection{Discussion}

The results from this study confirm the difference between the two methods of teaching English as a foreign language. The implementation of the CLT approach through drama activities primarily displayed a positive effect on the primary school students' speaking competence. The drama activities used in a drama-based program as a method of teaching EFL is effective in developing the speaking competence of primary school students. In the study, a drama-activities-infused program was administered to a class of 17 grade 4 students for four months. This was the experimental group. For comparison, another class of 17 students received regular grade 4 EFL instructions for the same amount of time.

At the end of the study period, the mean scores in all areas (speaking competence, speaking sub-competences, grammatical sub-competence, and attitudes and motivation) were compared by paired-samples t-tests. The results were analyzed in four ways: 1) the control and experimental groups' scores before the treatment; 2) control and experimental groups' scores after the treatment; 3) control group's scores before and after the study period, and 4) the experimental group's scores before and after the treatment.

The results showed improvements in the speaking competence and attitudes and motivation towards English in the experimental group and not in the control group. Since the control and experimental groups started with relatively equal levels of speaking competence and attitudes and motivations towards English, then the changes in the experimental group can be attributed to the drama-based program. This finding suggests that drama-based programs can develop the speaking competence of primary school students in Vietnam. The next section focuses on discussing the processes behind the results of the study. 


\subsubsection{The control and experimental groups started at the same level of speaking competence}

The result of the pre-tests revealed that the students were at a very low level of speaking competence. This finding revealed some reasons which have been mentioned in many previous studies and articles, such as in Denham (1992), Canh and Bernard (2009), Canh (2002), etc. Firstly, it is because the curriculum is exam-driven, which means that it is focused on a written test, but not on a speaking test. The students were even nervous and surprised during the test. Secondly, the traditional teaching approach is applied in almost all EFL classrooms, albeit the textbook recommends following the communicative approach. Thirdly, the students were taught by following the structure of the textbook. The teacher tried to finish all the items in the textbook and, therefore, had no time to see whether or not it was effective in developing any competences. Fourthly, the authentic situations were not explored in a normal EFL lesson. The simple materials in the textbook were introduced to the students, but sometimes there was no time left for the students to do the task by themselves because the teacher spent the majority of the time lecturing. Thus, the students just kept silent, listened, took notes, did the exercises and tried their best to get a high score on the written test. Through observation, it is easy to see that the communicative approach has nothing to do with them. To them, speaking was really not important. They could speak virtually nothing, and could only write down the correct answers. Therefore, the pre-test scores were very low in terms of the speaking sub-competence in both the control and experimental groups.

\subsubsection{There was a significant increase in the experimental group's speaking competence, compared to the control group, after implementing the drama based program.}

The findings of the study emphasized that drama did develop the experimental group students' speaking competence performance. This finding is in accordance with studies from Vitz (1984), Makita (1995), Dougill (1994), Gill (2005), Dudin (1994) and Ulas (2008). These studies found that experimental groups who were instructed using different drama techniques showed significant improvements in their oral communication when compared to a control group. The drama techniques included role-plays, simulations, improvisations, dramatization, and a drama-based lesson plan. The researchers acknowledged the usefulness of dramatic techniques, recommended more research in this area, and advocated the utilization of drama in teaching speaking. And these results are consistent with the assumptions of the literature mentioned in the previous chapter of this study. 
In the speaking competence pre-test, almost all of the students had difficulties in the grammar component. Some students commented that when speaking, they forgot how to speak in the present tense, use the correct articles and subject-verb agreements. However, in the post-test, the results showed that the students in the control and experimental groups used grammar correctly. This improvement in the grammatical sub-competence was due to a number of factors. The experimental group showed improvements in their grammar due to CLT, the drama activities, the drama-based lesson plan, and the performance on a stage that were implemented into their instruction. The control group showed improvements in their grammar due to the emphasis that the traditional method puts on this area.

Both the control and experimental groups mispronounced words in the speaking competence pre-test; however, only the experimental group showed significant improvements in the posttest. The experimental group showed improvements in pronouncing sounds, stresses, intonations and the assimilation of words, but some errors still remained.

The results showed that there was a significant difference between the mean vocabulary scores of the experimental group in the pre- and post-tests. In the post-test, a greater variety of vocabulary was used correctly and appropriately in the right context. It means that the students recognized vocabulary, and vocabulary chunks as well, that were appropriate in the contexts. They understood how the words combined with the conventional rules and acquired a variety of related words or topics.

Discourse: the students in this study were Grade 4 EFL students, so they were expected to be at the A1 speaking level by the end of elementary school. Although the A1 level sentence structure is simple and straightforward, the students spoke in fragmentary sentences and with no references or cohesive devices in the pre-test. The control group showed no improvement in the post-test, while the experimental group spoke in "more coherent, clear and logical structure of sentences” and knew "how to use cohesive references, devices, and connectors”.

Pragmatic: The students performed poorly in pragmatic competence in the pre-test, but a significant increase was revealed in the pragmatic competence of the experimental group in the post-test. This improvement is attributed to the CLT method, drama activities, dramabased activities, and the performance on stage that were implemented in the experimental group's instructions.

Fluency: In the pre-test, the students did not speak fluently, but were slow, hesitant, and frequently paused. During a conversation (Task number 3), there were sometimes long silences between the speaking. However, in the post-test, the students spoke more smoothly, 
and with fewer pauses and hesitations. This progress may be because making a conversation closely relates to real life, and it was frequently practiced in class.

In this section, the explanations for the improvements in each of the speaking-competences through employing a drama-based program are discussed. The drama-based program included of phases: a drama-based lesson plan and a performance on a stage. Both of the two phrases showed their effectiveness in developing each speaking sub-competence through five smaller procedures, the warm-up; pre-drama stage; drama stage; calming-down stage; and performance on the stage, which are each discussed below.

\section{Warm-up stages}

Using drama-based activities in the lessons may have helped the students to forget about their fear of using a foreign language and engage them in activities like "Anyone who...”, "Who stole the cookie from the cookie jar?”, “Who, what and where”, and "Freeze tag”. Activities with short sentences or "utterances” helped the students recognize that there are instances in which spoken grammar is different from written grammar, such as the omission of auxiliary verbs or pronouns (i.e., ellipsis). The drama-based activities helped the students to see how grammatical rules are applied in a simple sentence and to identify the relationships between grammar and purposes. Drama activities first introduced the students to the sounds. The activities that focused on pronunciation included greeting sounds, where the teacher or classmates make and imitate the same sounds. In these activities, students can identify the words and the way the words are stressed in that case. Drama activities, like "Anyone who" and "Hot seat" gave the students the opportunity to learn about the words, to practice, and to use the words repeatedly. Furthermore, movement and pantomime activities are ideal for developing vocabulary, while the students experience the feeling and the meaning of words.

The warm-up activities introduce students to how to make sentences in accordance with the nearby sentences. In other words, they learn that in a conversation, they need a smooth line of reasoning.

Pragmatic competence: drama activities helped develop the students' pragmatic competence by focusing on areas like an explanation, description, and discussion, e.g., freeze the image. These activities taught the students how to make forms for each purpose of speaking.

Through observation, the researcher realized that almost every lesson included drama activities that highly motivated the student to practice speaking without being afraid of making mistakes. Some drama activities included making friends, showing interest, information questions, exchanging personal information, lost and found, etc. 


\section{Pre-Drama stages}

These were the times the topics were introduced through 10-15 minutes of drama activities, such as miming, still images, settings, characters, dramatic hooks, choral, individual drills, chants, story elicitation and short improvisations.

The main advantage of the drama-based lesson plan was that the activities were designed or selected in order to target a specific grammar rule. For example, in Unit 1 the present tense was emphasized so that the students could introduce themselves and provide personal information. The modal verb "can” was deeply engrained to help the students to talk about their abilities in playing sports. Grammar was first presented during the pre-drama stage, and the students practiced it in pairs or in groups.

Drama-based lesson plans prepare the students for pronouncing the words they are going to perform in the drama-stage and allows the students to pronounce such words. In the predrama stage, the students learned about the way words are pronounced in different expressions and emotions. It helped raise the students' awareness of the importance of accuracy when pronouncing words.

The drama-based lesson plan draws the students' attention to the collection of words that they are going to use on the pre-drama stage. Role-play and simulation in the drama stage help students to think out what is going to happen in the next performance. They can prepare the available words in their memories.

In cooperation with their partners or group, the new words were exchanged and became a category of vocabulary about a relevant topic. They then discussed and selected which words were appropriate to the task they were going to perform.

In a drama-based lesson plan, the students have time to carefully prepare and organize the discourses in a cohesive and coherent way. The pre-drama stage introduced the topic of the lesson so students could think about what they were going to say or perform.

The drama-based lesson plan helped the students to think about the appropriate expressions that were going to be used to satisfy the social context in a certain topic (pre-drama stage).

The drama-based lesson plan helped to improve the students' fluency by encouraging them to speak freely without over-thinking about errors they might make. At the pre-drama stage, with the introduction of the topic, the students learned about the topic or the tasks and about what they were going to present or perform. They had enough time to prepare the grammar, pronunciation, vocabulary, discourse and pragmatic factors in order to do well in the drama 
stage. Having a set allocated time resulted in the student's handling the pressures and strains from using the communicative approach, therefore, their speech was increased and their pause times decreased.

\section{Drama stage}

The drama stage aimed to create the student space to prepare short improvisations or dialogues from the textbooks or by themselves following the required content. They then rehearsed and performed in pairs, groups or even in front of classmates. This productive stage focused them on developing their competences following the communicative approach, then almost all of the activities referred to improvisations, simulations, role-plays, dialogues, still images, etc.

While performing, the students realized how the grammatical rules worked and related to the meaning of other sentences, thus, they remembered and applied them correctly the next time. When the content of the lesson was taught, the students had adequate time to meet the grammatical requirements for their level and for the lesson. The authentic samples identified the way a word is pronounced, and the students practiced. By repeating the new words, they remembered and could use these new words in the real context with the repeated pronunciation while rehearsing. Pronunciation was challenged in the real performance.

While performing in the drama stage, their cohesion was raised because of learning through the available texts. The short dialogues in the text books which were used as a play to role-play, and the short conversations in the drama activities, such as "name game" and "greeting”, were really helpful in revealing how the sentences linked together. The students then performed their roles with a woken-up brain and were aware of what they should say and understand why they should speak in a role like this. Gradually, they could use some cohesive devices like "and”, “so” and "but” more actively, and in the right places.

Pragmatic: students experienced how the expressions were appropriately used in the drama stage. For example, in the post-tests, when being asked questions, the students could answer correctly and appropriately which some of them had been unable to do in the pre-tests.

The drama stage was an authentically real situation where the students' knowledge of all of the competences came into play and they were not interrupted by the teacher. The students tried using spoken language fluently and spontaneously in their own way.

\section{Calming-down stage}


The students had an opportunity to discuss what they had learned the lesson in the calmingdown stage, and grammar would be discussed. The drama-based lesson plan prepared, taught, and allowed the students to practice grammar thoroughly. In the calming-down stage, the students' common errors were listed and remedied so that they could improve next time. The calming-down stage helped students return to 'real life' and let them share their experiences and difficulties during the lesson. Therefore, they could correct the words they made mistakes with earlier with the help of the teacher and their classmates.

In the calming-down stage, the students focused on discourses when they had to look back on what they had presented or performed. These stages helped the students to know the gap between their performance and the expected performance.

In the calming-down stage, they had time to think back on their own and their peers' performances. They could compare which was better and what was more appropriate in an actual situation. The common errors from their performances were discussed, and remedies were offered for the next performance.

In the calming-down stage, the students had the chance to self-evaluate and draw experiences for the next time they performed. Drawing some tips for better awareness of their competences, they, of course, had become more confident with speaking and was speaking more fluently.

\section{Performance on the stage}

As Surkamp $(2010,2)$ stated, "staged plays can... serve as a means to encourage oral expression in the foreign language class”, and the performance in the drama-based lesson plan had an effect on developing the speaking competence of the students through the 4-month treatment.

The performance on stage helped the students to develop grammar because they learned how the sentences are formed grammatically in the script and imitated the grammar when speaking other sentences. Afterwards, they could make similar sentences on their own. The performance on a stage was really the chance for the students to show how far they have progressed in their pronunciation. The students repeatedly pronounced words in the script, and hence they could be corrected or make self-corrections at any point during the rehearsal. The performance at the ending of the program let the students use their vocabulary in an actual performance.

The performance helped the students to remember how the conversation was formed and the way that the sentences are put together in a play. They knew some discourse makers and 
would use them the next time they used the language. A performance on a stage gives the students time to prepare, read and understand the context of the performance (i.e., pragmatic). During the performance, the students realized whether or not their interpretations of the language and social context were correct and suitable, and vice versa. Afterwards, they could adjust their performances for the next time they perform. The performance on a stage at the end of the program was a chance for the students to show what they have learned during the program and, more importantly, the students showed that they could not only learn the language but also learn to use that language in a particular script with their own emotions.

\subsubsection{There was no significant improvement in the speaking competences of the control group after 4 months of regular instruction, with the exception of grammar in the grammatical competence}

The reasons why the control group showed no improvement in the other areas of speaking competence is likely due to the traditional methods of teaching as well. When language is grammar-focused, then the language is not presented as a means of communication (White 1988). The traditional method presumes that if a person knows the rules and terminology of a language, then they will be able to comprehend and speak the language (Boumova 2008). Scrivener added that "the teacher spends quite a lot of class time using the board and explaining things - as if 'transmitting' the knowledge"” (Scrivener 2005, 16). When students have learned the rules and the terminology, then they are expected to be able to speak the language. However, in employing this traditional approach, students only explore the narrow paths of the language because, as Broughton et al. (1994) stated, if the designed syllabuses are grammatical and are grouped by function, then the primary skills are usually not taught sufficiently. In other words, the regular instruction was not student-centred, but teachercentred and text book-centred. The teacher spent most of the time talking and writing on the board (i.e., "chalk and talk"). She explained the grammar rules, asked the students to work by themselves, called a student to write the answer on the board, and corrected the student in front of the entire class. The students focused on practicing the answers for some questions, used mechanical drills and other dialogue structures. The teacher tried to finish all of the items in the textbook but did not focus on what the students really understood after the lesson. Therefore, there was not enough time in the 45-minute lesson for both the textbook explanations and the students speaking. Subsequently, the speaking competence of the students was neglected. The students had no opportunity to feel motivated and to evaluate their performances. This meant that the control students did not practice the communicative approach, participated in no drama activities, and did not practice speaking. Thus, the control 
group only showed a significant improvement in their grammar but not in the other subcompetences or skills. Thus, the students in the control group showed some small progress in terms of their speaking competence, especially in the grammatical sub-competence of grammar. However, it was a small change, and the result was not significant. This finding affirmed that the group that was taught by the traditional method developed their knowledge of grammar. The traditional method consists of a "battery of grammatical rules" (Broughton et al. 1994). As Xu (1993) pointed out, if the grammar translation method and the student's native language are occasionally used, it is both economic and effective in explaining concepts. However, if used excessively, "grammar-translation can cut down on chances that some students, when trying to express themselves in English, are likely to produce Chinglish” (Xu 1993, 14). In this context, the control group students were likely to produce the language called 'Viet-lish'. ${ }^{15}$ The improvement in the grammar (grammatical sub-competence) of the control group was likely due to the traditional method's emphasis on teaching grammar.

\subsubsection{The control and experimental groups started with similar attitudes and motivation} levels, but after the intervention the attitudes and motivation of the experimental group was raised significantly compared with the control group

The findings of the questionnaire before the intervention showed that both the control and experimental groups had the same levels in their attitudes and motivation toward learning a foreign language (i.e., English), which were quite low. The obstacles in applying CLT in EFL classes in Vietnam (see Chapter 2) are due to the influences of Confucianism, the grammarbased examination system, the teacher-centred and/or textbook-centred methods used, and passive and unmotivated students. Thus, the students are not interested in learning English. They pay too much attention to grammar, try to avoid errors, are less confident, more anxious, and cannot speak properly. The findings also revealed that the students were not only unsatisfied with the English subject, but were also unsatisfied with their teacher and the way that their parents take care of their learning. Fifty-eight percent of the students in the experimental group did not agree that "My English teacher has a dynamic and interesting teaching style”, perhaps because of using the traditional teaching method. Almost all of the English teachers taught grammar exclusively, expected the students to be silent and do

\footnotetext{
15 'Viet-lish' is Vietnamese English. It refers to English which is used with a really strong Vietnamese accent, Vietnamese grammar and Vietnamese sentence structures rather than English grammar and peppered liberally with Vietnamese words.
} 
exercises, and sit in one place all the time. The students felt bored and unmotivated with learning, so they did not like the English course or the English teacher.

There was no response for Item number 7, “Attitudes towards English speaking people”, because living in the mountainous area of Vietnam, the students have no opportunity to see or talk to foreigners. Their families are farmers, and they did not even have a chance to watch any foreign films or television channels. Thus, the students did not know how to answer the question about English speaking people.

However, after four months of the intervention with the experimental group and the regular instruction for the control group, the results of the questionnaires were significantly changed. The findings of the questionnaires showed that there was a significant difference between the two groups, where the experimental group showed more positivity in their attitudes and motivation after the drama treatment. They responded more positively to all 12 items on the questionnaire, which queried the factors which might influence their attitudes and motivation towards learning a foreign language (i.e., speaking English). It is suggested that introducing the drama activities into the EFL class helped the students to overcome these difficulties by temporarily forgetting about all the rules of their usual classroom and only remembering about the rules of playing and the activities. There are several reasons that might have influenced the improvement in the experimental group’s responses in the questionnaire. Each step of the drama-based lesson plan (warm-up, pre-drama, drama, and calming-down stages) had a positive impact on their attitudes and motivation level. The drama activities used in the warm-up stage were energizing and different from the typical lesson. They helped the students to find motivation and to think positively, instead of being worried about being called upon in a previous lesson check. Non-verbal activities or simple activities, such as walking in space, word chains, tongue twisters and focusing on movement were used in order to elevate the students' bodies and senses. They learnt while moving and playing. It was an interesting class for them. Drama activities encourage motivation and positive attitudes in the students based on their experiences.

The pre-drama stage promoted motivation and positive attitudes in the students because they did not feel like they "have to learn”, but was more like a chance to learn by playing. There were some shy students at first, but day-by-day they became more motivated by the content of the lessons and by their classmates' or their own performances. A pre-drama stage helps them to prepare enough knowledge and sufficient grammar competence, discourse competence and pragmatic competence to be more confident to speak. 
By the drama stage, the students were so deeply enchanted by the lesson that they were eager to participate in the drama themselves. Through the drama stage, the students built up their need for learning the language in the most creative way, thus, they had more intrinsic and extrinsic motivation to learn and experience. Their attitudes were changed from being afraid of being on stage at the beginning of the program, to being excited to be in front of their audience and classmates.

Drama activities brought the experimental group's students to the playground whereby they could learn from playing. They must have been so excited when they were looking back at what they had done so far during the lesson. The calming-down stage was the time that they stopped being over-excited, looking back at what they had learned and readied their spirit and body for the next playground. They almost showed their willingness to learn more when the lesson ended.

Finally, the performance of “Peppa Pig learns about Numbers" elevated the students' motivation and positive attitudes. They prepared, rehearsed and performed with, and in front of, their peers. They did not care about the mistakes they made but were focused on the performance itself. At the end of the performance, the applause from the audience was a large extrinsic motivation factor.

Four months of the drama-based program was really helpful in developing the students' attitudes and motivation levels to learning a foreign language (i.e., English). They showed this improvement by their responses in the post-test in terms of 10 items, excepting for Item number 2, "Parental encouragement”, and Item number 7, “Attitudes towards English speaking people”. There was no significant difference between the scores of control and experimental groups in Item number 2 because their parents, who are almost all farmers, do not know what English is and have no time to care about the importance of the English language. For the parents, English is just another subject, and they wish that their children can pass and get high scores in all subjects, of course, including English. For Item number 7, "Attitudes towards English speaking people”, 37\% of the students in the control group and $34.56 \%$ of the students in the experimental group chose "No idea". However, after four months of learning with drama, the students had not had the chance to get to know and to talk with people who come from a native English-speaking country. This limitation was because of their level of proficiency. Their vocabulary was not developed enough for the activity of talking to people in an English-speaking country. However, this point of view would be changed by time, when the students acquired further knowledge of the language and were 
motivated to learn with positive attitudes; they will break the barriers and get to know more about people from English-speaking countries.

Among the other items, there were two items, Item numbers 5 and 6, which received mostly positive responses from the students of the experimental group, while these responses seem unchanged with students in the control group. Ninety-three percent of the experimental group rated Item number 5, “English Teacher Evaluation”, positively. According to their responses, the teacher in the experimental group appeared to be a good, pleasant teacher (Statement numbers 5 and 58) who is better than other teachers (Statement number 25), presents materials in an interesting way (Statement number 97), has a dynamic and interesting style (Statement number 46), and is a great source of inspiration to students (Statement number 69). The teacher received many positive responses. She was not a person who controlled all of the students' activities, nor a person who spoke all the time, but a facilitator promoting the process of communication between learners and between the learners and their tasks, an independent participant in the language group, a counsellor assisting students, and a manager setting up the framework for communicative activities.

The positive responses to Item number 6 revealed that even though English is not a compulsory subject, they still want to study English as much as possible (Statement numbers 70 and 100), that they loved learning English because learning English is great and better than any other subjects (Statement numbers 6 and 38), and because English is a very important part of the school program (Statement number 47).

These responses were because of the drama activities in the drama-based program which was conducted with the experimental group. Students who are enthusiastic about drama activities, and feel no fear about speaking during drama activities generally, do better in the CLT method and develop more positive self-perceptions. However, for the weaker students, even if they wanted to speak during drama activities, they may have been hampered by their low speaking competence. Nevertheless, all of the students will feel successful because they are having fun and the drama activities are rewarding. This point is in agreement with the study by Wihoit (1994), which found that to develop communication skills, the student should be active enough to interact with each other throughout the real-life situation.

The control group was taught by the regular teacher using the regular curriculum and the traditional teaching method, thus, they did not show any significant changes in their attitudes and motivation levels to learning English as a foreign language. 


\section{Chapter 10: Conclusion}

As the final chapter of this thesis, a summary of the findings, its limitations, and the future outlook of the study will be presented. The study is concluded by drawing upon the analysis of the results from Chapter 9. Based on the findings, recommendations will be made to the relevant parties, followed by suggestions for future studies.

\subsection{Summary}

The aim of this study was to answer the research question: what effects does drama have on developing the speaking competence of primary school students in the EFL classrooms in Vietnam? To answer this question, an analysis of the related literature was undertaken and a 4-month lesson plan was proposed, based on CLT principles, drama activities, a drama-based lesson plan and a performance on a stage.

In this empirical study, the speaking competences of two similar, but separate, groups of students were compared. One group (the control group) received the standard Vietnamese curriculum (i.e., predominantly the grammar-translation method), and served as a basis for comparison. The other group (the experimental group) was taught using the proposed drama lesson plan by the researcher of this study.

To quantify any similarities or differences between the two groups, and any changes within each group after the study period, the researcher evaluated the knowledge and skills components of the speaking competence before the start of the lesson plan (i.e., pre-test), and after the end of the lesson plan (i.e., post-test). The attitudes and motivation components of the speaking competence were evaluated in a questionnaire.

At the same time, the empirical study was conducted, the class observation was implemented with the aims to see the differences between two group students' class which were taught by two different methods of teaching, traditional method and communicative language teaching through drama activities.

The results of this study showed that the primary school EFL students in Vietnam improved significantly in almost all areas of their speaking competence after the implementation of the drama lesson plan. The control group only showed improvements in a subset of speaking competence (i.e., grammar and vocabulary) because their curriculum focused mainly on those areas. The experimental group also showed positive changes in their attitudes and motivation 
towards learning English after the drama lesson plan, while the control group’s attitudes and motivation remained unchanged.

\subsection{Significance}

The significance of these findings is considerable. As discussed in Chapter 2, there have been no studies about EFL in Vietnam, let alone using drama to teach English in Vietnamese primary schools. Furthermore, this study shows that students can still develop speaking competence, despite the limitations discussed in Section 10.3.

The group of students that received the drama lesson plan developed their speaking competence in grammatical competence, discourse competence, pragmatic competence, fluency, and improved their attitudes and motivation. These results are consistent with the literature that has shown drama's influence on the students' developing speaking skills, and their motivation and positive attitudes towards a language.

Of note is that the primary school students still developed speaking competence, despite the school being in a rural area in Vietnam, where access to technology and English are rare, and Confucianism is very prevalent. This suggests that drama-based teaching and/or the CLT approach can be applied in any region of the country.

\subsection{Strengths and limitations}

Like any study, this study has its own strengths and limitations. The strengths of this study are that it evaluated all areas of speaking competence, focusing on all speaking sub-competences, encouraged self-reflection, utilized authentic materials and was learner-centred. The limitations are the small sample size and the locality of the study. The study was designed to maximize its strengths and to minimize its limitations, as discussed below.

The major strength of this study is the learner-centred approach of CLT, where the focus in the classroom is not on the teacher, but rather on the students. The teacher is no longer the authoritative person, but they become a language advisor and a facilitator of discussions and needs. This allows the students to take on the task of their own learning and to speak more freely.

The lesson plan struck a balance in the development of each speaking sub-competence. In other words, the progress in one sub-competence was accompanied by the development of another sub-competence. This principle is akin to the one stated by Skehan (1998), who said that students not only develop and integrate a recently acquired competence but would also acquire new language rules and restructure their speaking methods. 
The students were given the opportunity to self-reflect on their performances, and the opportunity to improve in the next performance (Skehan 1998, Willis 1993, Lynch 2001, Basturkmen 2002). The calming-down stage in the drama-based lesson plan allowed students to manage their own learning and to focus more on their own strengths and weaknesses. By analyzing and critiquing themselves, they were more likely to correct their mistakes than when someone else corrects them. Exposing the students to authentic materials encouraged them to draw insights about the discourse markers used and the appropriateness of the conversation (Albanell 2014). It has been stated that awareness is the very first step to students developing their own discourses and pragmatic competences (Riggenbach 1990, Doughty 1991, Sun 2000, Guillot 2002, Hughes 2002). The performance on a stage proved to be effective in helping the students to focus on the fluency, accuracy, and complexity of their speaking.

The major limitation of this study was the small sample size, being 34 students in total. Since this study is a pioneer of drama lesson planning in Vietnam, the small sample size is acceptable to see if the lesson plan really works and to ascertain if more research in this area is necessary or warranted. Another limitation is that this study was carried in one rural primary school in Vietnam. There are 15,361 primary schools in Vietnam, and this primary school was chosen because it fits the description of an average rural public primary school. Lastly, according to Creswell (2003, 182), “One cannot escape the personal interpretation brought to qualitative data analysis”. The fact that the curriculum and data collection was both designed and implemented by the researcher means that there was a potential for bias to color the observations and field notes. However, the qualitative data in this study was triangulated and was also collected from the participants and their teachers. In addition, quantitative data were also collected from the participants.

Another important consideration is the effect of the researcher on the participants. The researcher was very careful not to reveal exactly what she was researching and emphasized that she wanted to observe their usual teaching in order to discover the difficulties and to produce solutions for better teaching in their coming careers. However, it is highly possible that the participants may have told the researcher what they thought they wanted to hear, or what they thought would help the researcher with their research.

\subsection{Recommendations}

The results suggest that drama activities are effective in the development of primary school students in Vietnam. The results showed that drama activities can develop their speaking 
competence in terms of their grammatical competence, discourse competence, pragmatic competence and fluency, and in their attitudes and motivation to learning.

Therefore, the first recommendation is addressed to primary schools in Vietnam similar to Truong Thinh Primary School. In light of the results, the teaching methodology should not rely on the traditional method to teach students to speak. The drama-based program should be introduced into all schools, but the teachers should take into consideration the students' ages, needs, interests and language levels before implementing the program.

Furthermore, it is suggested that teachers should not focus only on one competence, but to develop all speaking sub-competences in one syllabus. The traditional method favors the grammar and vocabulary competences of the grammatical competence, but teachers should also pay attention to the discourse competence, pragmatic competence, strategic competence and fluency and in the attitudes and motivation of the students. Since all of the sub-competences are inter-related, developing one speaking sub-competence can help develop the others.

Students and teachers should realize their changing roles, from the traditional approach to the communicative approach. Students are not passive learners, but are more active and are responsible for their speaking competence. The teacher is not an authority or a monitor, but the person who gives more opportunities and guidance for students to explore, to do and to evaluate by themselves. Thus, the students are more active and independent in order to decide how their learning process should be going.

To maximize the speaking time and quality of the teaching, students who are learning to speak should be grouped into small groups of approximately 15 - 20 students. This is in contrast with the usual class sizes, which are about 45 - 50 students.

Drama elements could have been part of the questionnaire, so future studies could find out more details about the students' motivation and attitudes to learning English through employing drama activities.

Teachers in CLT use authentic materials to teach their students, e.g., text-based and task-based materials, and realia (such as TV programs/film scripts). Authentic materials model real-life situations, so the students develop motivation and positive attitudes towards the English language and English-speaking people. Teachers in other methodologies should also implement authentic materials into their lesson planning.

Teachers should follow all stages of the drama-based lesson plan when implementing DIE. The warm-up stage for the upcoming lesson is more important than simply reviewing the 
previous lesson. It ensures that the students are not bored or stressed and that the students are energized and motivated for the next stage of the lesson. Teachers should ensure that there is a pre-drama stage so that students have time to practice and prepare for the drama stage. The drama stage is for performing the long-awaited task, while the calming-down stage is to return the students back to real life. The calming-down stage is necessary for the students to look back on what they did or said so that they can identify their own strengths and weaknesses. Therefore, the teachers should implement the entire drama-based lesson plan because it gives students time to be energized, prepare, practice, reflect and discuss.

Finally, performances on stage are highly recommended for teachers, because the applause and approval from the audience is a large extrinsic motivation factor for the student performers.

\subsection{Future directions}

Even though the significances of the results are considerable, future research is required in this area to elucidate the full benefits and limitations of drama in the Vietnamese EFL curriculum.

The importance of having competent Vietnamese speakers in English is well-recognized. However, the A1 level entails not only the speaking competence, but competency in reading, writing, and listening as well. Therefore, future studies should explore the effectiveness of drama in developing Vietnamese students' reading, writing and listening skills.

Furthermore, this study took place in a sample classroom of 34 over a period of 4 months. It would also be a good idea to conduct another study with a larger sample size and a longer study period using the same drama lesson plan.

Since this study was carried out in a primary school in Vietnam, it would be beneficial to determine if the same holds for students in a different age range, such as in secondary school, high school or university.

Another area to explore would be to use other methods of measuring attitudes and motivation. The attitudes and motivation were measured using a questionnaire in this study because it was deemed as the most quantifiable method. Future studies could also incorporate other methods, such as note taking, interviews or observations to explore in more detail and with greater accuracy the students' motivation and attitudes regarding learning a foreign language in general and speaking the English language in particular 
This pioneering study about DIE in Vietnam opens more doors about whether or not drama can develop the other areas of language competence, and if the results are still relevant for a larger sample size, longer study periods, different age groups, and with different evaluation methods. 


\section{References}

46th Icho. 2014. “46th International Chemistry Olympiad.” Hanoi, Vietnam. http://icho2014.hus.edu.vn/Education/0001/01/Overview-on-Vietnams-Education-System214.html.

Adlard, R., T. Ottway, and E. Procter-Legg. 2012. "Crowd-Sourcing with the Lingobee App: A Study in Facilitating Pollination across Language and Culture in Self-Directed Learning.” International Journal of Computer-Assisted Language Learning and Teaching 2 (4): 17-33. doi:10.4018/ijcallt.2012100102.

Akhyak, and Anik, I. 2013. “Improving the Students’ English Speaking Competence through Storytelling (Study in Pangeran Diponegoro Islamic College (STAI) of Nganjuk, East Java, Indonesia).” International Journal; of Language and Literature 1 (2).

Albanell, V.C. 2014. “Teaching Discourse Markers to EFL Primary Education Students.” Master Thesis, Universitat Jaume I.

Al-Jarf, R. 2006. "Large Student Enrollments in EFL Programs: Challenges and Consequences.” Asian EFL Journal Quarterly 8 (4): 8-34.

Almond, M. 2005. Teaching English with Drama. UK: Modern English Publishing.

Al-Tamimi, A., and M. Shuib. 2009. "Motivation and Attitudes towards Learning English: A Study of Petroleum Engineering Undergraduates at Hadhramout University of Sciences and Technology.” GEMA Online ${ }^{T M}$ Journal of Language Studies 9 (2): 29-55.

Ander, T. 2015. “Exploring CLT in A Grade 9 Nationwide Textbook: New Bridge to Success.” Master Thesis, Ankara: Ihsan Dogramac1 Bilkent University.

Anderson, B. 2010. “Current Trends and Future Uses.” Hershey, PA: Information Science Reference, 55-81. doi:10.4018/978-1-61520-717-6.ch003.

Anderson, M., Hughes, J., and J. Manuel. 2008. Drama and English Teaching: Imagination, Action, and Engagement. Oxford: Oxford University Press.

Armstrong, T. 2009. Multiple Intelligences in the Classroom. ASCD.

Athiemoolam, L. 2004. "Drama-In-Education and Its Effectiveness in English Second/Foreign Language Classes.” In The First International Language Learning 
Conference

(ILLC).

http://www.zsn.uni-

oldenburg.de/en/download/Logan_Malaysia_Conference.pdf.

Badger, R., and Xiaobiao Yan. 2008. “To What Extent Is Communicative Language Teaching a Feature of IELTS Classes in China?” IELTS Research Reports.

Bahrani, T., and Soltani.R. 2012. "How to Teach Speaking Skill?” Journal of Education and Practice 3 (2): 25-29.

Bang, Y. 2003. "Developing Communicative Competence through Drama-Oriented Activities in an EFL Classroom.” Tokyo-Japan. http://www.paaljapan.org/resources/proceedings/PAAL8/pdf/pdf003.pdf.

Baraldi, S.M. 2009. "Drama and Theater Practices in the Elementary Classroom That Create Conductive Environments for Non-English Speakers' English Language Acquisition.” Doctoral thesis, Arizona State University.

Barbu, L. 2007. “Using Drama Techniques for Teaching English.” Teachers’ Opinion. Passion for Communication. http://forum.famouswhy.com/index.php?showtopic=1150.

Barrett, K.A., and W.L Johnson. 2011. In "Gaming and Simulations: Concepts, Methodologies, Tools, and Applications, 1313-43. Developing Serious Games for Learning Language-in-Culture. IGI Global. http://www.igi-global.com/chapter/developing-seriousgames-learning-language/49451.

Bas, G. 2008. "Integrating Multiple Intelligences in EFL/ESL Classrooms.” Online Submission. http://files.eric.ed.gov/fulltext/ED503869.pdf.

Basturkmen, H. 2002. "Learner Observation of and Reflection on Spoken Discourse: An Approach for Teaching Academic Speaking.” TESOL Journal 11 (2): 26-30.

Belliveau, G., and W. Kim. 2013. "Drama in L2 Learning: A Research Synthesis.” Scenario: Langage-Culture-Literature VII (2).

Billíková, A., and Kissová, M. 2013. Drama Techniques in the Foreign Language Classroom. Nitra: Constantie the Philosopher University of Nitra- Faculty of Arts- Department of English and American Studies.

Bolton, G. 1993. “`A Brief History of Classroom Drama: British and Other English-Speaking influences.' Towards Drama as a Method in the Foreign Classroom” Frankfurt/M.:Peter Lang, 25-42. 
Booth, D., and J. Neelands. 1998. Writing in Role: Classroom Projects Connecting Writing and Drama. Hamilton, Ontario: Caliburn Enterprises.

Boumova, Bc.V. 2008. "Traditional vs. Modern Teaching Methods: Advantages and Disadvantages of Each.” Master’s Diploma thesis, Masaryk University.

Braddock, R., P. Roberts, C. Zheng, and T. Guzman. 1995. Survey on Skill Development in Intercultural Teaching Ò International Students. Sydney: Macquarie University, Asian Pacific Research Institute.

Breen, M.P., and C.N. Candlin. 1980. "The Essentials of a Communicative Curriculum in Language Teaching.” Applied Linguistics 1 (2): 89-112.

Broughton, G. 1994. Teaching English as a Foreign Language. 2nd ed. London: Routledge.

Broughton, G., and et al. 1994. Teaching English as a Foreign Language. 2nded. London: Routledge.

Brown, H.D. 1994. Teaching by Principles: An Interactive Approach to Language Pedagogy. Englewood Cliffs, New Jersey: Prentice Hall Regents.

—. 2000. Principles of Language Learning and Teaching. 4thed. White Plains, New York: Adision Wesley Longman.

—. 2001. Teaching by Principles: An Interactive Approach to Language Pedagogy. New York: Adision Wesley Longman Inc.

—. 2004. Language Assessment: Principles and Classroom Practices. Longman Pub Group.

- 2007. Principles of Language Learning and Teaching. New York: Pearson Education, Inc.

Buckingham, D. 2003. Media Education: Literacy, Learning and Contemporary Culture. Cambridge: Polity.

Burkart, G.S. 1998. Spoken Language: What It Is and How To Teach It. Eric.

Burns, A. 1998. “Teaching Speaking.” Annual Review of Applied Linguistics 18: 102-23.

Burns, A., and H. Joyce. 1997. Focus on Speaking. Sydney: National Center for English Language Teaching and Research.

Campbell, R., and R. Wales. 1970. “The Study of Language Acquisition.” In New Horizons in Linguistics, 242-60. In Lyons, J. (Ed.),. Harodsworth: Pinguin Books Ltd. 
Canale, M. 1983. "From Communicative Competence to Communicative Language Pedagogy.” In Language and Communication, 2-27. In J. C. Richards \& R. Schmidt (Eds.),.

Canale \& Swain. 1980. “Theoretical Bases of Communicative Approaches to Second Langage Teaching and Testing.” Applied Linguistics 1.

Canh, L.V. 1999. “Language and Vietnamese Pedagogical Contexts.” In. Vol. 3. Hanoi. http://www.language.ait.ac.th/hanoi_proceedings/canh.htm.

—_. 2001. “Language and Vietnamese Pedagogical Contexts.” Teacher's Edition, 34-40.

—. 2002. "Sustainable Professional Development of EFL Teachers in Vietnam.” Teachers Edition 10: 32-37.

Canh, L.V, and R. Bernard. 2009. "Curricular Innovation behind Closed Classroom Doors: A Vietnamese Case Study.” Prospects 24 (2): 20-33.

Chalak, A., and Kassaian Z. 2010. "Motivation and Attitudes of Iranian Undergraduate EFL Students towards Learning English.” GEMA: Online Journal of Language Studies 10 (2): 3756.

Chang, H.C, and G.R. Holt. 1991. "More than Relationship: Chinese Interaction and the Principle of Kuan-His.” Communication Quarterly 39 (3): 251-71.

Cheng, M. 2007. “Student Perceptions of Interactive Drama Activities.” Journal of Interactive Drama 2 (3).

Chiang, Y.V., and D.L. Schallert. 2012. "Instructional Design Meets Politeness Issues in Virtual Words.” In Immersive Environments, Augmented Realities, and Virtual Worlds: Assessing Future Trends in Education. IGI Global. http://www.igiglobal.com/chapter/instructional-design-meets-politeness-issues/74050.

Chomsky, N. 1965. Aspects of the Theory of Syntax. Cambridge: M.I.T. Press.

Chowdhury, R., and S. Farooqui. 2008. Teacher Training and Teaching Practice: The Changing Landscape of ELT in Secondary Education in Bangladesh. In L.Farrell, U.N.Singh and R.A.Giri (Eds) English Language Education in South Asia: From Policy to Pedagogy: 147-159. Delhi: Cambridge University Press.

Chua, C. L (ed.). 2005. Keeping My Mandarin Alive: Lee Kuan Yew's Language Learning Experience. Singapore: World Scientific and Global Publishing.

Close, Robin. 2004. “Television and Early Years Language Development.” The National Literacy Trust. 
Coleman, L.E. 2005. "Drama-Based English as a Foreign Language Instruction for Korean Adolescents.” Dissertation Abstract International 66.

Cook, V. 1991. Second Language Learning and Language Teaching. 2nd ed. London: Arnold. Cook, Vivian. 2013. Second Language Learning and Language Teaching. Routledge.

Cornbleet, S., and R. Carter. 2001. The Language of Speech and Writing. London: Routledge. Council for Cultural Co-operation, ed. 2009. Common European Framework of Reference for Languages: Learning, Teaching, Assessment. Cambridge: Cambridge Univ. Press [u.a.].

Council of Europe. 2001. Common European Framework of Reference for Language: Learning, Teaching, Teaching Assessment. Cambridge: Cambridge University Press.

Creswell, J.W. 2003. Research Design: Qualitative, Quantitative and Mixed Methods Approaches. London: Thousand Oaks.

Crystal, David. 2012. English as a Global Language. Cambridge University Press.

Daniela, Bacová, and Phillips Tim. 2000. As If. 1st ed. Bratislava: The British Council.

Darling-Hammond, L. 1998. "Teachers and Teaching: Testing Policy Hypotheses from a National Commission Report.” Educational Researcher 27 (1): 5-17.

Davies, P. 1990. “The Use of Drama in English Language Teaching.” TESL Canada Journal 8 (1): 87-99.

Davies, P., and E. Pearse. 2000. Success in English Teaching. Oxford: Oxford University Press. Oxford: Oxford University Press.

Deci, E.F., and R.M. Ryan. 2000. "Intrinsic and Extrinsic Motivations: Classic Definitions and New Directions.” Contemporary Educational Psychology 25: 54-67.

Demircioğlu, Şerife. 2010. "Teaching English Vocabulary to Young Learners via Drama." Procedia - Social and Behavioral Sciences, Innovation and Creativity in Education, 2 (2): 439-43. doi:10.1016/j.sbspro.2010.03.039.

Denham, P. 1992. “English in Vietnam.” World Englishes 11 (1): 61-69.

Devos, N. 2014. “A framework for classroom observations in English as a Foreign Language (EFL) teacher education.” Journal of Language and Linguistic Studies 10 (2): 17-28.

Dickson, L. 1995. “Autonomy and Motivation a Literature Review.” System 23 (2): 165-74.

Dodson, S. 2002. “The Educational Potential of Drama for ESL.” In Body and Language: Intercultural Learning through Drama. Greenwood Publishing Group. 
Dora To, Lai-wa, Yuk-lan Phoebe Chan, Yin Krissy Lam, and Shuk-kuen Yvonne Tsang. 2011. "Reflections on a Primary School Teacher Professional Development Programme on Learning English through Process Drama.” Research in Drama Education: The Journal of Applied Theatre and Performance 16 (4): 517-39. doi:10.1080/13569783.2011.617099.

Dornyei, Z. 1998. “Motivation in Second and Foreign Language Learning.” Language Teaching 31 (3): 117-35.

Dörnyei, Z. 2005. The Psychology of the Language Learner: Individual Differences in Second Language Acquisition. New Jersey: Lawrence Erlbaum Associates, Inc.

- 2007. Motivational Strategies in the Language Classroom. Cambridge: Cambridge University Press.

Doughty, C. 1991. “Second Language Instruction Does Make a Difference: Evidence from an Empirical Study of Relativization.” Studies in Second Language Acquisition 13 (4): 431-69.

Dougill, J. 1994. Drama Activities for Language Learning. London and Basingstoke: Macmillan Publishers LTD.

Dressman, M. 2007. "Theoretically Framed: Argument and Desire in the Production of General Knowledge about Literacy.” Reading Research Quarterly 42 (3): 332-63. doi:10.1598/RRQ.42.3.1.

Dundar, S. 2013. “Nine Drama Activities for Foreign Language Classrooms: Benefits and Challenges.” Procedia - Social and Behavioral Sciences, Akdeniz Language Studies Conference, May 2012, Turkey, 70 (January): 1424-31. doi:10.1016/j.sbspro.2013.01.206.

Dupont, Sherry. 2010. “The Effectiveness of Creative Drama as an Instructional Strategy to Enhance the Reading Comprehension Skills of Fifth -Grade Remedial Readers.” Reading Research and Instruction 31 (3).

Early, M., and C. Tarlington. 1982. “Off-Stage: Informal Drama in Language Learning.” ELT Documents 113.

Ellis, G. 1994. "The Appropriateness of the Communicative Approach in Vietnam: An Interview Study in Intercultural Communication.” http://files.eric.ed.gov/fulltext/ED378839.pdf.

Ellis, R. 1994. The Study of Second Language Acquisition. Oxford: Oxford University Press. _. 1997. Second Language Acquisition. Oxford: Oxford University Press. 
Even, S. 2011. “Drama Grammar: Towards a Performative Postmethod Pedagogy.” Language Learning Journal 39 (3): 299-312.

Farmer, D. 2007. 101 Drama Games and Activities. David Farmer.

Farrell, Thomas S. C., and George M. Jacobs. 2010. Essentials for Successful English Language Teaching. London; New York: Continuum.

Fernandez, J., and A. Coil. 1986. “Drama in the Classroom.” Practical Teaching 6 (3).

Ferraris, Christine, Christine Martel, and Laurence Vignollet. 2011. "LDL for Collaborative Activities.” In Instructional Design: Concepts, Methodologies, Tools, and Applications. IGI Global.

Finocchiaro, M., and C. Brumfit. 1983. The Functional-Notional Approach: from "Theory to Practice”. New York: Oxford University Press.

Fleming, M. 2006. “Drama and Language Teaching: The Relevance of Wittgenstein’s Concept of Language Games.” Humanizing Language Teaching Magazine. http://www.qou.edu/english/conferences/firstNationalConference/pdfFiles/muntherZyoud.pdf. Florez, M. 1998. “Improving Adult English Language Learners’ Pronunciation Skills.” In ERIC Digest National Clearinghouse for ESL Literacy Education, No.ED: 427553.

Fonseca, C.M., and J. Arnold. 2004. "Multiple Intelligence Theory and Foreign Language Learning: A Brain-Based Perspective.” IJES 4: 119-36.

Foster, P. 2001. "Rules and Routines: A Consideration of Their Role in the Task-Based Language Production of Native and Non-Native Speakers.” In Researching Pedagogic Task. Second Language Learning Teaching and Testing, 75-93. In M.Bygate, P.Skehan, and M.Swain.(Eds). London: Longman.

Fung, C.W. 2005. "A Study of the Effect of Anxiety in a Drama-Oriented Second Language Classroom.” Master Thesis, Faculty of Arts- University of Hong Kong.

Gabriella, K. 2013. “Applied Drama and Theatre-Drama Techniques in Teaching English for Specific Purpose.” Ph.D. Thesis (Extract), Târgu Mures.

Galloway, A. 1993. Communicative Language Teaching: An Introduction and Sample Activities. ERIC Clearinghouse on Language and Linguistics Washington DC.

Gardner, R.C. 1985. Social Psychology and Second Language Learning: The Role of Attitudes and Motivation. London: Edward Arnold. 
Gay, L.R. 2006. “Education Research, Competencies for Analysis and Application.” In Education Research, Competencies for Analysis and Application, 8thed. Ohio: Charles E, Merrill Publishing.

Gebhard, J. 2006. Teaching English as a Foreign or Second Language a Teacher SelfDevelopment and Methodology Guide. Ann Arbor: University of Michigan Press. http://search.ebscohost.com/login.aspx?direct=true\&scope=site\&db=nlebk\&db=nlabk\&AN= 581593.

Gill, C. 2005. "Drama as a Means of Improving the Advocacy Skills of Non-English Speaking Background Students.” The English Teacher 25: 72-86.

Goalen, P. 1996. “Educational Drama and Children’s Historical Writing: Process and Product 7(1) 75-91.” The Curriculum Journal 7 (1): 75-91.

Gomez, D. 2010. “Using Drama to Improve Oral Skills in the ESL Classroom.” International School Journal 30: 29-37.

Goodwin, J. 2001. “Teaching Pronunciation.” Teaching English as a Second or Foreign Language, in M.Celce-Murcia, 3: 26-45.

Guillot, M. 2002. "Corpus-Based Work and Discourse Analysis in FL Pedagogy: A Reassessment.” System 30 (1): 15-32.

Gupta, D. 2004. “CLT in India: Context and Methodology Come Together.” ELT Journal 58 (3): 266-69. doi:10.1093/elt/58.3.266.

Haas Dyson, A. 2010. “Writing Childhoods under Construction: Re-Visioning 'Copying' in Early Childhood." Journal of Early Childhood Literacy 10 (1): 7-31. doi:10.1177/1468798409356990.

Hamid, M. O., and R.B. Jr Baldauf. 2008. "Will CLT Bail out the Bogged down ELT in Bangladesh?” English Today 24 (3): 16-24. doi:10.1017/S0266078408000254.

Harmer, J. 2007. How to Teach English. Essex: Pearson Education.

Hastoyo, S. S. 2010. “Improving Students' Speaking Competence through Small Group Discussion.” Undergraduate, Surakarta: Sebelas Maret University.

Heathcote, D. 1995. Drama for Learning: Dorothy Heathcotes Mantle of the Expert Approach for Teaching Drama.". Portsmouth, NH: Heinemann. 
Heathcote, D., and Bolton, G.. 1994. Drama for Learning: Dorothy Heathcote's Mantle of the Expert Approach to Education. Dimensions of Drama Series. Heinemann, 361 Hanover St., Portsmouth, NH 03801-3912 (\$20). http://eric.ed.gov/?id=ED378628.

Hedge, T. 2008. Teaching and Learning in the Language Classroom. Oxford: Oxford University Pres.

Heller, W. L. 2010. In Literary Education and Digital Learning: Methods and Technologies for Humanities Studies. IGI Global. http://www.igi-global.com/chapter/teaching-shakespeareelementary-school-through/44722.

Hewgill, D., H. Noro, and C. Poulton. 2004. "Exploring Drama and Theatre in Teaching Japanese: Hirata Oriza’s Play, Tokyo Notes, in an Advanced Japanese Conversation Course.” Sekai-No Nihongo Kyooiku 14: 227-52.

Hines, M. 1973. Skits in English as a Second Language. New York: Regents.

Hinkel, E. 2011. Handbook of Research in Second Language Teaching and Learning. Routledge.

Hoecherl-Alden, G. 2006. “Connecting Language to Content: Second Language Literature Instruction at the Interrnediate Level.” Foreign Language Annals 39 (2): 244-54. doi:10.1111/j.1944-9720.2006.tb02264.x.

Holden, S. 1981. Drama in Language Teaching. England: Longman.

Holliday, A. 1994a. Appropriate Methodology and Social Context. Cambridge University Press.

—. 1994b. "The House of TESEP and the Communicative Approach: The Special Needs of State English Language Education.” ELT Journal 48 (1).

Holt, J.N. 2001. “Motivation as a Contributing Fator in Second Language Acquisition” 6 (6).

Hotwatt, A.P.R. 1984. A History of English Language Teaching. Oxford; New York: Oxford University Pres.

Hoyt, L. 1992. "Many Ways of Knowing: Using Drama, Oral Interaction and the Visual Arts to Enhance Reading Comprehension.” The Reading Teacher 45 (8): 580-84.

Hu, G. 2002. "Potential Cultural Resistance to Pedagogical Imports: The Case of Communicative Language Teaching in China.” Language, Culture and Curriculum 15 (2): 93-105. doi:10.1080/07908310208666636. 
—. 2005. “CLT Is Best for China’— an Untenable Absolutist Claim.” ELT Journal 59 (1): 65-68. doi:10.1093/elt/cci009.

Huang, G.H-C., and M. Gove. 2012. "Confucianism and Chinese Families: Values and Practices in Education.” International Journal of Humanities and Social Science 2 (3): 10-14. Huang, Y.I. 2008. “Role Play for ESL/EFL Children in the English Classroom.” The Internet TESL Journal 14 (2). http://iteslj.org/Techniques/Huang-RolePlay.

Hubbard, P. 1986. A Training Course for TEFL. Oxford University Press.

Huddleston, R., and Geoffrey, K. P. 2002. The Cambridge Grammar of English Language. Cambridge: Cambridge University Press.

Hughes, R. 2002. Teaching and Researching Speaking. Warlow: Longman.

Hui-Chun, L. 2003. “Using Poetry to Develop Teenagers' Speaking Competence at Han-Mei Languge Institute in Taiwan.” The University of Edinburgh.

Hunsaker, R.A. 2000. Understanding \& Developing the Skills of Oral Communication: Speaking and Listening. Englewood, Colo, Morton Pub. Co.

Hyland, K. 2009. “Language-Learning Simulations: A Practical Guide.”

Hymes, D. 1971. On Communicative Competence. Philadelphia, PA: University of Pennsyvania Press.

Hymes, D. 1972. “On Communicative Competence.” Sociolinguistics 269293: 269-293.

Islami, A. 2012. "Improving students's Speaking Competence by Using Teaching Aids". In Orbith 8 (1): 38-43.

Janudom, R., and Wasanasomsithi, P.. 2009. “Drama and Questioning Techniques: Powerful Tools for the Enhancement of Students' Speaking Abilities and Positive Attitudes towards EFL Learning.” ESP World 5 (26): 1-19.

Jones, K. 1982. Simulations in Language Teaching. 1sted. Cambridge: Cambridge University Press.

Jones, P. 1996. “Planning an Oral Language Program.” In Talking to Learn, 12-26. In Pauline Jones (Ed.). Melbourne, Australia: PETA.

Kagan, S. 1995. "We can talk: Cooperative Learning in the Elementary ESL Classroom.” ERIC Clearinghouse on Languages and Linguistics Washington DC 
Kam, H.W. 2004. “English Language Teaching in East Asia Today: An Overview.” In English Language Teaching in East Asia Today: Changing Policies and Practices, 2nded. Marshall Cavendish: Eastern Universities Press.

Kao, S.C. 2006. "Filial Piety of the Confucian Doctrine in Relation to Family Relationship in Taiwan.” presented at the Paper presented at the annual conference of the National Council on Family Relations, Minneapolis, MN.

Kao, S.M., and C. O’Neil. 1998. Words into Words: Learning a Second Language through Process Drama. Stamford, CT: Publishing Corporation.

Karim, K.M.R. 2004. “Teachers' Perceptions, Attitudes, and Expectations about Communicative Language Teaching (CLT) in Post-Secondary Education in Bangladesh.” Unpublish master thesis, University of Victoria.

Kayi, H. 2006. “Teaching Speaking: Activities to Promote Speaking in a Second Language.” The Internet TESL Journal 12 (11).

Kempe, A., and Holroyd, J. 2013. Speaking, Listening and Drama. Routledge.

Kennedy, P. 2002. “Learning Cultures Ad Learning Styles: Myth-Understandings Adult (Hong Kong) Chinese Learners.” International Journal of Lifelong Education 21 (5): 430-445.

Kim, S. 2006. “The Experience of Korean Parents’ Educational Zeal.” presented at the Paper presented at the annual conference of the National Council on Family Relations, Minneapolis, MN.

Kirk, R.E. 1995. Experimental Design: Procedures for the Behavioral Sciences. 3rded. Pacific Grove, CA: Brooks/Cole.

Kodotchigova, M. 2001. "Role Play in Teaching Culture: Six Quick Steps for Classroom Implementation.” The Internet TESL Journal. http://iteslj.org/techniques/kodotchigovaRoleplay.html.

Kramsch, C., and P. Sullivan. 1996. “Appropriate Pedagogy.” ELT Journal 50 (3): 199-212.

Kurowski, S.. 2011. "Drama in the English as a Foreign Language Classroom: A Multimodal Exploration.” Master of Arts in Applied Linguistics, United Kingdom: University of Birmingham.

Kuzu, A. 2008. "Views of Pre-Service Teachers on Blog Use for Instruction and Social Interaction.” Turkish Online Journal of Distance Education-TOJDE 8 (3). 
Larsen-Freeman, D. 2000. Techniques and Principles in Language Teaching. 2nd ed. Oxford University Press.

Larsen-Freeman, D, and D. Anderson. 2011. Techniques and Principles in Language Teaching. 2nd ed. Oxford University Press.

Lennartsson, F. 2008. “Students' Motivation and Attitudes towards Learning a Second Language.” presented at the British and Swedish students' points of view, School of Humanities- Vaexjoe University.

Lepper, M.R, D. Greene, and R.E Nisbett. 1973. "Undermining Children's Intrinsic Motivation with Extrinsic Reward: A Test of The 'over-Justification" hypothesis.” Journal of Personality and Social Psychology 28: 129-37.

Lepper, M.R, and M. Hodell. 1989. "Intrinsic Motivation in the Classroom.” In Ames, C and Ames, R(eds) Research on Motivation in Education.

Lien, L.Y. 2006. “Creating a Successful Educational Path for Children: The Experience of Taiwanese Mothers.” Paper presented at the annual conference of the National Council on Family Relations, Minneapolis, MN.

Lim, H.Y. 2003. "Successful Classroom Discussions with Adult Korean ESL/FL Learners.” The Internet TESL Journal 11 (5): 1-3.

Lin, Y.F. 2015. “Using Readers Theater as a Facilitator in Elementary School English Training.” Journal of Education and Learning 4 (2): 43-52.

Littlewood, W. 1981. Communicative Language Teaching: An Introduction. Cambridge: Cambridge University Press.

Littlewood, W., N. Liu, and C. Yu. 1996. “Hong Kong Tertiary Students' Attitude and Proficiency in Spoken English.” RELC Journal 27 (1): 70-88.

Liu, J. 2002. “Process Drama in Second-and Foreign Language Classroom.” In Body and Language: Intercultural Learning through Drama. Greenwood Publishing Group.

Liu, M. 2007. "Chinese Students"e Motivation to Learn English at the Tertiary Level." Asian EFL Journal 9 (1): 126-46.

Liu, N.F., and W. Littlewood. 1997. "Why Do Many Students Appear Reluctant to Participate in Classroom Learning Discourse? System, 25(3), 371-384.” System 25 (3): 371-84.

Lomicka, L., and Lord, G. 2011. "Podcasting-Past, Present, and Future.” In Academic Podcasting and Mobile Assisted Language Learning: Applications and Outcomes. IGI Global. 
Louma, S. 2004. Assessing Speaking. Cambridge: Cambridge University Press.

Louwerse, M., and Mitchel, H.. 2003. “Towards Taxonomy of a Set of Discourse Markers in Dialogue: A Theoretical and Computational Linguistic Account.” Discourse Processes 35 (3): 243-81.

Luoma, S. 2004. Assessing Speaking. Cambridge: Cambridge University Press.

Luyegu, E. 2011. In Technologies for Enhancing Pedagogy, Engagement and Empowerment in Education: Creating Learning-Friendly Environments. IGI Global. http://www.igiglobal.com/chapter/intercultural-awareness-learning/58013.

Lynch, T. 2001. "Seeing What They Meant: Transcribing as a Route to Noticing.” ELT Journal 55 (2): 124-32.

Mages, W. K. 2008. "Does Creative Drama Promote Language Development in Early Childhood? A Review of the Methods and Measures Employed in the Empirical Literature.” Review of Educational Research 78 (1): 124-52. doi:10.3102/0034654307313401.

Makita, Y. 1995. “The Effectiveness of Dramatic/role-Playing Activities.” The Japanese Language Classroom.

Maley, A., and A. Duff. 1978. Drama Techniques in Language Learning. Cambridge Handbooks for Language Teachers. Cambridge: Cambridge University Press.

- 1991. Drama Techniques in Language Learning- A Resource Book of Communication Activities for Language Teachers. Cambridge: Cambridge University Press.

Matthias, B. 2007. “Show, Don’t Tell Improvisational Theatre and the Beginning Foreign Language Curriculum.” In: SCENARIO 1 (1): 56-69.

McCaslin, N. 1998. Creative Drama in the Classroom and Beyond Studio City. CA: Players Press.

McCullough, C.N. 2000. "The Impact of Socio-Dramatic Play upon the Language Development of Language-Delayed Primary-Aged Children.” Unpublished doctoral thesis, State University of New York at Buffalo.

McDonald, E. 2011. Learning Chinese, Turning Chinese: Challenges to Becoming Sinophone in a Globalised World. Asia's Transformations. Abingdon, Oxon; New York: Routledge.

McLeod, S.A. 2007. "Skinner-Operant Conditioning." Simply Psychology. http://www.simplypsychology.org/operant-conditioning.html. 
McNaughton, M.J. 1997. “Drama and Children’s Writing: A Study of the Influence of Drama on the Imaginative Writing of Primary School Children.” Research in Drama Education: The Journal of Applied Theatre and Performance 2 (1): 55-86.

Memari, M. 2013. "How Appropriates Communicative Language Teaching (CLT) in EFL Context (an Iranian Case Study).” Journal of Life Science and Biomedicine 3 (6): 432-38.

Menon, G. (2008). Active-Learning pedagogies: Policy, Professional Development and Classroom Practice-A Case study of two post-conflict contexts: Afghanistan and Somaliland. Retrieved August 15, 2009 from www.equip123.net/.../E1-ActiveLearningPedagogiesAfghanistan.pdf

Messinger, P. R. 2010. In Handbook of Research on Digital Media and Advertising: User Generated Content Consumption. IGI Global. http://www.igi-global.com/chapter/handbookresearch-digital-media-advertising/43342.

Miccoli, L. 2003. “English through Drama for Oral Skills Development.” ELT Journal 57 (2): 122-29. doi:10.1093/elt/57.2.122.

Miller, Y., and J. Yang. 1997. "Counseling Taiwan Chinese in America: Training Issues for Counselors.” Counselor Education and Supervision 37 (1): 22-35.

Ministry of Education and Training. 2003. "Chương trình tự chọn môn tiếng Anh ở bậc Tiểu học [English Curriculum as an Optional Subject at Primary Level].” Ministry of Education and Training.

Moore, B., and H. Caldwell. 1990. “The Art of Planning: Drama as Rehearsal for Writing in the Primary Grades.” Youth Theatre Journal 4 (3): 13-20.

—. 1993. "Drama and Drawing for Narrative Writing in the Primary Grades.” Journal of Educational Research 87 (2): 100-110.

Mordecai, J. 1985. “Drama and Second Language Learning.” Spoken English 18 (2): 12-15.

Morely, J. 1996. "Second Language Speech/Pronunciation: Acquisition, Instruction, Standards, Variation, and Accent." In Linguistics, Acquisition and Language Variation: Current Trends and Future Prospects, 1-19. In J.Alatis et Al. (Eds). Washington D.C.: Georgetown University Press.

Morrow, K. 1981. "Principles of Communicative Methodology".” In Communication in the Classroom. In Johnson \& Morrow (1981). London: Longman. 
Nattinger, J., and J. DeCarrico. 1992. Lexical Phrases and Language Teaching. Oxford: Oxford University Press.

Neelands, Jonothan, David W Booth, and Suzanne Ziegler. 1993. Writing in Imagined Contexts: Research into Drama-Influenced Writing. Toronto: Toronto Board of Education.

Ngoc, K. M. 2014. “Towards a Holistic Approach to Developing the Language Proficiency of Vietnamese Primary Teachers of English.” Electronic Journal of Foreign Language Teaching 11 (2): 341-357.

Nguyen, A.H.T. 2007. "Pilot Intensive Program in HCM City: A Program That Meets the Needs of Society.” In Primary Innovations Regional Seminar: A Collection of Papers, 11316. In L.Grassick (Ed). Hanoi: British Council Vietnam.

Nguyen, H.T.M. 2011. "Primary English Language Education Policy in Vietnam: Insights from Implementation.” Current Issues in Language Planning 12 (2): 225-49. doi:10.1080/14664208.2011.597048.

Nguyen, V.X. 2004. "English Language Teaching in Vietnam Today: Policy, Practice, and Constraints.” In English Language Teaching in East Asia Today: Changing Policies and Practices, 2nd ed., 447-54. In H. W. Kam, \& R. Y. L. Wong (Eds.). Marshall Cavendish: Eastern Universities Press.

Nicholson, H. 2011. Theatre, Education, and Performance: The Map and the Story. Basingstoke, UK: Palgrave Macmillan.

Noels, K.A., I.G. Pelletier, C. Richard, and Vallerand J. Robert. 2003. "Why Are You Learning a Second Language? Motivational Orientations and Self-Determination Theory.” Language Learning 53 (1): 33-64.

Ntelioglou, B.Y. 2011. “'But Why Do I Have to Take This Class?’ The Mandatory DramaESL Class and Multiliteracies Pedagogy.” Research in Drama Education: The Journal of Applied Theatre and Performance 16 (4): 595-615. doi:10.1080/13569783.2011.617108.

Nunan, D. 1990. Designing Tasks for the Communicate Classroom. Cambridge: Cambridge University Press.

Nunan, D. 1991. “Communicative Tasks and the Language Curriculum.” TESOL Quarterly 25 (2): 279-95. Doi:10.2307/3587464.

O’Connor, P. 2010. Creating Democratic Citizenship through Drama Education. Stoke - on - Trent: Trentham Books. 
O’Malley, J.M., and A.U Chamot. 1990. Learning Strategies for Second Language Acquisition. Cambridge: Cambridge University Press.

O’Toole, J. 1992. The Process of Drama: Negotiating Art and Meaning. New York: Routledge.

Palmer, S. 2001. Speaking Frames: How to Teach Talk for Writing: Age 10-14. Oxford: Routledge.

Pandey, V. C. 2005. Intelligence and Motivation. Delhi: Isha Books.

Peterson, J. 2014. "West Teacher Explains Why the Vietnamese Hard to Learn English.” Bitlanders. http://www.bitlanders.com/blogs/west-teacher-explains-why-the-vietnamese-hardto-learn-english/661727.

Pham, H.H. 2005. ““Imported’ Communicative Language Teaching: Implications for Local Teachers. English Teaching Forum, 43(4), 12 November 2006. Retrieved from.” English Teaching Forum 43 (4). http://eca.state.gov/forum/vols/vol43/no4/p2.htm.

—. 2007. “Communicative Language Teaching: Unity within Diversity.” ELT Journal 61 (3): 193-201.

Phillips, S. 2000. Drama with Children. Resource Books for Teachers. Hong Kong: Oxford University Press.

PSO. 2014. Phutho Statistical Yearbook 2014. Statistical publishing house

Pohl, G. 2004. "Cross-Cultural Pragmatic Failure and Implications for Language Teaching.” Second Language Teaching and Learning 4. http://www.usq.edu.au/apacs/sllt/4/Pohl04.html.

Purdie, N., J. Hattie, and G. Douglas. 1996. "Student Conceptions of Learning and Their Use of Self-Regulated Learning Strategies: A Cross-Cultural Comparison.” Journal of Educational Psychology 88: 87-100.

Richards, J. 1985. “Conversational Competence through Roleplay.” RELC Journal 16 (1): 82-100.

Richards, J. 2006. Communicative Language Teaching Today. Cambridge University Press. http://www.qzabansara.com/Article/NF115831.pdf.

Richards, J. 2006. “Developing Classroom Speaking Activities: From Theory to practice.” Guidelines Singapore Periodical for Classroom Language Teachers Then Magazine for Language Teachers 28 (2): 3.

Richards, J \& Farrel, T.S.C. 2005. Professional development for language teachers. New 
York: Cambridge University Press

Richards, J and Rodgers, T. 2001. Approaches and Methods in Language Teaching: A Description and Analysis. Cambridge: Cambridge University Press.

Riggenbach, H. 1990. “Discourse Analysis and Spoken Language Instruction.” Annual Review of Applied Linguistics 2 (2): 152-63.

—. 1998. “Evaluating Learner Interactional Skills. Conversation at the Micro Level.” In Talking and Testing: Discourse Approaches to the Assessment of Oral Proficiency, 53-67. In R.Young \& A.He (Eds). Amsterdam: John Benjamins Publishing Company.

Rivers, W. 1987. Interactive Language Teaching. Cambridge: Cambridge University Press.

Roth, E. H., and Aberson, T. 2010. Compelling Conversations: Questions and Quotations on Timeless Topics: An Engaging ESL Textbook for Advanced Students. Chimayo Press.

Royka, J. 2002. “Overcoming the Fear of Using Drama in English Language Teaching.” The Internet TESL Journal 8 (12): 123-34.

Sam, W.Y. 1990. "Drama in Teaching English as a Second Language-A Communicative Approach.” The English Teacher 19: 1-11.

Savignon, S.J. 1972. Communicative: Competence: An Experiment in Foreign Language Teaching. Philadelphia: The Centre for Curriculum Development Inc.

Savignon, S. J. 2005. Communicative Language Teaching: Strategies and Goals. Handbook of research in second language teaching and learning.

Scharle, A., and A. Szabo. 2000. Learner Autonomy: A Guide to Developing Learner Responsibility. Cambridge: Cambridge University Press.

Schiller, Juliet. 2008. "Drama for At-Risk Students: A Strategy for Improving Academic and Social Skills among Public Middle School Students.” Online Submission. http://eric.ed.gov/?id=ED502068.

Scottish Office Education Department. 1992. Using Ethos Indicators in Primary School SelfEvaluation: Taking Account of the Views of Pupils, Parents, and Teachers. School Development Planning Support Materials. Scotland: GND Booth.

Scrivener, J. 2005. Learning Teaching. Macmillan: Oxford.

Segaowitz, N. 2000. “Automacity and Attentional Skill in Fluent Performance.” In Perspectives on Fluency, 200-219. In H.Riggenbach (Ed). Michigan: the University of Michigan Press. 
Singh, R.K. 2008. English Language Teaching: Some Aspects Recollected. Jaipur, IND: Global Media. http://site.ebrary.com/lib/alltitles/docDetail.action?docID=10416295.

Skehan, P. 1998. A Cognitive Approach to Language Learning. Oxford: Oxford University Press.

Son, T. L. 2011. "Teaching English in Vietnam: Improving the Provision in the Provision in the Private Sector.” Victoria University. http://vuir.vu.edu.au/16055/1/Son_Le_PhD.pdf.

Spada, N. 2007. “Communicative Language Teaching.” In International Handbook of English Language Teaching, edited by Jim Cummins and Chris Davison, 271-88. Springer International Handbooks of Education $15 . \quad$ Springer US. http://link.springer.com/chapter/10.1007/978-0-387-46301-8_20.

Sparch. 2004. "Creative Drama in English Learning: A Study of College Students Applying English Dramas to Elementary School Students.” http://sparc.nfu.edu.tw/ tcs/encouraging/94/TCS049.pdf.

Spitzberg, B.H., and W.R. Cupach. 1984. Interpersonal Communication Competence. Beverly Hills, CA: SAGE.

Spolsky, B. 2000. “Anniversary Article: Language Motivation Revisited.” Applied Linguistics 21 (2): 157-69.

Standage, M., Duda, J. and Ntoumanis, N. 2005. “A Test of Self-Determination Theory in School Physical Education.” British Journal of Educational Psychology 75: 411-33.

Stern, S. L. 1980. "Drama in Second Language Learning from a Psycholinguistic Perspective.” Language Learning 30 (1): 77-100. doi:10.1111/j.1467-1770.1980.tb00152.x.

Stewing, J.W, and Buege, C. 1994. Dramatizing Literature in Whole Language Classrooms. New York: Teachers College Press.

Stinson, M., and Freebody, K. 2006. “The DOL Project: An Investigation into the Contribution of Process Drama to Improved Results in English Oral Communication. 20, 2741.” Youth Theatre Journal 20: 27-41.

Stribling, P. 2003. “Motivation in the ESL/EFL Classroom: Rhetoric and Reality.” In, 1-5. Melbourne, Australia.

Su, Ting. 2005. “應用戲劇教學於高中英語聽講課之行動研究, (Action Research on Drama-Assisted High School English's Listening and Speaking Instruction).” 
http://thesis.lib.nccu.edu.tw/record/\#G0929510092.

http://nccuir.lib.nccu.edu.tw/handle/140.119/31818.

Subramaniam, G. 2008. “Confronting Asian Concerning in Engaging Learners to Online Education.” International Education Studies 1 (4): 10-14.

Sullivan, P. 2000. "Playfulness as Mediation I Communicative Language Teaching in a Vietnamese Classroom.” In Sociocultural Theory and Second Language Learning, 115-32. In J.P.Lantoff, ed. Oxford: Oxford University Press.

Sun, Y. 2000. “Using On-Line Corpus to Facilitate Language Learning.” ERIC Cleaninghouse on Languages and Linguistics ERIC Document Reproduction Service No.ED 442275.

Surkamp, C. 2010. "Lernort Theater: Potenziale, Methoden Und Anregungen Fuer Den Fremdsprachlichen Dramenunterricht.” In Lernorte Und Lernraeume Fuer Den Fremdsprachenunterricht, 78-94. In: Wolfgang Gehring (Ed.). Braunschweig: Bildungshaus Schulbuchverlage.

Taylor, P., and C.D. Warner. 2006. Structure and Spontaneity: The Process Drama of Cecily O’Neill. Staffordshire: Trentham Books Limited.

Thai, T.Q. 2005. “The Current Situation of Primary ELT in Vietnam.” Presented paper presented at the Teaching English Language at Primary Level Conference, Hanoi, Vietnam.

Thompson, J. 2009. Changing Chalk to Talk: The Reform of Teaching Methods in Vietnamese Higher Education. The George Washington University.

Thornbury, S. 2002. Teach Vocabulary. England: Longman.

- 2006. An A-Z of ELT: A Dictionary of Terms and Concepts Used in ELT. Oxford: Macmillan Education.

Toan, V. 2013. “English Teaching in Vietnam: Teacher're-Education.” Tuoitrenews5.vn. http://tuoitrenews.vn/education/8231/english-teaching-in-vietnam-teacher-reeducation.

Tomlinson, B., and Dat Bao. 2004. “The Contributions of Vietnamese Learners of English to ELT Methodology.” Language Teaching Research 8 (2): 199-222.

Torky, Shaimaa Abd EL. 2006. “The Effectiveness of a Task-Based Instruction Program in Developing the English Language Speaking Skills of Secondary Stage Students.” Online Submission. http://eric.ed.gov/?id=ED523922.

Tortello, R. 2004. “Tableaux Vivants in the Literature Classroom.” The Reading Teacher 58 (2): 206-8. 
Tri, B. 2001. "Viets Yearn for Knowledge after the Lost Years.” The Straits Time.

Trumbull, Elise, and Maria Pacheco. 2005. Leading with Diversity: Cultural Competencies for Teacher Preparation and Professional Development. Providence, RI: Education Alliance, Brown University.

Tuyet, T.T. 2013. “The Causes of Passiveness in Learning of Vietnamese Students.” VNU Journal of Education Research 29 (2): 72-84.

Twinkle Boost. 2015. "How to Use Peppa Pig to Promote Speech and Language Development (by a Speech and Language Therapist).” A Multi-Award Winning Social Enterprise.

Uddin, R. (2009). "Implementing Counseling Techniques: Role Play and Storytelling in Teaching Second Language Vocabulary to Adult Second Language Learners". Ph.D. Dissertation. The University of Mississippi. UMI Number: 3358517

Ulas, A. 2008. “Effects of Creative, Educational Drama Activities on Developing Oral Skills in Primary School Children.” American Journal of Applied Sciences 5 (7): 876-80.

UNESCO. 2011. “World Data on Education,” no. 7th Ed.

Ur, Penny. 2002. “The English Teacher as Professional.” In Methodology in Language Teaching: An Anthology of Current Practice, 388-92. Cambridge University Press.

Vaezi, Z. 2008. "Language Learning Motivation among Iranian Undergraduate Students.” World Applied Sciences Journal, 5 (1): 54-61.

Valgemaee, M. 1981. “Drama as an Art Form: Four Critical Approaches.” Journal of Baltic Studies 17 (4).

Van Dijk, Teun A. 1981. “'Discourse Studies and education.’ Applied Linguistics 2, No. 1 (1981): 1-26.” Applied Linguistics 2 (1): 1-26.

Van Van, H., N.Q. Tuan, P. Ha, D.T.N Hien, N.S Hung, D.N Loc, and T.T.N Minh. 2010. English 4. Hanoi, Vietnam: Ministry of Education and Training.

Van Van, Hoang. 2011. "The Current Situation and Issues of the Teaching of English in Vietnam.”立命館言語文化研究 (Language and Culture Studies) 22 (1).

Vernon, S. 2010. “The Benefits of Using Drama to Teach English: The Unmistakeable Benefits of Using Drama with Children Learning English.” Teaching English Games. http://www.teachingenglishgames.com/Articles/eslplays.htm.

Via, R. A. 1987. "'The magic if' of Theater: Enhancing language learning through drama". In W.M.Rivers (Ed.), Interactive Language Teaching:110-123. Cambridge: Cambridge 
University Press.

Vitz, K. 1984. “The Effect of Creative Drama in English as a Second Language.” Children's Theatre Review 33 (2): 22-23.

Wagner, B. J. 1998. Educational Drama and Language Arts: What Research Shows. Portsmouth, NH: Heinemann.

Wahba, K. M., Taha, Z. A and England, L. 2013. Handbook for Arabic Language Teaching Professionals in the 21st Century. Routledge.

Warschauer, M., and Kern, R. 2000. Network-Based Language Teaching: Concepts and Practice. New York: Cambridge University Press.

Wen, X. 1997. "Motivation and Language Learning with Students of Chinese.” Foreign Language Annals 30: 235-51. doi:10.1111/j.1944-9720.1997.tb02345.x.

White, R. V. 1988. The ELT Curriculum. Oxford: Blackwell Publishers Ltd.

Widdowson, H. 1998. "Skills, Abilities, and Contexts of Reality.” Annual Review of Applied Linguistics 18 (3): 323-33.

Widdowson, H.D., and A.P.R. Howatt. 2004. A History of English Language Teaching. Oxford: Oxford University Press.

Wihoit, D. 1994. “Enhancing Oral Skills: A Practical and Systematic Approach.” English Teaching Forum 32 (4): 32-37.

Wilhelm, J. D., and Brian Edmiston. 1998. Imagining to Learn: Inquiry, Ethics, and Integration through Drama. Portsmouth, NH: Heinemann.

Williams, R.T., and P. Lutes. 2010. "Using Video in the ESL Classroom." 高松大学紀要(Takamatsu’s University) 48: 1-13.

Willis, D 2007. “Society for Information Technology \& Teacher Education International Conference Annual March 26-30, San Antonio, Texas, USA. Chesapeake, Va: Association for the Advancement of Computing in Education.”

Willis, D. 1993. “Syllabus, Corpus, and Data-Driven Learning.” IATEFL Annual Conference Report: Plenaries, 25-31.

Winston, J. 2011. Second Language Learning through Drama: Practical Techniques and Applications. London: Routledge. 
Winston, Joe, ed. 2013. Second Language Learning Through Drama: Practical Techniques and Applications. London: Routledge.

Wisna, R. 2015. “Interactive Drama as a Teaching Strategy to Improve Students. (Study by Joni Listanto, Hamzah A.Machmoed, and Burhanuddin Arafah).” Presented at the Prezi web. https://prezi.com/a83gpjl5bj-m/interactive-drama-as-a-teaching-strategy-to-improvestudents/.

Wooland, B. 1993. The Teaching of Drama in the Primary School. 1st ed. London: Longman. Wright, S. 2002. "Language Education and Foreign Relation in Vietnam.” In Language Policies in Education: Critical Issues. Mahwah, New Jersey, London: Lawrence Erlbaum Associates.

Xu, H. 1993. "My Personal Philosophy in Teaching English as a Second Language: Some Methods I Used in Teaching English to Chinese Freshmen in Xi' a Foreign Language University.” Eric.

Yoshida, R. 2003. "Evaluations of Communicative Competence in Japanese by Learners and Native Speakers"." The Asian Studies Association of Australia (ASAA), no. 4. http://www.arts.unsw.edu.au/languages/asaa journal.

Young, R. 2002. “Discourse, Approaches to Oral Language Assessment.” Annual Review of Applied Linguistics 22 (2): 243-62.

Zachrias, N. T. 2012. Qualitative research methods for second language education. Newcastle upon Tyre: Cambridge Scholars.

Zafeiriadou, N. 2009. "Drama in Language Teaching: A Challenge for Creative Development.” ISSUES 23: 4-9.

Zhenhui, R. 2001. "Matching Teaching Styles with Learning Styles in East Asian Contexts.” The Internet TESL Journal 7 (7). http://iteslj.org/Techniques/Zhenhui-TeachingStyles.html. 


\section{Appendix A | Tools of data collection}

\section{A.1. Letters for conducting the empirical experiment in Vietnam}

Director of Truong Thinh Primary School

Truong Thinh-Phu Tho town

Phu Tho province

Vietnam

Goettingen, 01.07.2014

Dear Sir/ Madam,

My name is Bui Thi Hong Minh, a Ph.D. student in the English language teaching department at Goettingen University-Germany. My title of my project is "Developing Speaking Competence of Primary students through Drama activities”. The objectives of this study are to find out the answer to the question: whether drama activities can develop the speaking competence of primary students in English language classrooms and further than that a model of a lesson plan which using drama activities in teaching units is to be built.

In order to be complete, I am asking for your permission to attend at your site for collecting data through teaching activities for grade 5- students from August 2014 to November 2014. During this time, I would like to be a member of your school as an English teacher. If possible, I also would like to organize a workshop on this new method of teaching for the English teachers in your school. It's very grateful to you if you please inform this message to the teachers in your school because I am seeking for two volunteer teachers who help me with taking notes and make videos while I am teaching.

I really appreciate your necessary support in this important project.

I'm looking forward to hearing from you.

Yours sincerely,

Bui Thi Hong Minh

English Philology-Goettingen University

37075 Goettingen

tbui@gwdg.de/ 
Director of Truong Thinh Primary School

Phu Tho town-Phu Tho province

Vietnam

Vietnam, 05.07.2014

On behalf of the staff, I would like to thank you for your interest in implementing the research experiment in our school. We are very pleased for supporting you with all your requirements. I'm writing to confirm that we agree that you will be considered as our English teacher since 05.09.2014 to 07.12.2014, as indicated in your letter. The schedule of teaching units will be sent to you soon after $10^{\text {th }}$ August 2014. Mrs. Le (an English teacher) and Mr. Vinh ( an IT teacher) are willing to be volunteers with you during your experiment.

Please do not hesitate to contact me if you have any concerns.

All the best to you and your project!

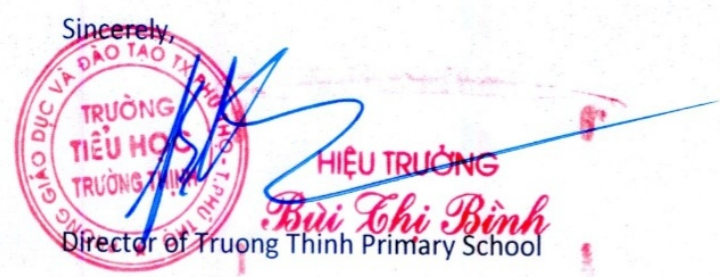

Phu Tho-Vietnam

Email: pthadung8@gmail.com

(0084)934673286 
Table A.1. A1 Level Simulation - Evaluation form

\begin{tabular}{|c|c|c|c|c|c|}
\hline \multicolumn{6}{|l|}{ Name: } \\
\hline \multicolumn{2}{|c|}{ Task completion assessment } & Comments & $\begin{array}{l}\text { Mark } \\
\text { (/5) }\end{array}$ & Comments & $\begin{array}{l}\text { Mark } \\
\text { (/5) }\end{array}$ \\
\hline \multicolumn{2}{|c|}{ Activity 1} & & & & \\
\hline \multicolumn{2}{|c|}{ Activity 2} & & & & \\
\hline \multicolumn{2}{|c|}{ Activity 3} & & & & \\
\hline \multicolumn{2}{|c|}{$\begin{array}{l}\text { Quality of production in } \\
\text { term of speaking } \\
\text { competence }\end{array}$} & Comments & $\begin{array}{l}\text { Mark } \\
\text { (/5) }\end{array}$ & Comments & $\begin{array}{l}\text { Mark } \\
\text { (/5) }\end{array}$ \\
\hline \multirow{3}{*}{ 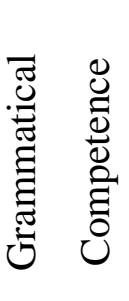 } & Grammar & & & & \\
\hline & Pronunciation & & & & \\
\hline & Vocabulary & & & & \\
\hline \multirow{2}{*}{ 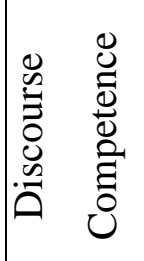 } & Coherence & & & & \\
\hline & $\begin{array}{l}\text { Managing } \\
\text { conversation }\end{array}$ & & & & \\
\hline \multicolumn{2}{|c|}{ Pragmatic } & & & & \\
\hline \multicolumn{2}{|c|}{ Fluency } & & & & \\
\hline $\begin{array}{l}\text { Total } \\
\text { compe }\end{array}$ & $\begin{array}{l}\text { (Overall speaking } \\
\text { tence score) }\end{array}$ & & & & \\
\hline
\end{tabular}


Table A.2. The rating scale rubrics for correcting students' speaking performance, part 1/4 (Torky 2006). Task complete with activities 1-3. Score 0-5.

\section{TASK COMPLETION}

\section{Activity 1 - Dialogue}

5 Responded to all questions, including the most important content points in his/her answers.

3 Responded to most questions, including the main content points, but had difficulty with the more challenging questions.

1 Responded effectively to the simply questions, but failed to answer the more complex or difficult questions.

0 Poor attempt at answering any of the questions posed, wrong answer or no answer at all.

\section{Activity 2 - Talking about photos}

5 Responded to all questions of the task, using prompts effectively and including all content points.

3 Reasonable achievement of A1 part of the task, using the visual prompts, including most content points, but had difficulty or did not do the A2 part of the task.

1 Responded to all questions.

0 Poor attempt to do the task, wrong response or no response at all.

\section{Activity 3 - Role play}

5 Responded to all the questions of the task, using the visual prompts (if possible). Very good performance in the corresponding to the selected task.

3 Good performance.

1 Performance is not so good.

0 Performance is not good or wrong for the task. 
Table A.3. The rating scale rubrics for correcting students' speaking performance, part 2/4 (Torky 2006).

Quality of production in terms of speaking competence grammatical competence, three areas. Scores 1-5

\begin{tabular}{ll}
\hline \multicolumn{2}{c}{ QUALITY OF PRODUCTION IN TERMS OF SPEAKING COMPETENCE } \\
\hline Grammar \\
5 A relatively effective use of grammatical rules (within level of proficiency A1.1) \\
$4 \quad$ Almost no grammatical inaccuracies except for occasional few grammatical errors \\
3 Some grammatical and word order errors occur which may cause misunderstanding \\
2 Frequent minor and major errors in grammar that impede comprehension; speech may be \\
characterized by a confusion of structural elements. \\
Almost all grammatical patterns inaccurate, except for a few stock phrases. Grammatical \\
mistakes severely hamper communication
\end{tabular}

\section{Pronunciation}

5 Pronunciation is intelligible. An acceptable rhythm of speech characterized by the appropriate use of stress, the smooth linking of words, and the use of appropriate intonation

4 Almost acceptable stress, linking of words, and intonation. Flaws in articulation, stress and intonation rarely disturb the listener.

3 Stress, intonation and linking words are sometimes faulty

2 Serious errors in pronunciation. Stress, intonation and phonemic articulation are generally poor and often heavily influenced by the mother language, which makes understanding difficult

1 Severe and constant intonation and pronunciation problems cause almost complete unintelligibility.

\section{Vocabulary}

5 The speaker uses relevant, adequate and correct vocabulary and word collocations (within her level of language proficiency

4 Almost appropriate range of words with few difficulties. Occasionally uses inappropriate words and word collocations

3 Vocabulary range is somewhat limited which might sometimes prevent communication of the message. Sometimes uses incorrect word collocations and some misunderstandings may arise from inaccurate word choice.

2 Frequent misuse of word, and limited vocabulary make comprehension quite difficult

1 Vocabulary is irrelevant, inadequate even for the most basic parts of the intended communication. Vocabulary is extremely limited 
Table A.4. The rating scale rubrics for correcting students' speaking performance, part 3/4 (Torky 2006).

Quality of production in terms of speaking competence Discourse competence scores 1-5

QUALITY OF PRODUCTION IN TERMS OF SPEAKING COMPETENCE

2 - DISCOURSE COMPETENCE

To organize discourse coherently and cohesively (coherence and cohesion)

5 Discourse is generally coherent with clear, logical organization. It contains enough details to be generally effective. Cohesive devices, references, fillers are used effectively

4 The speaker can almost structure the discourse according to the genre. The discourse according to the genre. The discourse is almost coherent. Few errors in the use of cohesive devices, which don't affect organization.

3 Discourse is sometimes affected by its unclear organization and it may lack enough details. Mostly simple cohesive devices are used. Referents and conjunctions are used sometimes incorrectly

2 Response is often incoherent, loosely organized and utterances hesitant, often incomplete and restricted in length. Response often lacks details. Rare use of even simple conjunctions.

1 Response is incoherent. Utterances halting, fragmentary with no references and no use of cohesive devices and lack of linguistic competence interferes with discourse competence

\section{To interact and manage the conversation effectively to keep the conversation going}

5 The speaker contributes fully and effectively throughout the interaction. She takes turns, maintains conversation through showing understanding, back-channeling, and expanding on responses or developing topics

4 The speaker contributes with ease for most of the interaction, with only occasional difficulties in negotiation. She can almost take turns, ensure comprehension, show understanding, backchannel and develop topics

3 The speaker contributes effectively for some of the interaction, but with intrusive deviations at times. Responses may be short without attempt at elaboration. Turns might sometimes be irrelevant to what is said.

2 Rarely able to understand enough to keep the conversation going. Difficulty in maintaining contributions throughout. The speaker's turns are always irrelevant to what was said

1 Communication is totally dependent on repetition, and repair. The conversation totally stops. 
Table A.5. The rating scale rubrics for correcting students' speaking performance, part 4/4 (Torky 2006).

Quality of production in terms of speaking competence Pragmatic competence and fluency scores $1-5$

\section{QUALITY OF PRODUCTION IN TERMS OF SPEAKING COMPETENCE}

\section{3 - PRAGMATIC COMPETENCE}

To express a range of functions effectively and appropriately (functional competence)

5 The speaker is able to fulfill a wide range of functions to satisfy the goal of the task. The speaker generally considers register and demonstrates appropriate response

4 The speaker is almost able to fulfill required functions clearly and effectively. Almost appropriate response to audience/situation. Errors not significant enough to be likely to cause social misunderstandings

3 The speaker may lack skill in selecting language to carry out the intended functions. Evidence of response to role and setting, but inappropriate responses may sometimes cause social misunderstanding

2 The speaker often lacks skill in selecting the language that addresses the intended functions. Functions most of the time are performed unclearly and ineffectively. Generally in appropriate response to audience/situation.

1 Unable to perform the functions in the spoken language. No evidence of ability to respond to audience/or register

\section{4 - FLUENCY}

\section{To speak fluently demonstrating a reasonable rate of speech}

5 The speaker can express herself fluently and smoothly with no pauses and hesitation

4 Delivery is smooth with few pauses that don't strain the listener or impede communication. Pauses to think of ideas rather than language

3 Occasional and noticeable hesitations. Communication is achieved but strains the listener at times. The speaker may pause to think of language.

2 Delivery is often slow and utterances and characterized by frequent pauses and hesitations that impede communication and constantly strain the listener.

1 Delivery so slow that only few words are produced. 


\section{Appendix B |Attitude and Motivation}

The following questionnaire is to survey about your attitudes and motivation toward learning English as a foreign language. There are no wrong or correct answers, please just answer accurately as possible. Using the scale below to answer:

\begin{tabular}{|c|c|c|c|c|}
\hline Number & Questions & Agree & Disagree & $\begin{array}{l}\text { No } \\
\text { idea }\end{array}$ \\
\hline 1 & $\begin{array}{l}\text { I wish I could speak many foreign languages } \\
\text { perfectly. }\end{array}$ & & & \\
\hline 2 & My parents try to help me to learn English. & & & \\
\hline 3 & $\begin{array}{l}\text { I don't pay much attention to the feedback I } \\
\text { receive in my English class. }\end{array}$ & & & \\
\hline 4 & $\begin{array}{l}\text { I don't get anxious when I have to answer a } \\
\text { question in my English class. }\end{array}$ & & & \\
\hline 5 & $\begin{array}{l}\text { I look forward to going to class because my } \\
\text { English teacher is so good. }\end{array}$ & & & \\
\hline 6 & Learning English is really great. & & & \\
\hline 7 & $\begin{array}{l}\text { If Vietnam had no contact with English- } \\
\text { speaking countries, it would be a great loss. }\end{array}$ & & & \\
\hline 8 & $\begin{array}{l}\text { Studying English is important because it will } \\
\text { allow me to be more at ease with people } \\
\text { who speak English. }\end{array}$ & & & \\
\hline 9 & $\begin{array}{l}\text { I have a strong desire to know all aspects of } \\
\text { English. }\end{array}$ & & & \\
\hline 10 & My English class is really a waste of time. & & & \\
\hline 11 & $\begin{array}{l}\text { I would get nervous if I had to speak English } \\
\text { to a foreigner. }\end{array}$ & & & \\
\hline 12 & Studying foreign languages is not enjoyable. & & & \\
\hline 13 & $\begin{array}{l}\text { I make a point of trying to understand all the } \\
\text { English I see and hear. }\end{array}$ & & & \\
\hline 14 & $\begin{array}{l}\text { I don't think my English teacher is very } \\
\text { good. }\end{array}$ & & & \\
\hline 15 & $\begin{array}{l}\text { Studying English is important because I will } \\
\text { need it in the future. }\end{array}$ & & & \\
\hline 16 & $\begin{array}{l}\text { I never feel quite sure of myself when I am } \\
\text { speaking in our English class. }\end{array}$ & & & \\
\hline 17 & $\begin{array}{l}\text { Knowing English isn't really an important } \\
\text { goal in my life. }\end{array}$ & & & \\
\hline 18 & I hate English. & & & \\
\hline
\end{tabular}




\begin{tabular}{|c|c|c|c|c|}
\hline Number & Questions & Agree & Disagree & $\begin{array}{l}\text { No } \\
\text { idea }\end{array}$ \\
\hline 19 & $\begin{array}{l}\text { I feel very much at ease when I have to } \\
\text { speak English. }\end{array}$ & & & \\
\hline 20 & $\begin{array}{l}\text { I would rather spend more time in my } \\
\text { English class and less in other classes. }\end{array}$ & & & \\
\hline 21 & $\begin{array}{l}\text { I wish I could read picture books in many } \\
\text { foreign languages. }\end{array}$ & & & \\
\hline 22 & $\begin{array}{l}\text { My parents feel that it is very important for } \\
\text { me to learn English. }\end{array}$ & & & \\
\hline 23 & $\begin{array}{l}\text { I don't bother checking my assignments } \\
\text { when I get them back from my English } \\
\text { teacher. }\end{array}$ & & & \\
\hline 24 & $\begin{array}{l}\text { I feel confident when asked to speak in my } \\
\text { English class. }\end{array}$ & & & \\
\hline 25 & $\begin{array}{l}\text { My English teacher is better than any of my } \\
\text { other teachers. }\end{array}$ & & & \\
\hline 26 & I really enjoy learning English. & & & \\
\hline 27 & $\begin{array}{l}\text { Most native English speakers are so friendly } \\
\text { and easy to get along with, we are fortunate } \\
\text { to have them as friends. }\end{array}$ & & & \\
\hline 28 & $\begin{array}{l}\text { Studying English is important because it will } \\
\text { allow me to meet and converse with more } \\
\text { and varied people. }\end{array}$ & & & \\
\hline 29 & $\begin{array}{l}\text { If it were up to me, I would spend all of my } \\
\text { time learning English. }\end{array}$ & & & \\
\hline 30 & I think my English class is boring. & & & \\
\hline 31 & $\begin{array}{l}\text { Speaking English anywhere makes me feel } \\
\text { worried. }\end{array}$ & & & \\
\hline 32 & I really have no interest in foreign language. & & & \\
\hline 33 & $\begin{array}{l}\text { I keep up to date with English by working } \\
\text { on it almost every day. }\end{array}$ & & & \\
\hline 34 & $\begin{array}{l}\text { The less I see of my English teacher, the } \\
\text { better. }\end{array}$ & & & \\
\hline 35 & $\begin{array}{l}\text { Studying English is important because it will } \\
\text { make me more educated. }\end{array}$ & & & \\
\hline 36 & $\begin{array}{l}\text { It embarrasses me to volunteer answers in } \\
\text { our English class. }\end{array}$ & & & \\
\hline 37 & $\begin{array}{l}\text { Is sometimes daydream about dropping } \\
\text { English? }\end{array}$ & & & \\
\hline 38 & $\begin{array}{l}\text { I'd rather spend my time on subjects other } \\
\text { than English. }\end{array}$ & & & \\
\hline 39 & It doesn't bother me at all to speak English. & & & \\
\hline
\end{tabular}




\begin{tabular}{|c|c|c|c|c|}
\hline Number & Questions & Agree & Disagree & $\begin{array}{l}\text { No } \\
\text { idea }\end{array}$ \\
\hline 40 & $\begin{array}{l}\text { I wish I could have many native English } \\
\text { speaking friends. }\end{array}$ & & & \\
\hline 41 & $\begin{array}{l}\text { I enjoy the activities of our English class } \\
\text { much more than those of my other classes. }\end{array}$ & & & \\
\hline 42 & $\begin{array}{l}\text { I would really like to learn many foreign } \\
\text { languages. }\end{array}$ & & & \\
\hline 43 & $\begin{array}{l}\text { My parents feel that I should continue } \\
\text { studying English all through my life. }\end{array}$ & & & \\
\hline 44 & $\begin{array}{l}\text { I put off my English homework as much as } \\
\text { possible. }\end{array}$ & & & \\
\hline 45 & $\begin{array}{l}\text { I am calm whenever I have to speak in my } \\
\text { English class. }\end{array}$ & & & \\
\hline 46 & $\begin{array}{l}\text { My English teacher has a dynamic and } \\
\text { interesting teaching style. }\end{array}$ & & & \\
\hline 47 & $\begin{array}{l}\text { English is a very important part of the } \\
\text { school program. }\end{array}$ & & & \\
\hline 48 & $\begin{array}{l}\text { My parents have stressed the importance } \\
\text { English will have for me when I left primary } \\
\text { school. }\end{array}$ & & & \\
\hline 49 & $\begin{array}{l}\text { Native English speakers are very sociable } \\
\text { and kind. }\end{array}$ & & & \\
\hline 50 & $\begin{array}{l}\text { Studying English is important because it will } \\
\text { become confident to me. }\end{array}$ & & & \\
\hline 51 & $\begin{array}{l}\text { I want to learn English so well that it will } \\
\text { become natural to me. }\end{array}$ & & & \\
\hline 52 & $\begin{array}{l}\text { To be honest, I really have little interest in } \\
\text { my English class. }\end{array}$ & & & \\
\hline 53 & $\begin{array}{l}\text { Native English speakers have much to be } \\
\text { proud about because they have given the } \\
\text { word much of value. }\end{array}$ & & & \\
\hline 54 & $\begin{array}{l}\text { It would bother me if I had to speak English } \\
\text { on the telephone. }\end{array}$ & & & \\
\hline 55 & $\begin{array}{l}\text { It is not important for us to learn foreign } \\
\text { languages. }\end{array}$ & & & \\
\hline 56 & $\begin{array}{l}\text { When I have a problem understanding } \\
\text { something in my English class, I always } \\
\text { have my teacher for help. }\end{array}$ & & & \\
\hline 57 & $\begin{array}{l}\text { My parents urge me to seek help from my } \\
\text { teacher if I am having problems with my } \\
\text { English. }\end{array}$ & & & \\
\hline 58 & $\begin{array}{l}\text { My English teacher is one of the least } \\
\text { pleasant people I know. }\end{array}$ & & & \\
\hline
\end{tabular}




\begin{tabular}{|c|c|c|c|c|}
\hline Number & Questions & Agree & Disagree & $\begin{array}{l}\text { No } \\
\text { idea }\end{array}$ \\
\hline 59 & $\begin{array}{l}\text { Studying English is important because it will } \\
\text { be useful in getting a good job. }\end{array}$ & & & \\
\hline 60 & $\begin{array}{l}\text { It worries me that other students in my class } \\
\text { seem to speak English better than I do. }\end{array}$ & & & \\
\hline 61 & I'm losing any desire I ever had to know. & & & \\
\hline 62 & Learning English is a waste of time. & & & \\
\hline 63 & $\begin{array}{l}\text { I would feel quite relaxed if I had to give } \\
\text { street directions in English. }\end{array}$ & & & \\
\hline 64 & $\begin{array}{l}\text { I like my English class so much I look } \\
\text { forward to studying more English in the } \\
\text { future. }\end{array}$ & & & \\
\hline 65 & $\begin{array}{l}\text { If I planned to stay in another country, I } \\
\text { would try to learn their language. }\end{array}$ & & & \\
\hline 66 & $\begin{array}{l}\text { My parents are very interested in everything } \\
\text { I do in my English class. }\end{array}$ & & & \\
\hline 67 & $\begin{array}{l}\text { I tend to give up and not pay attention when } \\
\text { I don't understand my English teacher's } \\
\text { explanation of something. }\end{array}$ & & & \\
\hline 68 & $\begin{array}{l}\text { I don't understand why other students feel } \\
\text { nervous about speaking English in class. }\end{array}$ & & & \\
\hline 69 & $\begin{array}{l}\text { My English teacher is a great source of } \\
\text { inspiration to me. }\end{array}$ & & & \\
\hline 70 & I plan to learn as much English as possible. & & & \\
\hline 71 & $\begin{array}{l}\text { I would like to know more native English } \\
\text { speakers. }\end{array}$ & & & \\
\hline 72 & $\begin{array}{l}\text { Studying English is important because I will } \\
\text { be able to interact more easily with speakers } \\
\text { of English. }\end{array}$ & & & \\
\hline 73 & $\begin{array}{l}\text { I would like to learn as much English as } \\
\text { possible. }\end{array}$ & & & \\
\hline 74 & To be honest, I don't like my English class. & & & \\
\hline 75 & $\begin{array}{l}\text { I would feel uncomfortable speaking English } \\
\text { anywhere outside the classroom. }\end{array}$ & & & \\
\hline 76 & $\begin{array}{l}\text { Most foreign languages sound harsh to } \\
\text { study. }\end{array}$ & & & \\
\hline 77 & I really work hard to learn English. & & & \\
\hline 78 & $\begin{array}{l}\text { I would prefer to have a different English } \\
\text { teacher. }\end{array}$ & & & \\
\hline 79 & $\begin{array}{l}\text { Studying English is important because other } \\
\text { people will respect me more if I know } \\
\text { English. }\end{array}$ & & & \\
\hline
\end{tabular}




\begin{tabular}{|c|c|c|c|c|}
\hline Number & Questions & Agree & Disagree & $\begin{array}{l}\text { No } \\
\text { idea }\end{array}$ \\
\hline 80 & $\begin{array}{l}\text { I get nervous when I am speaking in my } \\
\text { English class. }\end{array}$ & & & \\
\hline 81 & $\begin{array}{l}\text { To be honest, I really have no desire to learn } \\
\text { English. }\end{array}$ & & & \\
\hline 82 & I think that learning English is dull. & & & \\
\hline 83 & $\begin{array}{l}\text { I would feel comfortable speaking English } \\
\text { where both Iranian and English speakers } \\
\text { were present. }\end{array}$ & & & \\
\hline 84 & $\begin{array}{l}\text { I look forward to the time I spend in English } \\
\text { class. }\end{array}$ & & & \\
\hline 85 & $\begin{array}{l}\text { I enjoy meeting people who speak foreign } \\
\text { languages. }\end{array}$ & & & \\
\hline 86 & $\begin{array}{l}\text { My parents encourage me to practice my } \\
\text { English as much as possible. }\end{array}$ & & & \\
\hline 87 & $\begin{array}{l}\text { I can't be bothered trying to understand the } \\
\text { more complex aspects of English. }\end{array}$ & & & \\
\hline 88 & $\begin{array}{l}\text { Students who claim they get nervous in } \\
\text { English classes are just making excuses. }\end{array}$ & & & \\
\hline 89 & I really like my English teacher. & & & \\
\hline 90 & I love learning English. & & & \\
\hline 91 & $\begin{array}{l}\text { The more I get to know native English } \\
\text { speakers, the more I like them. }\end{array}$ & & & \\
\hline 92 & I wish I were fluent in English. & & & \\
\hline 93 & $\begin{array}{l}\text { I have a hard time thinking of anything } \\
\text { positive about my English class. }\end{array}$ & & & \\
\hline 94 & $\begin{array}{l}\text { I feel anxious if someone asks me something } \\
\text { in English }\end{array}$ & & & \\
\hline 95 & $\begin{array}{l}\text { I would rather see a cartoon movie dubbed } \\
\text { into our language than in its own language } \\
\text { with subtitles. }\end{array}$ & & & \\
\hline 96 & $\begin{array}{l}\text { When I am studying English, I ignore } \\
\text { distractions and pay attention to my task. }\end{array}$ & & & \\
\hline 97 & $\begin{array}{l}\text { My English teacher doesn't present materials } \\
\text { in an interesting way. }\end{array}$ & & & \\
\hline 98 & $\begin{array}{l}\text { I am sometimes anxious that the other } \\
\text { students in the class will laugh at me when I } \\
\text { speak English. }\end{array}$ & & & \\
\hline 99 & $\begin{array}{l}\text { I haven't any great wish to learn more than } \\
\text { the basics of English. }\end{array}$ & & & \\
\hline 100 & $\begin{array}{l}\text { When English is not compulsory, I will give } \\
\text { up the study of English because I am not } \\
\text { interested in. }\end{array}$ & & & \\
\hline
\end{tabular}




\begin{tabular}{|c|l|l|l|l|}
\hline Number & Questions & Agree & Disagree & $\begin{array}{l}\text { No } \\
\text { idea }\end{array}$ \\
\hline 101 & $\begin{array}{l}\text { I would feel calm and sure of myself if I had } \\
\text { to order a meal in English. }\end{array}$ & & & \\
\hline 102 & English is one of my favorite courses & & & \\
\hline 103 & $\begin{array}{l}\text { My parents think I should devote more time } \\
\text { to studying English. }\end{array}$ & & & \\
\hline 104 & I always trust native English speakers. & & & \\
\hline
\end{tabular}




\section{Appendix C | Performance on Stage}

\section{“Peppa Pig learns about Numbers”}

Written by: Neville Astley, Mark Baker, and Phillip Hall

\section{Characters in the play}

PEPPA PIG, the pig, daughter of Mommy Pig and Daddy Pig.

GEORGE PIG, brother of Peppa, son of Mommy Pig and Daddy Pig.

MOMMY PIG, the mother of Peppa and George, wife of Daddy Pig.

DADDY PIG, the father of Peppa and George, husband of Mommy Pig.

\section{NARRATOR}

TEACHER, the teacher of Peppa and her classmates.

ZOE, the zebra.

SUZY, the sheep.

REBECCA, the rabbit.

EMILY, the elephant.

PEDRO, the tiger.

CANDY, the cat.

RICHARD, the dog.

EDMUND, the duck.

CLASS, all the animals.

The scene is in a classroom.

\section{“Peppa Pig learns about Numbers”}

Peppa. I'm Peppa Pig. This is my little brother George Pig. This is Mommy Pig, and this is Daddy Pig.

Narrator. It is a school day for Peppa and her friends.

Teacher. Children, today we will be learning all about numbers. Does anybody know what numbers are?

Peppa. Are numbers for counting?

Teacher. Yes, Peppa. Who would like to do some counting now?

Class. Me! Me! Me! Me! Me! 
Teacher. Okay, Pedro.

Pedro. One, two, three, four.

Narrator. Pedro has counted to four.

Teacher. Well done, Pedro. Can anyone count higher than four?

Rebecca. Me! Me! Me!

Teacher. Rebecca.

Rebecca. One, two, three, four, five, six, seven.

Teacher. Excellent, Rebecca!

Candy. Teacher?

Teacher. Yes. Candy?

Candy. My mom can count up to ten.

Class. Wow!

Teacher. Yes, Candy. After seven, there is eight, nine, and ten.

Class. Eight, nine, ten.

Teacher. Very good!

Narrator. Ding dong, ding dong. It’s play time. Peppa Pig, Suzy Sheep, Zoe Zebra, and Rebecca Rabbit all like to skip outside.

Peppa. I like sand; I like sea; I like Suzy to skip with me.

Suzy. I like ping; I like pong; I like Zoe to skip along.

Zoe. I know. Let's see who can skip the most without stopping.

Rebecca. Squeak. I'll count. One, two, three, four, five, six, seven, eight, nine, ten. Zoe wins!

Zoe. Hooray!

Peppa. Hooray!

Suzy. Hooray!

Narrator. Pedro arrives.

Peppa Pedro, do you want to do some skipping?

Pedro. No thanks, Peppa. I'm hula-hooping. Wibble wobble, wibble wobble, wiggle waggle wee! Hula-hoop, hula-hoop, one, two, three.

Suzy. How many can you do without stopping?

Pedro. A million and three.

Peppa. Wow, that's a lot.

Zoe. Let's count them.

Peppa, Suzy, Zoe, and Rebecca. One, two, three, four, five, six, seven, eight.

Zoe. That was eight.

Pedro. I'm a bit tired. I'll do the rest later. 
Narrator. Emily Elephant arrives and laughs haha

Zoe. Can you do hula-hoops, Emily?

Emily. I can do them in my own special way.

Narrator. Emily Elephant is hula-hooping with her trunk.

Peppa, Suzy, Zoe, Rebecca, and Pedro. Great!

Rebecca. I think that was about one hundred.

Narrator. George Pig and Richard Dog arrive to play leap-frog. George likes to play leap-frog.

George. Khut khit (laugh).

Peppa. Leap-frog, everybody!

Class. Lie down as frogs so that Peppa can jump over each while the rest are counting from one to ten.

Narrator. Ding dong, ding dong. Play time is over.

Edmund. Teacher! We can all count to ten now!

Teacher. Very good, Edmund.

Richard. But we need to be playing to do it.

Teacher. Of course, Richard. Edmund, bring the skipping rope.

Narrator. Daddy Pig comes in.

Daddy Pig. Hello, I’ve come to collect Peppa and George.

George. Daddy! You are too early!

Daddy Pig. Oh!

Teacher. Not to worry. You can join in our game.

Daddy Pig. Oh, okay!

Teacher. Is everybody ready?

Class. Ready.

Teacher and class. One, two, three, four, five six, seven, eight, nine, ten.

Teacher. Good job, everyone! Oh, you look tired, Mr. Pig.

Daddy Pig. Oh, I’m fine. I could skip to a hundred.

Teacher. Good idea, Mr. Pig. To one hundred!

Daddy Pig. Oh, Maybe to twenty.

Teacher. Ok, to twenty.

Class. Eleven, twelve, thirteen, fourteen, fifteen, sixteen, seventeen, eighteen, nineteen, twenty.

(The characters bow to the audience).

\section{The End.}


Table D.1. T-tests comparing

Appendix D | T-Test

the pre-tests of the control and experimental groups.

\begin{tabular}{|c|c|c|c|c|}
\hline Pre-test & Group & Mean & $\begin{array}{l}\text { Standard } \\
\text { deviation }\end{array}$ & P-value \\
\hline \multirow{2}{*}{$\begin{array}{l}\text { Over speaking } \\
\text { performance }\end{array}$} & Control & 23.76 & 4.63 & \multirow{2}{*}{0.878} \\
\hline & Experimental & 24.00 & 4.23 & \\
\hline \multirow{2}{*}{$\begin{array}{l}\text { Grammatical } \\
\text { competence }\end{array}$} & Control & 7.41 & 1.33 & \multirow{2}{*}{0.447} \\
\hline & Experimental & 7.71 & 0.85 & \\
\hline \multirow{2}{*}{ Grammar } & Control & 2.47 & 0.72 & \multirow{2}{*}{0.409} \\
\hline & Experimental & 2.65 & 0.49 & \\
\hline \multirow{2}{*}{ Pronunciation } & Control & 2.00 & 0.50 & \multirow{2}{*}{0.087} \\
\hline & Experimental & 2.29 & 0.47 & \\
\hline \multirow{2}{*}{ Vocabulary } & Control & 2.94 & 0.56 & \multirow{2}{*}{0.311} \\
\hline & Experimental & 2.76 & 0.44 & \\
\hline \multirow[b]{2}{*}{ Discourse competence } & Control & 5.00 & 1.00 & \multirow[b]{2}{*}{0.134} \\
\hline & Experimental & 4.47 & 1.01 & \\
\hline \multirow{2}{*}{ Coherence } & Control & 2.47 & 0.51 & \multirow{2}{*}{0.212} \\
\hline & Experimental & 2.24 & 0.56 & \\
\hline \multirow[b]{2}{*}{ Managing conversation } & Control & 2.53 & 0.62 & \multirow[b]{2}{*}{0.159} \\
\hline & Experimental & 2.24 & 0.56 & \\
\hline \multirow{2}{*}{ Pragmatic competence } & Control & 2.24 & 0.56 & \multirow{2}{*}{0.755} \\
\hline & Experimental & 2.18 & 0.53 & \\
\hline \multirow[b]{2}{*}{ Fluency } & Control & 1.82 & 0.73 & \multirow[b]{2}{*}{0.663} \\
\hline & Experimental & 1.94 & 0.83 & \\
\hline
\end{tabular}


Table D.2. T-tests of the post-test comparing the control and experimental groups' mean scores in overall speaking performance and sub-competences.

Asterisk (*) denotes significant results $(\mathrm{p}<0.05)$.

\begin{tabular}{|c|c|c|c|c|}
\hline Post-test & Group & Mean & $\begin{array}{l}\text { Standard } \\
\text { deviation }\end{array}$ & P-value \\
\hline Over speaking & Control & 24.82 & 3.91 & \\
\hline performance & Experimental & 31.76 & 5.65 & \\
\hline \multirow{3}{*}{$\begin{array}{l}\text { Grammatical } \\
\text { competence }\end{array}$} & Control & 7.94 & 0.90 & \multirow{2}{*}{0.00} \\
\hline & Experimental & 9.18 & 0.81 & \\
\hline & Control & 3.24 & 0.66 & \multirow{2}{*}{0.73} \\
\hline \multirow{2}{*}{ Grammar } & Experimental & 3.18 & 0.53 & \\
\hline & Control & 2.00 & 0.35 & \multirow{2}{*}{0.00} \\
\hline Pronunciation & Experimental & 2.88 & 0.60 & \\
\hline \multirow{3}{*}{ Vocabulary } & Control & 2.71 & 0.47 & \multirow[b]{2}{*}{0.03} \\
\hline & Experimental & 3.12 & 0.60 & \\
\hline & Control & 5.12 & 1.22 & \multirow{2}{*}{0.01} \\
\hline Discourse competence & Experimental & 6.35 & 1.69 & \\
\hline \multirow{2}{*}{ Coherence } & Control & 2.53 & 0.51 & \multirow{2}{*}{0.03} \\
\hline & Experimental & 3.06 & 0.83 & \\
\hline \multirow{2}{*}{ Managing conversation } & Control & 2.59 & 0.80 & \multirow{2}{*}{0.02} \\
\hline & Experimental & 3.29 & 1.05 & \\
\hline \multirow{2}{*}{ Pragmatic competence } & Control & 2.47 & 0.51 & \multirow{2}{*}{0.02} \\
\hline & Experimental & 3.00 & 0.79 & \\
\hline \multirow[b]{2}{*}{ Fluency } & Control & 2.12 & 0.70 & \multirow[b]{2}{*}{0.00} \\
\hline & Experimental & 3.12 & 0.99 & \\
\hline
\end{tabular}


Table D.3. T-tests of the control group comparing the pre-test and post-test mean scores in overall speaking performance and speaking sub-competences.

Asterisk (*) denotes a significance result at $\mathrm{p}<0.05$.

\begin{tabular}{|c|c|c|c|c|}
\hline Control & Group & Mean & $\begin{array}{l}\text { Standard } \\
\text { deviation }\end{array}$ & P-value \\
\hline Over speaking & Control & 23.76 & 4.63 & \multirow{2}{*}{0.33} \\
\hline performance & Experimental & 25.24 & 3.93 & \\
\hline \multirow{2}{*}{$\begin{array}{l}\text { Grammatical } \\
\text { competence }\end{array}$} & Control & 7.41 & 1.33 & \multirow{2}{*}{0.48} \\
\hline & Experimental & 8.35 & 0.90 & \\
\hline \multirow{2}{*}{ Grammar } & Control & 2.47 & 0.72 & \multirow{2}{*}{$0.003^{*}$} \\
\hline & Experimental & 3.24 & 0.66 & \\
\hline \multirow[b]{2}{*}{ Pronunciation } & Control & 2.00 & 0.50 & \multirow[b]{2}{*}{1.00} \\
\hline & Experimental & 2.00 & 0.35 & \\
\hline \multirow{3}{*}{ Vocabulary } & Control & 2.94 & 0.56 & \multirow[b]{2}{*}{0.19} \\
\hline & Experimental & 2.71 & 0.47 & \\
\hline & Control & 5.00 & 1.00 & \multirow{2}{*}{0.76} \\
\hline Discourse competence & Experimental & 5.12 & 1.22 & \\
\hline \multirow{2}{*}{ Coherence } & Control & 2.47 & 0.51 & \multirow{2}{*}{0.74} \\
\hline & Experimental & 2.53 & 0.51 & \\
\hline \multirow{2}{*}{ Managing conversation } & Control & 2.53 & 0.62 & \multirow{2}{*}{0.87} \\
\hline & Experimental & 2.59 & 0.80 & \\
\hline \multirow{2}{*}{ Pragmatic competence } & Control & 2.24 & 0.56 & \multirow{2}{*}{0.21} \\
\hline & Experimental & 2.47 & 0.51 & \\
\hline \multirow[b]{2}{*}{ Fluency } & Control & 1.82 & 0.73 & \multirow[b]{2}{*}{0.24} \\
\hline & Experimental & 2.12 & 0.70 & \\
\hline
\end{tabular}


Table D.4. T-tests of the experimental group comparing the pre-test and post-test mean scores in overall speaking performance and speaking sub-competences.

Asterisk $(*)$ denotes a significance result at $\mathrm{p}<0.05$.

\begin{tabular}{|c|c|c|c|c|}
\hline Experimental & Group & Mean & $\begin{array}{l}\text { Standard } \\
\text { deviation }\end{array}$ & P-value \\
\hline Over speaking & Pre-test & 24.00 & 4.23 & \\
\hline performance & Post-test & 31.76 & 5.65 & $0.00^{2}$ \\
\hline \multirow{2}{*}{ Grammatical competence } & Pre-test & 7.71 & 0.85 & \multirow{2}{*}{$0.00^{*}$} \\
\hline & Post-test & 9.18 & 0.81 & \\
\hline \multirow{2}{*}{ Grammar } & Pre-test & 2.65 & 0.49 & \multirow{2}{*}{$0.01 *$} \\
\hline & Post-test & 3.18 & 0.53 & \\
\hline \multirow[b]{2}{*}{ Pronunciation } & Pre-test & 2.29 & 0.47 & \multirow[b]{2}{*}{$0.01 *$} \\
\hline & Post-test & 2.88 & 0.60 & \\
\hline \multirow{2}{*}{ Vocabulary } & Pre-test & 2.76 & 0.44 & \multirow{2}{*}{$0.02 *$} \\
\hline & Post-test & 3.12 & 0.60 & \\
\hline \multirow[b]{2}{*}{ Discourse competence } & Pre-test & 4.47 & 1.01 & \multirow[b]{2}{*}{$0.00 *$} \\
\hline & Post-test & 6.35 & 1.69 & \\
\hline \multirow[b]{2}{*}{ Coherence } & Pre-test & 2.24 & 0.56 & \multirow[b]{2}{*}{$0.00^{*}$} \\
\hline & Post-test & 3.06 & 0.83 & \\
\hline \multirow{2}{*}{ Managing conversation } & Pre-test & 2.24 & 0.56 & \multirow{2}{*}{$0.00 *$} \\
\hline & Post-test & 3.29 & 1.05 & \\
\hline \multirow[b]{2}{*}{ Pragmatic competence } & Pre-test & 2.18 & 0.53 & \multirow[b]{2}{*}{$0.00 *$} \\
\hline & Post-test & 3.00 & 0.79 & \\
\hline \multirow{2}{*}{ Fluency } & Pre-test & 1.94 & 0.83 & \multirow{2}{*}{$0.00 *$} \\
\hline & Post-test & 3.12 & 0.99 & \\
\hline
\end{tabular}


Appendix E | Typescript's for Pre-test and Post-test 
PRE-TEST:

\section{Pair 1}

-Good afternoon (4)

-What's your name? - My name is Huy

-What's your name? - My name is Anh

-How do you spell your name, Anh? -(silent)

-How do you spell your name? Huy. -(Silent)

8 -How are you?- I'm fine. Thank you. And you? - Fine, Thanks

9 -How are you today, Anh? - I'm fine. Thanks

10 -How old are you,Huy? -I'm ten years old

1 -How old are you, Anh?. -(Silent)

12 -Do you live playing chess Hu?.- Yes. I do

-What do you like to play, Anh?--(silent)

14 -Look at the picture

15 -Huy, How many are green? -There are 4

-How many are orange, Anh? -There are 4

-Huy, How many are purple? -There are 3

-Work in pair: Can you tell me about the weather?

-What's the weather like today? -(silent)

-How many...(silent) - Yes. -Do you want to continue?

- Do you like...-(Silent). - ok

- Thank you very much.Bye bye

-Good afternoon(4)

-What's your name? -My name is Nam

-What's your name? -My name is Nhat phong

-How do you spell your name? -Nhat phong.

(P..uh..H)..O...uh..N G

-How are you?- I'm... fine. Thank you

-Are you happy today? -Yes. I (silent)

-How old are you? -I'm nine years old

-And How old are you? -I'm nine years old

-Where are you from Nam?- (silent)

-Where are you from, Nhat Phong. -I'm from Vietnam

-Are you Vietnamese? -Yes. I (silent)

-Do you like play football? -Yes. I am

-What do you like to play? -(silent)

-Is your bleak time long, Nam?

-Look at the picture and answer my questions

-Can you count from 1 to 10, Nam? -1 2345 ..uh..6 78910

-What colors is this? -(silent)

-How many are red, Nam?- (silent)

-Phong, How many are red?- i...uh... and

-Ok. How many are yellow? -I'm 4

-Work in pair: Can you tell me about your family?

-How many people are there in your family? -They are 4. and

how many .... people are... the..in your family? -They are 4

-Who are they?-They are my father. mo..ther, sister and me

-What is your father's job? -He... a (worker)

-Thank you for your test. Good bye

\section{Pair 3}

-Good afternoon (4)

-What's your name? -My name is Phong

-What's your name? -My name is Thao

-How do you spell your name, Thao? That T- (silent)

-How do you spell your name, Phong. (silent)

-How are you today? I'm... (silent)

-How old are you,Thao?.- I'm ..I'm ten years old

-Do you like play hide and seek? -Yes. It is

-What do you like to play, Phong?- (silent)

-What is your mother' name?- (silent)

-Look at the picture

-How many are red, Phong? -Are .. 3

-How many are yellow? -4

-How many are blue, Thao? -3

-How many are green? -4

-Thao, Who's that? -(silent)

-Where is he from? (silent)

-Can you count from 1 to 10 ? -12345678 10

-Phong, What is this? -(silent)

-Look at here

-Who's that? -(silent)

-Work in pair. Ask and answer your family

-How many...(people) are (there) in the family?- 4

-And How.. many people are... (silent)'?

-Ok. Thank you for your test. Good bye

\section{Pair 4}

-Good afternoon(4)

-What's your name? -My name is Trang

-What's your name? -My name is Vuong

1 -How do you spell your name, Vuong? -That V-U-O-N-G

-And How do you spell your name, Trang?- That(silent)

-How are you? -l'm fine. Thank you

-How are you today? -Vuong. (silent)

-How old are you? -I'm ten years old

-Do you like playing football? -(silent)

-What do you like to play,Trang? -Yes. I do

8 -What do you like to play? -(silent)
-Look at the picture.

Vuong, what color is this? -(silent)

How many are red? -4

-Trang, how many are blue? -three

How many are green Trang?- Four

How many are purple? Vuong. (silent)

-Can you count from 11 to 20? .... Trang. -Can you count from 11 to 20 ? -(silent)

Work in pair: ask and answer about your school

What is the name of your school? -It TTPS

And What is the name of your school? -It TTPS

Is it big and nice? -Yes.l... yes. It is

Where is it? -It is Truong Thinh street

What class are you in? -I'm in class 4A

- And what class are you in? -l'm in class 4A too

Do you want to continue?

-Thank you for your test. Good bye!

Good afternoon (4)

What's your name? -My name is Hieu

-What's your name? -My name is Anh

How do you spell your name, Anh? -That A-N-H

Where are you from, Hieu? I'm.. I'm from Vietnamese

Are you Vietnamese? -l'm .. Phu Tho town

-I'm Vietnamese

ow old are you? -l'm ten years old

How ols are you, Hieu? -l'm ten years old

What do you do in your break time, Anh? -... (silent)

What do you like to play, Hieu? -(silent)

Do you like play football?- Do you like playing football

Look at the picture.

How many are green, Hieu? -It's 4

How many are orange, Anh? -There are 3.. green

How many are purple,Hieu? -l'm 3

What is this, Anh?- It is.. (silent)

-Anh, can you count from 1 to 10. -Yes. I can. 12345678

10

-Hieu, who's that? -Name is.. (silent)

How old is he? -i.... ten.. uh 13

What color is his hair?- (silent)

-Work in pair. Ask and answer the weather

-What is the (weather) like today? -It (cold) and ...

-How many .. (silent)?

What are they? -They are ...ss...ss (silent)

-Do you want to continue?

Thank you for your test. Goodbye

\section{Pair 6}

Good afternoon(4)

-What's your name?- My name Hien

-What's your name? -My name is Phuong

-What do you spell your name, Phuong?- (silent)

What do you spell your name, Hien? -That H- I -(E) -N

-How old are you, Hien?- I'm 9 years old

-How old are you, Phuong? -I'm 9 years old too

Do you like playing hide and seek, Phuong? - Yes. I do

What do you like to play, Hien?- Yes. I do

Do you like playing chess? -Yes. I do

-Phuong, where are you from? -I'm from Vietnam

-What nationality are you? -I'm Vietnamese

Are you Vietnamese? -Yes. i am

Where do you live?- (silent)

Phuong, where do you live?- I live Phu Tho town -Look at the picture

How many are green, Phuong? -l'm in 4

How many are orange? -There are 3 orangre

-How many are purple? -There are 3

-Phuong, what is this? -(silent)

-What is this?- (silent)

-Work in pair. Ask and answer about your school

-What is your name of your school.- It is TTPS

-And what is your name of your school. -It TTPS

(it is )big and nice? -Yes. It is

-What class are you in? -I'm class 4A

-What class are you in? -I'm class 4A too

-How many people are there your school? -There are 2 . (silent)

Ok. Do you want to continue? -(Silent)

-Thank you for your test. Goodbye

Good afternoon (4)

What's your name? -My nam is Thuy

-And what's your namr? -My name is Vinh

How do you spell your name, Vinh? -That $\mathrm{V}-\mathrm{I}-\mathrm{N}-\mathrm{H}$

-And how do you spell your name, Thuy. -That T- H -U- Y 
How old are you, Thuy? -l'm 10 years old How old are you, Vinh? -I'm 10 years old too Are you happy? -Yes. I am

-How are you, Thu?-. I'm five. Thank you, and you? -Fine. Thanks

-Where are you from, Thuy?- I'm from Phu Tho town Are you Vietnamese? -Yes. I am

What nationality are you, Vinh? -It's Vietnamese

Where do you live? -I live Phu Tho town

Do you like playing hide and seek? -No. i don't

What do you like to play, Vinh? - I..

-Do you like playing tennis, Thuy?- No. i don't

-What do you like to play? -(silent)

Look at the picture

-Can you count from 11 to 20, Vinh? -11 12 (13 14151617

18 19) 20

-Thuy, can you count from 1 to 10 ? -12345678910

-Thuy, who's that? -How old is he?- ..He.. 30

-What color his hair? -(silent)

-Vinh, what color are his eyes? -It's brown

What does he like?- He like basketball

-What does he dislike? -Like... basketball

-Work in pair: ask and answer the weather

-Good afternoon(2)

What's the weather like today? -It cold and cloudy

-Would you like cold weather? -No. i don't

-How many.. -ok

-Vinh, what are they? -They are .. (silent)

-Do you want to continue?

-Thank you for test. Goodbye.

-Good afternoon (4)

What's your name? -My name is Long

-And what's your namr? -My name is Nam

How do you spell your name? nam. That N-A-M

And how do you spell your name, Long? - That L-O-N-G

Where are you from, Long? -I'm from Vietnam

Where are you from, Nam?- I'm from Vietnam

-What nationality are you? -I'm Vietnamese

-Are you Vietnamese, too? -Yes. I am

-What group are you in?- I'm group.. I'm group 4A

-How are you today?- I'm fine. Thank you. And you?

-Fine. Thanks you?

-Ok. Look at the picture

-How many are red, Nam? -There are 4 red

-How many are yellow, Nam? -There are 4 yellow

How many are blue, Long? -There are 3 blue

-What is this, Long? - It's P??

What is this, Nam? - It's ... flower

Nam. Who's that? -Name John

-Where is he from? -He...the...ok

-How old is he? - He 15....13 years old

-What color his hair? -It brown

-What color are his eyes, Long?. -It brown

-What does he like, Long? -It.. (silent)

-Work in pair. Ask and answer about your schoo

-What is the name of your school? -It TT primary school

-What is the name of your school? -It TT primary school

-Is it (big) and nice? -Yes. It is

-Where is it?- It's TT street

-What class are you in?- I'm class 4A

-What class are you in? -I'm class $4 A$ too

-How many people are there in your school? -There are (200)

Is your school new or old? - It's old

-Are your ... ?- Yes. There are

Do you like play hide and seek? -Yes. I do

-What do you like? -I like play football

-Thank you for your test. Bye Bye

\section{Pair 9}

-Good afternoon (4)

What's your name? -My nam is Quan

-And what's your name? -My name is Mai

-Are you happy? -Yes. I am

-How are you today?- I'm fine. Thank you. And you?

-Fine.Thanks

-How are you today? -l'm fine. Thank you. And you? - Fine. Thanks

-Where are you from, Mai'?- I'm from Vietnam

-Are you Vietnamese? -Yes. I am

What nationality are you, Quan? -I'm Vietnamese

-What group are you in? -I'm group 4A

-Is your break time long, Mai? - Yes.. i...yes

-What do you do at bleak time, Quan? I play football

-Do you like playing football? -Yes. I like

What do you like to play, Mai? -I like playing badminton What subject do you like the most? -I like art and music How many people are there in your family? -There are 5 people

Who are they? - They are my (grandmother), my father, my mother, my brother and me

Look at the picture

Can you count from 11 to 20, Mai? -11 12 ...13 141516 ...(silent)

-How many are green, Quan? - There are 4

-How many are orange? -There 3

How many are purple, Mai? -There are 3

Who's that, Mai? -It..

Where's she from? -She from..

-Is she great? -(silent)

How old is she? -She is 15

What color is her hair? -It's brown

What color are her eyes? -It's (silent)

What does she like? -She like tennis

-What does she dislike, Quan? -She dislike go to cinema

Ok. Work in pair. Ask and answer the weather

What the weather like today? -It's cold and cloudy

-Do you like the cold weather? -No. I don't

-How many seasons in the Vietnam? -There are 4

-What are they? -They are spring, summer,... and do you like spring? Yes. I do

-Do you like summer? -No, I don't

-Thank you for your test. Good bye

\section{Pair 10}

-Good afternoon(4)

-What's your name? -My name is Huyen

-What's your name? -My name is Hai

-How are you today, Hai? I'm fine. Thank you. And you? - Fine. Thanks

-Are you happy? -Yes. I am

-Where do you live?-I live in Vietnam..in Phu Tho town

What nationality are you, Hai? -l'm Vietnamese

-Are you vnese too? -Yes. I am

-Do you like playing hide and seek? -Yes. I do

What do you like to play, Huyen? -I live playing badminton

-Is your bleak time long? -Yes. It is

-Look at the picture

-How many are orange? -There are 3

-How many are purple, Huyen? -There are 3

-Who's that, huyen?- That is John

-What nationality is he? -He's a American

-How old is he? -He 13 years old 
-Hang, how many rooms are there in a house? -There are 6

-What are they? -They are bedroom, bathroom, living room, kitchen, bedroom and kitchen

-Are they big and nice? -Yes. They are.

Can you count from 11 to 20. Nhi? -11 12131415161718 1920

What color is this? -This is flower

How many are red? -There... there are 4

-How many are yellow, Hang? -There are 4 yellow

Work in pair: ask and answer about your school

-What is the name of your school? -It's TTprimary school

What is the name of your school? -It TT primary school

Is it big and nice? -Yes. It is

-Where is it? -It is Truong Thinh street

And where is it? -It is Truong Thinh street.

What class are you in? -I'm in class 4A

And What class are you in? -I'm in class $4 A$ too

How many people are there in your school? -There are 200 people

-Is your school new or old? -It's old

-Do you like your school? -Yes. I do

-Are your friend...? - Yes. They are

Do you like playing hide and seek? -Yes. I do

What do you like playing? -I like playing football -Ok. Thanks for your test. Goodbye

\section{Pair 12}

Good afternoon (4))

-What's your name? -My name is Oanh

What's your name? -My name is Duong

-How do you spell your name. Duong? -(silent)

-How do you spell your name, Oanh? -O-A-N-H

How old are you?- I'm 10 years old

-When's your birthday? -It's 21 of September

-When's your birthday, Duong?- It's.. 8 (silent)

-How are you today? - I'm fine. Thank you

-Are you happy. Oanh? -Yes. I am

-What do you do at break time, Oanh?- I play badminton

-Do you play badminton? -Yes. I do

-How many people are there in your family, Duong? -There are 4 people

Who are they?- They are father, mother, sister and me

Look at the picture

-Oanh, what is this? - It's a p

-How many are green, Oanh? -There are 4 green

How many are orange, Duong? -There are 3

-How many are purple? -There are 3

-What is this, Duong?- It's a apple

-Oanh, what is this? -This a flower

Who's that? -It's John

-Where is he from?- He's from USA

What nationality is he? - He is...from American

-How old is he? -He... 13 years old

What color is his hair? -It's brown

What color are his eyes, Duong? -It's a brown

-What does he like? -He likes basketball

What does he dislike? -He..likes.. swimming

-Work in pair: ask and answer in the weather

What the weather like today? -It's cold and cloudy

Do you like the cold weather? -No, I don't

How many seasons in the Vietnam? -There are 4

-What are they? -They are spring, summer, autumn and winter -and do you like spring? Yes. I do

-Do you like summer? -No. i don't because it's hot -What do you usually do in the summer? - I usually go out with my sister

-Thank you for your test. Goodbye.

\section{Pair 13}

Good afternoon (4))

-What's your name? -My name is Giang

-What's your name? -My name is Quan

How do you spell your name. Quan? -Q-U-A-N

-How do you spell your name, Giang? -G - I- A-N-g

-Where are you from, Giang? -I'm from Phu Tho town

What nationality are you? -I'm Vietnamese

-What nationality are you, Quan? -I'm Vietnamese

How old are you? I'm fine. Thank you. -And you?

-How are you, Giang?- I'm fine. Thank you. And you?

I'm fine, thanks

-How old are you? -l'm 9 years old

-When's your birthday, Giang? -... it's in October

-When's your birthday, Quan? -It's in (August)

-What do you do in bleak time, Quan? -I play football

Do you like playing chess? -Yes. I am

-Look at the picture

-What is this, Giang? -This.. football

How many are green, Giang? -There are 4 green How many are orange, Quan? -There are 3 green How many are purple, Quan? -There are 3 purple What is this, Giang? -This is apple

Who's that? -That is john

Where is he from? -I'm from ... the (USA)

What nationality is he? - He is America

How old is he? - He is..

Quan, how old is he? - He is...13 years old

What color is his hair? Her..(silent)

-Work in pair, ask and answer about your family

How many people are there in your family? There are 4 How many people are there in your family? -There are 4 -Who are they? -They are my father. My mother, my sister and me

Who are they? -They are my father. My mother, my sister and me

-What is your father's job? - He is farmer

-What is your father's job? - He is worker

-How old is he? - He is 35 years old

How old is your father? - He is 40

What is your mother name? -Her name is hue

-What is your mother name? -Her name is dung

What does she do? -She is a teacher

-What does your mother do? -She's a doctor

-Is she friendly? -Yes. She is

-And is your mother friendly? -Yes. She is

-How old your sister? -She is 17 years old

-How old your sister? -She is 4 years old

-What 's your sister name? -Her name is Huong

-What 's your sister name? -Her name is Hue

-What do you do?- I am a pupil

What do you do? -I am a pupil too

Are you happy today? -Yes. I am

Thank you for your test. Goodbye

\section{Pair 14}

-Good afternoon (4))

-What's your name? my name is Van

-What's your name? my name is Giang

-How do you spell your name, Giang? G-I-A-N-G

-How do you spell your name. Van? $V-A-N$

- How are you today?- I'm fine. Thank you

-And how are you today?- I'm fine. Thank you

-Are you happy? -Yes. I am

Where are you from, Van? -l'm from Vietnam

-What nationality are you?- I'm Vietnamese

-Where are you from, Van?- I'm from
-Are you Vietnamese? -Yes, I am

-What do you do at bleak time, Van? I play hide and seek? 
Good afternoon (4))

What's your name? My name is Duong

What's your name? My name is Giang

How do you spell your name? G -I-A-N-G

-How do you spell your name? D-U-O-N-G

How are you today? -I am fine. Thank you. And you? Fine. Thanks

How are you today? Fine. Thanks

-How old are you, Giang? I'm 10 years old

.

When is your birthday? It the (14) of december

When's your birthday, Giang? It's ... october

-Where are you from? -I'm from Vietnam

Are you Vietnamese? -Yes. I am

Are you Vietnamese too? -Yes. I am

What do you do at bleak time? -I play badminton

Do you like playing badminton? Yes. I do

Do you like playing chess, Giang? -... i play.. yes. I do

Look at the picture

Giang, what is this? -This is flower

How many are yellow, Giang? -2 ye..

How many are red, Duong? -2 red

How many are green, Viet Giang? -2 green

Can you count from 11 to 20, Duong? -1112 131451617

181920

Work in pair: ask and answer about the weather

What the weather like today? -It's cold and cloudy

-Do you like the cold weather? No. i don't

How many seasons are there in the Vietnam?- There are 4

What are they? They are (spring), summer,-autumn and -

winter and do you like ...spring? -Yes. I do

-Do you like summer? -No. i don't. because (it's) hot

-What do you usually do in the summer? - I usually go out with my sister

-Thank you for your test. Goodbye

\section{Pair 16}

Good afternoon (4))

-What's your name? -My name is $\mathrm{Vu}$

What's your name? -My name is Tu

Where are you from, Tu? -I'm from Vietnam

-Are you Vietnamese? -Yes. I am

-What nationality are you, Vu? -l'm Vietnamese

How old are you? -I'm 10 years old

-Are you 10 years old too? -Yes.... I ...

Where do you live tu? -I live ... i live pt town

What do you do at bleak time, Vu?- (silent)

-Do you like playing football? - Yes. I do

What do you like to play, Tu? -(silent)

Look at the picture

How many are green, Tu? -There are 4

How many are orange, Vu? -There are 3

How many are purple, Tu? -There are 3

What is this? -It's ... bowl

And what is this? It's flowe

-Ask and answer about the family

How many people are there in your family? -There are 4

How many people are there in your family? -There are 4

-Who are they? -They are my mother ..ah...my father. My -

mother, my sister and me

What is your father's do..ah.. job? -He is farmer

What is your father's job? - He is a worker

-How old is he?- He is 35 years old

-How old is your father? - He is 40

What is your mother name? -Her name is Hien

What is your mother name?- Her name is Hieu

-What does she do?- She is a teacher

-And what does your mother do? -She's a doctor

Is she ...(friendly)? -Yes. She is

-Is your mother...(silent)? -Yes. She is

How old your sister? -She is ...6 years old

-How old your sister? -She is 5 years old

-What's your sister name? - Her name is van

-What's your sister name? - Her name is linh

What do you do? -I am a pupil

What do you do? -I am a pupil too

-Are your...uhm.. happy today? -Yes. I am

-Thank you for your test. Goodbye

-Good afternoon (4))

-What's your name? -My name is Trang

What's your name? -My name is Thien

Where are you from, Thien?- I'm from Vietnam

And where are you from, Trang?- I'm from Vietnam

Are you Vietnamese, Trang? -Yes. I do

What nationality are you,Thien? -l'm from Vietnamese

-How are you today?- I'm fine. Thanks
617 -Are you happy , Trang? (silent)

618 -How are you today, Trang? -I'm fine. Thank you

619 -When's your birthday, Trang?- The fifth of October

620 -When's your birthday, Thien?- It.. (silent)

621 -What do you do at bleak time, Thien? -I'm playing football

622 -Do you likr playing hide and seek, Trang?- Yes. I do

623 -Is your break time long, Thien? -(silent)

624 -Look at the picture

625 -How many are green, Thien? -There are 4

626 -How many are orange, Trang? -There are 3

627 -How many are purple, Trang? -There are 3

628 -What is this, thien?- It... (apple)

629 Who's that, Thien? -That (john)

630 -Where is he from? -.. from.. usa

631 -How old is he? He.. is ..he is...(silent)

632 -Does he like playing basketball? - Yes. I do

633 -Work in pair: ask and answer about your school

634 -What is the name of your school?- It's TT primary school

635 -And what is the name of your school? -It's TT primary school

636 -Is this big and nice? -Yes. It is

637 -Is this big and nice? -No. it isn't. -It's small

638 -Where is it?- It is Truong Thinh street.

639 -What class are you in? -I'm in class 4A

640 -And what class are you in? -I'm in class 4A too

641 -How many people are there in your school? -There are( 200)

642 people

643 -Is your school new ...(or) old? -It's old

644 -Do you like your school? -Yes. I do

645 -Are your friend...? Yes. They are

646 -Do you like playing hide and seek? -Yes. I do

647 -What do you like playing? -I like playing chess

648 -Ok. Thanks for your test. Goodbye

649 POST-TEST:

650 Pair 1

651 -Good morning (4)

652 - What is your name? - My name is Huy.

653 - And what is your name? - My name is Anh.

654 - How do you spell your name, Anh? ...(silent).Ok

655 - How do you spell your name, Huy?

656 -That..(silent). Ok

657 - How are you today? - Uhm, fine, thank you.

658 - And you? Fine. (Thank you)

659 - What do you do, Huy? - I'm a people.

660 - And what do you do, Anh? - I'm a people too.

661 - How old are you, Anh? - I'm ten years old.

662 - And how old are you, Huy? - I'm (ten) years old.

663 - Where are you from, Huy? - I'm from VN.

664 - And where are you from, Anh? - I'm from VT.

665 - Are you Vietnamese, Anh? ..(silent). Ok

666 - What nationality are you, Huy? - I'm Vietnamese.

667 - What day is this today, Anh? - This Monday

668 - Do you have English on Wednesday? - No, (we have)

669 English on..(silent)

670 - What do you do on Wednesday, Huy? - I go to (school).

671 Ok

672 - What is the date today, Anh? - It the six of... Ok

673 - When is your birthday? - It on the fifth of may

674 - When is your birthday, Huy? - It the fifth of october. Ok

675 - What can you do, Anh? - Yes, i can

676 - Can you cook, Huy? - Yes, i can

677 - Where are you your school, Anh? - It in Truong Thinh

678 (street). - And what about you? What the name of your

679 school? - It Truong Thinh street too

680 - What class are you in ,Anh? - I'm in class four A.

681 - And what class are you in, Huy?- I'm in class four A.

682 - What do you like doing, Anh? - I like watching tv.

683 - And what do you like doing, Huy? - I like play

684 badminton.

685 - What is your hobby, Anh? - I like riding a bike

686 - What is your hobby, Huy? - I like flying a kite

687 - What subject do you have today, Anh? - I have

688 Vietnamese and music

689 - Do you have music today? - Yes, i do. Ok

690 - Do you have art and history today, Huy?

691 - Yes..no I don't.

692 - Who is your art teacher, Huy? - It mrs. Tam. Ok

693 - Who is your music teacher, Anh? - It mr tien

694 - Where was you yesterday,Anh? - I'm a people

695 - Where was you yesterday, Huy? - I was at home.

696 - What did you do yesterday? - I painted a picture. Ok

697 - What did you do last night, Anh? ... (silent).ok 
698 Now, we continue with test 2: talking about picture

699 - How many room are there in a house, Huy?

700 - There are six rooms in a house.

701 - What are they? -A living room, a (dying room), a kitchen

702 and 2 (bedroom)

703 -Who that, Anh? -It Mary.

704 -Where is she from? ..(silent). Ok

705 -What nationality is she? ..(silent).ok

706 -How old is she, Huy? -She nine years old

707 -What does she like? -She like.. uhm

708 -What does she dislike? -She dislike doing car.

709 -What is this, Anh?..(silent).ok

710 -What color is this, Huy? -It blue and white.

711 -What are there? -There are some of toys

712 -How many toys are there? -There are ten toys.

713 -What colors are there, Anh? -They are..(silent)

714 -What colors are there, Huy? -They are (red) yellow and

715 black.

716 -Is this your school bag, Anh? -Yes, is he.

717 -Is that your pen? -No. it isn't my pen.

718 -What do you do at bleak time, Huy? -I play the piano.

719 -And what about you, Anh? -I play chess.

720 -Do you like badminton, Huy? -Yes, i do.

721 -And do you like Hide and seek?- no, i don't. i like the

722 keeping.

723 -Who that man? -He is my father.

724 -Really? He is young. And what does he do? -He doctor.

725 -How many doors are there in the living room, Anh? -

726 There is one.

727 -How many windows are there? ..(silent).ok

728 -How many windows are there, Huy? -There are two

729 windows

730 -How many chairs are there, Anh? -There are six

731 -What the weather like, Huy? -It some (nice) and beautiful

732 -What the weather like in Phu Tho today, Anh? ..(silent).ok

733 Now, we continue with test 3

734 Work in pair.

735 -What does in this today? -It Monday

736 -And what the date to...(silent). -It the fifth of october. Oh.

737 It Mourit's birthday today

738 -Is he having a party? -Yes. He is have birthday Mourit
Pair 2

Good morning(4)

-What is your name? -my name is Phong

-And what is your name? -my name is Nam

-How do you spell your name, Nam? -That $n$ a m

-How do you spell your name, Phong? -That p (h o n g)

-How are you? -I'm fine, thank you.

-And you?-I'm fine. Thank you

-What do you do, Phong? -I'm a (pupil)

-What do you do, Nam? -I'm (pupil) too

-How old are you, Phong? -I'm ten years old

-How old are you, Nam? -I'm ten years old too

-Where are you from, Nam? -I'm from VN

-Where are you from? -I'm from VT city

-Are you Vietnamese? -Yes

-What nationality are you? -I'm vietnamese

-What day is this today, Nhat Phong? -It Wednesday.- Do

you have english on Wednesday? -No. we have english on Friday.

-What do you do on Wednesday? -I go to school

-Do you have music on Wednesday, Nam?

-It..(silent)

-What do you do on Wednesday?- I go to school

-What is the date today, Nhat Phong? -It the six of january

-When is your birthday, Nhat Phong? -It on fifth of may

-When is your birthday, Nam? - It...uh (silent)

-What can you do, Nam? -I can play football

-Can you cook, Nhat Phong? -Yes, i can

-Where is your school? -It is Truong Thinh street.

-What about you? What name of your school, Nhat Phong?

-It in Truong Thinh street too.

-What class are you in, Nam? -I'm in class four A
-What class are you in, Phong? -He in class.. i'm in class four A

-What do you like doing, Nhat Phong? -I like watching tv

-What do you like doing, Nam?- I like playing badminton

-What is your hobby, Nam? -I like (riding) a bike

-What is your hobby, Phong? -I like ??

-What subject do you have today, Nhat Phong?- I have

Vietnamese and music

-Do you have music today, Nam? -Yes, i do.

-Do you have art, Phong? -No I don't.

-Who is your music teacher, Nhat Phong? -It is mrs. Tam.

-Who is your art teacher, Nam? -It..(silent)

-Where was you yesterday,Nhat Phong? -I was at school

-What did you do yesterday? -I painted a picture.

-Where was you last night, Nam?- I was at school

-What did you do last night?- I painted a picture

Now , we continue with test 2: talking about a picture

-Who that it Mary?

Where is she from,

Phong? -She froms Italy

-What nationality is she? -She is Italian.

-How old is she, Nam? -She nine years old

-What does she like, Nam? -She like..(silent)

-What does she dislike? -She..uh.. dislike.. uh.. doing..ok

-What does she dislike, Phong? -She dislike do.

-What is this, Nhat Phong? -It a (hat)

-What color is this, Phong? -It blue and white.

-How many room are there in a house, Nam?

-There are six rooms in a house. -What are they? -A living room..(silent).ok

What are they, Nam? -They are.. (silent)

-What are they, Nhat Phong? -They are some of toys -How many toys are there? -There are ten toys.

-What colors are there, ? -They are red yellow and black. -Is this your school bag, Nam? -Yes, it is. -Is that your pen? -No. it isn't my pen it is

-Is this your rubber, Phong? -Yes, it is. -Is that your ruler? -No it isn't. it pen is here

-What do you do at bleak time? -I playing badminton

-Do you like badminton, Nhat Phong? -Yes i do

-Do you like hide and seek, Nam? -No i don't. i like

skating

-Who that man? -He is my father. -Really? He is young. what does he do?- He (doctor).

-How many doors are there in the living room, Nam? -

There are one. There are is one.

-How many windows are there, Nam? -There are two

-How many chairs are there, Phong? -There are six

-What subject do you have today, Phong? -I have math and english

-When do you have art? -Yes, i do.

Now, we continue with test 3

Work in pair.

-Tell me about the weather in VN. What the weather are in $\mathrm{HN}$ in the summer.

-It is..uh..

-what do you usually do in summer. -It..(silent)

-How many (reason) are there in the $\mathrm{VN}$ - There are

four..(silent)

\section{Pair 3}

Hello(2) hi(2)

-What is your name? -my name is Thao

-And what is your name? -my name is Phong

-How do you spell your name, Phong? (Silent)

-How do you spell your name, Thao? -That is..(silent)

-How are you, Phong? -I'm fine, thank you. And you?-ok

-And how are you, Thao? fine. Thank you

-What do you do, Phong? -I'm..(silent)

-What do you do, Thao? -I'm pupil too

-How old are you, Phong? -I'm ten years old

-How old are you, Thao? -I'm ten years old too

-Where are you from, Phong? -I'm from VN

-Are you Vietnamese? ..(silent)

-Where are you from, Thao? -I'm from VT city

-What nationality are you? -I'm vietnamese 
851 -What day is this today, Phong? -Uh..(silent).

852 -Do you have english on Wednesday? -No. (silent).ok

853 -What do you do on Wednesday, Thao?-I go to school

854 -What is the date today, Thao? -It the six of june

855 -When is your birthday? -It on the fifth of may

856 -What is the date today, Phong?- (silent)ok

857 -When is your birthday? -It... uh (silent)

858 -What can you do, Phong? -I can play football

859 -Can you cook, Thao? -Yes, i can

860 -Where is your school? I'm in Truong Thinh street.

861 -What about you? -What the name of your school? -It in

862 Truong Thinh primary school.

863 -What class are you in, Thao? -I'm in class four A

864 -What class are you in, Phong? -He in class four B

865 -What do you like doing, Phong?- (I) like watching tv

866 -What do you like doing, Thao?- I like playing football

867 -What do you like hide and seek? -Yes, i can

868 -What is your hobby, Phong? -I ..like (silent)

869 -What is your hobby, Thao? -I like playing a kite

870 -What subject do you have today, Thao? -I have

871 vietnamese and music

872 -Do you have music today? -Yes, i do.

873 -What subject do you have today, Phong? (silent)

874 -Who is your music teacher, Phong? ..(silent)

875 -Who is your art teacher, Thao? -It is (mr) Tien

876 -Where was you yesterday, Thao? -I was school

877 -What did you do yesterday? -I painted the picture.

878 -Where was you last night, Phong? (silent)

879 Now , we continue with test 2: talking about a picture

880 -What is this, Phong? (silent)

881 -What is this, Thao? -It is a hat.

882 -What color is this? -Uh..(silent)

883 -What are these, Thao? -They are..(silent)

884 -How many toys are there, Phong? (silent)

885 -What color are they, Thao? They are (silent)

886 -Who that, Thao? -It's .. it's.. it's Nga

887 -Where is she from? And from VN

888 -What nationality is she? -She vienamese

889 -How old is she? -She nine years old

890 -What does she like, Phong?(silent)

891 -What does she dislike, Thao? -She..like..did.. doing

892 -How many room are there in a house, Thao?

893 -There are six rooms in a house. -What are they? -A living

894 room, a ? room, a kitchen room and 2 bedroom.

895 -Is this your school bag, Phong? -Yes, it is. -Is that your

896 pen?- No. it isn't my pen.. it

897 -What do you do at bleak time, Thao? -I play.. badminton

898 -What about you, Phong? - i... playing chess

899 -Do you like chess? -Yes i do

900 -Do you likehide and seek, Thao? -No i don't. i like kiting.

901 -Who that man, Phong? -He..my... -what does he do? -

902 He..are doctor

903 Thao. How many doors are there in the living room? -

904 There are one.

905 -How many windows are there?-There are two windows

906 -How many chairs are there? - There are six

907 -Do you have any go fish? -Yes, i do

908 -Where are the cat? -There are five..ok

909 -What the weather like today, Phong? -I'm..it..

910 sunny...and..(silent)

911 -What the weather like Phu Tho today, Thao? -I’m..(silent)

912 Now, we continue with test 3

913 Work in pair.

914 -Tell me about the weather in VN today. Work in pair.

915 What the weather like in HN...(silent)

916 -Tell me about your school?...(silent)

917 -What the name of your school? -It Truong Thinh

918 (primary) street. And what name of (you name). it Truong

919 Thinh primary school. I'm Truong Thinh(Phong)

920 Ok. Thank you. Bye(2)

921

922
How do you spell your name, Trang? -That (silent)

How are you, Trang? -I'm fine, thank you. And you?

-What do you do, Vuong?- I'm a pupil

What do you do, Trang? - I'm pupil too

-How old are you, Vuong? -I'm ten years old

-How old are you, Nam? -I'm ten years old too

-Where are you from, Vuong? -I'm from VN -Are you Vietnamese? -Are you Vietnamese? (silent)

-Where are you from, Ttrang? -I'm from VT city -What nationality are you? - I'm vietnamese

-Do you have any dog? -There i do.. i have two (silent)

-What day is this today, Vuong? -It Wednesday. -Do you have english on Wednesday? -No. we have english on

Friday.

-What do you do on Wednesday? -I go to school

-Do you have art on Wednesday, Trang? -No, we have english on.

-What do you do on Wednesday? - I go to school

What is the date today, Vuong? -It the six of january

-When is your birthday? -It on fifth of may

When is your birthday, Trang? -It on fifth of may

-What can you do, Trang? -I can play football

-Can you cook, Nhat Vuong? -Yes, i can

-Where is your school, Trang? -It is Truong Thinh street.

-What name of your school, Vuong? -It in Truong Thinh street too.

-What class are you in, Vuong? -I'm in class four A

-What class are you in, Trang? - i'm in class four A

-What do you like doing, Trang? -I ... play watching tv

-Do you like playing badminton? (silent)

-What is your hobby, Vuong? - I like riding a bike

-What is your hobby, Trang? - I like (silient)

-What subject do you have today, Trang? - I have

vietnamese and music

-Do you have music today? -Yes, i do.

What subject do you have today, Vuong? - I have

vientnamese and music

-Do you have vietnamese today?- No I don't.

-Who is your vietnamese teacher, ? -It is mrs. Tam.

-Who is your art teacher, Trang? -It mr Tien

-What is Trang doing? She is listening to music

-Does she like playing hide and seek? (silient)

Now , we continue with test 2: talking about a picture

-How many room are there in a house, Vuong?

-There are six rooms in a house.

-What are they? - A living room, a (dying room), a kitchen, two bedroom

-Who that, Trang? -It Mary

Where is she from? -She from vn

-What nationality is she? -She is vn

-How old is she? -She nine years old

-What does she like? -She.. listen.

-What does she dislike, Vuong? -She dislike doing picture

-What does she like, Vuong? -She like..(silent)

-Is she pretty? (silent)

-What is this, Vuong? -It is a..(silent)

-What are they, Trang? -They are.. (silent)

-What color is this? (silent)

-What is this, Trang? -It .. a... what color is this? It a

(silent)

-What are these, Vuong? -They are (silent)

How many toys are there? There are ten toys.

-What colors are they? -They are (silent)

-Is this your school bag, Trang? -Yes, it is. -Is that your

pen? -No. it isn't .my pen it is

-Do you like badminton, Vuong? -Yes i do

-Do you like hide and seek? -No i don't. i like skating

-Do you like chess? -Yes, i do

-Do you like flyman club??? -No, i don't. i like keeping??

-Who that man, Trang? -He is my ..(silent) .

-what does he do? -He a doc..(silent)

-How many doors are there in the living room, Vuong? There is one

-How many windows are there? -There are two windows -How many chairs are there, Trang? (silent)

-What is the weather today, Vuong? -It sunny and (silent)

-What is the weather Phu Tho today, Trang? -It (silent) 
1005 Now, we continue with test 3: talking about your family

1006 -How many people are there in your family?

1007 -There are..

1008 -Are you happy today? -Yes, i'm

1009 -Who are they? -They are my..teacher..(??) my sister and

1010 me

1011 -What is your father job?- He is..(silent)

1012 Thank you. Good bye

1013

1014

1015

1016

1017

1018 What is your name? my name is hieu

1019 And what is your name? my name is anh

1020 How do you spell your name, anh? That a $\mathrm{n} h$

1021 How do you spell your name, hieu? That a..(silent)

1022 How are you today? I'm fine, thank you. And you? fine.

1023 Thanks

1024 What do you do? I'm a pupil

1025 What do you do, hieu? I'm pupil too

1026 How old are you, hieu? I'm ten years old

1027 How old are you, anh? I'm ten years old too

1028 Where are you from, anh? I'm from VN

1029 Are you Vietnamese? Yes

1030 Where are you from? I'm from VT city

1031 What nationality are you? I'm vietnamese

1032 What day is this today, anh? It Wednesday. Do you have

1033 english on Wednesday? No. we have english on Friday.

1034 What do you do on Wednesday? I go to school

1035 Do you have music on Wednesday, nam? It..(silent)

1036 What do you do on Wednesday? I go to school

1037 Do you have vietnamese on Wednesday, hieu? No..we

1038 have english..(silent)

1039 What do you do on Wednesday? I go to school

1040 What is the date today, hieu? It the six of.. (silent)

1041 When is your birthday? october

1042 When is your birthday, anh It on the fifth of may

1043 What can you do, hieu? I can play football

1044 Ca you play tennis? Yes, i can

1045 Can you cook, anh? Yes, i can

1046 What can you do? I can cooking

1047 Where is your school, anh? It truong thinh street.

1048 -What name of your school, Hieu? -It in Truong Thinh

1049 primary school

1050 -What class are you in? -I'm in class four A

1051 -What class are you in? -He in class.. i'm in class four B

1052 -Do you like your school?- Yes, i like

1053 -What do you like doing, Hieu? -I like watching tv

1054 -What do you like doing, Anh?-I like playing badminton

1055 -Do you like playing chess, Hieu? (silent)

1056 -What is your hobby, Hieu? -I like playing ..the football..a

1057 football

1058 -What is your hobby,Anh? -I like fly a kite

1059 -What subject do you have today? -I have vietnamese and

1060 music

1061 -Do you have music today? -Yes, i do.

1062 -What subject do you have today? -Vietnamese and math

1063 -Do you have math today? -No I don't.

1064 -Who is your math teacher?- It miss..(silent)

1065 -Who is your vietnamese teacher, Anh? - It miss Hoa

1066 -What do you do, Hieu? - I'm a pupil

1067 -What do you do, Anh? -I'm pupil too

1068 -Where was you last night? -I..i was...i was at school

1069 . -What did you do last night? - I painted a picture.

1070 -Where was you yesterday, Hieu? -I have.. i was at home

1071 -What did you do yesterday? -I (silent)

1072 -Do you have any dog? -Yes. I (don't). i have two

1073 -Where are the dogs?- Where are..(silent)

1074 -Do you like them? -Yes. I do

1075 -Do you have any cat, Anh? -Yes, i do. I have 2 cats

1076 -Where are the cats? -They are..(silent)

1077 -Do you like them? -Yes. I do

1078 Now , we continue with test 2: talking about a picture

1079 -What are these, Hieu? -They are(silent)

1080 -How many toys are there? -They are ten toys

1081 -What colors are they? -They are (silent)
-What colors are they,Anh? -They are red, yellow and black

-What is this, Anh? -It is (silent)

What colors is this? -This blue and white

-Who that? -it Nga

-Where is she from,Hieu? -She froms vn

-What nationality is she? -She is vietnamese

-How old is she? -She nine years old

-What does she like? -She like..(silent)

-What does she dislike? -She (silent)

-Is she friendly? -It a..(silent)

-How many room are there in a house, Anh?

-There are six rooms in a house.

-What are they? -A living room, a .. room, a kitchen and 2 bedroom

-Is this your school bag, Hieu? -Yes, it is. -Is that your pen? - No. it isn't it my pen

-Is this your ruler, Anh? -Yes, it is. -Is that your rubber?No it isn't.

-What do you do at bleak time, Hieu? -I playing football

-And what about you, Anh? -I playing a chess

-Do you like football Hieu? -Yes i do

-Do you like play hide and seek, Anh? -no i don’t. i like sketching

-Who that man, Hieu? -He ..my ... -what does he do?- He

How many doors are there in the living room, Anh? -

There is one

-How many windows are there? -There are two widows

-How many chairs are there, Anh? -There are six

-What is the weather like today, Hieu?

-It..(silent)

-What is the weather like in Phu Tho today,Anh? -It cold and cloudy

Now. We continue with task 3: tell me about the story: cat and mouse

What day is this today? -It monday

-What...(silent). -It the fifth of october

$-\ldots$ is it Mary’s birthday today? ()$^{\wedge * \% \& \%} \%^{\wedge}$

-Yes.it is

-What the happy? Thank you. Good bye

\section{Pair 6}

Good morning(4)

-What's your name?- my name is Hien

-And what's your name? -my name is Phuong

-How do you spell your name, Phuong? -That p h u o n g

-How do you spell your name, Hien? -That h i e $n$

-How are you today? I'm fine, thank you. And you? fine.

Thanks

-What do you do, Phuong? - I'm a pupil

-What do you do, Hien? -I'm pupil too

-How old are you, Phuong? -I'm nine years old

-How old are you, Hien? -I'm nine years old too

-Where are you from? -I'm from VN

-Are you Vietnamese? (silent)

-Where are you from? -I'm from Phu Tho town

-What nationality are you?- I'm vietnamese

-What day is this today, Phuong?- It Wednesday. -Do you

have english on Wednesday?- No. we have english on Friday.

-What do you do on Monday, Phuong? -I go to school

-Do you have history on monday,Hien? -No, we have history on friday

-What do you do on Wednesday?-I go to school

-What is the date today, Phuong? -It the six of september

-When is your birthday, Phuong? -It on the fifth of may

-When is your birthday, Hien? -It on the fifth of (silent)

-What can you do, Hien? -I can play piano

-Can you cook, Phuong? -Yes, i can

-Where is your school, Hien? -It Truong Thinh street.

-What name of your school, Phuong? -It in Truong Thinh primary school

-What class are you in, Hien?- I'm in class four A

-What class are you in,Phuong? -i'm in class four A

-What do you like doing, Hien? -I like watching tv 
-What do you like doing, Phuong? -I like playing badminton

-What's your hobby, Hien? -I like riding a bike

-What's your hobby,Phuong? -I like flying a kite

-What subject do you have today,Hien? -I have vietnamese and music

-Do you like the music? -Yes, i do

-Who is your music teacher, Phuong? -It (silent)

-Who is your art teacher, Hien?-It mr Tien

-What do you do, Phuong? -I'm a pupil

-What do you do, Hien? -I'm pupil too

-Where was you yesterday? -I was at home

-What did you do yesterday? -I painted a picture.

-Where was you last night, Phuong? -I was at home

-What did you do last night? -I (silent)

-Do you have any dog? -Yes. I do. i have two dogs

-Where are the dogs? -They are in..(silent)

-Do you like them? -Yes. I do

-Where's Sapa, Hien? -It in south Vietnam

-Is this very beautiful? -Yes.it is

-Where's Ho Chi Minh city? -It in (silent)

-Is it beautiful? -Yes, it is

-Where is your town, Hien? -It's in Phu Tho

-Is this big and nice? -Yes, it is

Now , we continue with test 2: talking about a picture

-Who that? - it Nga

-Where is she from? -She froms vn

-What nationality is she? -She is Vietnamese

-How old is she? -She nine years old

-What does she like? -She like..(silent)

-What does she dislike, Hien? -She likes doing..(silent)

-What is this, Hien? -It a..(silent)

-What colors is this? -It blue and white

-How many room are there in a house, Hien?

-There are six rooms in a house.

-What are they? -A living room, a kitchen and 2 bedroom

-What are these? -They are some toys

-How many toys are there? -There are ten toys

-What colors are there? -There are red, yellow and black

-Is this your school bag, Phuong? -Yes, it is. -Is that your pen?- No. it isn't. it my pen is here

-Is this your rubber, Anh? -Yes, it is. -Is that your ruler? Yes. It is

-What do you do at bleak time, Phuong? -I play badminton -And what about you, Hien?- I play chess

-Do you like badminton, Phuong? -Yes i do

-Do you like hide and seek, anh? no i don't. i like skating -Who that man,Phuong? -He ..my father.

-really? he is young. what does he do? -He is a doctor.

-Who that woman? -He,, my father :3

-What does the mother do? -He a..(silent)

-How many doors are there in the living room, Hien? There is one

-How many windows are there? -There are two windows -How many chairs are there, Phuong? - There are six -What is the weather like today, Hien?- It's sunny and hot -What is the weather like in Phu Tho today,Phuong? - it cold

Now. We continue with task 3: tell me about the nice weekend

-Hi, did yo have nice weekend? -Hello. Yes, i did -What did you do? -I was my mother's birthday. -We have big party. -The food was go.. \&\%\&

-What did you do? -Oh, i.. at home

-What did you like your night weekend? -Yes. I did

\section{Pair 4}

Good morning(4)

-What's your name? -my name is Thuy

-And what's your name? -my name is Vinh

-How do you spell your name, Vinh? -That v i n h

-How do you spell your name, Thuy? -That t h u y

-How are you today? -I'm fine, thank you.

-And you?- I'm fine. Thank you

-What do you do, Vinh? -I'm a pupil

-What do you do, Thuy? -I'm pupil too

How old are you, Vinh? -I'm ten years old -How old are you, Thuy? -I'm ten years old too -Where are you from, Thuy? -I'm from VN

-Where are you from, Vinh? -I'm from Viet Tri city -Are you Vietnamese? -Yes. I'm

-What nationality are you, Thuy? - I'm Vietnamese

-What day is this today, Vinh? - It Wednesday.

-Do you have history on Wednesday? -No.i don't. we have english on friday

-What do you do on friday? -I go to school

-What day is this today, Thuy? -It the six of january

-When is your birthday? -It the fifth of may

-When is your birthday, Vinh? -It on the fifth of june

-What can you do, Vinh? -I can play football

-What can you do, Thuy? -I can cook

-Can you cook, Thuy? -Yes, i can

-Where is your school,Vinh? -It Truong Thinh street.

-What name of your school? -It in Truong Thinh primary school

-What name of your school, Thuy? - It in Truong Thinh primary school

-What class are you in? -I'm in class four A

-What class are you in, Vinh?- i'm in class four A

-What do you like doing, Thuy? -I like watching tv

-What do you like doing? -I like watching tv

-Do you like playing badminton? -Yes. I do

-What's your hobby, Vinh? -I like riding a bike

-What's your hobby,Thuy? -I like riding a bike

-What subject do you have today?- I have math, music

-Do you like the music? - No. i don't

-What subject do you have today, Thuy? - I have

vietnamese and music

-Do you like the music? -Yes, i do

-Who is your music teacher, Thuy? -It's mrs Tam

-Who is your art teacher, Vinh? -It mr Tien

-Where was you last night? - I was at home

-What did you do last night? - I painted a picture -Where was you yesterday, Thuy? -I was at home -What did you do yesterday? -I painted a picture. -Do you have any dog, Thuy ? -Yes. I do. i have two dogs -Where are the dogs? -They are in a below of the table

-Do you like them? -Yes. I do

-Where's Sapa, Vinh? -It in north Vietnam

-Is this very beautiful? -Yes.it is

-Where's Ho Chi Minh city,Thuy?- It in (silent)

-Is it very beautiful? -Yes, it is

-Where is your town? -It's Phu Tho

-Is this big and nice? -Yes, it is

Now, we continue with test 2: talking about a picture

-Who that? - it Nga

-Where is she from? -She froms vn

-What nationality is she? -She is vietnamese

-How old is she? -She nine years old

-What does she like? -She like ... shop

-What does she dislike,? -She dislike father

-What is this, Thuy? -It a...(silent)

-What colors is this? -It blue and window -How many room are there in a house, Thuy? -There are six rooms in a house.

-What are they? -A living room, a( dying room), a kitchen and 2 bedroom 
1313 -How many windows are there? -There are two windows

1314 -How many chairs are there,Thuy? -There are six

1315 -What is the weather like today, Vinh? -It’s sunny and

1316 cloudy

1317 -What is the weather like in Phu Tho today, Thuy? - it cold

1318 and cloudy

1319 Now. We continue with task 3: talking about your family

1320 -Hi, did yo have nice weekend? -Hello. Yes, i did

1321 -How many people are there in your family?

1322 -There are four

1323 -How many people are there in your family?

1324 -There are four. -Who are they? -They are my mother, my

1325 father, my sister and me

1326 -What is your father job? - \%\&\%* he a working

1327 -How old is he? -He thirty

1328 -How old is your father? $-\wedge \% \wedge$

1329 -What is your mother name? -her name Bich

1330 -What is your mother name?- her name An

1331 -What does she do? -She a teacher

1332 -And what does your mother do? -She a teacher

1333 -Is she pretty? -Yes. It is....

1334 -Do you love your family? -Yes, i do

\section{Pair 8}

\section{Good morning(4)}

-What's your name? -my name is Long

-And what's your name? -my name is Nam

-How do you spell your name? -That $\mathrm{n}$ a $\mathrm{m}$

-How do you spell your name? -That l o n

-How are you today, Long?- I'm fine, thank you. -And you? -fine. Thank you

-What do you do, Nam? -I'm a pupil

-What do you do, Long? -I'm pupil too

-How old are you, Nam? -I'm ten years old

-How old are you, Long? -I'm ten years old too

-Where are you from? -I'm from VN

-Are you Vietnamese? -Yes. I'm

-Where are you from, Nam? -I'm from Phu Tho town

-What nationality are you? -I'm Vietnamese

-What day is this today, Long? -It's monday.

-Do you have history on monday? -No. we have history on monday

-What do you do on Monday?- I go to school

-Do you have english on Wednesday, Nam?- No, we have english on friday

-What do you do on friday? -I go to school

-What is the date today, Nam? -It the six of septembe

-When is your birthday, Nam?- It on the fifth of may

-When is your birthday, Long? -It on the eighteen of october

-What can you do, Long? -I can play $\$ \% \$$

-Can you cook?- Yes, i can

-What can you do, Nam? -I can play badminton

-Can you play chess? -No. i can't

-Where is your school, Nam? -It in Truong Thinh street.

-What name of your school, Nam?- It in Truong Thinh primary school

-What name of your school, Long? - It in Truong Thinh primary school too

-What class are you in? -I'm in class four A

-What class are you in,Nam?- i'm in class four A

-What do you like doing, Nam? -I like watching tv

-What do you like doing, Long? -I like playing badminton

-What's your hobby? -I like riding a bike

-What's your hobby,Nam? -I like flying a kite

-What subject do you have today,Long? -I have vietnamese and music

-Do you have the music today?- No. i don't

-What subject do you have today,Nam ? - I have math,

vietnamese and music

-Do you have the english today? -No. i don't

-Who is your english teacher, Nam? -It mr Tien

-Who is your music teacher,Long? -It mrs Tam

-Where was you last night, Long? -I was at home

-What did you do last night ? - I painted a picture
-Do you like watching tv? -No. i don't
1390 -Where was you yesterday, Nam? - I was at school

1391 -What did you do yesterday? -I water a flower

1392 -Do you have any dog? -Yes. I do. i have two dogs

1393 -Where are the dogs, Long? - They... are in (silent)

1394 -Do you like them? -Yes. I do

1395 -Where’s Sapa, Nam? - It in north Vietnam

1396 -Is this very beautiful, Long? -Yes.it is

1397 -Where's Ho Chi Minh city? - It in sourth Viet Nam

1398 -Is it very beautiful, Nam? -Yes, it is

1399 -Where is your town, Nam? -It's in Phu Tho province

1400 -Is this big and nice? -Yes, it is

1401 Now, we continue with test 2: talking about the picture

1402 -How many room are there in a house, Long?

1403 -There are six rooms in a house.

1404 -What are they? -A living room, a dying room, a kitchen

1405 and 2 bedroom

1406 -Who's that, Nam?- it Mary

1407 -Where is she from? -She froms Italy

1408 -What nationality is she? -She is Italian

1409 -How old is she? -She nine years old

1410 -Is she pretty? (silent)

1411 -What does she like doing? -She like -- shop and $\wedge \$$

1412 -What is this, Long? -It's a hat

1413 -What colors is this? - It blue and (white)

1414 -What is this, Nam? -It's.. (silent)

1415 -What colors is this? - This black and grown

1416 -What are these, Nam? -There are toys

1417 -How many toys are there? -There are ten toys

1418 -What colors are they? -They are red, yellow and black

1419 -Is this your school bag, Long? -Yes, it is. -Is that your

1420 rubber? -No. it isn't. it pen is here

1421 -Is this your ruler, Nam? -No. it isn't. -Is that your pen? -

1422 Yes. It is

1423 -What do you do at bleak time, Nam? -I play badminton

1424 -And what about you, Long? -I play chess

1425 -Do you like chess? -Yes i do

1426 -Do you like badminton, Nam? -No. i don't. i like

1427 sketching

1428 -Who that man, Long? -He is my father.

1429 -really? he's young. what does he do? -He is a doctor.

1430 -Who that woman, Nam? -He's my mother. -What does she

1431 do? (silent)

1432 -How many doors are there in the living room, Nam? -

1433 There is one

1434 -How many windows are there, Nam? -There are two

1435 windows

1436 -How many chairs are there, Long? -There are six

1437 Now. We continue with task 3: tell me about your nice

1438 weekend

1439 -Hi. Did you have a nice weekend. -Hello. Yes. I did. I was 1440 great

1441 -What did you do? -I was my brother's birthday. -We have

1442 big party. The food was good. And my brother's friend

1443 were ...

1444 -What did you do? -Wow.it ... They at home ...the house

1445 and watch tv

1446

1447

1448

1449
-Did you like.. your nice (weekend)? -Yes. I did

\section{Pair 9}

Hello(2) hi(2)

-What's your name? - my name is Mai

-And what's your name? - my name is Quan

-How do you spell your name, Quan? -That q u a n

-How do you spell your name, Mai? -That m a i

-How are you today? -I'm fine, thank you. And you? - fine.

Thanks

-What do you do, Quan? -I'm a pupil

-What do you do, Mai? - I'm pupil too

-How old are you, Mai? -I'm ten years old

-How old are you, Quan? -I'm ten years old too

-Where are you from, Mai? -I'm from VN

-Are you Vietnamese? -yes

-Where are you from, Quan? - I'm from Viet Tri city

-What nationality are you, Quan? - I'm Vietnamese

-What day is this today, Mai? - It Wednesday.

-Do you have history on Wednesday? -No. we have history on thusday. 
1467 -What do you do on thusday? - I go to school

1468 -Do you have english on wednesday? -No, we have english 1469 on monday

1470 -What do you do on monday? -I go to school

1471 -What is the date today, Mai? - It the six of january

1472 -When is your birthday, Mai? -It on the fifth of may

1473 -When is your birthday, Quan? -It on the fifth of june

1474 -What can you do, Quan? -I can play football

1475 -Can you play the piano? -Yes. I can

1476 -What can you do, Mai? -I can play badminton

1477 -Can you cook? -Yes, i can

1478 -Can you cook well? -Yes. I can

1479 -Where is your school, Mai? - It Truong Thinh street.

1480 -What name of your school? - It in Truong Thinh primary

1481 school

1482 -What name of your school, Quan? - It in Truong Thinh

1483 primary school

1484 -What class are you in? - I'm in class four A

1485 -What class are you in,Mai? - i'm in class four b

1486 -Is this big and nice? -yes

1487 -What do you like doing,Mai? -I like watching tv

1488 -Do you like watching tv? -Yes, i'm

1489 -What do you like doing, Quan? -I like playing badminton

1490 -Do you like badminton? -Yes. I'm

1491 -What's your hobby, Mai? -I like (riding) a bike

1492 -What's your hobby, Quan? -I like fly a kite

1493 -What subject do you have today? -I have math. English,

1494 vietnamese and science

1495 -Do you have math today? -Yes, i do

1496 -What subject do you have today, Mai? - I have vietnamese

1497 and music

1498 -Do you have music today? -No. i don't

1499 -Who is your music teacher? - It mrs. Tam

1500 -Who is your vietnamese teacher, Quan? - It mr Tien

1501 -Where was you yesterday? -I was at school

1502 -What did you do yesterday? -I painted a picture.

1503 -Where was you last night, Mai? -I was at home

1504 -What did you do last night? -I was.. watching tv

1505 -Do you have any dog, Mai? -Yes. I do. i have two dogs

1506 -Where are the dogs? -They are in dogs of the table

1507 -Do you like them? -Yes. I do

1508 -Where's Sapa, Quan? - It in north Vietnam

1509 -Is this very beautiful? -Yes.it is

1510 -Where’s Ho Chi Minh city, Mai?- It in south Viet Nam

1511 -Is it beautiful? -Yes, it is

1512 -Where is your town, Quan? - It's in Phu Tho province

1513 -Is this big and nice? -Yes, it is

1514 -Where is your house, Mai? -It in pt province

1515 -Is this small? -Yes, it is

1516 Now, we continue with test 2:

1517 -How many rooms are there in a house, Mai?

1518 -There are six rooms in a house.

1519 -What are they? -A living room, a dying room, a kitchen

1520 and 2 bedroom

1521 -Who's that, Quan? - it Mary

1522 -Where is she from? -She froms vn

1523 -Is she Vietnamese? -Yes. She is

1524 -How old is she? -She nine years old

1525 -What does she like? -She like \%^\%^ shop \%^\%\&

1526 -What does she dislike? -She dislike doing father

1527 -What is this, Mai? -It a hat

1528 -What colors is this?-It blue and white

1529 -What are these, Quan? -They are some toys

1530 -How many toys are there? -There are ten toys

1531 -What colors are they? -They are red, yellow and black

1532 -Is this your rubber, Mai? -Yes, it is. - Is that your pen? -

1533 Yes. It is . my pen is here

1534 -Is this your ruler, Quan? -Yes. It is. -Is that your rubber? -

1535 No. it isn't

1536 -What do you do at bleak time, Mai? -I play badminton

1537 -And what about you, Quan? - I play football

1538 -Do you like football? -Yes i do

1539 -Do you like hide and seek, Mai? - Yes. I do

1540 -Do you like skating? -No. i don't

1541 -Who that man, Quan? -He is my father..

1542 - really? he is young .what does he do? -He is a doctor.

1543 -Who that woman, Mai? -She is my mother.
-Really? She is old. What does she do? -She is a teacher -How many doors are there in the living room, Quan? There is one

-How many windows are there? -There are two windows -How many chairs are there ? -There are six

What is the weather like today, Mai? -It's sunny and warm -What is the weather like in Phu Tho today,Mai? - it (cold and cloudy)

Now. We continue with task 3: tell me about the weather in vn today

- What is the weather like in Ha Noi in summer? - It is very hot and sunny

-What do you usually doing in the summer? -I usually go swimming

-How many season in the Viet Nam? -There are four season

-What are they? -They are spring, summer, autumn and winter

-Why is summer a raining season.? - Because it very hot and it often rain

Is the weather in a autumn hot? - No. it isn't. it cold and windy

-Do you like the weather in Viet Nam ? -Yes. I do. I love it so much

Pair 10

Good moring(4)

--What's your name?- my name is Huyen

-And what's your name? - my name is Hai

-How do you spell your name, Hai? - That h a i

-How do you spell your name,Huyen? -That h u y e n

-How are you today, Hai? I'm fine, thank you.

- And you? fine. Thank you

-What do you do, Hai? -I'm a pupil

-What do you do, Huyen? -I'm a pupil too

-How old are you, Huyen?- I'm nine years old

-How old are you, Hai? -I'm ten years old

-Where are you from, Hai? -I'm from VN

-Are you Vietnamese? -Yes. I am

-What nationality are you, Huyen? -I'm Vietnamese

-What day is this today, Huyen? -It's wednesday. -Do you

have history on wednesday? -No. we have history on

Monday and wed and friday

-What do you do on friday? -I go to school

-Do you have english on Tuesday,Hai? - No, we have english on thusday

-What do you do on tuesday?- I go to school

-What is the date today, Hai? -It the six of january

-When's your birthday, Hai? -It's on the fifth of june

-When's your birthday, Huyen? -It's on the thirty of may

-What can you do, Huyen? -I can play badminton

-Can you cook? -No. i don't

-What can you do,Hai? -I can play hide and seek

-Can you listen to music? -Yes. It is

-Where is your school, Hai?- It's in Truong Thinh street.

-What's the name of your school, Hai? - It in Truong Thinh primary school

-What's the name of your school, Huyen? -It in Hung

Vuong primary school

-What class are you in? -I'm in class $5 \mathrm{~A}$

-Is your classroom big and nice? -No.. no. it isn't. it's small

-What class are you in, Hai? - i'm in class four A

-Is your classroom small? -Yes, it is

-What do you like doing, Hai? -I like listening to music

-Do you like listening to music? -Yes. I do

-What do you like doing, Huyen? -I like playing hide and seek

-Do you like skeeping? -No. i don't

-What's your hobby, Huyen? -I like riding a bike

-What's your hobby, Hai? -I like flying a kite

-What subject do you have today, Hai? -I have Vietnamese and music and art

-Do you have music today? -Yes. I do

-What subject do you have today, Huyen? - I have math

vietnamese and english

-Do you have the math today? -Yes. I do

-Who is your math teacher, Huyen? - It's mrs Hoa

-Who is your vnese teacher, Hai? -It mrs Hoa 
1621 -Where was you yesterday, Hai? - I was at home

1622 - What did you do last yesterday? -I watching.. watch tv

1623 -Where was you last night, Huyen? -I was in i was at home

1624 -What did you do last night? -I water a flower

1625 -Do you have any dog, Hai? -Yes. I do. i have two dogs

1626 -Where are the dogs? -They are in.. of the table

1627 -Do you like them? -Yes. I do

1628 -Do you have any cat, Huyen? -Yes. I do. I have one cat

1629 -Where is the cat? -There are in .. the table

1630 -Do you like it? -Yes. I do

1631 -Where's Sapa , Huyen ? - It is north Vietnam

1632 -Is this very beautiful? -Yes.it is

1633 -Where's Ho Chi Minh city, hai? It is south Viet Nam

1634 -Is this very beautiful? -Yes, it is

1635 -Where is your town?- It's in Phu Tho province

1636 -Is this big and nice? -Yes, it is

1637 Now, we continue with test 2: talking about the picture

1638 -Who's that, Huyen? -It's Mary

1639 -Where is she from? -She froms China

1640 -What nationality is she? -She is Chinese

1641 -How old is she? -She ten years old

1642 -Is she friendly? -Yes. She is

1643 -What does she like? -She like yellow t-shirt and a pair of

1644 trousers

1645 -What does she dislike, Huyen? -She dislikes doing.. father

1646 -What is this, Hai? -It's a hat

1647 -What colors is this? -It's blue and white

1648 -How many rooms are there in a house, Huyen?

1649 -There are 6 rooms in a house

1650 -What are they? -A living room, a dying room, a kitchen

1651 and 2 bedrooms

1652 -What are these, Hai? -There are some toys

1653 -How many toys are there? -There are nine toys

1654 -What colors are they? -They are orange, yellow and black

1655 - Is this your ruler, Huyen? -Yes, it is. -Is that your rubber?

1656 -No. it isn't. my rubber is here

1657 -What do you do at bleak time, Hai? -I play skating

1658 -And what about you, Huyen? -I play badminton

1659 -Do you like badminton? -Yes i do

1660 -Do you like hide and seek, Hai? -No. i don't. i like skating

1661 -Who that man, Huyen? - he is my father.

1662 -.really? he's young. what does he do? -He's a worker

1663 -Who that woman, Hai? -He's ... she's my mother.

1664 -really. he's old. What does she do? -She's a teacher

1665 -How many doors are there in the living room, Huyen? -

1666 There is one

1667 -How many windows are there? -There are 3 windows

1668 -How many chairs are there? -There are 5

1669 -What is the weather like today,Hai? -It's cold and cloudy

1670 -What's the weather like in pt today.- It's cold and cloudy

1671 Now. We continue with task 3

1672 -Can you tell me about the weather in Viet Nam

1673 -What's the weather like in Ha Noi in summer?

1674 -It's very hot and sunny

1675 -What do you usually do in summer?- I usually go

1676 swimming

1677 -How many seasons are there in Viet Nam?

1678 -There are 4 seasons

1679 -What are they? -They are spring, summer, autumn and

1680 winter

1681 -Why is summer raining season? -Because it's very hot

1682 and it often rains

1683 -Is the weather in autumn hot? -No. it isn't. it's cool and

1684 windy

1685 -Do you like the weather in Viet Nam ? - Yes. I do. I love it

1686 so much

1687 Thank you. Gb.bb

1688

1689

1690 Pair 11

1691 Hello(2)hi(2)

1692 -What's your name? -my name is Nhi

1693 -And what's your name? -my name is Hang

1694 -How do you spell your name, Hang? - That h a n g

1695 -How do you spell your name, Nhi? - That n h i

1696 - How are you today, Nhi? -I’m fine, thank you.

1697 -And you?
1698 -How are you, hang? fine. Thank you

1699 -What do you do, Hang? -I'm a pupil

1700 -What do you do, Nhi? -I'm a pupil too

1701 -How old are you, Nhi? -I'm ten years old

1702 -How old are you, Hang? -I'm ten years old too

1703 -Where are you from, Hang? -I'm from Phu Tho town

1704 -Are you Vietnamese? -Yes. I am

1705 -What nationality are you, Nhi? -I'm Vietnamese

1706 -What day is this today, Hang?- It's wednesday. --Do you

1707 have geography on Wednesday? -No. we have history on

1708 friday

1709 -What do you do on wednesday? -I go to school

1710 -Do you have english on Monday, Nhi? -No, we have

1711 english on friday

1712 -What do you do on Monday? -I go to school

1713 -What is the date today, Hang? -It the six of january

1714 -When's your birthday, Hang? - It on the fifth of may

1715 -When's your birthday, Nhi? -It on the second of july

1716 -What can you do, Nhi? -I can play football

1717 -Can you cook? -Yes, i can

1718 -What can you do, Hang? -I can play badminton

1719 -Can you listen to music? -No. i can't

1720 -Can you sing Vietnamese song? -Yes. I can

1721 -Where is your school, Hang?- It's in Truong Thinh street.

1722 -What the name of your school, Nhi? - It in Truong Thinh

1723 primary school

1724 -What class are you in? -I'm in class four A

1725 -What class are you in, Hang? - i'm in class four A too

1726 - What do you like doing, Hang? - I like playing badminton

1727 -Do you like doing, Nhi? - I like watching tv

1728 -What's your hobby, Nhi? - I like riding a bike

1729 - What's your hobby,Hang? - I like watching tv

1730 -What subject do you have today, Hang?- I have math

1731 vietnamese and science

1732 -Do you have the science today? -Yes. I do

1733 -What subject do you have today, Nhi? -I have music,

1734 vietnamese and math

1735 -Do you have vietnamese today?. -I don’t

1736

1736

1737

-Who is your math teacher, Nhi? -It miss Nga

-Who is your vietnamese teacher, Hang? - It miss Tam -Where was you last weekend? - I was at home -What did you do last weekend? -I water a flower and when on the picnic

-Where was you last night, Nhi? -I was at home -What did you do last night? -I painted a picture -Do you have any rabbit, Hang? -Yes. I do. i have two .. dogs

-Where are the rabbits? -They are in front of the table -Do you like them? -Yes. I do

-Do you have any cat, Nhi? -Yes. I do. -Where are the cat? -There are in the ..of the table -Do you like them? -Yes. I do -Where's Sapa,Hang ? - It in (north) Vietnam - Is this very beautiful? - Yes.it is -Where's Ho Chi Minh city, Nhi? - It in south Viet Nam -Is this very beautiful? -Yes, it is

-Where is your town, Hang? -It's in Phu Tho town -Is this big and nice? -Yes, it is

Now, we continue with test 2: talking about the picture -How many rooms are there in a house, Nhi?

-There are 6 rooms in a house

-What are they? -A living room, a dying room, a kitchen and 2 bedrooms

-What is this, Hang? - It's a hat

-What colors is this? - It red and blue

-What are these, Hang? - There are toys

-How many toys are there? -There are ten toys

-What colors are they? -They are blue, yellow and black

- Who's that, Hang? - it Nga

-Where is she from? - She froms Viet Nam

-What nationality is she? - She is vnese

-How old is she? -She nine years old

-Is she pretty? -Yes. She is

-What does she like? -She like yellow skirt and pain shoe -What does she dislike? -She dislike doing father -Is this your rubber, Nhi? -Yes, it is. -Is that your ruler? No. it isn't. my ruler is here 
-Is this your school bag, Hang? -Yes, it is. -Is that your rubber? -No. it isn't. my rubber is here -What do you do at bleak time, Nhi? -I play badminton And what about you, Hang? -I playing chess -Do you like chess? -Yes i do

-Do you like hide and seek, Nhi? -No. i don't. i like skating -Who that woman, Hang? -what does she like? -she like cook

-What does she do? -She is a nurse

-Who that man, $\mathrm{N}$ hi? -she's my father. -really?. he's young What does he do? -He's a doctor -How many doors are there in the living room, Hang? There is one

-How many windows are there, Hang? -There are 4 windows

How many chairs are there, Nhi? -How..There are 6 -What's the weather like in Phu Tho today, Hang? - It's sunny and warm

Now. We continue with task 3

Talking about your school

-What is the name of your school? -It Truong Thinh primary school

-What is the name of your school? -It Truong Thinh primary school -Is this big and nice? -Yes. It is -Where is this? -It is Truong Thinh street -What class are you in? -i'm in class four A -What class are you in? -i'm in class four A

-How many people are there in your school? -There are 200 people

-Is your school new or old? -It's old

-Do you like your school? - Yes. I do

-Are \#\$\%\$. -Yes. They are

-@\#\$\#?-Yes. I do

-What do you like play? - I like play football

\section{Pair 12}

Hello(2)hi(2)

-What's your name? - my name is Duong

-And what's your name? - my name is Oanh

-How do you spell your name? -d u o n g

-How do you spell your name, Oanh? -That o a n h

-How are you today, Oanh? - I'm fine, thank you. - And

you? fine. Thank you

- What do you do, Duong? -I'm a pupil

- What do you do, Oanh? - I'm pupil too

- How old are you? - I'm ten years old

- How old are you, Duong? - I'm ten years old too

- Where are you from, Duong? - I'm from VN

- Are you Vietnamese? -Yes. I do

-Where are you from, Oanh? -I'm from Viet Tri city -What nationality are you, Oanh? - I'm Vietnamese -What day is this today, Duong? - It's wednesday. - Do you have geography on wednesday? -No. we have geography on friday

-What do you do on monday? - I go to school

-Do you have ehistory on Tuesday, Oanh?- No, we have history on friday

-What do you do on tuesday? -I go to school -What is the date today, Duong? - It the six of january

-When's your birthday? -It's on the .... of july

-What can you do? - I can play badminton

-Can you cook? -Yes, i can

-What can you do, Oanh? -I can play football

-Can you sing Vietnamese song? -No. i can't

-Where is your school, Duong? -It's in Truong Thinh street.

-What the name of your school, Duong? -It's in Truong Thinh primary school

-What the name of your school, Oanh? -It Truong Thinh primary school

-What class are you in, Oanh? -I'm in class $4 \mathrm{~A}$

-What class are you in, Duong? -i'm in class four A too

-Is your classroom big and nice? -Yes. It is

-What do you like doing, Oanh? -I like watch tv

-What do you like doing, Duong? -I like playing volleyball

-What's your hobby, Duong? -I like riding a bike

-What's your hobby,Oanh?- I like flying a kite -What subject do you have today,Oanh? -I have math vietnamese and english

-Do you have the music today? -Yes. I do

-What subject do you have today, Duong? -I have math, vietnamese and science

-Do you have science today? -No. i don't -Who is your science teacher? -It miss Nga

-Who is your math teacher? - It miss Nga too - Where was you last weekend, Duong? -I was at home -What did you do last weekend? -I painted a picture -Where was you last night, Oanh? -I watch tv -What did you do last night? -I play badminton -Do you have any rabbit, Oanh? -Yes. I do. i have two rabbits

-Where are the rabbits? -They are in front of the table -Do you like them? -Yes. I do -Do you have any cat, Duong? -Yes. I do

-Where are the cats? -There are in front of the table too -Do you like them? -Yes. I do

-Where's Sapa, Duong ? - It’s in north Vietnam

-Is this very beautiful? -Yes.it is

-Where’s Ho Chi Minh city, Oanh? - It's south Viet Nam

- Is this beautiful? - Yes, it is

- Where is your hometown? - It's in Phu Tho province

- Is this big and nice? -Yes, it is

Now, we continue with task 2: talking about the picture -What are these, Duong? - There are some toys

-How many toys are there? -There are ten toys -What colors are they? -They are red, yellow and black -What is this, Oanh? - It's a hat

-What colors is this? -It blue and white -Is this big? -Yes. It is

-How many rooms are there in a house, Duong? --There are 6 rooms in a house

-What are they? -A living room, a dying room, a kitchen and 2 bedrooms

-Who's that, Oanh? - It's Nga

Where is she from? -She froms Viet Nam

-Is she Vietnamese? - She.. Vietnamese...yes. she is -How old is she? -She nine years old

-What does she like? -She like pink shirt and a pair of \%\$ -What does she dislike? -She dislike do father

-Is this your rubber, Duong? - Yes, it is. -Is that your ruler? -No. it isn't. my ruler is here

-What do you do at bleak time, Oanh? -I play badminton

-And what about you, Duong? - I play chess

-Do you like chess? -Yes i do

-Do you like hide and seek, Oanh? -No. i don't. i like skating

-Who that woman? - He is father. ]

- What does she do? -She's a doctor

-How many doors are there in the living room, Oanh? -

There is one

-How many chairs are there? -There are 6

-Who's that man, Oanh? -He is a father.

-Really? He's old. What does he do. -He's a doctor

Now. We continue with task 3

Talk about the family

-How many people are there in your family

-There are 4 
-what do you do? -I'm a pupil

1931 - are you happy today? - Yes. I'm

1932 - and do you love your family? -Yes. I do

1933 Pair 13

$1934 \mathrm{Hi}(2)$ hello(2)

1935 - What's your name? - my name is Giang

1936 - And what's your name? - my name is Quan

1937 - How do you spell your name, Quan? - That qua n

1938 - How do you spell your name, Giang? - That g i a n g

1939 - How are you today, Quan? - I'm fine, thank you. - And

1940 you? -Fine. Thanks

1941 -What do you do, Giang? -I'm a pupi

1942 -What do you do, Quan? -I'm a pupil too

1943 - How old are you? - I'm ten years old

1944 - How old are you? - I'm ten years old too

1945 - Where are you from, Quan? - I from VN

1946 - Are you Vietnamese? - I'm from..(silent)

1947 - Where are you from, Giang? - I'm from Viet Nam

1948 -What nationality are you? -I'm from Vietnamese

1949 -What day is this today, Quan? -It's wednesday.

1950 -Do you have history on wednesday? - No. we have english

1951 on friday

1952 -What do you do on friday? -I go to school

1953 -Do you have geography on monday, Giang?

1954 - No, we have geography on friday

1955 -What do you do on monday? -I go to school

1956 -What is the date today, Quan? -It the six of january

1957 -When's your birthday, Quan? - It on the fifth of june

1958 -When is your birthday, Giang? -It's on the fifth of june

1959 -What can you do, Giang? -I can play football

1960 -Can you sing vnese song? -Yes. I can

1961 -What can you do, Quan? - I can play badminton

1962 - Can you cook? - Yes, i can

1963 - Where is your school, Giang? -It's in Truong Thinh

1964 street.

1965 -What name of your school? -It in Truong Thinh primary

1966 school

1967 -What the name of your school, Quan? -It's Truong Thinh

1968 primary school

1969 -What class are you in, Quan? -I'm in class 4 A

1970 -Is your classroom big and nice? -Yes. It is

1971 -What class are you in, Giang? - i'm in class four A

1972 -Is this small? -Yes. It is

1973 -What do you like doing, Giang? - I like watching TV

1974 -What do you like doing, Quan? - I like play football

1975 -What's your hobby, Quan? -I like riding a bike

1976 -What's your hobby, Giang? -I like fly a kite

1977 -Is your bleak time long, Quan? -No. it isn't

1978 -Do you like playing chess? -Yes. I do

1979 -What do you like play, Giang? -I like play badminton

1980 -What do you do in your break time? -I like playing

1981

1982 -What subject do you have today, Quan? -I have english,

1983 math and vnese

1984 -Do you have vnese today? -Yes. I do

1985 -What subject do you have today, Giang? -I have math,

1986 vietnamese and english

1987 -Do you have english today? -Yes. I do

1988 -Who is your english teacher? -It miss Minh

1989 -Who is your vietnamese teacher, Quan? - It's miss Nga

1990 -What do you do, Quan? -I'm a pupil

1991 -Where was you ylast weekend? -I was at home

1992 -What did you do last weekend? -I painted a picture

1993 -Where was you yesterday, Giang? -I was at home

1994 -What did you do yesterday? -I painted a picture

1995 -Do you have any rabbits, Quan? -Yes. I do. i have two

1996 dogs

1997 -Where are the rabbits? -They are in.... (silent)

1998 -Do you like them? -Yes. I do

1999 -Where’s Sapa, Giang ? - It in north Vietnam

2000 -Is this very beautiful? -Yes.it is

2001 -Where's Ho Chi Minh city, Quan? - It's in (silent)

2002 -Is this very beautiful? -Yes, it is

2003 - Where's your hometown, Quan? - It's in Phu Tho

2004 - Is this big and nice? -Yes, it is

2005 Now, we continue with test 2: talking about the picture
-Who's that, Giang? -It's ma... it's Nga

-Where is she from? -She froms vn

-What nationality is she? -She's Vietnamese

-How old is she? -She nine years old

-What does she like? -She likes pink, street and a pair of trousers

-What does she dislike? -She dislikes doing (silent)

-Is she pretty? (silent)

-How many rooms are there in a house, Quan?

-There are 6 rooms in a house

What are they? -A living room, a (dying) room, a kitchen and 2 bedrooms

-What is this, Giang? -It's a hat

-What colors is this? -It's blue and white

-Is this small? -Yes. It is

-What are these, Quan? -There are some toys

-How many toys are there? -There are ten toys

-What colors are they? -They are orange, yellow and black

-Are they big? (silent)

-Is this your rubber, Giang? -Yes, it is. -Is that your ruler? -No. it isn't. my pen is here

-What do you do at bleak time, Quan? -I play badminton

-And what about you, Giang? -I play chess

-Do you like chess? -Yes i do

-Do you like hide and seek Quan? -No. i don't. i like skating

-Who that woman, Giang? -He’s my father.

-what does she do? -she ...(silent)

-How many windows are there, Quan? -There are 2 windows

How many chairs are there? -There are 6

-What is the weather like in pt today, Giang? -It's sunny and warm

Now. We continue with task 3

Can you tell me about the story: cat and mouse

-What day is this today? -It's Monday

-And what's the date? -It's the fifth of october

-Oh. It's Mourit's birthday today

-Is he having a party today? -Yes. He is. Happy birthday Mourit

Thank you. Gb.bb

\section{Pair 14}

Hello(2)hi(2)

What's your name?- my name is Van

-And what's your name?- my name is Giang

-How do you spell your name, Giang? -That g i a n g

-How do you spell your name, Van? -That v a n

-How are you today, Giang? -I'm fine, thank you. -And you? - fine. Thank you

-What do you do, Van? -I'm a pupil

-What do you do, Giang? -I'm a pupil too

-How old are you, Giang? -I'm ten years old

-How old are you, Van? -I'm ten years old too

-Where are you from, Van? -I'm from VN

-Where are you from, Giang? -I'm from Phu Tho town

-Are you Vietnamese? -Yes

-What nationality are you? - I'm Vietnamese

-What day is this today, Van? - It's wednesday.

-Do you have history on wednesday? -No. we have history on friday

-What do you do on friday? - I go to school

-Do you have english on Monday, Giang? - No, we have english on friday

-What do you do on monday? -I go to school

-What is the date today, Van? -It the six of january

-When's your birthday? -It on the fifth of june

-When's your birthday, Giang? -It on the second of july

-What can you do, Van? -I can play football

-Can you sing Vietnamese song? -Yes. I can

-What can you do, Giang? -I can play piano

-Can you cook? - No. i don't

-Where is your school, Giang? -It's in Truong Thinh street.

-What name of your school? -It in Truong Thinh primary school

-What's the name of your school, Van? -It in Truong Thinh primary school too 
2083 -What class are you in? -I'm in class $4 \mathrm{~A}$

2084 -Is your classroom big and nice? -It's big

2085 -What class are you in, Giang? - i'm in class four A

2086 -Is your classroom small? -Yes. i..uh

2087 -Is your bleak time long, Van? -No. it isn't

2088 -What do you like to play, Giang? -I like play badminton

2089 -Have you got a big family? -Yes. I have

2090 -What do you like doing, Van? -I like watching tv

2091 -What do you like doing, Giang. -I like playing volleyball

2092 -What's your hobby, Van? - I like riding a bike

2093 -What's your hobby, Giang? -I like flying a kite

2094 -What subject do you have today, Van? -I have math

2095 vietnamese and music and english

2096 -Do you have the english today? -Yes. I do

2097 -What subject do you have today, Giang? -I have a math,

2098 music, english and vietnamese

2099 -Do you have the Vietnamese today? -Yes. I do

2100 -Who is your vnese teacher, Giang? - It's miss Nga

2101 -Who is your english teacher, Van? -It mrs Minh

2102 -Where was you last weekend, Van ? - I was at home

2103 -What did you do last weekend? -I painted a picture

2104 -Where was you last night, Giang? -I was at home

2105 -What did you do last night? -I.. i was.. i was painted a

2106 picture

2107 -Do you have any dog? -Yes. I do. i have two dogs

2108 -Where are the dogs? -They are in..(silent)

2109 -Do you like them? -Yes. I do

2110 -Do you have any rabbit, Van? -Yes. I do. I have two

2111 -Where are the rabbits? -There are in .. of the table

2112 -Do you like them? -Yes. I do

2113 -Where’s Sapa, Giang ? -It is north Vietnam

2114 -Is this very beautiful? - Yes.it is

2115 -Where's Ho Chi Minh city, Van? - It is sourth Viet Nam

2116 -Is this very beautiful? -Yes, it is

2117 -Where's your home town? -It's in Phu Tho

2118 -Is this big and nice? -Yes, it is

2119 Now, we continue with test 2: talking about the picture

2120 -Who's that, Giang? -It's Nga

2121 -Where is she from? -She froms Viet Nam

2122 - Is she vnese? - Yes. She is

2123 - How old is she? - She nine years old

2124 - What does she like? - She like pink, t-shirt and a pain of

2125 (silent)

2126 -What does she dislike? -She dislikes going (silent)

2127 -What is this, Van? - It's a hat

2128 -What colors is this? -It's blue and white

2129 -Is this small? -Yes. It is

2130 -How many rooms are there in a flat, Giang?

2131 -There are 6 rooms

2132 -What are they? -A living room, a dying room, a kitchen

2133 and 2 bedrooms

2134 -What are these, Van? -There are some toys

2135 -How many toys are there? -There are ten toys

2136 -What colors are they? -They are red, yellow and black

2137 -Are they big? -Yes. Are they

2138 -Is this your school bag, Giang? -Yes, it is.

2139 -Is that your rubber? - No. it isn't

2140 -What do you do at bleak time, Van? -I play badminton

2141 -And what about you, Giang? -I play chess

2142 -Do you like chess? - Yes i do

2143 -Do you like badminton, Van? -No. i don't. i like skating

2144 -Who that woman, Giang?- she is my mother.

2145 -really? she's young. what does she do? -She's a teacher

2146 -Who that man, Van? she's my father.

2147 - really. he's young. What does he do? - He's a doctor

2148 -How many doors are there in the living room, Giang? -

2149 There is one

2150 - How many windows are there? -There are 2 windows

2151 -How many chairs are there, Van? -There are 6

2152 -What is the weather like Phu Tho today, Giang? -It's

2153 sunny and cloudy

2154 Now. We continue with task 3

2155 Talking aboout the weather today

2156 -What's the weather like in hn in the summer?

2157 -It's very hot and sunny

2158 -What do you usually do in summer?- I usually go swiming

2159

-How many seasons are there in the Viet Nam?
2160 -There are 4 seasons

2161 -What are they? -They are spring, summer, autumn and

2162 winter

2163 -Why a summer raining season? -Because it's very hot and

2164 it often rain

2165 -Is the weather in autumn hot?- No. it isn't. it's cool and

2166 windy

2167 -Do you like the weather in Viet Nam? - Yes. I do. I love it

2168 so much

2169 Thank you. Gb.bb

\section{Pair 15}

Good morning(4)

- What's your name? - my name is Giang

- And what's your name? - my name is Duong

-How do you spell your name, Duong? - That d u o n g

- How do you spell your name, Giang? - That g i a n g

- How are you today, Giang? - Uh..i..I'm fine, thank you.

- And how are you? -fine. Thanks

- What do you do, Giang? - I'm a pupil

- What do you do, Duong?- I'm a pupil too

- How old are you, Duong? - I'm eight years old

- How old are you, Giang? - I'm eight years old too

- Where are you from, Giang? -I'm from VN

-Are you Vietnamese? -Yes. I am

-Where are you from, Duong? - I'm from Viet Tri city

-What nationality are you? - it's Vietnamese

-What do you do in bleak time, Duong? -I play hide and seek

-Is your bleak time long? -No. it isn't

-Do you like playing chess? -Yes. I do

- What day is this today, Giang? - It's wednesday.

- Do you have history on wednesday? - No. we have english on friday

- What do you do on monday? - I go to school

-Do you have geography on Monday, Duong? -Yes. I do

-What do you do on monday? -I go to school

-What's the date today, Giang ?- It the six of january

-When's your birthday? -It's on the fifth of may

-When's your birthday, Duong? -It's the fifth of june

-What can you do, Giang? -I can play football

-Can you sing vnese song? -No. i can't

-Where is your school, Duong? -It's in Truong Thinh ..street.

-What's the name of your school? - It in Truong Thinh

primary school

-What's the name of your school? -It in Truong Thinh primary school

-What class are you in? -I'm in class $4 \mathrm{~A}$

-Is your classroom big ?- yes. i have

-What class are you in, Duong? - i'm in class four A too

- Is your classroom small? -Yes

-What do you like doing, Duong? -I like playing badminton

-What do you like doing, Giang? -I like watching tv

-What's your hobby, Duong? -I like riding a bike

-What's your hobby, Giang? -I like flying a kite

-What subject do you have today, Duong? -It's math,

vietnamese and music

-Do you have english today? -Yes. I do

-What's subject do you have today, Giang? -I have

vietnamese and math

-Do you have the math today? -Yes. I do

-Who is your math teacher? -It's mrs Tam

-Who is your vietnamese teacher, Duong? -It mr Tien

-Where was you last night, Giang? -I was at home

-What did you do last night? -I painted a picture

-Where was you last weekend? -I was at home

-What did you do last weekend, Duong? -I like playing badminton

-Do you have any rabbits? -Yes. I do. i have two.. dogs -Where are the rabbits? -They are in.. front of the table -Do you like them? -Yes. I do

Now. we continue with task 2. talking about the picture

-Who's that, Duong? - It's Nga

-Where is she from? -She froms vn

-Is she vietnamese? -Yes..yes. she is 
2237 -How old is she? - She nine years old

2238 -What does she like? -She like pink...uh.. a pair of trousers

2239 -What does she dislike? -She likes doing...(silent)

2240 -How many rooms are there in a house, Giang?

2241 -There are 6 rooms in a house

2242 -What are they? -A living room, a dying room, a kitchen

2243 and 2 bedrooms

2244 -What is this, Duong? -It's a hat

2245 -What colors is this? -It's blue and white

2246 -Is this big? -no

2247 -What are these, Giang? -There are some toys

2248 -How many toys are there? -There are ten toys

2249 -What colors are they? -They are red, yellow and black

2250 -Are they big? -yes

2251 -Is your rubber? -Yes, it is. -Is that your pen? -No. it

2252 isn't.it my pen.. my pen is here

2253 -What do you do at bleak time, Giang? -I play badminton

2254 -And what about you, Duong? -I play football

2255 -Do you like football? - Yes i do

2256 -Do you like hide and seek, Giang? -No. i don’t. i like

2257 skating

2258 -Who that woman, Duong? - he is my father.

2259 - What does she do? -she's a doctor

2260 -Who that man, Giang? -He’s my father

2261 -Really. he's old. What does he do? - he's a teacher

2262 - How many doors are there in the living room, Duong? -

2263 There is one

2264 -How many windows are there? -There are 2 windows

2265 -How many chairs are there? -There are 6

2266 -What is the weather like today, Giang? - It’s sun..sunny

2267 and warm

2268 -What's the weather like in Phu Tho today, Duong?. -It's

2269 cold and cloudy

2270 Now. We continue with task 3

2271 Work in pair: talking about the weather in vn today

2272 - What's the weather like in Ha Noi in summer?

2273 -It's... It's very hot and sunny

2274 -What do you usually do in summer? -It usually go

2275 swimming

2276 -How many seasons are there in Viet Nam? -There are 4

2277 seasons

2278 -What are they? -They are spring, summer, autumn and

2279 winter

2280 -Why is summer is raining season? -Because it's very hot

2281 and it often rains

2282 -Is the weather in autumn hot? -No. it isn't. it’s cool and

2283 windy

2284 -Do you like the weather in Viet Nam ? - Yes. I do. I love it

2285 so much

2286 Thank you. Gb.bb

2287

\section{Pair 16}

Hi(2)hello(2)

-And what's your name? -my name is Tu

2292 -How do you spell your name, ?- That $t \mathrm{u}$

2293 - How do you spell your name? - That $\mathrm{v} u$

2294 - How are you today, Tu? - I'm fine, thank you.

2295 - And you? fine. Thank you

2296 - What do you do, Tu? - I'm a pupil

2297 -What do you do, Vu? -I'm a pupil too

2298 -How old are you, Vu? -I'm nine years old

2299 -How old are you? -I'm nine years old too

2300 -Where are you from, Tu? -I'm from VN

2301 -Are you Vietnamese? -Yes. I am

2302 -Where are you from, Vu? -I'm from Phu Tho town

2303 -What nationality are you? - I'm Vietnamese

2304 -What do you do at bleak time? -I play hide and seek

2305 -Is your bleak time long? -No. it isn't

2306 -How many people are there in your family?

2307 -There are 4

2308 -Who are they? -There are my mother, my father, my sister

2309 and me

2310 -Have you got a big family, Vu? -Yes. I am

2311 -What day is this today, Tu? - It's Wednesday

2312 -Do you have history on wednesday? -No. we have english

2313 on...ah... have history on friday
2314 -What do you do on monday? - I go to school

2315 -Do you have geography on Tuesday, Vu?

2316 -Yes.ah..no we have...on friday

2317 -What do you do on monday? -I go to school

2318 -What's the date today, Tu ? -It's the six of june

2319 -When's your birthday, Tu? -It's on the it's on

2320 the....ah..it's on the fifth of january

2321 -What can you do, Vu? -I can play football

2322 -Can you sing vietnamese song? -Yes. I can

2323 -What can you do, Tu? -I can play badminton

2324 -Can you cook? -No. i don't.no. i can't

2325 -Where is your school, Tu? -It's in Truong Thinh ..street.

2326 -What's the name of your school? - It's Truong Thinh

2327 primary school

2328 -What's the name of your school, Vu? - It in Truong Thinh

2329 primary school too

2330 -What class are you in? -I'm in class $4 \mathrm{~B}$

2331 -Is your classroom big ? -yes. it is

2332 -What do you like doing, Tu? -I like playing football

2333 -What do you like doing, Vu? -I like flying a kite

2334 -What's your hobby, Tu? -I like riding a bike

2335 -What's your hobby, Vu? -I like flying a kite

2336 -What subject do you have today, Vu? - It's math,

2337 vietnamese english and history

2338 -Do you have history today? -Yes. I do

2339 -What's subject do you have today, Tu? - I have math,

2340 english and vietnamese

2341 - Do you have math today?- No. i don't

2342 -Who is your math teacher? -It's mrs Tam

2343 -Who is your english teacher, Vu? - It mr Tien

2344 -Where was you yesterday, Vu? -I was at school

2345 -What did you do yesterday? -I painted a picture

2346 -Where was you last night, Tu? - I...i...ah...i was at home

2347 - What did you do last night? -I ...painted a picture

2348 -Do you have any dog, Tu? -Yes. I do. i have two dogs

2349 -Where are the dogs? -They are in front of the .. (silent)

2350 -Do you like them? -Yes. I do

2351 Now. we continue with task 2. talking about the picture

2352 -Who’s that, Duong? -It’s Nga

2353 -Where is she from? -She froms vn

2354 -Is she vietnamese? - Yes..yes. she is

2355 - How old is she? - She nine years old

2356 -What does she like? -She like pink...uh.. a pair of trousers

2357 -What does she dislike? -She likes doing..(silent)

2358 -Where's Sapa. Tu? - It's in Viet Nam

2359 -Is this very beautiful, Vu? -Yes. It is

2360 -Where Ho Chi Minh city? - It's south Viet Nam

2361 - Is this very beautiful? - Yes. It is

2362 - Where is your home town, Vu? - It's in Phu Tho ..

2363 province

2364 - Is this big and nice? - Yes. It is

2365 Now, we continue with task 2: talking about the picture

2366 - What is this, Vu? - It's a hat

2367 - What colors is this? - It's .. blue and white

2368 - Is this big? - Yes. It is

2369 - How many rooms are there in a house, Tu? -There are 6

2370 rooms in a house

2371 -What are they? -A living room.. ah a living room, a dying room, a kitchen and 2 bedrooms

2374 -Where is she from? - She froms Viet Nam

2375 - What nationality is she? - She's Vietnamese

2376 - How old is she? - She nine years old

2377 - What does she like? - Does she like pink t-shirt and a pair

2378 of trousers

2379 - Is she pretty? - Yes, it is

2380 -What are these, Tu? - There are some toys

2381 - How many toys are there? - There are ten toys

2382 - What colors are they? - They are red, yellow and white

2383 - Are they big? - Yes ah yes, they are

2384 - Is this your school bag, Vu? -Yes. It isn't.

2385 - Is that your rubber? - No. it isn't

2386 - What do you do at bleak time, Vu? - I play badminton

2387 - And what about you, Tu? - I play chess

2388 - Do you like chess? - Yes i do

2389 - Do you like hide and seek, Vu? - No. i don’t. i like

2390 skating 
2391 - Who that man? - he is my father,

2392 -Really. He's old. what does he do? - he's ... doctor

2393 - Who that woman, Tu? - He's my father

2394 - What does she do? - she's .. she's (silent)

2395 - How many doors are there in the living room? - There

2396 are...ah there is one

2397 - How many windows are there? - There are 2 windows

2398 - How many chairs are there? - There are 6

2399 - What is the weather like today, Vu? - It's sunny and

2400 (warm)

2401 - What's the weather like in PhuTho today, Tu?. - It's

2402 cold and cloudy

2403 Now. We continue with task 3

2404 Can you tell me about your night weekend

2405 - Hi. Did you have a night weekend. - Hello. Yes. I did. It’s

2406 .... Was...great

2407 - What did you do? - It was my brother's birthday. We

2408 have a big party. The food was good and my brother was

2409 thirteen,

2410 - What did you do? - Oh..i ..i.. i at home when the house

2411 and watch tv

2412 - Did you like your night weekend? (silent)

2413 Thank you. gb

2414 Pair 17

2415 Good morning (4)

2416 - What's your name? - my name is Trang

2417 - And what's your name? - my name is Thien

2418 - How do you spell your name? - That th i e n

2419 - How do you spell your name, Trang? - That t r a n g

2420 - How are you today, Trang? - I'm fine, thank you. -And

2421 you, Thien? -fine. Thank you

2422 - What do you do, Thien? - I'm a pupil

2423 - What do you do, Trang? - I'm a pupil too

2424 - How old are you, Trang? - I'm eight years old

2425 - How old are you? - I'm nine years old

2426 - Where are you from, Thien? - I'm from Phu Tho town

2427 - Are you vietnamese? - Yes. I am

2428 - Where are you from, Trang? - I'm from Viet Tri city

2429 - What nationality are you? - I'm Vietnamese

2430 -What do you do at bleak time, Thien? - I play hide and

2431 seek

2432 - Is your bleak time long? -No. it isn't

2433 - Do you like playing chess, Trang? - Yes. I do

2434 - What do you like to play. Thien? - I like playing

2435 badminton

2436 - How many people are there in your family? - There are 4

2437 -Who are they? -There are my mother, my father, my sister

2438 and me

2439 -Have you got a big family, Trang? - Yes. I have

2440 - Where's Sapa. Thien? It's in north VietNam

2441 -Is this very beautiful? -Yes. It is

2442 -Where's Ho Chi Minh city, Trang? - It's south VietNam

2443 - Is this very beautiful? -Yes. It is

2444 - Where is your town, Thien? - It's in Phu Tho province

2445 - Is this big and nice? -Yes. It is

2446 -What day is this today, Thien? - It's wednesday. - Do you

2447 have history on wednesday? - No. we have ... history on

2448 friday

2449 - What do you do on friday? - I go to school

2450 -Do you have english on wednesday? -No.we have english

2451 on friday

2452 -What do you do on friday? -I go to school

2453 -What's the date today, Thien ? -It's the six of january

2454 -When's your birthday? - It's on the fifth of june

2455 - When's your birthday, Trang? - It's on the second of july

2456 - What can you do, Trang? -I can play chess

2457 -Can you sing vietnamese song? -Yes. I can

2458 -What can you do, Thien? -I can play football

2459 -Can you cook? -No. i can't

2460 -Where is your school, Thien? - It's in Truong Thinh

2461 ..street.

2462 -What's the name of your school?-It's Truong Thinh

2463 primary school

2464 -Is your school big? -Yes. It is

2465 -What's the name of your school, Trang? It in Hung Vuong

2466 street

2467 -Is your school small? -No. it isn't. it’s big
2468 -What class are you in, Trang? -I'm in class 4 a

2469 -Is your classroom big and nice ? -yes. it is

2470 -What class are you in, Thien? - I'm in class 4

2471 -Is your class small? -No. it isn't

2472 -What do you like doing, Thien? -I like watching tv

2473 -What do you like doing, Trang? -I like playing badminton

2474 -What's your hobby, Trang? -I like riding a bike

2475 - What's your hobby, Thien? -I like flying a kite

2476 -What subject do you have today, Trang? -It's

2477 vietnamese, music and art

2478 -Do you have art today? -I have.. yes. I do

2479 -What's subject do you have today, Thien? - I have math,

2480 vietnamese and misuc

2481 -Do you have music today? -Yes. I do

2482 -Who is your music teacher? - It's mrs Tam

2483 -Who is your art teacher, Trang? -It mr Tien

2484 -Where was you last night, Thien? -I was at home

2485 -What did you do last night? - I ...i painted a picture

2486 -Where was you last weekend, Trang ? - I was at home

2487 -What did you do last weekend? - I painted a picture

2488 -Do you have any rabbits? -Yes. I do. i have two rabbits

2489 -Where are the rabbits? -They are in front of table

2490 -Do you like them? -Yes. I do

2491 -Thien, Do you have any dog? - Yes. I do. I have 2 dogs

2492 -Where are the dogs? -There are in front of the table

2493 -Do you like them? -Yes. I do

2494 Now. we continue with task 2. talking about the picture

2495 -Who's that, Thien? -It's Nga

2496 -Where's she from? - She froms vn

2497 -What nationality is she? -She's vietnamese

2498 -How old is she? -She nine years old

2499 -What does she like? -She like pink t-shirt and a pair of

2500 trousers

2501 -What does she dislike? -She dislike doing $\wedge \& \%$

2502 -How many rooms are there in a flat, Trang? -There are 6

2503 rooms flat

2504 - What are they? - they are a living room.. ah a living

2505 room, a dying room, a kitchen and 2 bedrooms

2506 - What is this, Thien? - It's a hat

2507 - What colors is this? - It's blue and white

2508 - Is this small? - Yes.

2509 - What are these, Trang? - There are some..some toys

2510 - How many toys are there? - There are ten toys

2511 - What colors are they? - They are red,blue and yellow ]

2512 - Are they big and nice? - Yes

2513 - Is this your school bag, Thien? - Yes. It is.

2514 - Is that your rubber? -No. it isn't

2515 -What do you do at bleak time, Trang? - I play badminton

2516 - And what about you, Thien? - I play chess

2517 - Do you like chess, Thien? -Yes i do

2518 -Do you like hide and seek, Trang? - No. i don't. i like

2519 skating

2520 -Who that woman,? -She(silent)

2521 - What does she do? - she's siste

2522 - How many doors are there in the living room, Thien? -

2523 There are..there is one

2524 - How many windows are there? There are 2 windows

2525 - How many benches are there, Trang? - There are 6

2526 - What is the weather like today, Trang? - It's sunny and

2527 hot

2528 - What's the weather like in Phu Tho today, Thien?. - It's

2529 cold and cloudy

2530 Now, we continue with task 2: talking about the picture

2531 - How many doors are there in the living room? - There

2532 are..ah there is one

2533 - How many windows are there? - There are 2 windows

2534 - How many chairs are there? - There are 6

2535 - What is the weather like today? - It's sunny and (warm)

2536 - What's the weather like in Phu Tho today, Tu?. - It's

2537 cold and cloudy

2538 Can you tell me about the weather today. Work in pair

2539 - What's the weather like in hn in summer? - It's only hot

2540 and sunny

2541 - What do you usually in summer? - I usually go swimming

2542 - How many (seasons) are there in VietNam?

2543 - There are 4 seasons 
2544 - What are they? - They are (spring), summer, autumn and

2545 winter

2546 - Why is summer is raining season? - Because it's very hot

2547 and it often rains

2548 - Is the weather in autumn hot? - No. it isn't. it's cool and

2549 windy

2550 - Do you like the weather in VietNam? - Yes. I do. I love it

2551 so much

2552 Thank you. Good bye. 